SANDRA MAYUMI NISHI

Efeito da infecção pelo Toxoplasma gondii na expressão de genes associados à resposta imune em tecidos de suínos 


\section{Efeito da infecção pelo Toxoplasma gondii na expressão de genes associados à resposta imune em tecidos de suínos}

Tese apresentada ao Programa de Pós-graduação em Epidemiologia Experimental e Aplicada às Zoonoses da Faculdade de Medicina Veterinária e Zootecnia da Universidade de São Paulo para a obtenção do título de Doutor em Medicina Veterinária

\section{Departamento:}

Medicina Veterinária Preventiva e Saúde Animal

\section{Área de Concentração}

Epidemiologia Experimental e Aplicada às Zoonoses

\section{Orientadora:}

Profa. Dra. Solange Maria Gennari 
Autorizo a reprodução parcial ou total desta obra, para fins acadêmicos, desde que citada a fonte.

DADOS INTERNACIONAIS DE CATALOGAÇÃO-NA-PUBLICAÇÃO

(Biblioteca da Faculdade de Medicina Veterinária e Zootecnia da Universidade de São Paulo)

T. 1433 Nishi, Sandra Mayumi

FMVZ Efeito da infecção pelo Toxoplasma gondii na expressão de genes associados à resposta imune em tecidos de suínos / Sandra Mayumi Nishi. - São Paulo : S. M. Nishi, 2004.

149 f. : il.

Tese (doutorado) - Universidade de São Paulo. Faculdade de Medicina Veterinária e Zootecnia. Departamento de Medicina Veterinária Preventiva e Saúde Animal, 2004.

Programa de Pós-graduação: Epidemiologia Experimental e Aplicada às Zoonoses.

Área de concentração: Epidemiologia Experimental e Aplicada às Zoonoses.

Orientador: Profa. Dra. Solange Maria Gennari.

1. Suínos. 2. Toxoplasma gondii. 3. Imunologia. 4. Expressão gênica. 5. Real-Time RT-PCR. I. Título. 


\section{UNIVERSIDADE DE SÃO PAULO \\ Faculdade de Medicina Veterinária e Zootecnia \\ Cidade Universitária "Armando de Salles Oliveira" \\ Comissão Bioética \\ CERTIFICADO}

Certificamos que o Projeto intitulado "Avaliaçāo da resposta imune em suínos infectados pelo Toxoplasma gondif' Protocolo $\mathrm{n}^{\circ}$ 250/2003, utilizando 8-10 porcos, sob a responsabilidade da Prof ${ }^{a}$ Dr $^{a}$ Solange Maria Gennari, está de acordo com os princípios éticos de experimentação animal da Comissão de Bioética da Faculdade de Medicina Veterinária e Zootecnia da Universidade de São Paulo e foi aprovado em reunião de 27/02/2003.

(We certify that the Research "Evaluation of swine immune responses and immunogenetic control of anti parasite responses" protocol number 250/2003, utilizing 8-10 pigs, under the responsability of Prof ${ }^{a} \mathrm{Dr}^{\mathrm{a}}$ Solange Maria Gennari, agree with Ethical Principles in Animal Research adopted by Bioethic Commision of the Faculty of Veterinary Medicine and Zootechny of University of São Paulo and was approved in 02/27/2003 meeting.)

São Paulo, 07 de março de 2003

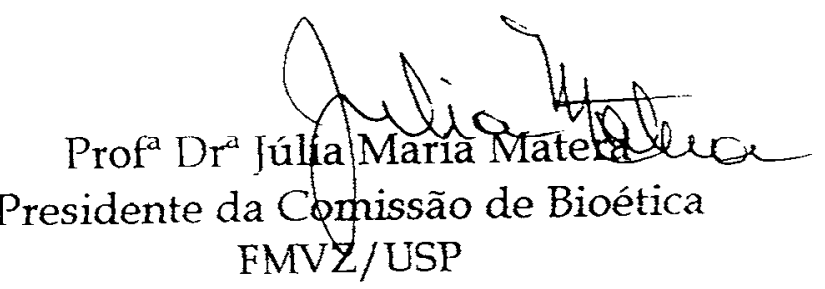




\section{FOLHA DE AVALIAÇÃO}

Nome da autora: NISHI, Sandra Mayumi

Título: Efeito da infecção pelo Toxoplasma gondii na expressão de genes associados à resposta imune em tecidos de suínos

Tese apresentada ao Programa de Pós-graduação em Epidemiologia Experimental e Aplicada às Zoonoses da Faculdade de Medicina Veterinária e Zootecnia da Universidade de São Paulo para obtenção do título de Doutor em Medicina Veterinária

São Paulo, 30 de novembro de 2004

\section{Banca Examinadora}

Prof. Dr.

Instituição:

Assinatura:

Julgamento:

Prof. Dr.

Instituição:

Assinatura:

Julgamento:

Prof. Dr.

Instituição:

Assinatura:

Julgamento:

Prof. Dr.

Instituição:

Assinatura:

Julgamento:

Prof. Dr.

Instituição:

Assinatura:

Julgamento: 


\section{Dedico esta tese aos meus queridos familiares,}

À minha avó Toshiko Sakajiri (in memorian),

Aos meus pais, Izabel e Tadahisa,

Aos meus irmãos Augusto e Sérgio,

À minha cunhada Rivânia e a minha sobrinha Talita,

Aos meus tios João (in memorian) e Akiko,

Aos meus primos-irmãos Priscila e Daniel,

Aos tios Edu, Akemi e Raquelzinha,

Pela paciência aos meus caprichos...

Pela confiança, mesmo sem entender o que faço,

Pelo respeito às minhas decisões,

Pelo carinho em todos os momentos e sem restrições. 
Os experimentos apresentados nesta tese fazem parte de um projeto envolvendo equipes de pesquisadores do Animal and Natural Resources Institute (ANRI) e Beltsville Human Nutrition Research Center (BHNRC) do Departamento de Agricultura dos Estados Unidos da América (USDA). Esta tese representa, desta forma, somente uma pequena parte dos experimentos realizados e é um reflexo do esforço e do empenho de vários profissionais.

É uma tarefa difícil listar nomes e expressar em palavras minha gratidão a todos aqueles que de alguma forma participaram na execução do experimento e também àqueles que indiretamente contribuíram para que esta tese pudesse ser realizada. Com certeza haverá aqueles que não foram aqui citados, mas não deixo de estender meus sinceros agradecimentos a todas as pessoas responsáveis para a minha formação pessoal e profissional.

Agradeço à Solange Maria Gennari, minha orientadora no curso de Mestrado, por lançar a oportunidade de dar continuidade a minha formação acadêmica. Minha gratidão por sempre abrir portas para novos horizontes, pela confiança e pela terna amizade.

À Joan K. Lunney, pesquisadora-chefe do antigo IDRL, atualmente pesquisadora do Animal Parasitic Diseases Laboratory do ARS, USDA. Joan foi, sem dúvida, a grande incentivadora para a consolidação deste trabalho. Minha gratidão pela receptividade, abrindo as portas do IDRL e à introdução ao mundo da imunologia. Agradeço por todo apoio profissional e pessoal, pela confiança e pelo carinho nos momentos mais difíceis.

Harry Dawson, pesquisador do Nutrient Requirement \& Function Laboratory (NRFL), BHNRC, USDA, é a mente idealizadora deste experimento. Agradeço pelas inúmeras sugestões, pela bem-humorada paciência e pela dedicação, sempre disposto a dividir o vasto e invejável conhecimento no campo da biologia molecular, da bioinformática e da imunologia. 
À Terezinha Padilha, pelo incentivo e pela constante dedicação à formação de pesquisadores e o intercâmbio entre as instituições. Minha especial gratidão, estendida também a David Bounds, pelo carinhoso apoio e pela ajuda em todos os momentos que precisei.

Ao Joseph Urban Jr, pesquisador chefe do Nutrient Requirement \& Function Laboratory pelo planejamento, pela paciência e pelo apoio indispensável para a execução dos experimentos.

Ao JP Dubey, pesquisador do APDL, pelas palavras de apoio, pela contribuição e pelas sugestões críticas para a condução dos experimentos.

Ao Federico Zuckermann, do Departamento de Patobiologia da Universidade de Illinois, pela paciência e pelo suporte necessário para a concretização do intercâmbio.

À Ethiopia Beshah pela amizade e pelo carinho. Obrigada por dividir os conhecimentos técnicos, pelas advertências e pela visão criteriosa que foi importante para a manutenção da boa qualidade dos resultados.

À Gloria Solano-Aguilar, pesquisadora do NRFL, pela inspiração e sugestões na realização do experimento.

Ao Atabak Royaee, pós-doc do antigo IDRL, atualmente pós-doutorando da Universidade de Massashussets, pelas sugestões úteis para a análise dos resultados e pelo companheirismo.

Agradecimentos especiais a Daniel Kuhar e a Yi Chong, pela ajuda no processamento das amostras, pela dedicação e pela amizade, imprescindíveis para a conclusão dos experimentos e a manutenção de um alegre ambiente de trabalho.

Aos colegas de laboratório Alexander Rustico Domingo, Tonya Ledbetter, Jenny Kessler, Jeremy Samon, Pat Boyd e Chika Obele pelo agradável convívio e pela ajuda, mesmo que involuntária, na manutenção da rotina laboratorial. 
Ao Samuel Shen e ao Oliver Kwok por toda atenção dispensada e pelo fornecimento dos isolados de Toxoplasma gondii, pela realização das provas de aglutinação modificada e auxílio na digestão das amostras para a prova de PCR.

Ao William Hare, médico veterinário responsável pelo Serviço Veterinário do ANRI-USDA, pela realização das provas de avaliação hepática e do hemograma.

À Pat Allen e ao Eli Miramontes por permitir a utilização do laboratório e auxílio na realização das deteminações de óxido nítrico.

Ao Sreekumar Chirukandoth pelo auxilio nos exames histopatológicos.

À Dolores Hill por permitir a utilização do laboratório para a realização das provas de ELISA.

Além do corpo científico agradeço às secretárias Ruth Flester e Judy Sirk pela carinhosa dedicação e pela constante atenção aos procedimentos burocráticos.

Aos queridos colegas Ricardo Araújo, Karen Tunin, Danielle Seipel da Silva, Hilda F. J. Pena, Rodrigo Martins Soares, João L. Garcia, Manoella Vianna, Jorge T. de Souza e Flora Piasentin pelo apoio, pela amizade e pelo companheirismo durante o período nos EUA.

A todos os colegas cientistas e funcionários do ANRI e do NRFL, USDA pelo agradável convívio diário. 
Meus agradecimentos ao prof. Silvio A. Vasconcellos pela atenção e pela dedicação na condução do curso de pós-graduação

À Maria Cristina Paick, Ana Virgínia P. de Almeida Prado, Danival Lopes Moreira e Tânia Delonero por toda a atenção dispensada e pelo empenho no bom funcionamento do Departamento.

Às secretárias Sandra, Cláudia e Dayse do Serviço de Pós-graduação e à bibliotecária Elza M. Faquim da Biblioteca Virginie Buff D'Apice da FMVZ-USP pela simpática paciência e pela ajuda nos procedimentos burocráticos.

Muito obrigada,

Sandra Nishi 


\section{Agradecimentos adicionais}

Ao National Pork Producers (EUA) e ao USDA pela concessão da bolsa durante todo o período de execução dos trabalhos nos EUA e do suporte financeiro para a realização dos experimentos.

À Coordenação de Aperfeiçoamento de Pessoal de Nível Superior (CAPES) pela concessão da bolsa durante o período final de elaboração da tese.

À Pró-reitoria de Pós-graduação da Universidade de São Paulo pela concessão de uma das passagens. 


\section{RESUMO}

NISHI, S. M. Efeito da infecção pelo Toxoplasma gondii na expressão de genes associados à resposta imune em tecidos de suínos. [Effect of Toxoplasma gondii infection on immune related tissue gene expression in pigs]. 2004. 149f. Tese (Doutorado em Medicina Veterinária) - Faculdade de Medicina Veterinária e Zootecnia, Universidade de São Paulo, São Paulo, 2004.

A toxoplasmose é uma zoonose de ampla distribuição mundial afetando homens e diversas espécies animais. Levantamentos sorológicos indicam elevados índices de infecção, porém relatos de doença severa é rara. A infecção pelo $T$. gondii induz uma intensa resposta imune mediada pelo interferon- $\gamma($ IFN- $\gamma)$ que rapidamente controla a multiplicação parasitária. Com o objetivo de explorar a resistência da espécie suína à toxoplasmose como modelo de estudo para a compreensão dos mecanismos de defesa a infecção, foram realizadas infecções orais com 4,5 x $10^{5}$ oocistos (cepa VEG) e colheitas de amostras de linfonodo hepato-esplênico (LN HS), mesentérico (LN M) e íleo-cólico (LN IC), fígado, sangue, íleo, jejuno, baço e timo aos 2, 4, 7 e 14 dias pós-infecção (DPI). Analisou-se a expressão de 69 genes ligados a resposta de defesa às infecções pela Real-Time RT-PCR*. LN M, LN HS e fígado foram as amostras que apresentaram a maior quantidade de genes e maior intensidade de ativação enquanto que células mononucleares de sangue periférico (CMSP) e timo apresentaram reduzida resposta à infecção. A expressão e a produção de IFNG foram mais altas nas amostras de LN M e LN HS comparadas às amostras de LN traqueo-bronquial e CMSP, indicando diferentes níveis de resposta local. Intensa indução de resposta inata e inflamatória foi observada em vários tecidos, envolvendo os genes IL1B, IL6, IFNA1, TNF, ORM1, MYD88, TLR2, TLR4; estimulação de resposta Th1, mediada por IFNG incluiu os genes IRF1, IL23A, IL18, STAT1, SOCS1, SOCS3, ICSBP1, TBX21; balanceada pela expressão de citocinas regulatórias IL10, TGFB1 e TGFB3. Uma proeminente indução de ARG1, INDO and SLC11A1 indica ativação de mecanismos de proteção do hospedeiro envolvendo 
metabolismo de aminoácidos (arginina, triptofano) e ferro. A presença de parasitas foi detectada no LN M aos 2DPI pela Real-Time PCR e pela imunohistoquímica. Aumento do número de parasitas no 4DPI foi seguida de intensa resposta inflamatória, edema e necrose tecidual no 7DPI principalmente no fígado e no LN M. Elevados níveis de AST sérico no 7DPI confirmam a lesão de hepatócitos. A diminuição da inflamação e da quantidade de parasitas no 14DPI sugerem controle da proliferação parasitária. Elevados níveis de haptoglobina e óxido nítrico séricos detectados aos 4 DPI $(\alpha=0,05)$ indicam respectivamente a ativação de proteínas de fase aguda e de macrófagos. A análise de citometria de fluxo mostra elevação da porcentagem de células CD2/CD16 DP sugerindo envolvimento de células NK e não foram observadas alterações na porcentagem de células $\mathrm{CD} 4^{+} / \mathrm{CD}^{+}, \mathrm{CD}^{+} / \mathrm{CD} 25^{+}$. A estimulação na expressão gênica, a produção de IFN- $\gamma$, as determinações séricas e lesões histológicas apresentam padrão similar, com início de resposta no 2DPI, elevação no 4DPI e 7DPI e diminuição no 14DPI. A análise da expressão de mRNA nos tecidos revelou alguns dos mecanismos de defesa do hospedeiro ativados durante a infecção pelo T. gondii. Observou-se uma equilibrada ativação de citocinas pró- e anti-inflamatórias envolvendo uma intrincada rede de mecanismos co-estimulatórios e regulatórios coordenando a resposta do tipo Th1. *Siglas dos genes segundo o Human Gene Nomenclature Committee (HGNC).

Palavras-chave: Suínos. Toxoplasma gondii. Imunologia. Expressão gênica. Real-Time RTPCR 


\begin{abstract}
NISHI, S. M. Effect of Toxoplasma gondii infection on immune related tissue gene expression in pigs. [Efeito da infecção pelo Toxoplasma gondii na expressão de genes associados à resposta imune em tecidos de suínos]. 2004. 149f. Tese (Doutorado em Medicina Veterinária) - Faculdade de Medicina Veterinária e Zootecnia, Universidade de São Paulo, São Paulo, 2004.
\end{abstract}

Toxoplasmosis is a widespread zoonosis affecting humans and large range of animal species worldwide. Serological surveillance indicates high infection rates, but rarely is associated to severe disease. T. gondii (Tg) infection induces a strong IFN- $\gamma$ dominated immune response that rapidly controls parasite replication. Pig resistance to toxoplasmosis was explored as an experimental model to evaluate host defense mechanisms. Pigs were fed $4.5 \times 10^{5}$ oocysts (VEG strain) and hepato-splenic (HS LN), mesenteric (MLN) and ileal lymph nodes (I LN), liver, blood, ileum, jejunum, spleen and thymus samples were collected at 2, 4, 7 and 14 days after infection (DAI). Gene expression analysis for a panel of 69 immune related genes were performed by Real-Time RT-PCR*. Most intense response were detected in MLN, HS LN and liver samples, whereas low changes were observed in periferic blood monocytes (PBMC) and thymus. IFNG mRNA expression and protein production were higher in MLN and HSLN cells than in tracheo-bronchial LN and PBMC, suggesting different levels of local response. Intense innate and inflammatory induction were observed in most of the tissues involving IL1B, IL6, IFNA1, TNF, ORM1, MYD88, TLR2, TLR4; stimulation of IFNG dominated Th1 response included IRF1, IL23A, IL18, STAT1, SOCS1, SOCS3, ICSBP1, TBX21; balanced by expression of regulatory cytokines IL10, TGFB1 and TGFB3. Prominent ARG1, INDO and SLC11A1 upregulation indicate activation of host amino acid (arginine and tryptophan) and iron protective mechanisms. Tg parasites were detected by Real-Time PCR and immunohistochemistry in MLN as early as 2DAI. Increase of parasite burden at 4DPI was followed by an intense inflammatory response, edema and tissue necrosis in liver and LNM at 7DPI. Increased serum AST levels at 7DPI confirmed liver damage. Reduced parasite 
numbers and inflammatory response suggest control of parasite replication at 14 DPI. High serum haptoglobin and nitric oxide at 4DAI $(\alpha=0.05)$ indicate acute phase protein and macrophage activation, respectively. Flow citometry analysis showed increased percentage of CD2/CD16 DP suggesting involvement of NK cells, whereas no changes were observed at $\mathrm{CD}^{+} / \mathrm{CD} 8^{+}, \mathrm{CD}^{+} / \mathrm{CD} 25^{+}$cells. Gene expression stimulation, IFN- $\gamma$ production, serum determinations and histological lesions showed similar pattern, of induction at 2DPI, increasing at 4DPI and 7DPI and decreasing at 14DPI. Tissue mRNA expression analysis revealed some of the host defense mechanisms activated during T. gondii infection. A balance of pro- and anti-inflammatory cytokine activation, involving an intricated co-stimulatory and regulatory mechanisms that coordinates Th1 response was observed.*Gene names according to Human Gene Nomenclature Committee (HGNC).

Keywords: Pig. Toxoplasma gondii. Immunology. Gene expression. Real-Time RT-PCR 
Figura 3.1 - Organograma de colheita e exame das amostras dos suínos experimentais - Beltsville -2003

Figura 3.2 - Visualização gráfica da amplificação pela Real-Time PCR. O $\mathrm{ABI7700}$ detecta a emissão de fluorescência - $\Delta \mathrm{Rn}$ (nas ordenadas) ao longo dos 40 ciclos térmicos da reação (na abscissa). Os resultados são expressos em valores de $\mathrm{Ct}$ que indica o número de ciclos necessários para que o sinal fluorescente atinja o limiar de detecção - Beltsville - 2003

Figura 4.1.1 - Efeito da infecção pelo $T$. gondii na expressão gênica no linfonodo mesentérico (LN M), no linfonodo hepato-esplênico (LN HS), nas células mononucleares do sangue periférico (CMSP), no fígado, no baço e no timo de suínos mensurado pela Real-Time RT-PCR. Aumento ou diminuição da expressão de mRNA nos grupos infectados em relação ao controle nãoinfectado - Beltsville - 2003

Figura 4.1.2 - Efeito da infecção pelo T. gondii na expressão gênica no linfonodo íleo-cólico (LN IC), no jejuno (JEJ) e no íleo de suínos mensurado pela Real-Time RT-PCR. Aumento ou diminuição da expressão de mRNA nos grupos infectados em relação ao controle não-infectado - Beltsville - 2003

Figura 4.2.1 - Efeito da infecção pelo T. gondii na expressão de genes no linfonodo mesentérico (LN M), no linfonodo hepato-esplênico (LN HS), no fígado, no íleo e no jejuno de suínos mensurado pela Real-Time RT-PCR. Aumento ou diminuição da expressão de mRNA nos grupos infectados em relação ao controle nãoinfectado - Beltsville - 2003 


\section{LISTA DE QUADROS}

Quadro 3.1 - Genes avaliados pela Real-Time RT-PCR nos suínos infectados por T. gondii. Função primária, siglas dos genes, nomes e nomes alternativos, número de acesso no Genbank das seqüências utilizadas para o desenho dos primers e sondas e número do experimento (EXP) em que foi testado - Beltsville 2003

Quadro 4.1.1 - Detecção de T. gondii em tecidos de suínos nos diferentes dias pós-infecção (DPI) pelas técnicas de PCR e imunohistoquímica (IHQ) - Beltsville - 2003 


\section{LISTA DE GRÁFICOS}

Gráfico 4.1.1 - Níveis de aspartato aminotransferase (AST) sérico em suínos dos grupos controle e infectados pelo $T$. gondii - Beltsville 2003

Gráfico 4.1.2 - Níveis de IFN- $\gamma$ sérico em suínos dos grupos controle e infectados pelo $T$. gondii medido pelo método de ELISA Beltsville -2003

Gráfico 4.1.3 - Produção de IFN- $\gamma$ por células mononucleares do sangue periférico (CMSP), do linfonodo mesentérico (LN M), do linfonodo hepato-esplênico (LN HS) e do linfonodo traqueobronquial (LN TB) de suínos dos grupos controle e infectados pelo $T$. gondii durante cultivo em ConA por 24 horas medida pelo método de ELISA - Beltsville - 2003

Gráfico 4.1 .4 - Níveis de óxido nítrico (NO) no soro de suínos dos grupos controle e infectados pelo $T$. gondii medido pelo método de Griess - Beltsville - 2003

Gráfico 4.1.5 - Níveis de haptoglobina em suínos dos grupos controle e infectados pelo T. gondii medido por método colorimétrico Beltsville -2003

Gráfico 4.2.1 - Variação dos níveis de aspartato aminotransferase (AST) sérico em suínos dos grupos Controle e infectados pelo T. gondii Beltsville -2003

Gráfico 4.2.2 - Produção de IFN- $\gamma$ por células mononucleares do sangue periférico (CMSP), células do linfonodo mesentérico (LN M) e do linfonodo hepato-esplênico (LN HS) de suínos dos grupos controle e infectados pelo $T$. gondii durante cultivo em ConA por 24 horas medida pelo método de ELISA - Beltsville - 2003 . 99 
Gráfico 4.2.3 - Níveis de haptoglobina em suínos dos grupos controle e infectados pelo T. gondii medido por método colorimétrico. Letras distintas entre grupos experimentais indicam diferença estatística significante $(\alpha=0,05)$ - Beltsville -2003 
Tabela 4.1.1 - Média e desvio-padrão (DP) dos valores de aspartato aminotransferase (AST), alanino aminotransferase (ALT), gamaglutamil transferase (GGT), bilirrubinas totais (TBILI), bilirrubina direta (DBILI), proteínas totais (PT), globulinas (GLOB), albumina (ALB) e proporção albumina/globulina $(\mathrm{A} / \mathrm{G})$ das amostras de soro de suínos infectados com $T$. gondii e controles não infectados. Diferença estatística (Estat.) segundo teste de Tukey-Kramer $(\alpha=0,05)$ - Beltsville -2003

Tabela 4.1.2 - Variação da expressão de antígenos de superfície em células do linfonodo mesentérico em suínos após a infecção por T. gondii. Média das porcentagens relativas, respectivos desvio padrão (DP) e diferença estatística (Estat.) entre os grupos experimentais - Beltsville -2003

Tabela 4.1.3 - Variação da expressão de antígenos de superfície em células do linfonodo hepato-esplênico em suínos após a infecção por $T$. gondii. Média das porcentagens relativas, respectivos desvio padrão (DP) e diferença estatística (Estat.) entre os grupos experimentais - Beltsville - 2003

Tabela 4.1.4 - Variação da expressão de antígenos de superfície em células do linfonodo traqueo-bronquial de suínos após a infecção por $T$. gondii. Média das porcentagens relativas, respectivos desvio padrão (DP) e diferença estatística (Estat.) entre os grupos experimentais - Beltsville -2003

Tabela 4.1.5 - Variação da expressão de antígenos de superfície em células mononucleares do sangue periférico de suínos após a infecção por T. gondii. Média das porcentagens relativas, respectivos desvio padrão (DP) e diferença estatística (Estat.) entre os grupos experimentais - Beltsville - 2003 
Tabela 4.1.6 - Resultados da Real-Time RT-PCR em amostras de linfonodo mesentérico dos suínos do EXP I. Valores médios de $\mathrm{Ct} \mathrm{e}$ respectivos desvios padrões (DP) nos grupos controle e infectados de acordo com o dia após a infecção com T. gondii. Diferença estatística (Estat.) segundo o teste de Tukey-Kramer $(\alpha=0,05)$ - Beltsville -2003

Tabela 4.1.7 - Resultados da Real-Time RT-PCR em amostras de linfonodo hepato-esplênico dos suínos do EXP I. Valores médios de $\mathrm{Ct}$ e respectivos desvios padrões (DP) nos grupos controle e infectados de acordo com o dia após a infecção com $T$. gondii. Diferença estatística (Estat.) segundo o teste de Tukey-Kramer $(\alpha=0,05)$ - Beltsville -2003

Tabela 4.1.8 - Resultados da Real-Time RT-PCR em amostras de células mononucleares do sangue periférico dos suínos do EXP I. Valores médios de $\mathrm{Ct}$ e respectivos desvios padrões (DP) nos grupos controle e infectados de acordo com o dia após a infecção com T. gondii. Diferença estatística (Estat.) segundo o teste de Tukey-Kramer $(\alpha=0,05)$ - Beltsville -2003

Tabela 4.1.9 - Resultados da Real-Time RT-PCR em amostras de fígado dos suínos do EXP I. Valores médios de $\mathrm{Ct}$ e respectivos desvios padrões (DP) nos grupos controle e infectados de acordo com o dia após a infecção com $T$. gondii. Diferença estatística (Estat.) segundo o teste de Tukey-Kramer $(\alpha=0,05)$ - Beltsville - 2003

Tabela 4.1.10 - Resultados da Real-Time RT-PCR em amostras de baço dos suínos do EXP I. Valores médios de $\mathrm{Ct}$ e respectivos desvios padrões (DP) nos grupos controle e infectados de acordo com o dia após a infecção com T. gondii. Diferença estatística (Estat.) segundo o teste de Tukey-Kramer $(\alpha=0,05)$ - Beltsville - 2003

Tabela 4.1.11 - Resultados da Real-Time RT-PCR em amostras de timo dos suínos do EXP I. Valores médios de $\mathrm{Ct}$ e respectivos desvios padrões (DP) nos grupos controle e infectados de acordo com o dia após a infecção com T. gondii. Diferença estatística (Estat.) segundo o teste de Tukey-Kramer $(\alpha=0,05)$ - Beltsville - 2003 
Tabela 4.1.12 - Resultados da Real-Time RT-PCR em amostras de linfonodo íleo-cólico dos suínos do EXP I. Valores médios de $\mathrm{Ct}$ e respectivos desvios padrões (DP) nos grupos controle e infectados de acordo com o dia após a infecção com $T$. gondii. Diferença estatística (Estat.) segundo o teste de Tukey-Kramer $(\alpha=0,05)$ - Beltsville -2003

Tabela 4.1.13 - Resultados da Real-Time RT-PCR em amostras de jejuno dos suínos do EXP I. Valores médios de Ct e respectivos desvios padrões (DP) nos grupos controle e infectados de acordo com o dia após a infecção com $T$. gondii. Diferença estatística (Estat.) segundo o teste de Tukey-Kramer $(\alpha=0,05)$ - Beltsville - 2003

Tabela 4.1.14 - Resultados da Real-Time RT-PCR em amostras de íleo dos suínos do EXP I. Valores médios de $\mathrm{Ct}$ e respectivos desvios padrões (DP) nos grupos controle e infectados de acordo com o dia após a infecção com $T$. gondii. Diferença estatística (Estat.) segundo o teste de Tukey-Kramer $(\alpha=0,05)$ - Beltsville - 2003

Tabela 4.1.15 - Variação da expressão gênica em suínos após infecção pelo $T$. gondii mensurado pela Real-Time RT-PCR. Aumento (valores positivos) ou diminuição (valores negativos) da expressão de RNAm nos linfonodos mesentérico ( $\mathrm{LN} \mathrm{M}$ ), hepato-esplênico (LN HS) e células mononucleares do sangue periférico (CMSP) dos grupos infectados em relação ao controle não-infectado Beltsville -2003

Tabela 4.1.16 - Variação da expressão gênica em suínos após infecção pelo $T$. gondii mensurado pela Real-Time RT-PCR. Aumento (valores positivos) ou diminuição (valores negativos) da expressão de RNAm em amostras de fígado, baço e timo dos grupos infectados em relação ao controle não-infectado - Beltsville 2003

Tabela 4.1.17 - Variação da expressão gênica em suínos após infecção pelo $T$. gondii mensurado pela Real-Time RT-PCR. Aumento (valores positivos) ou diminuição (valores negativos) da expressão de RNAm no linfonodo íleo-cólico (LN IC), no jejuno e no íleo dos grupos infectados em relação ao controle não-infectado Beltsville -2003 
Tabela 4.2.1 - Média e desvio-padrão (DP) dos valores de aspartato aminotransferase (AST), alanino aminotransferase (ALT), gamaglutamil transferase (GGT), bilirrubinas totais (TBILI), bilirrubina direta (DBILI), fosfatase alcalina (ALP), proteínas totais (PT), globulinas (GLOB), albumina (ALB) e proporção albumina/globulina $(\mathrm{A} / \mathrm{G})$ em amostras de soro de suínos infectados com $T$. gondii e controles não infectados. Diferença estatística (Estat.) segundo teste de Tukey-Kramer $(\alpha=0,05)$ Beltsville - 2003

Tabela 4.2.2 - Média e desvio-padrão (DP) da contagem do número total de leucócitos $(\mathrm{Leu})$, número total $(\mathrm{T})$ e relativo $(\%)$ de neutrófilos $(\mathrm{Ne})$, linfócitos (Li), monócitos (Mo), Eosinófilos (Eo), basófilos $(\mathrm{Ba})$, número total de eritrócitos $(\mathrm{He})$, concentração de hemoglobina $(\mathrm{Hb})$, volume globular $(\mathrm{Hct})$, volume corpuscular médio (MCV), hemoglobina corpuscular média $(\mathrm{MCH}) \mathrm{e}$ concentração hemoglobínica corpuscular média (MCHC) em suínos infectados com $T$. gondii e controle não-infectado. Diferença entre os grupos experimentais (Estat.) segundo teste de Tukey-Kramer, $\alpha=0,05$ - Beltsville -2003

Tabela 4.2.3 - Resultados da Real-Time RT-PCR em amostras de linfonodo mesentérico dos suínos do EXP II. Valores médios de $\mathrm{Ct}$ e respectivos desvios padrões (DP) nos grupos controle e infectados de acordo com o dia após a infecção com T. gondii. Diferença estatística (Estat.) segundo o teste de Tukey-Kramer $(\alpha=0,05)$ - Beltsville -2003

Tabela 4.2.4 - Resultados da Real-Time RT-PCR em amostras de linfonodo hepato-esplênico dos suínos do EXP II. Valores médios de Ct e respectivos desvios padrões (DP) nos grupos controle e infectados de acordo com o dia após a infecção com $T$. gondii. Diferença estatística (Estat.) segundo o teste de Tukey-Kramer $(\alpha=0,05)$ - Beltsville -2003

Tabela 4.2.5 - Resultados da Real-Time RT-PCR em amostras de fígado dos suínos do EXP II. Valores médios de Ct e respectivos desvios padrões (DP) nos grupos controle e infectados de acordo com o dia após a infecção com $T$. gondii. Diferença estatística (Estat.) segundo o teste de Tukey-Kramer $(\alpha=0,05)$ - Beltsville -2003 
Tabela 4.2.6 - Resultados da Real-Time RT-PCR em amostras de íleo dos suínos do EXP II. Valores médios de $\mathrm{Ct}$ e respectivos desvios padrões (DP) nos grupos controle e infectados de acordo com o dia após a infecção com $T$. gondii. Diferença estatística (Estat.) segundo o teste de Tukey-Kramer $(\alpha=0,05)$ - Beltsville -2003

Tabela 4.2.7 - Resultados da Real-Time RT-PCR em amostras de jejuno dos suínos do EXP II. Valores médios de Ct e respectivos desvios padrões (DP) nos grupos controle e infectados de acordo com o dia após a infecção com $T$. gondii. Diferença estatística (Estat.) segundo o teste de Tukey-Kramer $(\alpha=0,05)$ - Beltsville -2003

Tabela 4.2.8 - Variação da expressão gênica em suínos após infecção pelo $T$. gondii, mensurado pela Real-Time RT-PCR. Aumento (valores positivos) ou diminuição (valores negativos) da expressão de RNAm nos linfonodos mesentérico ( $\mathrm{LN} \mathrm{M}$ ), hepato-esplênico (LN HS) e fígado dos grupos infectados em relação ao controle não-infectado - Beltsville - 2003

Tabela 4.2.9 - Variação da expressão gênica em suínos após infecção pelo $T$. gondii, mensurado pela Real-Time RT-PCR. Aumento (valores positivos) ou diminuição (valores negativos) da expressão de RNAm no íleo e no jejuno dos grupos infectados em relação ao controle não-infectado - Beltsville - 2003 
Ac

ALP

ALT

ANOVA

ANRI

ARS

AST

BARC

BHQ

CD

cDNA

CMSP

ConA

CRP

$\mathrm{CSF}$

DC

DNA

DNase

DP

DPI

EDTA

ELISA

FAM

FCM

FITC

HBSS

HE

HEPES
Anticorpo

Fosfatase alcalina

Alanino aminotransferase

Análise de variância

Animal and Natural Resources Institute

Agricultural Research Service

Aspartato aminotransferase

Beltsville Agricultural Research Center

Black Hole Quencher

Antígeno de superfície

DNA complementar

Células mononucleares do sangue periférico

Concanavalin A, lectina da Conavalia ensiformis

Proteína C-Reativa

Fator estimulador de colônia

Célula dendrítica

Ácido desoxirribonucléico

Desoxirribonuclease

Duplo positivos

Dias pós-infecção

Ácido etileno diaminotetracetato sódico

Ensaio imunoenzimático

6-carboxifluoresceína

Citometria de fluxo

Isotiocianato de fluoresceína

Hank's Balanced Salt Solution

Hematoxilina e eosina

$N$-2-hydroxyethylpiperazine- $N$ '-2-ethanesulfonic acid

\footnotetext{
${ }^{1}$ Devido ao uso consagrado na literatura técnica, algumas abreviaturas seguem as iniciais de sua grafia em inglês.
} 


\begin{tabular}{|c|c|}
\hline HGNC & Human Gene Nomenclature Committee \\
\hline HUGO & Human Genome Organization \\
\hline IDRL & Immunology and Disease Resistance Laboratory \\
\hline IFN & Interferon \\
\hline $\operatorname{Ig}$ & Imunoglobulina \\
\hline IHQ & Imunohistoquímica \\
\hline IL & Interleucina \\
\hline INDO & Indoleamine 2,3-dioxygenase \\
\hline iNOS & NO sintase induzível \\
\hline ITS1 & Internal Transcribed Spacer 1 \\
\hline LN & Linfonodo \\
\hline LN HS & Linfonodo hepato-esplênico \\
\hline LN IC & Linfonodo íleo-cólico \\
\hline LN M & Linfonodo mesentérico \\
\hline LN TB & Linfonodo traqueo-bronquial \\
\hline MAT & Teste de aglutinação mofidicado \\
\hline mRNA & RNA mensageiro \\
\hline NCBI & National Center for Biotecnology Information \\
\hline NK & Célula Natural Killer \\
\hline NO & Óxido nítrico \\
\hline NRFL & Nutrient Requirements and Functions Laboratory \\
\hline PBESL & Parasite Biology, Epidemiology and Systematics Laboratory \\
\hline PBS & Solução salina tamponada \\
\hline PCR & Reação em cadeia pela polimerase \\
\hline PE & Ficoeritrina \\
\hline PMA & Phorbol 12-myristate 13-acetate \\
\hline RNA & Ácido ribonucléico \\
\hline RNase & Ribonuclease \\
\hline ROX & 6-carboxy-x-rhodamine \\
\hline RT & Transcrição reversa \\
\hline SFB & Soro fetal bovino \\
\hline SLA & Swine Leukocyte Antigen \\
\hline STAg & Antígeno solúvel de $T$. gondii \\
\hline
\end{tabular}


TAMRA 5-(and 6)-carboxytetramethylrhodamine

Tc Linfócito T citotóxico

TET Tetrachloro-6-carboxyfluorescein

TGF Fator transformador de crescimento

Th Linfócito T helper

TIGR The Institute for Genomic Research

TLR Receptor tipo Toll

TNF Fator de necrose tumoral

USDA The United States Department of Agriculture 
$\alpha-$ alfa

$\beta$ - beta

$\gamma$ - gama

$\delta / \Delta$ - delta

$\mu$ - micro

${ }^{\circ} \mathrm{C}$ - graus Celsius 


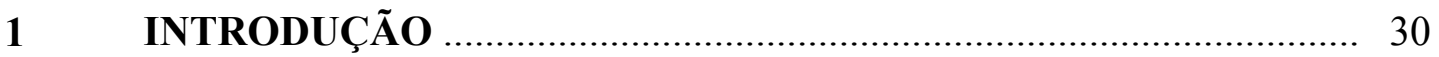

2 REVISÃO DA LITERATURA ……………………………........ 32

3 MATERIAL E MÉTODO ……………………………………....... 45

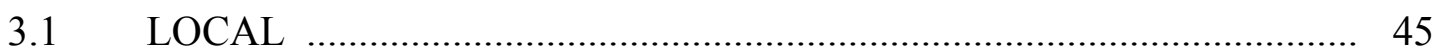

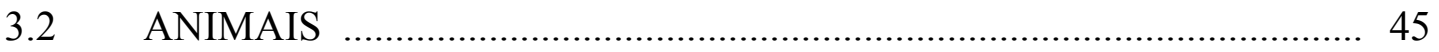

3.3 Toxoplasma gondii _........................................................................ 46

3.4 DELINEAMENTO EXPERIMENTAL ................................................ 46

3.5 SACRIFÍCIO DOS SUÍNOS E COLHEITA DAS AMOSTRAS ............ 49

3.6 ISOLAMENTO E PREPARO DAS CÉLULAS _.................................... 50

3.6.1 Separação de Células Mononucleares do Sangue Periférico ……….... 51

3.6.2 Separação de Células dos Linfonodos ……………………………...... 51

$3.7 \quad$ CULTURA IN VITRO _.................................................................. 52

3.8 ANÁLISE DE SUBPOPULAÇÕES DE CÉLULAS ................................ 53

3.9 PREPARO DAS AMOSTRAS PARA A REAL-TIME RT-PCR ............ 53

3.9.1 Extração de RNA …………………………………………………... 54

3.9.2 Quantificação de RNA por Espectrofotometria ………...................... 54

3.9.3 Tratamento com DNase ………………………………………….... 55

3.9.4 Determinação da Concentração e da Qualidade do RNA …………..... 55

3.9.5 Síntese de cDNA ………………………………………………….... 56

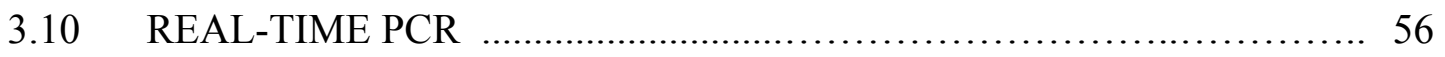

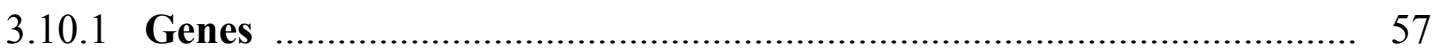

3.10.2 Otimização da Real-Time PCR ……………………………………....... 62 
3.10.3 Condições da Reação e Análise dos Resultados

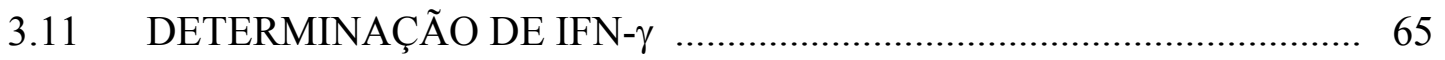

3.12 PERFIL HEPÁTICO E HEMOGRAMA .................................................. 65

3.13 DETERMINAÇÃO DE ÓXIDO NÍTRICO ...........................................6 66

3.14 DETERMINAÇÃO DE HAPTOGLOBINA ........................................... 66

3.15 DETECÇÃO DE ANTICORPOS ANTI-T. gondii .................................. 66

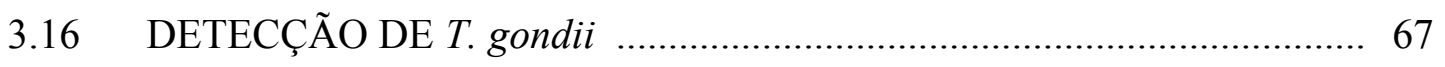

3.17 ANÁLISE ESTATÍSTICA ............................................................. 67

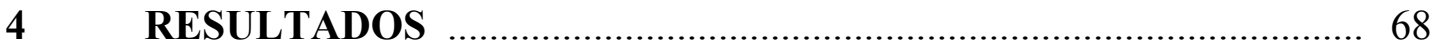

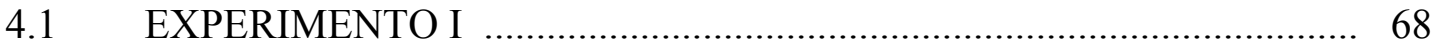

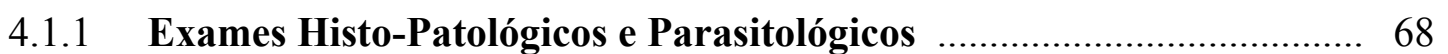

4.1.2 Pesquisa de Anticorpos Anti-T. gondii ......................................... 70

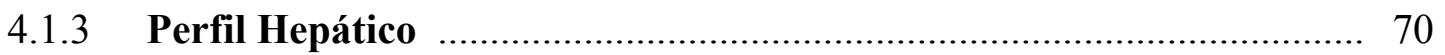

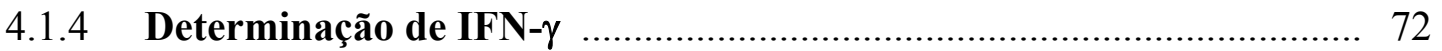

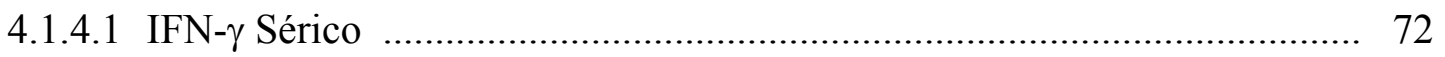

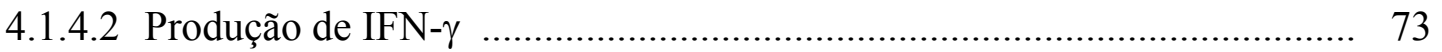

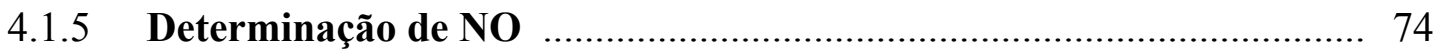

4.1.6 Determinação de Haptoglobina ….................................................. 75

4.1.7 Análise de Subpopulações de Células f................................................. 75

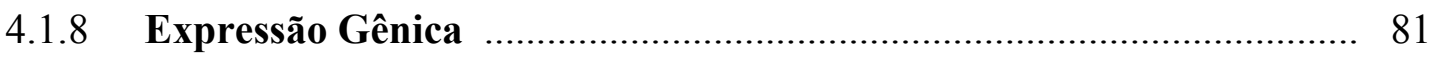

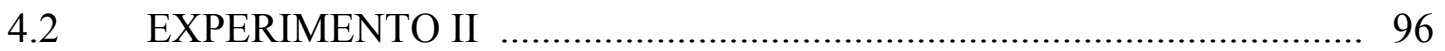

4.2.1 Pesquisa de Anticorpos Anti-T. gondii ............................................. 96

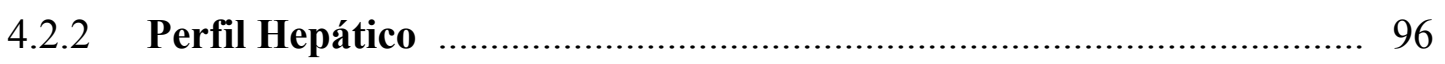

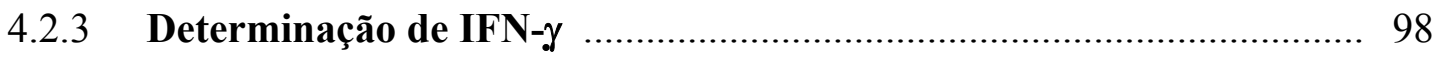




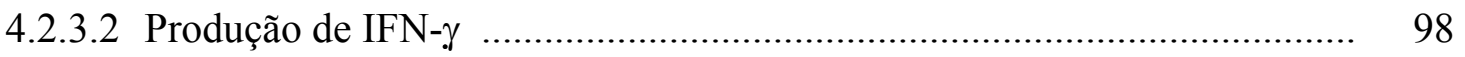

4.2.4 Determinação de Haptoglobina ….......................................................... 99

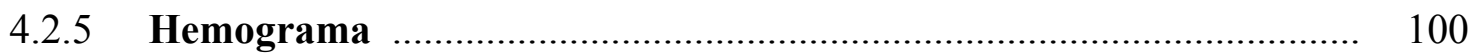

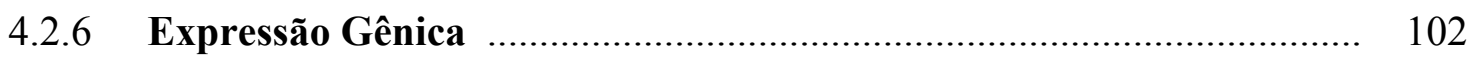

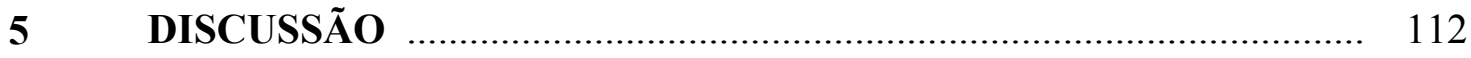

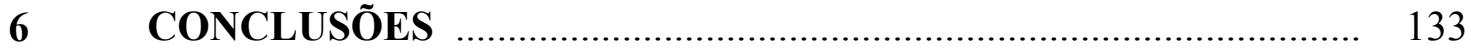

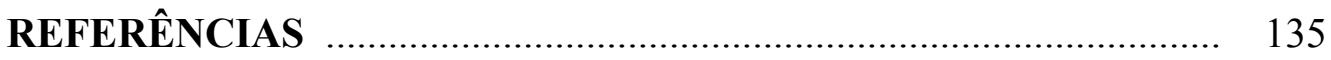

APÊNDICES _.......................................................................... 145 


\section{INTRODUÇÃO}

A toxoplasmose é uma zoonose de ocorrência mundial causada pelo protozoário Toxoplasma gondii (NICOLLE; MANCEAUX, 1908). Este agente se destaca por possuir uma ampla diversidade de hospedeiros incluindo várias espécies de mamíferos e aves. Inquéritos sorológicos indicam um elevado número de infectados tanto na população humana quanto nos animais, entretanto relatos de quadros clínicos severos e infecções letais são pouco freqüentes (DUBEY; BEATTIE, 1988).

O T. gondii é um parasita intracelular obrigatório, capaz de invadir e se multiplicar no interior de qualquer célula nucleada, sem predileção por tipo tecidual. A infecção se caracteriza na maior parte dos casos por uma fase inicial aguda de intensa replicação do parasita, seguida de uma fase crônica, assintomática em que o parasita se reproduz lentamente.

Os mecanismos de defesa do hospedeiro exercem um papel crucial no controle da atividade do parasita. Na fase inicial da infecção ocorre o processo de reconhecimento antigênico e ativação do sistema de defesa específica. A consolidação da resposta imunológica específica inibe eficientemente a replicação do $T$. gondii, porém não é capaz de destruí-lo. O T. gondii por sua vez possui mecanismos de evasão do sistema imune, assumindo uma forma de baixa imunogenicidade formando cistos em tecidos onde se mantém viável por anos, provavelmente por toda vida do hospedeiro.

Alterações na função imunológica do hospedeiro podem reativar a infecção crônica, o que a caracteriza como uma doença oportunista. Quando associado a doenças debilitantes e imunossupressoras produz lesões intensas devido a reprodução descontrolada do parasita que levam o indivíduo a óbito (DUBEY; BEATTIE, 1988). 
O principal modelo experimental para o estudo da toxoplasmose é a infecção em camundongos. A manipulação genética e os recursos de biologia molecular fornecem informações valiosas para a compreensão dos mecanismos biológicos envolvidos na etiologia da doença. Existem, entretanto, diferenças metabólicas entre humanos e camundongos que deverão ser estudadas com a utilização de espécies animais de grande porte como modelo experimental (HEIN; GRIEBEL, 2003; MESTAS; HUGHES, 2004).

Em comparação aos camundongos, os suínos apresentam maior resistência à infecção pelo T. gondii, comportando-se de modo parecido aos humanos. Os sintomas clínicos são pouco intensos e similares aos observados em outras infecções sistêmicas. Quando aparentes os sintomas são observados nas primeiras semanas pós-infecção, incluindo febre, linfoadenomegalia, hiporexia e apatia. Após este breve período, a infecção é controlada pelo sistema imune e o parasita se mantém latente em cistos teciduais (DUBEY; BEATTIE, 1988; DUBEY et al., 1996).

Apesar do grande número publicações sobre o assunto, os mecanismos responsáveis pelo controle da multiplicação e da manutenção dos cistos teciduais em fase de latência ainda não foram completamente identificados. O presente trabalho explora a resistência da espécie suína à toxoplasmose como modelo de estudo para a compreensão dos mecanismos de defesa envolvidos durante a fase aguda da infecção. Foram quantificados a expressão de 69 genes em diferentes tecidos do hospedeiro, obtendo-se assim a variação da expressão dos genes em diferentes dias após a infecção e também o padrão de resposta nos diferentes tecidos. Paralelamente à expressão gênica nos tecidos, a resposta imunológica foi abordada por indicadores séricos, cultura de células e histopatologia. 


\section{REVISÃO DE LITERATURA ${ }^{1}$}

Infecções experimentais em camundongos são o ponto inicial para o estudo dos mecanismos de defesa à toxoplasmose. A facilidade de manutenção de linhagens isogênicas, aliada à possibilidade de manipulação genética, a obtenção de várias gerações em um curto espaço de tempo e a elevada suscetibilidade da espécie à infecção pelo $T$. gondii tornou o camundongo o modelo padrão para esse tipo de estudo. A supressão ou a introdução de genes em camundongos geneticamente modificados permitiu determinar o papel fisiológico da proteína por eles codificada frente a diversas condições experimentais.

Por outro lado, infecções em culturas de células mostraram a capacidade de resposta de diferentes isolados de células ao parasitismo. Tipos celulares de origens e de funções variadas como células epiteliais (DENNEY; ECKMANN; REED, 1999), fibroblastos (BLADER; MANGER; BOOTHROYD, 2001; BRENIER-PINCHART et al., 2002; CHANNON et al., 2002), células dendríticas e macrófagos (CHAUSSABEL et al., 2003; ROBBEN et al., 2004), esplenócitos (GAZZINELLI et al., 1993; ROBBEN et al., 2004) responderam à infecção pelo $T$. gondii por meio de liberação de diferentes fatores ligados à quimiotaxia, à indução de resposta inflamatória e com efeito microbicida.

Ambos modelos experimentais, camundongos e cultivo em células, têm sido intensamente explorados no estudo da interação hospedeiro-parasita. Ao considerar diferenças biológicas entre espécies e condições laboratoriais artificiais torna-se difícil a extrapolação de

\footnotetext{
${ }^{1}$ Nota da autora: Na revisão de literatura foram utilizadas as siglas e abreviaturas adotadas na publicação original. No experimento da tese, foram utilizadas as siglas de genes conforme o Human Gene Nomenclature Committee (HGNC) do Human Genome Organization (HUGO) apresentandas no site $<$ http://www.gene.ucl.ac.uk/nomenclature $>$ em janeiro de 2004. Devido a constantes atualizações na nomenclatura, eventuais diferenças podem ser notadas entre as siglas aqui publicadas e siglas atualmente vigentes. As proteínas seguem a nomenclatura do The Journal of Immunology Standard Abbreviations <http://www.jimmunol.org/misc/authorabbrev.shtml>. Desta maneira, "IFNG", "TNF", "IL12A", "NOS2A" referem-se aos genes e "IFN- $\gamma$ ", ”TNF- $\alpha$ ", “IL12p35", "iNOS” referem-se às respectivas proteínas.
} 
dados experimentais para a compreensão de fenômenos reais. A defesa contra a infecção pelo T. gondii é formada por uma cascata de eventos, envolvendo componentes da imunidade inata que irão exercer importante papel na consolidação da resposta específica

A resposta inata pode ser observada em diferentes tipos celulares, independente de sua origem ou função primária (YAP; SHER, 1999). Embora inespecífica, possui componentes importantes para a ativação, a diferenciação celular e a consolidação da defesa específica.

O controle efetivo da infecção pelo $T$. gondii é feito pela imunidade mediada por células. A defesa celular envolve a ativação escalonada de tipos celulares especializados que se interagem através da expressão de antígenos de superfície, da secreção de mediadores específicos, conhecidos como citocinas, e sua interação sobre receptores próprios. Desta maneira, a avaliação do perfil das citocinas produzidas durante uma dada infecção, fornece importantes pistas a respeito do grau e da forma de ativação da imunidade celular. $\mathrm{Na}$ literatura as citocinas são também encontradas sob as designações quimiocinas, linfocinas e fatores de crescimento (PAUL, 1999).

A imunidade humoral representada pela produção de anticorpos específicos é o principal indicador para o diagnóstico da toxoplasmose na população. Possui grande valia para a detecção dos indivíduos infectados, porém não fornece informações sobre o estado imune ou a resistência do hospedeiro (DUBEY; BEATTIE, 1988; FILISETTI; CANDOLFI, 2004).

As citocinas são moléculas proteicas, produzidas e secretadas pelas células em resposta a um estímulo, isto é, sua produção é induzida em um dado momento e cessa tão logo o fator estimulatório seja eliminado ou reprimido. Exercem função local sobre os tecidos e podem possuir atividade autócrina, agindo sobre as próprias celulas produtoras, ou parácrina, isto é, agindo sobre diferentes alvos celulares (PAUL, 1999). 
Diferentes padrões de citocinas são secretados em resposta a diferentes formas de infecção, resultando em diferentes respostas efetoras. A partir destas observações, desenvolveu-se o conceito do paradigma das respostas do tipo Th1/Tc1 e tipo Th2/Tc2. A resposta $\mathrm{Th} 1 / \mathrm{Tc} 1$, envolveria as células $\mathrm{T}$ helper e citotóxicas mediadas por citocinas como o interferon gama (IFN- $\gamma$ ) e fator de necrose tumoral alfa (TNF- $\alpha)$ que são induzidas por infecções intracelulares, como por exemplo vírus e bactérias. A resposta Th2/Tc2 por sua vez, estaria associada às citocinas interleucina-4 (IL-4), IL-5 e IL-13 produzidas em resposta a infecções extracelulares, por exemplo helmintos. As respostas Th1 e Th2 são contrabalanceadas por mecanismos de inibição, desta forma, citocinas Th1 inibem a expressão de citocinas Th2 e a ausência de estimulação Th1 levaria a produção de resposta Th2 (JANKOVIC; LIU; GAUSE, 2001; PEARCE; SCOTT; SHER, 1999; SZABO et al., 2003).

No que se refere à toxoplasmose, a citocina-chave para o estudo da resistência é o IFN- $\gamma$ envolvendo a atividade de células Th1. Infecções experimentais em camundongos revelam que a produção de IFN- $\gamma$ é um passo crítico para a proteção do hospedeiro contra a infecção pelo T. gondii. A ausência do gene ou a deficiência na produção de IFN- $\gamma$ ou de seu respectivo receptor leva à replicação descontrolada do parasita e o hospedeiro evolui rapidamente para a morte (FUJIGAKI et al., 2002; SCHARTON-KERSTEN et al., 1996b; YAP; SHER, 1999).

A produção de IFN- $\gamma$ por linfócitos $\mathrm{T}$ e células NK é responsável pela ativação de macrófagos e das próprias células NK (FILISETTI; CANDOLFI, 2004) e está fortemente associado a indução da conversão de taquizoítos para bradizoítos (BOHNE; HEESEMANN; GROSS, 1993; JONES; BIENTZ; ERB, 1985).

Este efeito protetor do IFN- $\gamma$ deve, entretanto, possuir mecanismos regulatórios visando impedir efeitos imunopatológicos. Ao comparar de linhagens de camundongos suscetíveis e resistentes à toxoplasmose aguda observou-se, de forma intrigante, níveis de 
IFN- $\gamma$ séricos mais elevados nas linhagens sucetíveis que nas resistentes. Esta elevada concentração de IFN- $\gamma$ foi associada a um processo inflamatório agudo com edema e necrose tecidual bastante intensas no fígado e no linfonodo mesentérico (MCLEOD et al., 1989). A produção exacerbada de IFN- $\gamma$ foi também observada nas infecções letais causadas por isolados de T. gondii altamente virulentos (GAVRILESCU; DENKERS, 2001; MORDUE et al., 2001).

Para melhor compreender a cascata de ativação da resposta Th1 e tomando o IFN- $\gamma$ como referência, diversos trabalhos buscam identificar os mediadores resposáveis pela indução da produção de IFN- $\gamma$, a sinalização intracelular e as vias efetoras ativadas pelo IFN$\gamma$

Ao longo da infecção a ativação do sistema imune ocorre por mecanismos múltiplos. Além de reconhecimento de antígenos do $T$. gondii, a lesão celular e citólise geram sinais não específicos que alertam as células fagocitárias da presença do agressor (SCOTT; HUNTER, 2002).

Os mecanismos de defesa ativados nesta fase precoce da infecção são mecanismos inespecíficos porém importantes para a organização da resposta específica. Nesta fase inicial, células fagocitárias como as células dendríticas (DC), monócitos e macrófagos desempenham um papel essencial no reconhecimento do agente invasor, na apresentação antigênica e geração sinais específicos para as células efetoras (PAUL, 1999).

Nos camundongos a IL-12 é a principal citocina indutora da produção de IFN- $\gamma$. As DCs controlam a magnitude e a qualidade da resposta Th1 com a produção de interleucina-12 (IL-12) (SCOTT; HUNTER, 2002). A ausência de IL-12 aumenta a suscetibilidade à infecção, com menor produção de mediadores inflamatórios, maior replicação parasitária e morte em menor espaço de tempo (ARAUJO et al., 2001). Tanto parasitas íntegros quanto antígenos solúveis são capazes de induzir IL-12 e desta forma, estimular células efetoras 
como linfócitos T e células Natural Killer (NK) a produzir IFN- $\gamma$ (GAZZINELLI et al., 1994). Nas células NK a síntese de IFN- $\gamma$ é dependente de IL-12 e pode ser aumentada pelo IFN- $\gamma$, pelo TNF- $\alpha$ e pela IL-2 (GAZZINELLI et al., 1993). Acredita-se que na fase inicial da infecção, as células NK e os macrófagos são os principais responsáveis pela resistência inata, não-específica (FILISETTI; CANDOLFI, 2004).

A IL-12 é também citada como importante citocina na manutenção da resistência contra a toxoplasmose crônica. Camundongos IL-12 deficientes conseguiram responder à infecção quando tratados com IL-12 exógena. Ao redor de três semanas após a interrupção do tratamento observou-se um intenso aumento do número de cistos imaturos no cérebro, associadas a áreas de necrose e morte por encefalite aguda (YAP; PESIN; SHER, 2000).

Da mesma maneira que as DCs e as células NK, os macrófagos também contribuem na modulação da imunidade pela secreção de IL-12 e se destacam por exercer funções efetoras anti-microbianas. A produção de reagentes oxidativos, óxido nítrico e atividade de enzimas lisossomais constituem alguns dos vários mecanismos microbicidas dos macrófagos (STAFFORD; NEUMANN; BELOSEVIC, 2002).

O mecanismo de ativação do sistema imune é controlado por uma intrincada rede de citocinas. Parte destes mecanismos já são bem definidos no modelo experimental dos camundongos, mas alguns experimentos em suínos sugerem possíveis diferenças na resposta entre as espécies. Um exemplo é a via de ativação da produção de IFN- $\gamma$ pela ação da IL-12. Solano-Aguilar et al. (2002) não obtiveram êxito ao estimular a produção de IFN- $\gamma$ em linfócitos de suínos in vitro utilizando IL-12 recombinante (rIL-12) espécie específica. O mesmo experimento utilizando linfócitos de bovinos, a rIL-12 suína mostrou-se ativa, estimulando a produção de IFN- $\gamma$.

Ao comparar a indução de mRNA em culturas de células mononucleares do sangue periférico de suínos e bovinos, observa-se um aumento da expressão de IL12Rß2 nos bovinos, 
mas não nas células de suínos, o que leva a supor que a baixa resposta dos suínos à IL-12 esteja ligada à reduzida quantidade de receptores próprios (SOLANO-AGUILAR et al., 2002).

Este fato leva a considerar a possibilidade de vias alternativas de indução da produção de IFN- $\gamma$ independentes da IL-12. Sabe-se que camundongos infectados e tratados com anticorpos monoclonais (mAc) anti-IL12 são capazes de produzir IFN- $\gamma$ (SCHARTONKERSTEN et al., 1996a).

O estudo da atividade das citocinas deve portanto englobar todo um conjunto de citocinas que apresentam funções similares, pois sabe-se que diferentes citocinas são capazes de produzir o mesmo efeito final e agindo muitas vezes em sinergismo (LUNNEY, 1998). Um exemplo deste efeito é observado na ação sinérgica da IL-18 em relação à IL-12, aumentando a produção de IFN- $\gamma$ (CAI; KASTELEIN; HUNTER, 2000).

Camundongos deficientes de STAT4, proteína envolvida na sinalização intracelular da IL-12, são muito sensíveis a infecção pelo $T$. gondii por apresentar baixos níveis de IFN- $\gamma$. A administração associada de IL-2 e IL-18 foi capaz de induzir a produção de IFN- $\gamma$ e aumentar a sobrevida dos camundongos (CAI et al., 2000).

Este mesmo efeito foi observado em camundongos portadores de uma deficiência na sinalização da IL-12 que conseguiram recuperar a produção de IFN- $\gamma$ quando tratados com IL-18 (YAP et al., 2001).

Ao pensar em similaridades estruturais, a IL-23 se assemelha à IL-12 ao compartilhar a mesma a subunidade p40. Ambas são citocinas heterodiméricas, diferindo entre si pela associação das subunidades p19 e p35, respectivamente.

Infecções experimentais em camundongos e estimulação de DCs in vitro indicaram uma elevação da expressão de mRNA para IL23, levantando uma possível via alternativa de ativação do IFN- $\gamma$. Entretanto, em camundongos geneticamente modificados, a supressão dos 
genes p40 e p35 geraram maiores prejuízos à resposta contra o T. gondii do que a do gene p19 (LIEBERMAN et al., 2004).

Em infecções in vivo fica evidente que juntamente com o IFN- $\gamma$ outras citocinas inflamatórias agem na proteção contra o T. gondii. A deficiência de receptores para o TNF- $\alpha$ e a enzima iNOS também levam a uma maior suscetibilidade a infecção por $T$. gondii (YAP et al., 1998; YAP; SHER, 1999).

Em humanos os mecanismos de ativação associados a taquizoítos vivos, mortos e antígenos solúveis de $T$. gondii (STAg) são distintos. Parasitas vivos induzem a produção de IL-12 por DC humanas envolvendo vias ligadas a interação de antígenos CD40 e seu respectivo ligante, o CD40L, o que não é observado em estudos com lisados do $T$. gondii (SUBAUSTE; WESSENDARP, 2000). Nos camundongos esta interação CD40-CD40L não é essencial à resposta imune, pois DCs de camundongos deficientes em CD40 são capazes de produzir IL-12 em resposta a STAg e infecção com parasitas vivos (REICHMANN et al., 2000).

A interação CD40-CD40L é citada como uma das possíveis vias que substituem a via de sinalização do TNF (PEARCE; SCOTT; SHER, 1999).

Na imunidade inata a molécula adaptadora MyD88 está vinculada a ativação dos receptores Toll-like (TLR). Sabe-se que esta via dos TLRs também está envolvida na resposta à infecção, pois camundongos deficientes do gene MYD88 apresentam baixos níveis de IL-12 sérico e uma multiplicação descontrolada do T. gondii (SCANGA et al., 2002).

Em oposição ao raciocínio anterior em que diferentes citocinas levam ao mesmo efeito final, é importante ressaltar que uma citocina pode possuir funções múltiplas, isto é, uma única citocina é capaz de induzir diversas vias efetoras. O estudo de uma única citocina fornece uma lista de possíveis formas de controle da infecção pelo T. gondii, entretanto não é possível afirmar qual a via mais importante. 
Ao se falar em célula efetora e atividade anti-microbiana sabe-se que não somente células derivadas da medula óssea, mas também células somáticas de origem nãohematopoiética respondem ao estímulo do IFN- $\gamma$ e do TNF- $\alpha$, isto é, potencialmente vários tipos celulares podem responder às citocinas. O mecanismo efetor responsável pelo controle do T. gondii ainda não foi elucidado, existindo várias teorias sobre os possíveis fatores envolvidos.

A produção de reagentes tóxicos como o óxido nítrico (NO) é um dos mecanismos envolvidos no controle das infecções intracelulares por bactérias. A enzima responsável pela produção de NO pelas células é a NO sintase (NOS). Esta enzima é encontrada em diversas isoformas, sendo a iNOS a forma expressa em células imunes ativadas (STAFFORD; NEUMANN; BELOSEVIC, 2002). A indução da iNOS é observada em vários tipos celulares, entretanto a função microbicida do óxido nítrico (NO) parece estar restrita aos monócitos e macrófagos (NATHAN; XIE, 1994).

Em camundongos a indução da iNOS e a produção de NO é importante na defesa macrofágica contra o $T$. gondii, porém acredita-se que não seja o único mecanismo envolvido (HAYASHI et al., 1996; YAP; SHER, 1999). Infecções não-letais em camundongos normais tornam-se letais em camundongos deficientes do gene para a iNOS (DENKERS, 1999). Nos humanos, esta atividade ainda é controversa.

Ativação de mecanismos de depleção de nutrientes ao parasita é a outra hipótese para a diminuição da atividade dos taquizoítos. O IFN- $\gamma$ induz uma intensa produção de indoleamine 2,3-dioxigenase (INDO) nos macrófagos. Esta enzima que seria responsável pela depleção de triptofano necessário para a replicação do T. gondii (PFEFFERKORN, 1984). Porém somente a depleção de triptofano não é suficiente para garantir a inibição da multiplicação do parasita (MACKENZIE et al., 1999). 
A interação entre as diversas vias efetoras podem levar a resultados diferentes do esperado. A produção de NO pode inibir a expressão de INDO em macrófagos ativados por IFN- $\gamma$ (ALBERATI-GIANI et al., 1997).

A ativação da enzima arginase leva a depleção de arginina. A ausência de arginina, substrato para a enzima NO sintase, levaria a uma baixa produção de NO favorecendo o crescimento parasitário (VINCENDEAU et al., 2003).

Conforme avançam os conhecimentos acerca das citocinas observa-se uma necessidade de uma maior compreensão das múltiplas interações que regem a resposta imune. Partindo-se do conceito de que o equilíbrio entre citocinas pro e anti-inflamatórias seria fundamental para assegurar o combate da infecção sem levar a auto-destruição de tecidos do organismo, a ativação de fatores reguladores cumprem um importante papel na fase de recuperação e regeneração celular (DENKERS, 1999). A atividade regulatória é desempenhada tanto no meio extracelular por meio da secreção de citocinas regulatórias ou no intracelular pela ação de supressores da sinalização.

O efeito da hiperativação inflamatória e imunológica foi descrito em camundongos com infecções letais. Foram observadas excessiva produção de citocinas como IFN- $\gamma$ e TNF$\alpha$ associada a lesões intensas em tecido hepático e cerebral (MORDUE et al., 2001).

Dentre as citocinas regulatórias a IL-10 e o TGF- $\beta$ são as prováveis citocinas envolvidas no controle do efeito Th1 durante a toxoplasmose aguda. Embora primariamente classificada como uma citocina Th2, trabalhos recentes têm sugerido associar a IL-10 a células T regulatórias (COUSINS; LEE; STAYNOV, 2002; VOLK et al., 2001). Sabe-se que a IL-10 possui efeito inibitório sobre as citocinas IL-2, IFN- $\gamma$, TNF- $\alpha$ e fator estimulador de colônia granulocítica-macrofágica (GM-CSF), inibindo a resposta Th1, por supressão da IL12 (LEONARD, 1999). 
A lesão mais severa observada em camundongos deficientes em IL-10 infectados por T. gondii foi a necrose aguda de segmentos intestinais e do fígado. Interessantemente o bloqueio do efeito do IFN- $\gamma$, da IL-12 ou das células $\mathrm{CD}^{+}$por meio de anticorpos monoclonais prolongou a sobrevida destes camundongos (SUZUKI et al., 2000).

O TGF- $\beta$ inibe a atividade macrofágica induzida pelo IFN- $\gamma$ por meio da inibição da produção de TNF- $\alpha$ (LANGERMANS et al., 2001).

O efeito inibitório pode ocorrer no meio intracelular. Normalmente a junção da citocina em seu receptor produz uma sinalização intracelular que envolve a ativação de moléculas intracelulares como JAKs (Janus family kinases) e STATs (Signal transducers and activators of transcription). Cabe aos supressores da sinalização das citocinas (suppressors of cytokine signaling - SOCS) regular a sinalização intracelular (FUJIMOTO; NAKA, 2003).

SOCS1 foi inicialmente descrito como uma molécula induzida por STAT (STATinduced STAT inhibitor). Atualmente sabe-se que é induzida também pela insulina, lipopolissacarídeos (LPS), CpG DNA e outras moléculas que não ativam STATs. É um regulador negativo da sinalização de várias citocinas, entre elas IFN- $\gamma$, IL-6 e IL-4 (FUJIMOTO; NAKA, 2003).

A ausência do gene SOCS1 em camundongos causa morte antes de três semanas de vida, com retardo no crescimento, linfocitopenia, doença hepática e falência múltipla de órgãos. Os linfócitos destes camundongos apresentam-se ativados, mesmo quando criados em condições specific-pathogen-free (SPF). Camundongos SOCS1 e IFNG duplo negativos não apresentam as lesões inflamatórias observadas nos somente SOCS1 negativos e possuem uma sobrevida maior (FUJIMOTO; NAKA, 2003).

O padrão da resposta contra diferentes agentes indica que ocorrem diferentes mecanismos de ativação da imunidade adaptativa. Monócitos e células dendríticas humanas infectadas in vitro apresentaram padrões de expressão gênica distintos quando incubadas com 
Mycobacterium tuberculosis, Leishmania major, Leishmania donovani, T. gondii e Brugia malayi (CHAUSSABEL et al., 2003).

Frente a complexidade de fatores envolvidos na resposta a infecção pelo $T$. gondii e considerando a possibilidade da ativação de vias distintas a aquelas observadas nos camundongos, a espécie suína foi escolhida como modelo de estudo para o presente experimento.

A compilação das informações até aqui reunidas foi empregada para listar os principais genes de interesse no estudo da infecção pelo T. gondii. A compreensão dos fatores envolvidos na resistência dos suínos a toxoplasmose aguda poderá no futuro apontar novos caminhos para o desenvolvimento de adjuvantes de vacinas, imunoestimulantes e de terapias.

A técnica da Real-Time PCR foi escolhida por permitir a quantificação do produto da PCR de uma forma bastante acurada e de uma maneira bastante simples quando comparada às provas de PCR competitivo (BUSTIN, 2000; ZARLENGA; HIGGINS, 2001). Robustez, boa linearidade e capacidade de detecção de pequenas variações de DNA a tornaram uma boa alternativa para os estudos de resistência a doenças, resposta a drogas e funções metabólicas.

Visando o emprego da espécie suína como modelo para o estudo de resistência a doenças e afecções nutricionais, Dawson et al. (2001) catalogaram seqüências de suínos publicadas em diferentes bancos de acesso público (Genbank, TIGR), desenvolveram e testaram primers e sondas espécie específicos.

Os primeiros testes da Real-Time RT-PCR em suínos avaliaram o padrão de resposta de 24 genes à infecção por T. gondii e por Ascaris suum. Os resultados mostraram-se bastante consistentes com o esperado, revelando uma tendência a indução de citocinas Th1 na toxoplasmose e citocinas Th2 na infecção pelo A. suum (DAWSON et al., 2002a).

A boa performance da Real-Time RT-PCR levou à ampliação da lista de genes a serem testados. Um outro experimento avaliou-se 12 genes em amostras de linfonodo 
mesentérico e fígado de suínos infectados por T. gondii. Em ambos os tecidos houve forte indução dos genes IFNG e IRF1. Além destes dois genes, no fígado observou-se alterações também em outros genes associados à indução da resposta Th1, como HLX1, MYD88, STAT1, TBX21, CD8A, CD8B e CD28 (DAWSON et al., 2004).

Nos experimentos iniciais de Dawson et al. (2002a) os suínos foram necropsiados após 7 e 14 dias pós-infecção (DPI) pelo T. gondii e observou-se uma forte indução de IFNG no dia 7 e uma diminuição da resposta no dia 14, sugerindo uma tendência a resolução do processo após este período. No presente experimento as necrópsias foram realizadas em dias mais precoces de infecção e avaliados um maior número de genes.

Os genes foram selecionados com base em dados registrados em publicações recentes a respeito dos fatores ligados à resistência e à imunopatologia da toxoplasmose e foram categorizados segundo a função primária em: 1) genes housekeeping (constitutivo); 2) defesa inata e inflamatória; 3) resposta $\mathrm{Th} 1$; 4) resposta $\mathrm{Th} 2$; 5) efetor; 6) regulatório; 7) coestimulatório e 8) apoptose. 
Os principais objetivos deste trabalho foram:

- a quantificação da expressão gênica em tecidos de suínos infectados pelo T. gondii,

- a avaliação da variação da expressão em diferentes períodos durante a infecção aguda,

- a observação do padrão de resposta local em diferentes tecidos e desta forma,

- identificar possíveis genes associados a resistência a infecção.

Complementando a avaliação da expressão gênica, a resposta imune dos suínos foi também acompanhada por meio de determinações séricas de IFN- $\gamma$, óxido nítrico e haptoglobina; análise de subpopulações de células por citometria de fluxo e cultura de células para mensuração de produção de IFN- $\gamma$. A presença do T. gondii foi confirmada pela identificação do parasita nos tecidos e associado a lesões histopatológicas. 


\section{MATERIAL E MÉTODO}

\subsection{LOCAL}

O experimento foi realizado nas instalações do Departamento de Agricultura dos Estados Unidos da América (USDA), na cidade de Beltsville, Estado de Maryland, EUA. Os suínos experimentais foram mantidos em instalações próprias da Unidade de Parasitologia Animal (APU) seguindo as Normas de Biosegurança do USDA. Todo material biológico foi processado nos Laboratórios: Immunology and Disease Resistance Laboratory (IDRL), Parasite Biology, Epidemiology and Systematics Laboratory (PBESL) ${ }^{1}$, pertencentes ao Animal and Natural Resources Institute (ANRI) e Nutrient Requirements and Functions Laboratory (NRFL), do Beltsville Human Nutrition Research Center, Agricultural Research Service (ARS), USDA.

\subsection{ANIMAIS}

Suínos Poland China x Landrace provenientes da fazenda experimental do USDA, foram alojados em instalações apropriadas com ração comercial balanceada e água ad libitum. O manejo diário dos animais assim como todo procedimento experimental foram executados pelo pessoal técnico responsável seguindo as normas de conduta aprovadas pelo Beltsville Area Animal Care and Use Committee do ANRI, USDA.

\footnotetext{
${ }^{1}$ Atualmente IDRL foi incorporado ao PBESL e denominado Animal Parasitic Diseases Laboratory.
} 
Antes do início do experimento, amostras de sangue foram colhidas para detecção de anticorpos séricos anti-T. gondii por meio da prova de aglutinação modificada (MAT).

\subsection{Toxoplasma gondii}

Foram utilizadas amostras de $T$. gondii das cepas VEG e RH fornecidas pelo PBESL.

Oocistos de T. gondii da cepa VEG foram isolados de fezes de gatos experimentalmente infectados (DUBEY et al., 1996). Após a esporulação, a infectividade e a viabilidade dos oocistos foram testados em camundongos (DUBEY et al., 1998) e utilizados como inóculo nas infecções experimentais.

A cepa VEG foi primariamente isolada de um paciente humano portador de HIV, é caracterizada como um isolado avirulento para camundongos e é genotipicamente classificada como do tipo III baseada em análise do gene SAG (DUBEY et al., 1996; HOWE et al., 1997).

Taquizoítos de T. gondii da cepa RH foram isolados e purificados do líquido ascítico de camundongos experimentalmente infectados e utilizados como controle positivo nas reações de PCR.

\subsection{DELINEAMENTO EXPERIMENTAL}

Foram realizados dois experimentos similares, utilizando suínos com idades variando de três a cinco meses de idade infectados oralmente com $4,5 \times 10^{5}$ oocistos de $T$. gondii (cepa 
VEG). Os animais infectados foram necropsiados após dois, quatro, sete e 14 dias de infecção. Para cada dia de infecção, foi necropsiado um animal controle.

Os grupos experimentais foram denominados “2DPI”, “4DPI”, “7DPI” e "14DPI” de acordo com o tempo de infecção em dias pós-infecção e "Controle" para o grupo de animais não-infectados.

\section{EXPERIMENTO I}

No primeiro experimento (EXP I) foram utilizados doze animais. Os grupos 2DPI e 4DPI eram constituídos por três animais, enquanto que os grupos Controle, 7DPI e 14DPI eram formados por dois animais.

A resposta de defesa dos animais foi avaliada por meio de:

- Mensuração da expressão gênica em amostras de linfonodos mesentérico (LN M), hepato-esplênico (LN HS), íleo-cólico (LN IC), células mononucleares do sangue periférico (CMSP), fígado, baço, timo, jejuno e íleo por meio de transcrição reversa seguida de reação em cadeia pela polimerase em tempo real (Real-Time RT-PCR).

- Mensuração dos níveis séricos de IFN- $\gamma$, de óxido nítrico (NO) e de haptoglobina.

- Produção de IFN- $\gamma$ pelas células mononucleares do sangue periférico (CMSP) e linfonodos.

- Análise de subpopulações de células por citometria de fluxo (FCM).

A presença do T. gondii e as lesões teciduais foram avaliadas por meio de:

- Detecção de T. gondii em amostras de LN M, fígado, pulmão, baço e íleo por meio da Real-Time PCR. 
- Exames histopatológicos corados pela Hematoxilina e Eosina (HE) e imunohistoquímica (IHQ).

- Função e lesão hepática foi avaliada por meio de mensuração sérica de enzimas hepáticas, proteínas totais, albumina, globulinas, bilirrubinas total e direta.

A partir dos resultados preliminares do EXP I, procedeu-se um segundo experimento (EXP II), em que foram testados um painel distinto de genes na Real-Time RT-PCR. Foram mantidos 30 genes do painel anterior, excluídos 18 e incluídos 18 novos genes.

\section{EXPERIMENTO II}

No segundo experimento (EXP II) foram utilizados 16 animais, quatro controles e três animais para cada grupo infectado (2DPI, 4DPI, 7DPI e 14DPI).

A resposta imune destes animais foi acessada por meio de:

- Mensuração da expressão gênica em linfonodos mesentérico e hepato-esplênico, fígado, jejuno e íleo utilizando Real-Time RT-PCR.

- Mensuração dos níveis séricos de haptoglobina.

- Produção de IFN- $\gamma$ pelas CMSP, células dos LN M e LN HS.

A infecção e a lesão causada pelo T. gondii foi avaliada por meio de:

- Exames histopatológicos corados pela HE e IHQ.

- Perfil hepático por meio de mensuração sérica de enzimas hepáticas, proteínas totais, albumina, globulinas, bilirrubinas total e direta. 


\subsection{SACRIFÍCIO DOS SUÍNOS E COLHEITA DAS AMOSTRAS}

Animas foram sacrificados por superdosagem de anestésicos e imediatamente necropsiados. Amostras de tecidos e sangue foram separados e adequadamente acondicionados para cada prova a ser realizada (Figura 3.1):

1) Colheita de tecidos para mensuração de expressão mRNA: Fragmentos de linfonodos mesentérico, traqueo-bronquial, íleo-cólico e hepato-esplênico; jejuno, íleo, fígado, baço e timo foram colhidos e imediatamente congelados em nitrogênio $\left(\mathrm{N}_{2}\right)$ líquido, transportados ao laboratório e mantidos em freezer $-70^{\circ} \mathrm{C}$ até o processamento.

2) Sangue total em tubos contendo anti-coagulante (ácido etileno diaminotetracetato sódico - EDTA) para separação das CMSP e hemograma.

3) Linfonodos (hepato-esplênico, traqueo-bronquial, mesentérico) em meio de colheita (Apêndice A) para separação de células mononucleares para FCM e cultivo em meio para avaliação da produção de IFN- $\gamma$.

4) Amostras de LN M, fígado, baço, pulmão e íleo foram mantidas em gelo e enviadas ao laboratório para extração de DNA para detecção de $T$. gondii. 
5) LN M, fígado, baço, pulmão e íleo foram fixados em formol tamponado para exame histopatológico.

6) Sangue para separação de soro para detecção de anticorpos séricos anti-T. gondii, avaliação do perfil hepático, IFN- $\gamma$ sérico, NO e haptoglobina.

Todos os animais e material descartável utilizados foram incinerados após a colheita das amostras.

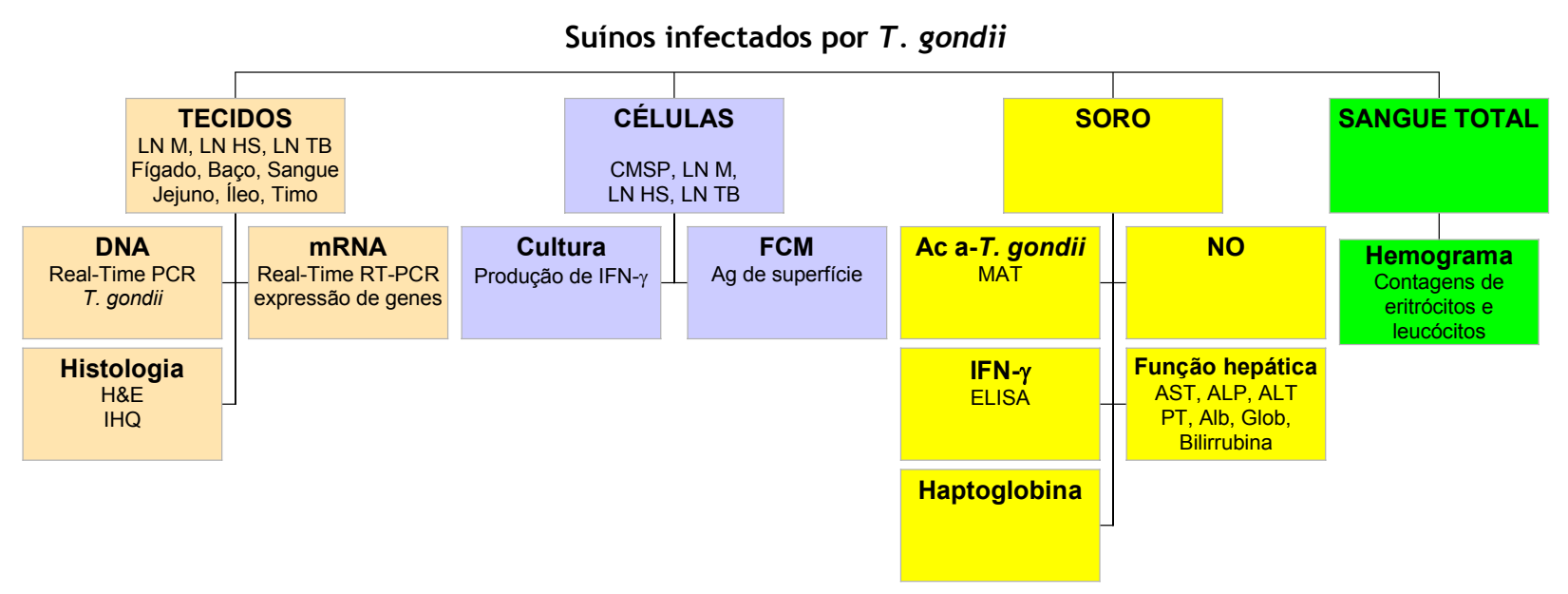

Figura 3.1 - Organograma de colheita e exame das amostras dos suínos experimentais Beltsville - 2003

\subsection{ISOLAMENTO E PREPARO DAS CÉLULAS}

Procedeu-se o isolamento de células do sangue periférico e dos linfonodos mesentérico, hepato-esplênico e traqueo-bronquial para a realização das culturas in vitro (item 
3.7), análise fenotípica de subpopulações por citometria de fluxo (item 3.8) e extração de RNA (item 3.9.1).

\subsubsection{Separação de Células Mononucleares do Sangue Periférico}

Células mononucleares circulantes no sangue periférico foram separadas por meio de gradiente de densidade. Para isto, foram colhidos 15 a $20 \mathrm{ml}$ de sangue total em tubos contendo EDTA e imediatamente enviados ao laboratório para o processamento.

Células mononucleares foram separadas utilizando o meio para separação de linfócitos (Lymphocyte Separation Medium, LSM, Cappel, Aurora, EUA) ${ }^{2}$ conforme instruções da bula. As células recuperadas foram lavadas em meio PBL (Apêndice B) e ressuspensas em meio blastogênico (Apêndice C).

A determinação do número total de células e a estimativa da porcentagem de células vivas foram feitas por microscopia óptica utilizando Azul de Trypan e hemocitômetros de Neubauer.

\subsubsection{Separação de Células dos Linfonodos}

A separação das células dos linfonodos foi realizado segundo Solano-Aguilar (2000). (SOLANO-AGUILAR et al., 2000). As amostras de linfonodo removidas durante a necrópsia

\footnotetext{
${ }^{2}$ Composição LSM=6,2g Ficoll e 9,4 Na diatrizoate $/ 100 \mathrm{ml}$; Densidade $=1.0770-1.0800 \mathrm{~g} / \mathrm{ml} \mathrm{a} 20^{\circ} \mathrm{C}$.
} 
foram imediatamente colocadas em tubos cônicos contendo meio de colheita (Apêndice A) e mantidas em recipientes contendo gelo.

Após a remoção tecido conjuntivo e adiposo adjacente, o linfonodo foi delicadamente cortado em pequenos fragmentos em placas de Petri contendo meio de colheita, liberando as células do tecido. A suspensão de células foi filtrada em malhas de nylon estéreis de $210 \mu \mathrm{m}$.

As células foram lavadas em HBSS (Hank's Balanced Salt Solution, Gibco, EUA) ou RPMI-1640 (Invitrogen, Calsbad, EUA) e ressuspensas em meio blastogênico. A contagem do número total de células e da porcentagem de viabilidade foi realizada seguindo o mesmo procedimento descrito acima.

\subsection{CULTURA IN VITRO}

Para avaliação da atividade das CMSP e das células dos LN, estas foram incubadas a 2,5 x 10\% $/ \mathrm{ml}$ em meio de cultura completo (Apêndice D) estimuladas com Concanavalin A (ConA - Sigma, Saint Louis, EUA) a $10 \mu \mathrm{g} / \mathrm{ml}$ por 48 horas a $37^{\circ} \mathrm{C}$ e $5 \%$ de $\mathrm{CO}_{2}$. Ao término do período de incubação o sobrenadante foi separado por centrifugação e mantido a $-20^{\circ} \mathrm{C}$ para posterior mensuração de IFN- $\gamma$. 


\subsection{ANÁLISE DE SUBPOPULAÇÕES DE CÉLULAS}

A caracterização fenotípica de sub-populações de CMSP e células isoladas dos LN M, HS e TB foi realizada por citometria de fluxo após a identificação por meio de anticorpos monoclonais anti: CD45 (clone 74-9-3), SLAI (clone PT85), CD2 (clone MSA4), CD16 (clone G7), CD3 (clone BB23 8E6), CD25 (clone 231-3B2), CD4 (clone 74-12-4), CD8 (clone 76-2-11), SLAII DQ (clone TH16), SWC3 (clone 74-22-15B) e CD21 (clone CC51) (SAALMUELLER et al., 1998). Após incubação com anti-Ig específico (IgG1, G2a ou G2b) conjugado a isotiocianato de fluoresceína (FITC) ou ficoeritrina (PE), a proporção relativa das sub-populações foi estimada após a leitura de dez mil células por citometria de fluxo no EPICS-XL MCL (Beckman-Coulter, EUA). Foram também realizadas as determinações de populações de células duplo-positivas (DP) para CD2/CD16, CD3/CD25, CD4/CD8 e SWC3/SLADQ. (SOLANO-AGUILAR et al., 2001; SOLANO-AGUILAR et al., 2000).

\subsection{PREPARO DAS AMOSTRAS PARA A REAL-TIME RT-PCR}

As amostras de tecidos e células foram conservadas em freezer $-70^{\circ} \mathrm{C}$ para a determinação da expressão gênica. Foram realizadas extrações do RNA, determinação da concentração do RNA, remoção de possíveis resíduos de DNA genômico, verificação da qualidade e da concentração do RNA após o tratamento com DNase e síntese de cDNA. 


\subsubsection{Extração de RNA}

Amostras de células ou de tecido foram homogenizadas no reagente Trizol $^{\circledR}$ (Invitrogen, Carlsbad, EUA). Foram empregadas as proporções de: $1 \times 10^{7}$ células em $1 \mathrm{ml}$ de reagente Trizol ${ }^{\circledR}$ ou até $50 \mathrm{mg}$ de tecido em $1 \mathrm{ml}$ de reagente Trizol ${ }^{\circledR}$. Os tecidos congelados foram inicialmente macerados com cadinho e pistilo em nitrogênio líquido e imediatamente homogenizadas em Trizol ${ }^{\circledR}$ utilizando homogenizador de tecidos (Polytron ${ }^{\circledR}$, EUA).

O RNA foi extraído seguindo protocolo do fabricante (Invitrogen, Carlsbad, EUA) e mantido em freezer $-70^{\circ} \mathrm{C}$.

\subsubsection{Quantificação de RNA por Espectrofotometria}

Amostras de RNA foram diluídas em tampão Tris-EDTA (10mM Tris-HCl, $1 \mathrm{mM}$ EDTA pH 8,0). A concentração do RNA foi estimada após leitura da absorvância a 260 e 280 nm em espectrofotômetro (DU640, Beckman Coulter, EUA). 


\subsubsection{Tratamento com DNase}

Com intuito de remover possíveis resíduos de DNA genômico, todas as amostras de RNA foram adsorvidas em colunas RNeasy (Qiagen, Valencia, EUA) e incubadas com DNase (RNase-free DNase set, Qiagen, Valencia, EUA).

\subsubsection{Determinação da Concentração e da Qualidade do RNA}

A concentração e a integridade do RNA foram mensuradas pelo RNA 6000 nano Assay utilizando o equipamento Agilent 2100 Bioanalyzer (Agilent Technologies, Palo Alto, EUA). A quantificação do RNA foi determinado baseado no padrão RNA 6000 Ladder (Ambion, Austin, EUA). 


\subsubsection{Síntese de cDNA}

cDNA foi sintetizado por transcriptase reversa a partir de $10 \mu \mathrm{g}$ de RNA total utilizando Superscript II Rnase $H^{-}$Reverse Transcriptase e Oligo(dT) $)_{12-18}$ (Invitrogen, Carlsbad, EUA) em presença de inibidores de ribonucleases (RNaseOUT recombinant ribonuclease inhibitor, Invitrogen, Carlsbad, EUA), seguindo as recomendações do fabricante. As amostras de cDNA foram mantidas em freezer $-20^{\circ} \mathrm{C}$ até a realização das provas de Real-Time PCR.

\subsection{REAL-TIME PCR}

Reagentes espécie específicos foram desenvolvidos para a realização da Real-Time PCR. Antes do início dos experimentos, a capacidade de deteç̧ão das variações na expressão dos genes foi testado em suínos submetidos a diferentes infecções (DAWSON et al., 2002b). 


\subsubsection{Genes}

A seleção dos genes foi realizada a partir de dados obtidos da literatura referente a defesa contra a toxoplasmose em camundongos. Foi dada ênfase à resposta associada ao IFN$\gamma$, genericamente conhecida como resposta Th1 e também incluídos genes ligados à indução, modulação, apoptose e resposta inflamatória conforme apresentado no quadro 3.1. Os genes podem possuir funções diferentes das aqui listadas porém foram arbitrariamente organizados segundo a função primária pela qual foi testado.

As siglas seguem a nomenclatura oficial adotada para genes humanos conforme o Human Gene Nomenclature Committee (HGNC) do Human Genome Organization (HUGO). Devido a constantes atualizações na nomenclatura, possíveis diferenças podem ser notadas entre as siglas aqui adotadas e as atualmente vigentes. As informações do quadro referem-se às publicadas em janeiro de 2004 no site $<$ http://www.gene.ucl.ac.uk/nomenclature $>$ e foram mantidos os nomes originais em inglês. 


\begin{tabular}{|c|c|c|c|c|}
\hline $\begin{array}{c}\text { Função } \\
\text { primária }\end{array}$ & Gene & Nome e nomes alternativos & $\begin{array}{l}\text { Número de } \\
\text { acesso }\end{array}$ & EXP \\
\hline Housekeeping & RPL13A & Ribosomal protein L13a & Z84103 & I \\
\hline Housekeeping & RPL32 & Ribosomal protein L32 & F14630 & I e II \\
\hline $\begin{array}{l}\text { Inato / } \\
\text { Inflamatório }\end{array}$ & IFNA1 & Interferon, alpha 1 & X57191 & I e II \\
\hline $\begin{array}{l}\text { Inato / } \\
\text { Inflamatório }\end{array}$ & IL1B & Interleukin 1 , beta & X74568 & I e II \\
\hline $\begin{array}{l}\text { Inato / } \\
\text { Inflamatório }\end{array}$ & IL6 & Interleukin 6 , interferon beta 2 & M86722 & I e II \\
\hline $\begin{array}{l}\text { Inato / } \\
\text { Inflamatório }\end{array}$ & ORM1 & Orosomucoid $1, \alpha$-acid glycoprotein & M35990 & $\mathrm{I}$ \\
\hline $\begin{array}{l}\text { Inato / } \\
\text { Inflamatório }\end{array}$ & TNF & $\begin{array}{c}\text { Tumor necrosis factor; TNF superfamily, } \\
\text { member } 2 \text {, TNFA }\end{array}$ & X54001 & I e II \\
\hline $\begin{array}{l}\text { Inato / } \\
\text { Inflamatório }\end{array}$ & TNFRSF1A & $\begin{array}{l}\text { Tumor necrosis factor receptor superfamily, } \\
\text { member 1A, TNFR p55, TNFR1 }\end{array}$ & U19994 & $\mathrm{I}$ \\
\hline $\begin{array}{l}\text { Inato / } \\
\text { Inflamatório }\end{array}$ & TLR2 & Toll-like receptor 2 & BF442348 & I e II \\
\hline $\begin{array}{l}\text { Inato / } \\
\text { Inflamatório }\end{array}$ & TLR4 & Toll-like receptor 4 & TC43435 & I e II \\
\hline $\begin{array}{l}\text { Inato / } \\
\text { Inflamatório }\end{array}$ & CRP & C-Reactive protein, pentraxin-related & AB005545 & II \\
\hline $\begin{array}{l}\text { Inato / } \\
\text { Inflamatório }\end{array}$ & MYD88 & $\begin{array}{l}\text { Myeloid differentiation primary response } \\
\text { gene } 88, \text { MyD } 88\end{array}$ & AY435217 & II \\
\hline $\begin{array}{l}\text { Inato / } \\
\text { Inflamatório }\end{array}$ & FCGR3A & $\begin{array}{l}\text { Fc fragment of IgG, low affinity IIIa, } \\
\text { receptor, CD16 }\end{array}$ & AF372453 & II \\
\hline $\begin{array}{l}\text { Inato / } \\
\text { Inflamatório }\end{array}$ & IL8 & Interleukin 8, CXCL8 & M86923 & $\mathrm{II}^{*}$ \\
\hline $\begin{array}{l}\text { Inato / } \\
\text { Inflamatório }\end{array}$ & CCL2 & Chemokine (C-C motif) ligand 2, MCP-1 & Z48479 & $\mathrm{II}^{*}$ \\
\hline $\begin{array}{l}\text { Inato / } \\
\text { Inflamatório }\end{array}$ & CCL5 & Chemokine (C-C motif) ligand 5, RANTES & F14636 & $\mathrm{II}^{*}$ \\
\hline
\end{tabular}

Quadro 3.1 - Genes avaliados pela Real-Time RT-PCR nos suínos infectados por $T$. gondii. Função primária, siglas dos genes, nomes e nomes alternativos, número de acesso no Genbank das seqüências utilizadas para o desenho dos primers e sondas e número do experimento (EXP) em que foi testado - Beltsville - 2003 
(continua)

\begin{tabular}{|c|c|c|c|c|}
\hline $\begin{array}{l}\text { Função } \\
\text { primária }\end{array}$ & Gene & Nome e nomes alternativos & $\begin{array}{l}\text { Número de } \\
\text { acesso }\end{array}$ & EXP \\
\hline Th1 & IFNG & Interferon gamma & X53085 & I e II \\
\hline Th1 & IFNR1 & Interferon gamma receptor $1, \mathrm{CDw} 119$ & & II \\
\hline Th1 & IL12A & $\begin{array}{c}\text { Interleukin } 12 \mathrm{~A} \text { (Natural killer cell } \\
\text { stimulatory factor } 1 \text {, cytotoxic lymphocyte } \\
\text { maturation factor } 1, \mathrm{p} 35)\end{array}$ & L35765 & I e II \\
\hline Th1 & IL12B & $\begin{array}{c}\text { Interleukin } 12 \mathrm{~B} \text { (Natural killer cell } \\
\text { stimulatory factor } 2 \text {, cytotoxic lymphocyte } \\
\text { maturation factor } 2, \mathrm{p} 40 \text { ) }\end{array}$ & U08317 & I e II \\
\hline Th1 & IL12RB2 & Interleukin 12 receptor, beta 2 & AF448143 & I e II \\
\hline Th1 & IL15 & Interleukin 15 & U58142 & I e II \\
\hline Th1 & IL18 & $\begin{array}{l}\text { Interleukin } 18, \text { interferon-gamma-inducing- } \\
\text { factor }\end{array}$ & AF176949 & I e II \\
\hline Th1 & IL18R & Interleukin 18 receptor & AB079258 & II \\
\hline Th1 & IL23A & Interleukin 23, alpha subunit p19, SGRF & $\mathrm{AB} 030002$ & I \\
\hline Th1 & IRF1 & Interferon regulatory factor 1 & TC86234 & I e II \\
\hline Th1 & HLX1 & H2.0-like homeo box 1 & TC98154 & $\mathrm{II} * *$ \\
\hline Th1 & ICSBP1 & IFN consensus sequence binding protein 1 & AY435218 & $\mathrm{II}^{* *}$ \\
\hline Th1 & TBX21 & T-bet & AY435216 & II ** \\
\hline Th1 & LEP & Leptin & F167719 & I \\
\hline Th1 & LEPR & Leptin Receptor & AF203034 & I \\
\hline Th1 & STAT1 & $\begin{array}{l}\text { Signal transducer and activator of } \\
\text { transcription } 1,91 \mathrm{kDa}\end{array}$ & TC95137 & I e II \\
\hline Th1 & STAT4 & $\begin{array}{l}\text { Signal transducer and activator of } \\
\text { transcription } 4\end{array}$ & AB020984 & I e II* \\
\hline Th1 & SOCS1 & $\begin{array}{l}\text { Suppressor of cytokine signalling 1, STAT- } \\
\text { induced STAT inhibitor 1, SSI1 }\end{array}$ & TC63788 & I \\
\hline Th1 & SOCS2 & $\begin{array}{l}\text { Suppressor of cytokine signalling 2, STAT- } \\
\text { induced STAT inhibitor 2, SSI2 }\end{array}$ & BE031084 & I \\
\hline
\end{tabular}

Quadro 3.1 - Genes avaliados pela Real-Time RT-PCR nos suínos infectados por T. gondii. Função primária, siglas dos genes, nomes e nomes alternativos, número de acesso no Genbank das seqüências utilizadas para o desenho dos primers e sondas e número do experimento (EXP) em que foi testado - Beltsville - 2003 
(continua)

\begin{tabular}{|c|c|c|c|c|}
\hline $\begin{array}{l}\text { Função } \\
\text { primária }\end{array}$ & Gene & Nome e nomes alternativos & $\begin{array}{l}\text { Número de } \\
\text { acesso }\end{array}$ & EXP \\
\hline Th2 & IL4 & Interleukin 4 & X68330 & I e II \\
\hline Th2 & IL5 & $\begin{array}{c}\text { Interleukin 5, colony-stimulating factor, } \\
\text { eosinophil }\end{array}$ & SSC010088 & I e II* \\
\hline Th2 & IL13 & Interleukin 13 & AF385626 & I e II \\
\hline Th2 & GATA3 & GATA binding protein 3 & TC62266 & II \\
\hline Th2 & STAT6 & $\begin{array}{l}\text { Signal transducer and activator of } \\
\text { transcription } 6\end{array}$ & TC56734 & I \\
\hline Th2 & SOCS3 & $\begin{array}{l}\text { Suppressor of cytokine signalling 3, STAT- } \\
\text { induced STAT inhibitor 3, SSI3 }\end{array}$ & BM485092 & I \\
\hline Efetor & INDO & Indoleamine-pyrrole 2,3 dioxygenase, IDO & TC38943 & I e II \\
\hline Efetor & NOS2A & Nitric oxide synthase 1 , inducible, iNOS & U59390 & I e II \\
\hline Efetor & ARG1 & Arginase 1 , liver & AYO39112 & I e II \\
\hline Efetor & SLC11A1 & $\begin{array}{c}\text { Solute carrier family } 11 \text {, proton-coupled } \\
\text { divalent metal ion transporters, member } 1 \\
\text { (Natural Resistance Associated Macrophage } \\
\text { Protein, NRAMP1) }\end{array}$ & AF132037 & I e II \\
\hline Efetor & SLC11A2 & $\begin{array}{c}\text { Solute carrier family } 11 \text {, proton-coupled } \\
\text { divalent metal ion transporters, member } 2 \\
\text { (Natural Resistance Associated Macrophage } \\
\text { Protein, NRAMP2) }\end{array}$ & AW417353 & I \\
\hline Efetor & IGM & IgM, Immunoglobulin M constant region & M92050 & I e II \\
\hline Efetor & IGG & IgG, Immunoglogulin G constant region & AF062384 & I e II \\
\hline Efetor & IGA & IgA, Immunoglobulin A constant region & U12594 & I e II \\
\hline Efetor & CD19 & B-lymphocyte antigen & AF466765 & I \\
\hline Regulatório & IL2 & Interleukin 2 & X56750 & I \\
\hline Regulatório & IL2RA & Interleukin receptor, alpha; CD25 & $\mathrm{U} 78317$ & I \\
\hline Regulatório & IL10 & Interleukin 10 & L20001 & I e II \\
\hline
\end{tabular}

Quadro 3.1 - Genes avaliados pela Real-Time RT-PCR nos suínos infectados por T. gondii. Função primária, siglas dos genes, nomes e nomes alternativos, número de acesso no Genbank das seqüências utilizadas para o desenho dos primers e sondas e número do experimento (EXP) em que foi testado - Beltsville - 2003 


\begin{tabular}{|c|c|c|c|c|}
\hline $\begin{array}{l}\text { Função } \\
\text { primária }\end{array}$ & Gene & Nome e nomes alternativos & $\begin{array}{l}\text { Número de } \\
\text { acesso }\end{array}$ & EXP \\
\hline Regulatório & TGFB1 & Transforming growth factor, beta 1 & M23703 & I e II \\
\hline Regulatório & TGFB2 & Transforming growth factor, beta 2 & X70142 & I \\
\hline Regulatório & TGFB3 & Transforming growth factor, beta 3 & $\mathrm{X} 14150$ & $\mathrm{I}$ \\
\hline Regulatório & CSF2 & $\begin{array}{l}\text { GM-CSF, Colony stimulating factor } 2, \\
\text { granulocyte-macrophage }\end{array}$ & D21074 & I \\
\hline Regulatório & MHC2TA & MHC class II transactivator, CIITA & AY084053 & I e II \\
\hline $\begin{array}{l}\text { Co- } \\
\text { estimulatório }\end{array}$ & ICOS & Inducible T-cell co-stimulator & BE015025 & II \\
\hline $\begin{array}{l}\text { Co- } \\
\text { estimulatório }\end{array}$ & CD3E & $\begin{array}{l}\text { CD3E antigen, epsilon polypetide (TiT3 } \\
\text { complex) }\end{array}$ & U08270 & I e II \\
\hline $\begin{array}{l}\text { Co- } \\
\text { estimulatório }\end{array}$ & $\mathrm{CD} 28$ & CD28 antigen, (Tp44) & AY435219 & II $* *$ \\
\hline $\begin{array}{l}\text { Células T/ } \\
\text { Co- } \\
\text { estimulatório }\end{array}$ & CD69 & $\begin{array}{c}\text { CD69 antigen, p60, early T-cell activation } \\
\text { antigen }\end{array}$ & AF484233 & I e II \\
\hline $\begin{array}{l}\text { Co- } \\
\text { estimulatório }\end{array}$ & CTLA4 & $\begin{array}{l}\text { Cytotoxic T-lymphocyte-associated protein } \\
\text { 4, CD152 }\end{array}$ & AF220248 & II \\
\hline $\begin{array}{l}\text { Co- } \\
\text { estimulatório }\end{array}$ & TNFRSF5 & $\begin{array}{l}\text { Tumor necrosis factor receptor superfamily, } \\
\text { member } 5 \text {, CD } 40\end{array}$ & AF248545 & II \\
\hline $\begin{array}{l}\text { Co- } \\
\text { estimulatório }\end{array}$ & TNFSF5 & $\begin{array}{l}\text { Tumor necrosis factor (ligand) superfamily, } \\
\text { member5, CD40L, CD154 }\end{array}$ & AF263915 & II \\
\hline $\begin{array}{l}\text { Co- } \\
\text { estimulatório }\end{array}$ & CD80 & B7-1, CD28 antigen ligand 1, B7-1 antigen & AB049760 & II \\
\hline $\begin{array}{l}\text { Co- } \\
\text { estimulatório }\end{array}$ & CD86 & B7-2, CD28 antigen ligand 2, B7-2 antigen & L76099 & II \\
\hline Apoptose & TNFRSF6 & $\begin{array}{l}\text { Tumor necrosis factor receptor superfamily, } \\
\text { member 6; CD95; Fas }\end{array}$ & SSJ001202 & $\mathrm{II} * *$ \\
\hline Apoptose & CASP1 & Caspase, Apoptosis-related cysteine protease & AB027296 & II \\
\hline
\end{tabular}

*somente em amostras de jejuno do EXP II, ** exceto as amostras de jejuno do EXP II

Quadro 3.1 - Genes avaliados pela Real-Time RT-PCR nos suínos infectados por T. gondii. Função primária, siglas dos genes, nomes e nomes alternativos, número de acesso no Genbank das seqüências utilizadas para o desenho dos primers e sondas e número do experimento (EXP) em que foi testado - Beltsville - 2003 


\subsubsection{Otimização da Real-Time PCR}

As seqüências dos genes a serem testados foram obtidas de bancos de dados públicos do National Center for Biotechnology Information (Genbank, NCBI) e do The Institute for Genomic Research (TIGR). Os primers e as sondas foram desenhados utilizando o software Primer Express versão 1.5a (PE Applied Biosystems, Foster City, EUA). Os critérios para desenho de primers e sondas estão listados no apêndice E. Primers e sondas foram sintetizados por Biosource (Biosource International Inc., Camarillo, EUA).

O processo de padronização da reação e a avaliação dos primers e sondas foram apresentadas em encontros por Dawson et al. (2002b) e os resultados enviados para publicação. No apêndice F está um resumo dos principais passos seguidos para a avaliação de cada conjunto de primers e sonda.

A lista completa contendo as seqüências e as concentrações ótimas dos primers e das sondas estarão disponibilizadas na homepage do USDA < http://www.anri.barc.usda.gov>.

\subsubsection{Condições da Reação e Análise dos Resultados}

Os ensaios foram realizados no ABI Prism 7700 Sequence Detection System (PE Applied Biosystems, Foster City, EUA) e os resultados analisados utilizando o software Sequence Detection System versão 1.7a (SDS 1.7a, PE Applied Biosystems).

Para cada reação foram utilizados 100ng de cDNA (quantidade de cDNA calculado a partir da quantidade de RNA, item 3.9.5). 
As reações foram preparadas utilizando o Brilliant ${ }^{\mathrm{TM}}$ Quantitative PCR Core Reagent kit (Stratagene, La Jolla, EUA) segundo as recomendações do fabricante. A concentração de cloreto de magnésio $\left(\mathrm{MgCl}_{2}\right)$ foi ajustado para 5,5mM e volume final da reação foi $25 \mu$.

Os pares de corantes fluorescentes, indicador e de extinção, foram respectivamente FAM-TAMRA e TET-BHQ1. Para todas as reações utilizou-se o corante ROX como referência.

$\mathrm{O}$ termo-ciclador foi programado para realizar $50^{\circ} \mathrm{C}$ por 2 minutos; $95^{\circ} \mathrm{C}$ por 10 minutos e 40 repetições de $95^{\circ} \mathrm{C}$ por 15 segundos e $60^{\circ} \mathrm{C}$ por um minuto.

Ao final da reação todas as curvas de amplificação foram analisadas e os resultados da Real-Time PCR expressos em valores de Ct (número de ciclos necessários para atingir o limiar de detecção). O limiar de detecção foi determinado a partir dos níveis basais de fluorescência detectados nos ciclos iniciais (entre os ciclos três e dez) mais 20 vezes o desvio padrão (Figura 3.2).

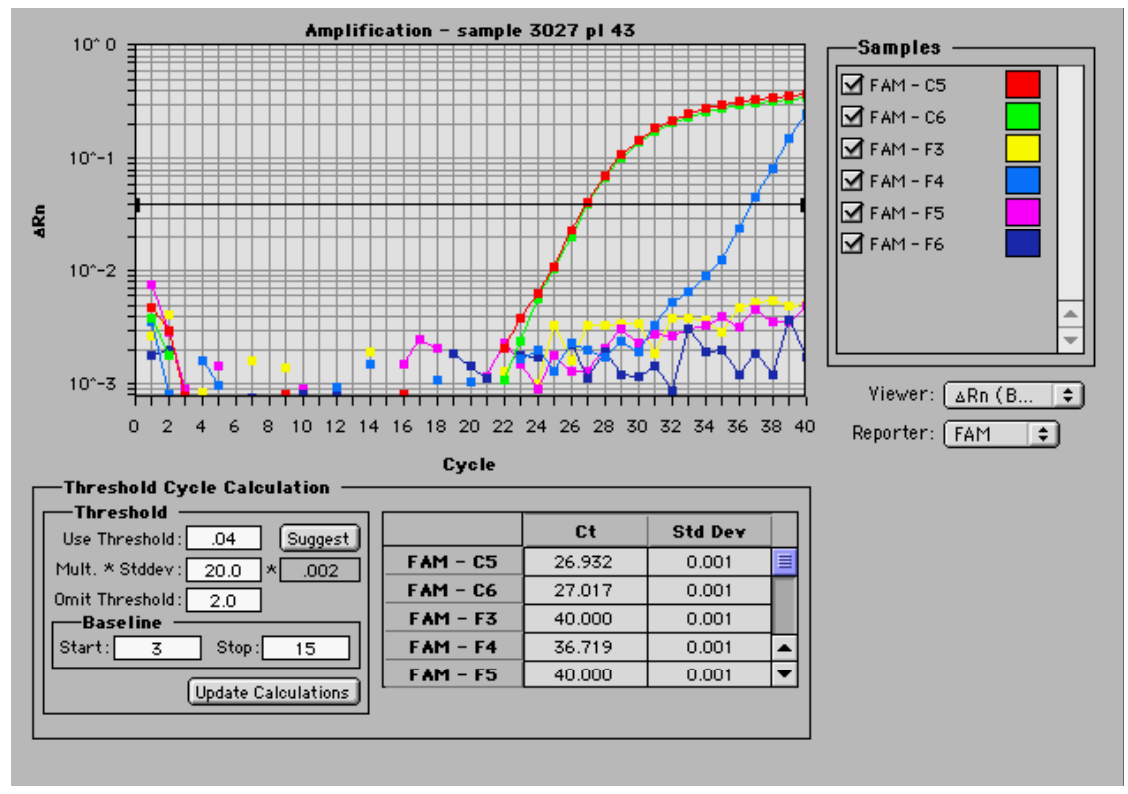

Figura 3.2 - Visualização gráfica da amplificação pela Real-Time PCR. O ABI7700 detecta a emissão de fluorescência - $\Delta \mathrm{Rn}$ (nas ordenadas) ao longo dos 40 ciclos térmicos da reação (na abscissa). Os resultados são expressos em valores de Ct que indica o número de ciclos necessários para que o sinal fluorescente atinja o limiar de detecção - Beltsville - 2003 
Todas as amostras foram testadas em duplicatas. Para a análise quantitativa foi adotada a mesma quantidade de cDNA (100ng) em todas as reações e utilizou-se as médias dos valores de $\mathrm{Ct}$ obtidos das duplicatas. Os resultados médios foram agrupados em Controle, 2DPI, 4DPI, 7DPI e 14DPI e submetidos a análise de variância (ANOVA). Utilizou-se o Teste de Tukey-Kramer para comparações múltiplas entre os grupos infectados e controle com significância de 0,05 (JMP 5.0.1.2, SAS Institute Inc, Cary, EUA). Os resultados foram expressos em aumento ou diminuição da expressão gênica comparando-se os grupos infectados ao controle.

Para o cálculo da variação da expressão gênica utilizou-se a diferença absoluta entre as médias do grupo infectado e controle elevado ao logaritmo de base dois.

Variação da expressão gênica $=2^{|\overline{\mathrm{m} C t i}-\overline{\mathrm{m} C t c}|}$

Onde:

$\mathrm{mCti}=$ média dos valores de Ct dos animais do grupo infectado $(2,4,7$ ou $14 \mathrm{DPI}) \mathrm{e}$ $\mathrm{mCtc}=$ média dos valores de $\mathrm{Ct}$ dos animais do grupo controle

Os valores numéricos foram convertidos em representação gráfica utilizando os softwares Treeview versão 1.60 e GeneCluster v. 2.20 (Stanford University, 1998). Foi estabelecido a cor vermelha para diminuição da expressão gênica e verde para aumento da expressão. A intensidade da cor indica a magnitude da resposta, isto é, quanto maior indução ou inibição, maior a intensidade da cor. Variação menor a 1,5 entre controle e infectados indicada em branco (DAWSON et al., 2002b) 


\subsection{DETERMINAÇÃO DE IFN- $\gamma$}

A detecção de IFN- $\gamma$ presente no sobrenadante dos meios de cultura foi feito pelo método de ELISA. Utilizou-se os monoclonais produzidos pelo clone P2G10 para a captura e P2C11 para a detecção de IFN- $\gamma$ (MATEU DE ANTONIO et al., 1998).

A determinação de IFN- $\gamma$ sérico foi medido por um ELISA comercial que utiliza os monoclonais 5B8 e 13C5, para a captura e para a detecção, respectivamente (Cytosets, Biosource, Camarillo, CA, EUA).

\subsection{PERFIL HEPÁTICO E HEMOGRAMA}

Determinação do perfil hepático (valores séricos de aspartato aminotransferase (AST), alanino aminotransferase (ALT), gama glutamil transferase (GGT), bilirrubinas totais (TBILI), bilirrubina direta (DBILI), proteínas totais (PT), globulinas (GLOB), albumina (ALB) e proporção albumina/globulina $(\mathrm{A} / \mathrm{G})$ ) e do hemograma (contagem do número total de leucócitos (Leu), número total $(\mathrm{T})$ e relativo $(\%)$ de neutrófilos $(\mathrm{Ne})$, linfócitos $(\mathrm{Li})$, monócitos (Mo), eosinófilos (Eo), basófilos $(\mathrm{Ba})$, número total de eritrócitos $(\mathrm{He})$, concentração de hemoglobina $(\mathrm{Hb})$, volume globular $(\mathrm{Hct})$, volume corpuscular médio $(\mathrm{MCV})$, hemoglobina corpuscular média $(\mathrm{MCH})$ e concentração hemoglobínica corpuscular média (MCHC)) foram realizados pelo serviço veterinário do ARS, USDA. 


\subsection{DETERMINAÇÃO DE ÓXIDO NÍTRICO}

Óxido nítrico (NO) foi medido pelo método de Griess (VERDON; BURTON; PRIOR, 1995) em soro previamente centrifugado em filtro Centricon YM 30kDa, (Millipore Corp, Beveryl, MA) a $5000 \mathrm{xg}$ durante uma hora. $\mathrm{NO}_{3}{ }^{-}$foi reduzido a $\mathrm{NO}_{2}{ }^{-}$com nitrato reductase e mensurado colorimetricamente contra curvas padrão de $\mathrm{NO}_{3}$ e $\mathrm{NO}_{2}(0,5$ a $0,0156 \mu \mathrm{M})$.

\subsection{DETERMINAÇÃO DE HAPTOGLOBINA}

Determinação dos níveis haptoglobina sérica foi realizada utilizando o kit Haptoglobin (TP801, Tri-Delta Development Ltd., Kildare, Irlanda) de acordo com as instruções do fabricante.

\subsection{DETECÇÃO DE ANTICORPOS ANTI-T. gondii}

Anticorpos séricos anti-T. gondii foram detectados pela prova de aglutinação modificada - MAT (DUBEY, 1997; DUBEY; DESMONTS, 1987). Foram consideradas positivas todas as amostras de soro reagentes a partir da diluição 1:25. 


\subsection{DETECÇÃO DE T. gondii}

Pesquisa de T. gondii em fragmentos de fígado, pulmão, linfonodo mesentérico, íleo e baço foi realizada por meio de Real-Time PCR. Tecidos foram previamante digeridos em tripsina (DUBEY, 1998) e DNA foi extraído utilizando proteinase K e DNeasy (Qiagen, Valencia, EUA). A concentração de DNA foi estimada em espectrofotômetro (Beckman Coulter DU640, EUA) com leituras a 260 e $280 \mathrm{~nm}$. Real-Time PCR foi realizado utilizando TaqMan buffer (Applied Biosystems, Foster City, EUA) e conjunto de primers e sonda específicos ITS1 para a detecção de T. gondii (JAUREGUI et al., 2001) e primers 18S (TaqMan Ribosomal control, Applied Biosystems, Foster City, EUA) para a detecção de gene housekeeping. Como controle positivo utilizou-se DNA de taquizoítos de T. gondii.

\subsection{ANÁLISE ESTATÍSTICA}

Os grupos controle e infectados foram comparados por análise de variância (ANOVA) e teste de Tukey-Kramer com comparações múltiplas entre os grupos infectados e controle e valor de $\alpha=0,05$ (JMP versão 5.0.1a, SAS Institute, Cary, EUA). 


\section{RESULTADOS}

A análise preliminar dos resultados de expressão gênica medida pela técnica da RealTime RT-PCR revelou diferenças no tempo de resposta entre os animais infectados dos EXP I e EXP II. A resposta tecidual dos animais do EXP I tende a uma maior intensidade no 4DPI, enquanto que no EXP II, o pico da resposta parece estar aos 7DPI.

No EXP I foram utilizados leitões mais jovens, com idade média de três meses, enquanto que no EXP II, a idade média dos animais era de quatro e meio a cinco meses. Utilizou-se o mesmo lote de oocistos de $T$. gondii em ambos experimentos, calculando-se a quantidade de oocistos viáveis após testes em camundongos. O intervalo entre os EXP I e EXP II é de 11 meses.

Considerando estas diferenças na resposta tecidual os resultados foram mantidos em separado.

\subsection{EXPERIMENTO I}

\subsubsection{Exames Histo-Patológicos e Parasitológicos}

A presença de T. gondii nos tecidos foi detectada por métodos moleculares (PCR) e imunológicos (IHQ) conforme mostra o quadro 4.1.1. No 2DPI o parasita foi detectado somente em amostras de LN M. No 4DPI foi encontrado em todos os tecidos testados e em quantidades maiores. No 7DPI há um destacado aumento das lesões histopatológicas 
principalmente no LN M e fígado, com intenso infiltrado inflamatório, acompanhado de áreas difusas de edema e necrose. Em um animal foram detectados grande número de parasitas e no outro, não foi detectado nenhum parasita, mas ambos com lesões similares. No 14DPI, houve menor isolamento de parasitas e alterações menos intensas nos tecidos. Não foi detectado $T$. gondii nas amostras dos suínos do grupo controle.

\begin{tabular}{|c|c|c|c|c|c|c|c|c|c|c|c|}
\hline \multirow{2}{*}{\multicolumn{2}{|c|}{$\begin{array}{l}\text { Método } \\
\text { Grupo } \\
\text { Animal }\end{array}$}} & \multicolumn{5}{|c|}{ PCR* } & \multicolumn{5}{|c|}{ IHQ** } \\
\hline & & LNM & Fígado & Pulmões & Baço & Íleo & LNM & Fígado & Pulmões & Baço & Íleo \\
\hline \multirow{3}{*}{ 2DPI } & 1 & ++ & - & - & - & - & - & - & - & - & - \\
\hline & 2 & + & - & - & - & - & + & - & - & - & - \\
\hline & 3 & - & - & - & - & - & + & - & - & - & - \\
\hline \multirow{3}{*}{ 4DPI } & 4 & +++ & ++ & ++ & ++ & ++ & +++ & + & + & - & - \\
\hline & 5 & +++ & ++ & ++ & ++ & ++ & + & - & - & - & + \\
\hline & 6 & ++ & - & - & + & + & + & - & + & + & - \\
\hline \multirow{2}{*}{ 7DPI } & 7 & - & - & - & & & - & - & - & & \\
\hline & 8 & +++ & ++ & ++ & NT & NT & + & - & - & NT & NT \\
\hline \multirow{2}{*}{ 14DPI } & 9 & - & - & + & & & - & - & - & & \\
\hline & 10 & + & + & - & NT & NT & - & - & - & NT & NT \\
\hline
\end{tabular}

Quadro 4.1.1 - Detecção de T. gondii em tecidos de suínos nos diferentes dias pós-infecção (DPI) pelas técnicas de PCR e imunohistoquímica (IHQ) - Beltsville - 2003

Tabela resumida listando a presença de $T$. gondii juntamente com os valores séricos individuais de aspartato aminotransferase (AST), óxido nítrico (NO), haptoglobina e IFN$\gamma$, assim como a produção de IFN- $\gamma$ pelas CMSP e células dos LN M, LN HS e LN TB dos animais experimentais encontra-se no apêndice G. 


\subsubsection{Pesquisa de Anticorpos Anti-T. gondii}

Todos os animais apresentavam-se soronegativos antes da inoculação de T. gondii. A prova de MAT não detectou anticorpos específicos nos animais dos grupos Controle, 2DPI, 4DPI e 7DPI. Os dois animais do grupo 14DPI apresentaram reação positiva à diluição 1:50.

\subsubsection{Perfil Hepático}

A tabela 4.1.1 apresenta os valores médios de aspartato aminotransferase (AST), alanino aminotransferase (ALT), gamaglutamil transferase (GGT), bilirrubinas totais (TBILI), bilirrubina direta (DBILI), fosfatase alcalina (ALP), proteínas totais (PT), globulinas (GLOB), albumina (ALB) e proporção albumina/globulina (A/G) no soro dos animais experimentais. Não foram observadas alterações estatisticamente significantes nos testes de avaliação hepática em relação ao grupo Controle.

Foi detectado um discreto aumento de AST sérico no grupo 4DPI e uma maior elevação no 7DPI, entretanto sem diferença estatística significante (Gráfico 4.1.1). 
Tabela 4.1.1 - Média e desvio-padrão (DP) dos valores de aspartato aminotransferase (AST), alanino aminotransferase (ALT), gamaglutamil transferase (GGT), bilirrubinas totais (TBILI), bilirrubina direta (DBILI), proteínas totais (PT), globulinas (GLOB), albumina (ALB) e proporção albumina/globulina (A/G) das amostras de soro de suínos infectados com $T$. gondii e controles não infectados. Diferença estatística (Estat.) segundo teste de Tukey-Kramer $(\alpha=0,05)$ - Beltsville -2003

\begin{tabular}{|c|c|c|c|c|c|c|c|c|c|c|c|c|c|c|c|}
\hline \multirow{2}{*}{$\begin{array}{c}\text { Determinação } \\
\text { sérica }\end{array}$} & \multicolumn{3}{|c|}{ Controle } & \multicolumn{3}{|c|}{ 2DPI ${ }^{1}$} & \multicolumn{3}{|c|}{ 4DPI } & \multicolumn{3}{|c|}{ 7DPI } & \multicolumn{3}{|c|}{ 14DPI } \\
\hline & Média & DP & Estat. $^{2}$ & Média & DP & Estat. & Média & DP & Estat. & Média & DP & Estat. & Média & DP & Estat. \\
\hline $\operatorname{AST}(\mathrm{U} / \mathrm{l})$ & 28,0 & 7,1 & A & 28,3 & 0,6 & A & 57,7 & 1,5 & A & 102,0 & 100,4 & A & 30,0 & 9,9 & A \\
\hline $\operatorname{ALT}(\mathrm{U} / \mathrm{l})$ & 21,5 & 3,5 & $\mathrm{AB}$ & 22,7 & 3,1 & $\mathrm{AB}$ & 18,3 & 2,1 & B & 28,5 & 2,1 & A & 21,5 & 2,1 & $\mathrm{AB}$ \\
\hline GGT (U/l) & 38,5 & 2,1 & A & 33,7 & 3,2 & A & 35,0 & 12,2 & A & 25,0 & 0,0 & A & 17,0 & 5,7 & A \\
\hline TBILI (mg/dl) & 0,1 & 0,0 & A & 0,1 & 0,0 & A & 0,2 & 0,1 & A & 0,3 & 0,1 & A & 0,2 & 0,1 & A \\
\hline DBILI (mg/dl) & 0,1 & 0,0 & A & 0,1 & 0,0 & A & 0,1 & 0,1 & A & 0,2 & 0,1 & A & 0,1 & 0,0 & A \\
\hline PT (g/dl) & 5,9 & 1,0 & A & 5,8 & 0,3 & A & 6,0 & 0,5 & A & 5,2 & 0,8 & A & 5,4 & 0,8 & A \\
\hline GLOB (g/dl) & 2,8 & 0,6 & A & 2,6 & 0,1 & A & 3,2 & 0,5 & A & 2,9 & 0,4 & A & 3,4 & 0,5 & A \\
\hline $\operatorname{ALB}(\mathrm{g} / \mathrm{dl})$ & 3,1 & 0,4 & A & 3,1 & 0,2 & A & 2,5 & 0,5 & A & 2,3 & 0,4 & A & 2,0 & 0,3 & A \\
\hline $\mathrm{A} / \mathrm{G}$ & 1,1 & 0,1 & A & 1,2 & 0,0 & A & 0,6 & 0,5 & A & 0,8 & 0,0 & A & 0,6 & 0,0 & $\mathrm{AB}$ \\
\hline
\end{tabular}

${ }^{1}$ DPI - dias pós-infecção, ${ }^{2}$ letras distintas na mesma linha indicam diferença estatística

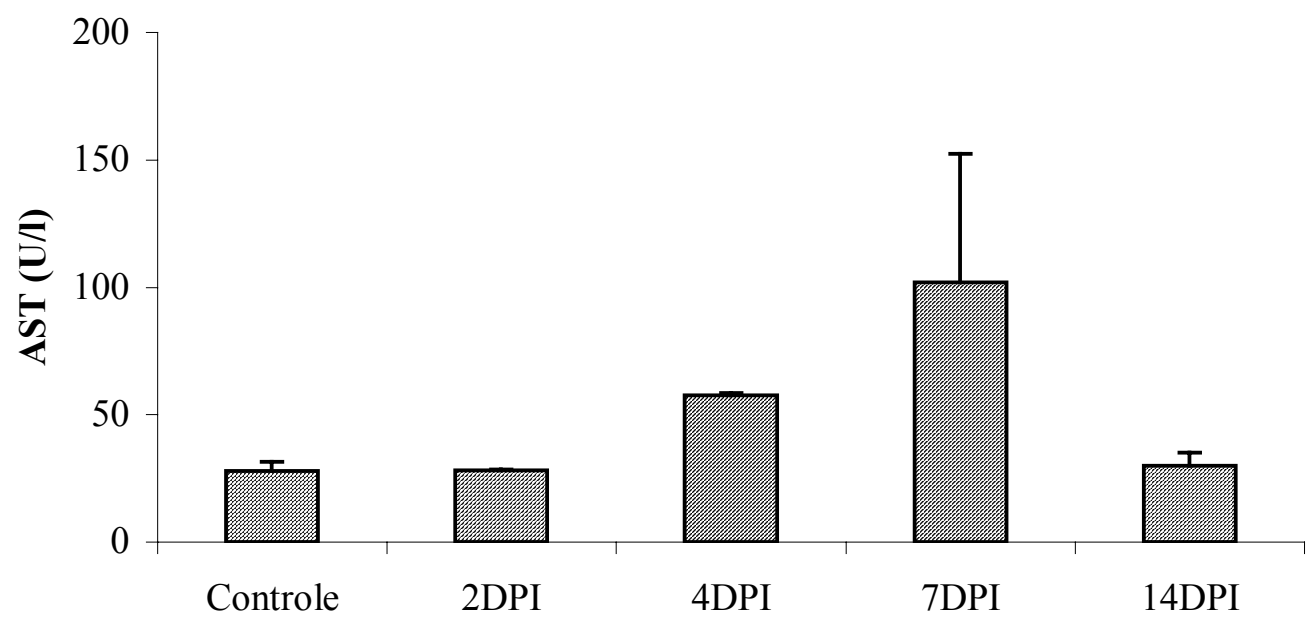

Gráfico 4.1.1 - Níveis de aspartato aminotransferase (AST) sérico em suínos dos grupos controle e infectados pelo T. gondii - Beltsville - 2003 


\subsubsection{Determinação de IFN- $\gamma$}

O limiar de detecção da técnica de ELISA descrito por Mateu de Antonio et al. (1998) foi de $1,2 \mathrm{ng} / \mathrm{ml}$. O IFN- $\gamma$ do sobrenadante do cultivo de células foi adequadamente mensurado por esta técnica, porém não foi possível determinar a quantidade de IFN- $\gamma$ presente no soro.

As amostras de soro foram então testadas utilizando o kit Cytosets (Biosource, Camarillo, EUA) que utiliza um par de monoclonais distinto e apresentou o limiar de detecção de $400 \mathrm{pg} / \mathrm{ml}$.

\subsubsection{IFN- $\gamma$ Sérico}

Não foi detectado IFN- $\gamma$ sérico nos animais dos grupos Controle e 14DPI. O pico de produção de IFN- $\gamma$ foi detectado no 4DPI (Gráfico 4.1.2). Estatisticamente esta elevação dos níveis de IFN- $\gamma$ sérico não foi significante.

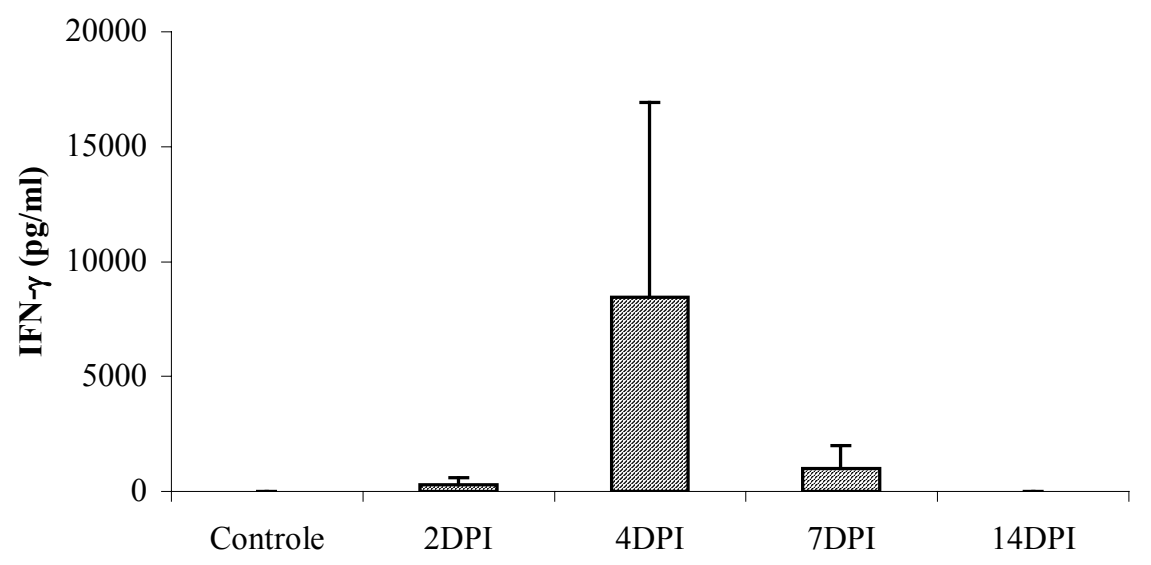

Gráfico 4.1.2 - Níveis de IFN- $\gamma$ sérico em suínos dos grupos controle e infectados pelo T. gondii medido pelo método de ELISA - Beltsville - 2003 


\subsubsection{Produção de IFN- $\gamma$}

Com intuito de avaliar a produção de IFN- $\gamma$, procedeu-se o isolamento e o cultivo de células dos LN e PBMC in vitro. A quantificação de proteínas presentes no sobrenadante destas células demonstra que células dos LN M e HS isoladas dos animais do 7DPI produziram maior quantidade de IFN- $\gamma$ que as células do LN TB e PBMC (Gráfico 4.1.3). Todavia esta elevação na produção, não foi estatisticamente significante.

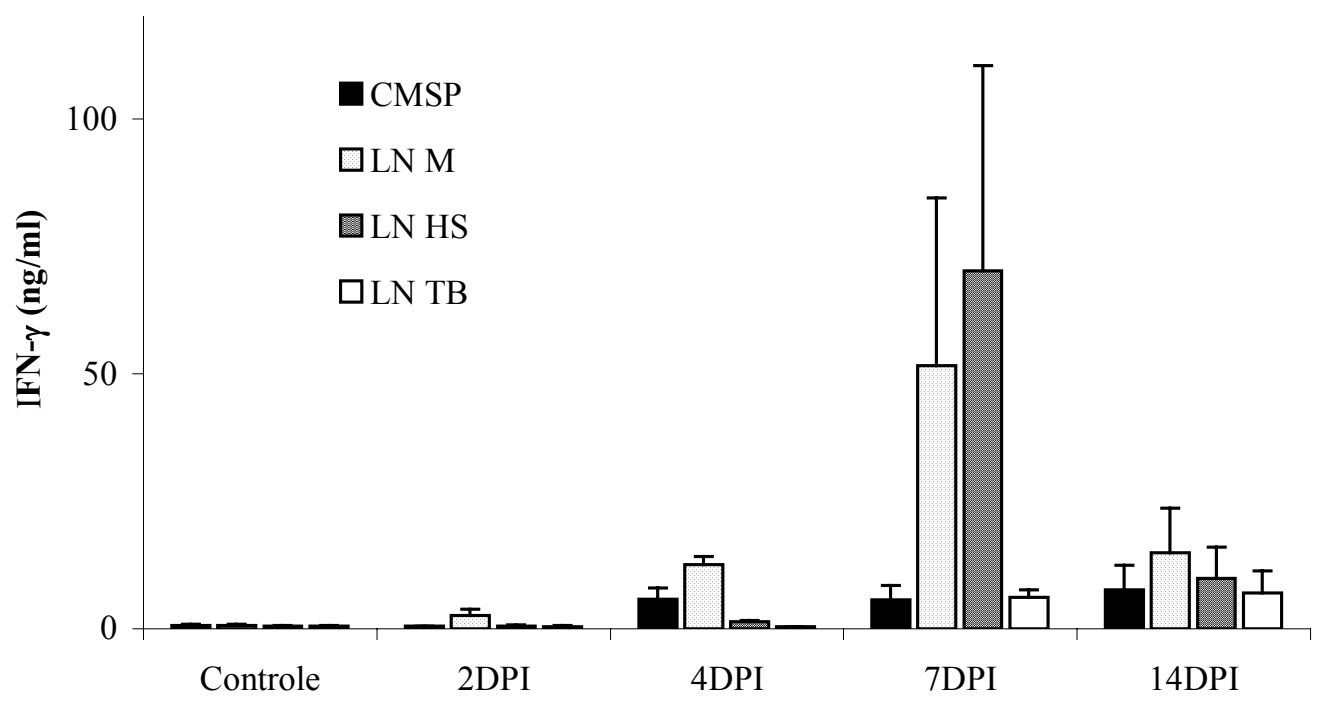

Gráfico 4.1.3 - Produção de IFN- $\gamma$ por células mononucleares do sangue periférico (CMSP), do linfonodo mesentérico (LN M), do linfonodo hepato-esplênico (LN HS) e do linfonodo traqueo-bronquial (LN TB) de suínos dos grupos controle e infectados pelo $T$. gondii durante cultivo em ConA por 24 horas medida pelo método de ELISA - Beltsville - 2003 


\subsubsection{Determinação de NO}

O gráfico 4.1.4 representa os níveis de NO presentes no soro dos animais experimentais. Foram detectados valores significantemente maiores de NO sérico no 4DPI.

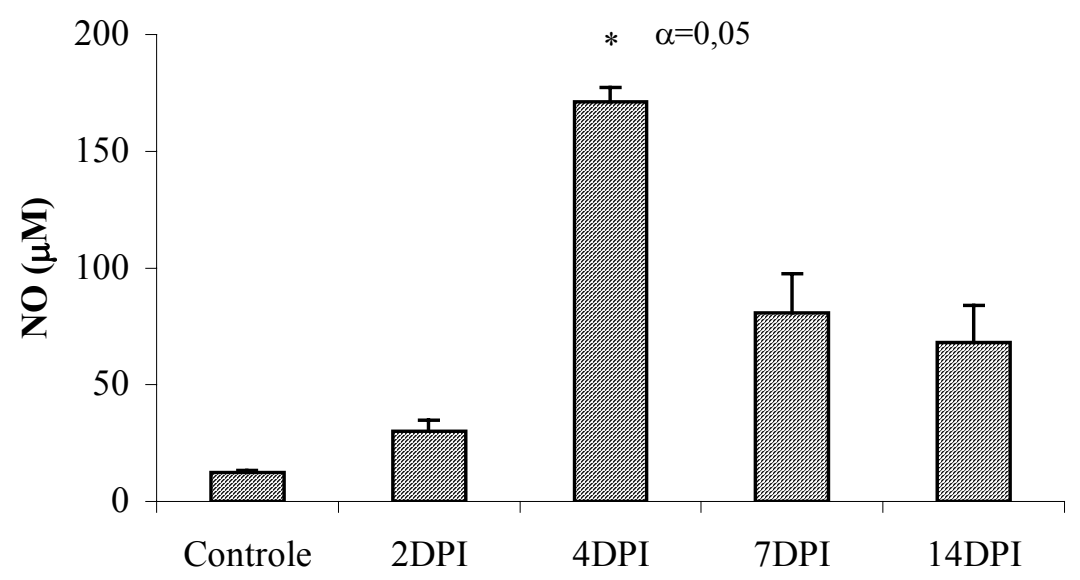

Gráfico 4.1.4 - Níveis de óxido nítrico (NO) no soro de suínos dos grupos controle e infectados pelo T. gondii medido pelo método de Griess - Beltsville - 2003 


\subsubsection{Determinação de Haptoglobina}

O gráfico 4.1.5 apresenta os resultados de haptoglobina sérica dos animais experimentais. Foi detectado um aumento significante dos níveis de haptoglobina nos animais dos grupos 4DPI, 7DPI e 14DPI em relação ao grupo Controle.

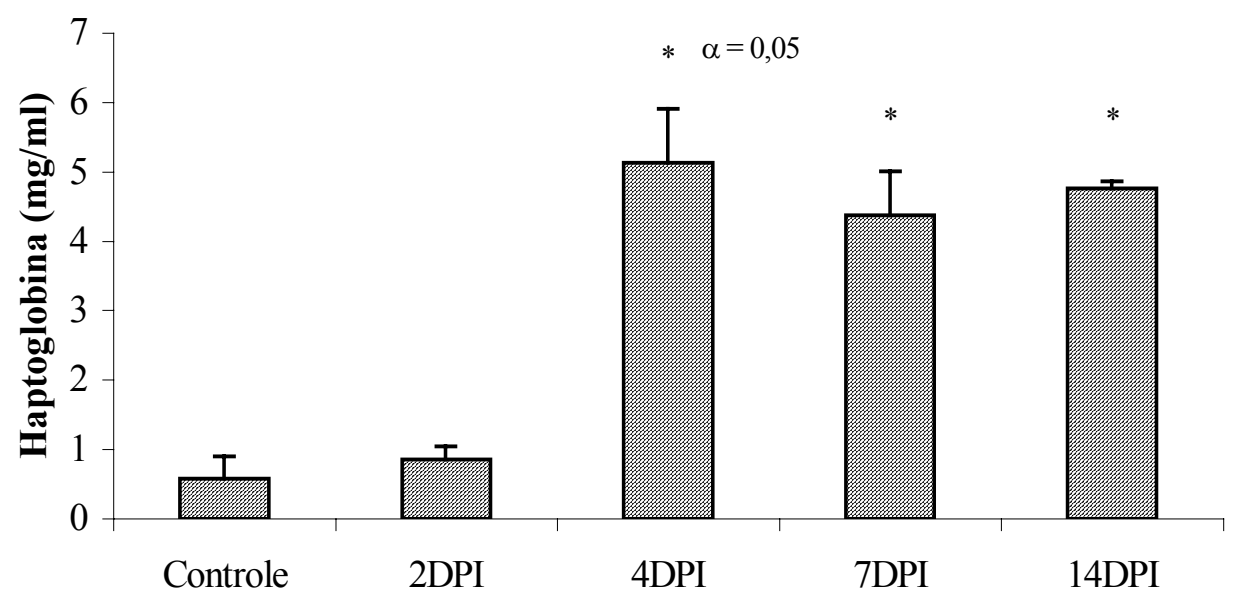

Gráfico 4.1.5 - Níveis de haptoglobina em suínos dos grupos controle e infectados pelo $T$. gondii medido por método colorimétrico - Beltsville - 2003

\subsubsection{Análise de Subpopulações de Células}

As tabelas 4.1.2 a 4.1.5 apresentam a proporção fenotípica de subpopulações de células dos LN M, LN HS, LN TB e CMSP.

No LN M foi observado uma tendência de aumento na concentação relativa de células CD2/CD16 duplo positivos (DP) referente à população de células NK no 4DPI e 7DPI. No 
14DPI esta elevação foi estatisticamente significante. Não foram observadas alterações dignas de nota na proporção das demais subpopulações de células.

No LN HS a variação da população de CD2/CD16 DP também apresentou uma ligeira, porém não significativa elevação no 4DPI e 14DPI. Aumento significante na porcentagem (\%) células NK foi detectada no 7DPI. Não foram detectadas alterações dignas de nota nas demais subpopulações de células.

No LN TB detectou-se uma elevação signficativa da proporção de células NK nos grupos 4DPI, 7DPI e 14DPI. Não foram detectadas alterações estatiticamente significativas nas demais subpopulações de células.

Nas CMSP a variação na proporção de células NK não foi estatisticamente significante quando comparada aos valores do grupo Controle, entretanto observa-se uma elevação na \% de células NK no 4DPI e 14DPI, com pico no 7DPI.

Ainda nas CMSP há uma elevação não significativa na \% de SWC3 / SLA DQ DP no 4DPI e 7DPI e de CD21 no 7DPI. 


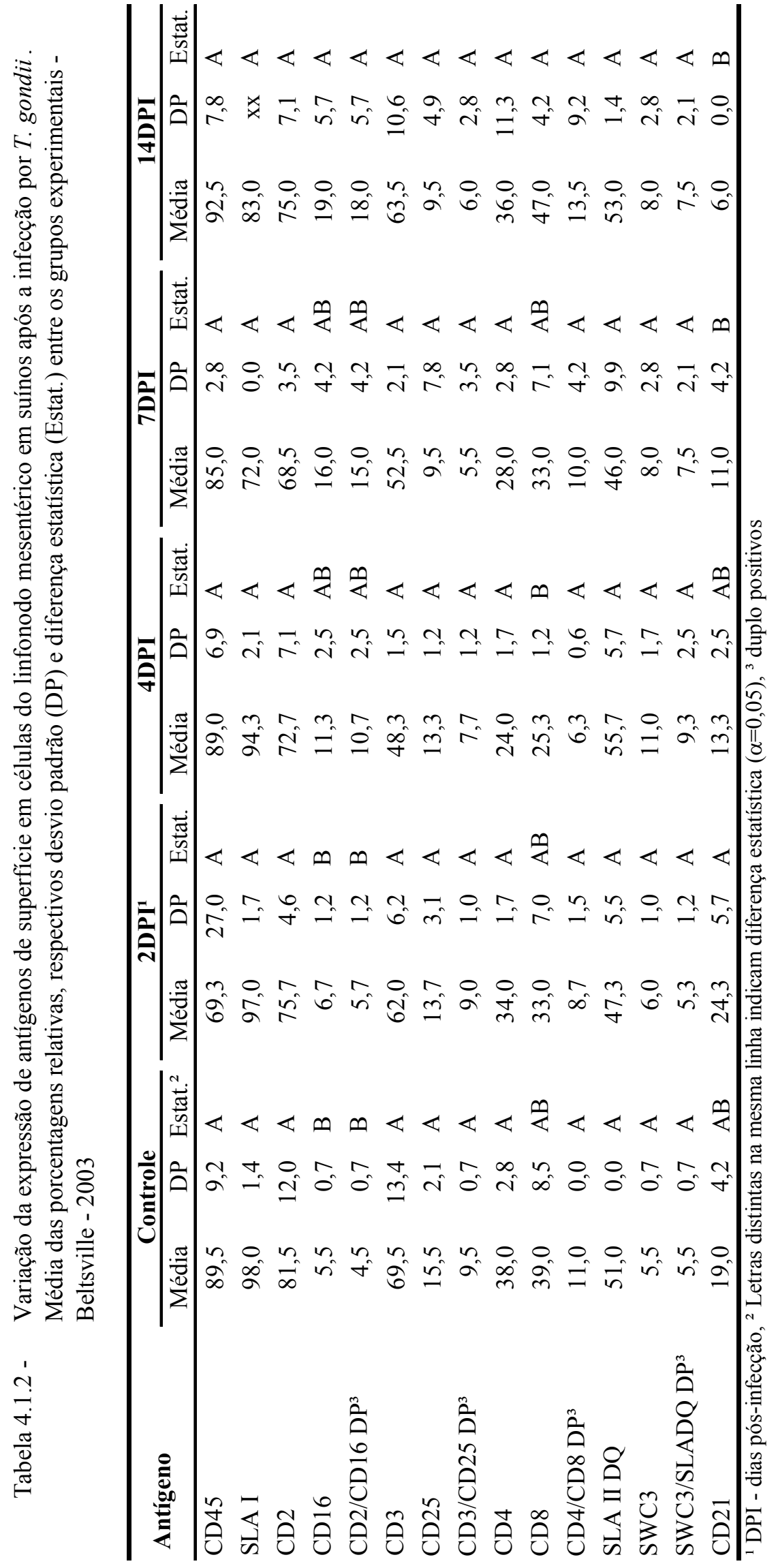




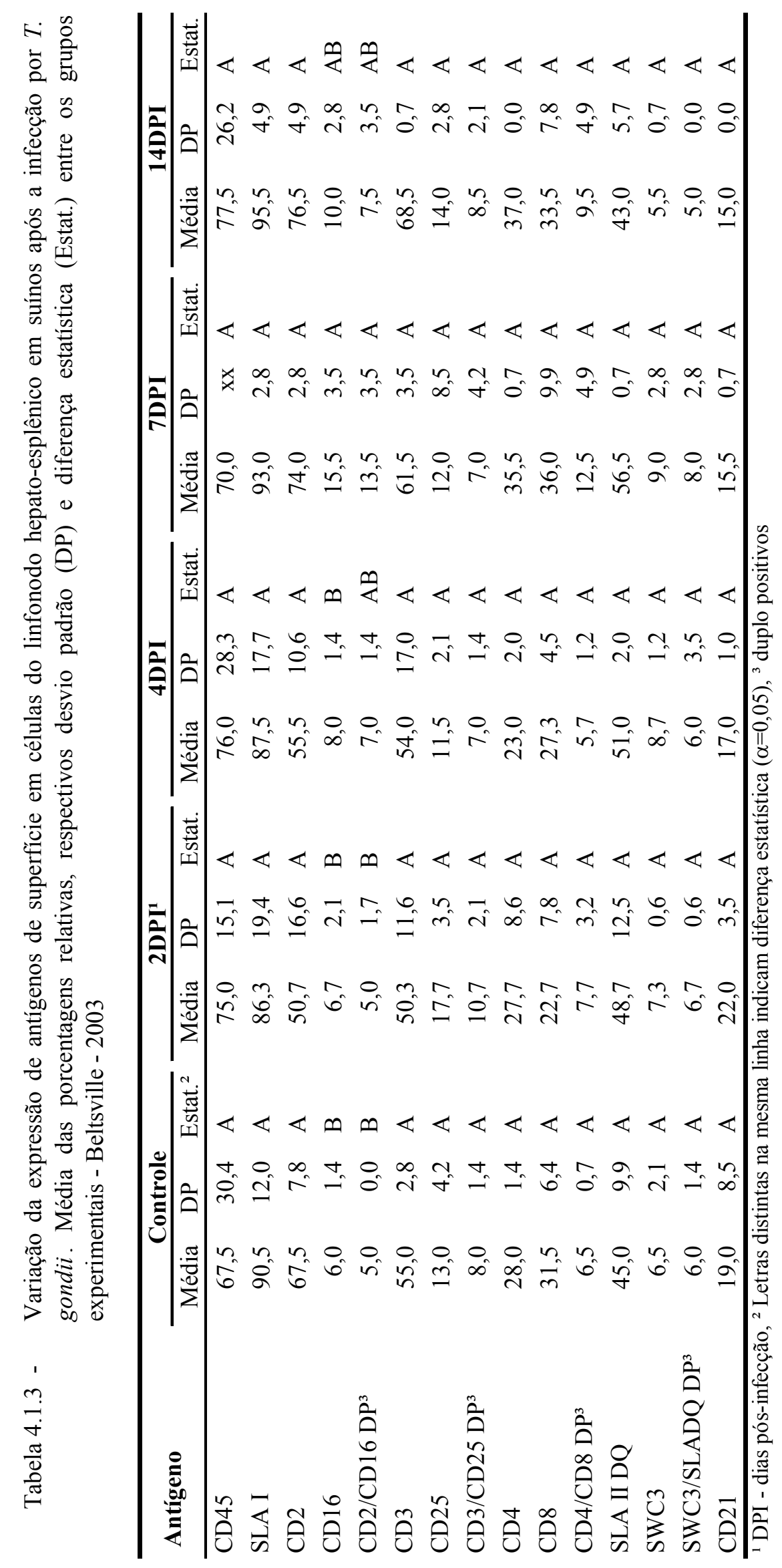


2

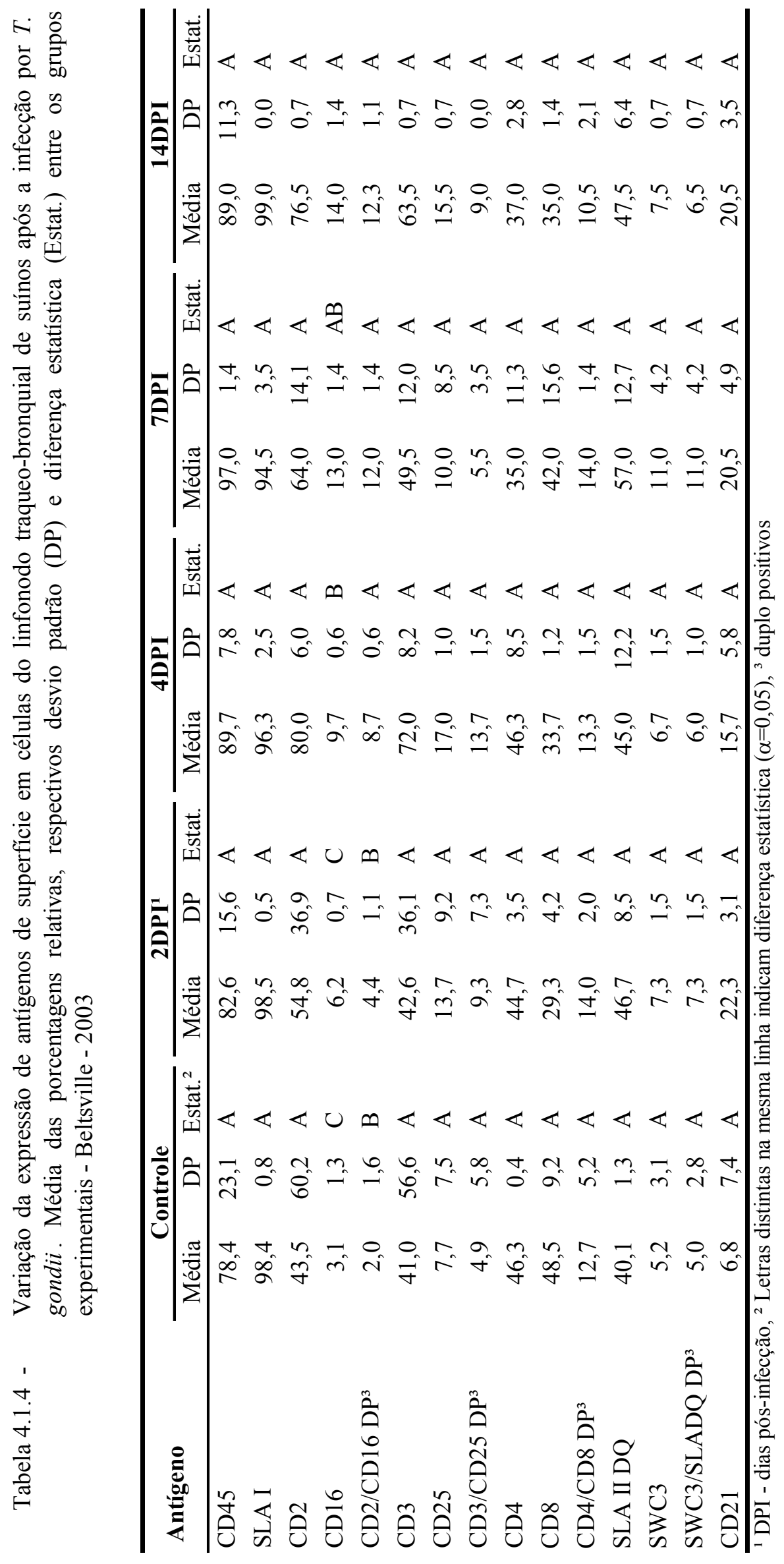




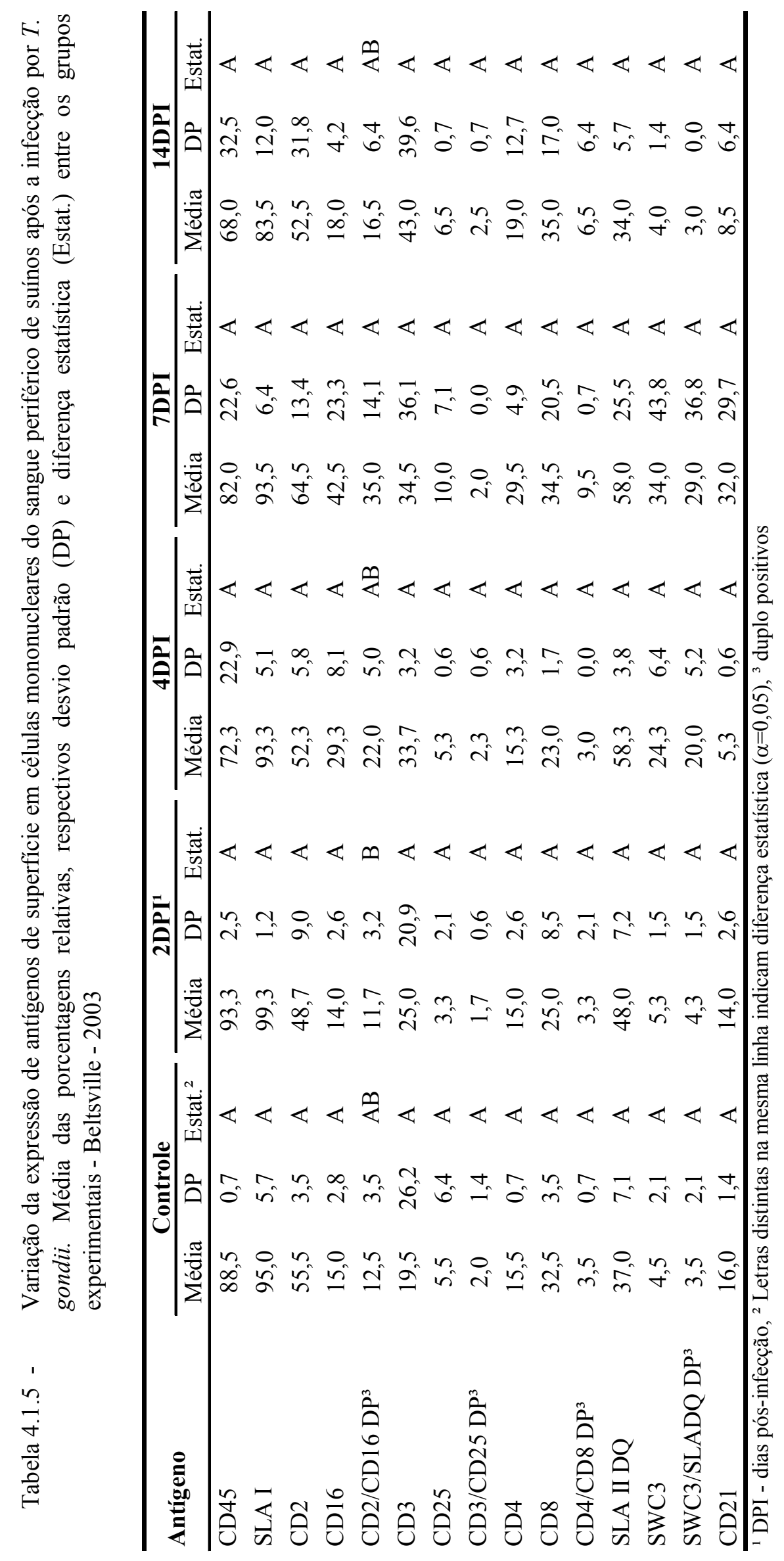




\subsubsection{Expressão Gênica}

Os resultados do Real-Time RT-PCR são expressos em Ct. Este número é utilizado na quantificação das seqüências-alvo amplificadas pela reação da polimerase. Os genes expressos em altas quantidades possuem valores de Ct baixos, enquanto que os genes de baixa expressão, apresentam valores de Ct elevados.

As tabelas 4.1.6 a 4.1.14 mostram os valores médios de Ct, respectivos desvios padrões e a diferença estatística entre grupos experimentais pelo teste de Tukey-Kramer $(\alpha=0,05)$.

Baseados nos valores $\mathrm{Ct}$, calculou-se a variação da expressão gênica comparando os grupos infectados (2DPI, 4DPI, 7DPI ou 14DPI) frente ao grupo controle. As figuras 4.1.1 e 4.1.2 ilustram o aumento ou a diminuição da expressão de mRNA nos diferentes tecidos pelo RealTime RT-PCR. Foram testados 48 genes nas amostras de LN M, LN HS, CMSP dos grupos 2DPI, 4DPI, 7DPI e 14DPI. As amostras de fígado, baço e timo foram somente colhidas nos grupos 2DPI e 4DPI. Foram testados 24 genes em amostras de jejuno, íleo e linfonodo IC.

As tabelas 4.1.15 a 4.1.17 referem-se às figuras 4.1.1 e 4.1.2 e mostram a variação da expressão de mRNA em valores numéricos, permitindo a observação da magnitude da resposta de forma mais pormenorizada. 
Tabela 4.1.6 - Resultados da Real-Time RT-PCR em amostras de linfonodo mesentérico dos suínos do EXP I. Valores médios de Ct e respectivos desvios padrões (DP) nos grupos controle e infectados de acordo com o dia após a infecção com T. gondii. Diferença estatística (Estat.) segundo o teste de Tukey-Kramer $(\alpha=0,05)$ - Beltsville - 2003

\begin{tabular}{|c|c|c|c|c|c|c|c|c|c|c|c|c|c|c|c|}
\hline \multirow{2}{*}{ Gene } & \multicolumn{3}{|c|}{ Controle } & \multicolumn{3}{|c|}{ 2DPI ${ }^{1}$} & \multicolumn{3}{|c|}{ 4DPI } & \multicolumn{3}{|c|}{ 7DPI } & \multicolumn{3}{|c|}{ 14DPI } \\
\hline & Média & DP & Estat. $^{2}$ & Média & DP & Estat. & Média & DP & Estat. & Média & $\mathrm{DP}$ & Estat. & Média & DP & Estat. \\
\hline RPL13A & 21,4 & 0,6 & $\mathrm{~A}$ & 20,2 & 1,0 & $\mathrm{~A}$ & 22,7 & 1,1 & $\mathrm{~A}$ & 20,4 & 0,8 & $\mathrm{~A}$ & 20,4 & 1,6 & $\mathrm{~A}$ \\
\hline RPL32 & 16,4 & 1,1 & A & 17,2 & 0,4 & A & 16,4 & 0,7 & A & 16,8 & 0,8 & A & 17,4 & 1,0 & A \\
\hline IFNA & 30,5 & 1,9 & A & 29,1 & 0,6 & A & 29,6 & 5,5 & A & 29,8 & 0,3 & A & 31,2 & 0,8 & A \\
\hline IL1B & 29,7 & 0,8 & A & 25,2 & 0,7 & A & 24,7 & 2,5 & A & 29,9 & 0,7 & A & 26,5 & 4,3 & A \\
\hline IL6 & 26,1 & 0,1 & A & 22,6 & 1,0 & B & 23,4 & 1,1 & $\mathrm{AB}$ & 25,5 & 0,8 & $\mathrm{AB}$ & 23,1 & 1,0 & $\mathrm{AB}$ \\
\hline ORM1 & 28,7 & 0,2 & A & 26,7 & 1,3 & A & 25,1 & 2,8 & A & 27,6 & 1,3 & A & 28,2 & 1,1 & A \\
\hline TNF & 26,3 & 1,6 & A & 26,4 & 0,5 & A & 24,2 & 0,6 & A & 26,7 & 1,1 & A & 27,1 & 1,4 & A \\
\hline TNFRSF1A & 22,0 & 1,6 & A & 20,7 & 0,1 & A & 23,3 & 1,0 & A & 21,7 & 0,5 & A & 21,1 & 2,4 & A \\
\hline TLR2 & 23,5 & 1,4 & A & 22,8 & 1,0 & A & 23,8 & 1,4 & A & 22,9 & 0,6 & A & 22,4 & 1,6 & A \\
\hline TLR4 & 22,6 & 1,0 & A & 22,7 & 0,3 & A & 23,4 & 1,2 & A & 23,4 & 0,4 & $\mathrm{~A}$ & 22,3 & 1,7 & A \\
\hline IFNG & 27,2 & 1,2 & A & 23,1 & 1,0 & B & 23,1 & 1,2 & B & 25,8 & 1,0 & $\mathrm{AB}$ & 24,1 & 1,7 & $\mathrm{AB}$ \\
\hline IL12A & 33,3 & 1,2 & A & 30,9 & 1,5 & A & 33,0 & 1,0 & A & 31,8 & 0,4 & A & 31,7 & 1,9 & A \\
\hline IL12B & 28,0 & 1,3 & $\mathrm{AB}$ & 27,6 & 0,6 & B & 31,5 & 1,1 & A & 27,8 & 0,1 & B & 28,0 & 1,8 & $\mathrm{AB}$ \\
\hline IL12RB2 & 33,2 & 2,8 & $\mathrm{~A}$ & 32,2 & 1,0 & A & 31,6 & 2,9 & A & 32,3 & 0,4 & A & 29,8 & 4,0 & A \\
\hline IL15 & 29,4 & 0,2 & A & 26,2 & 0,6 & A & 29,2 & 2,0 & A & 29,7 & 1,6 & A & 27,5 & 0,8 & A \\
\hline IL18 & 20,2 & 0,1 & A & 20,6 & 0,6 & A & 21,0 & 1,0 & A & 20,1 & 0,5 & A & 19,7 & 0,5 & A \\
\hline IL23A & 36,3 & 0,1 & $\mathrm{~A}$ & 37,1 & 1,1 & A & 31,7 & 5,1 & A & 35,5 & 0,7 & A & 35,4 & 2,2 & A \\
\hline IRF1 & 19,3 & 1,1 & A & 18,4 & 0,3 & $\mathrm{AB}$ & 17,2 & 0,5 & B & 18,4 & 0,4 & $\mathrm{AB}$ & 19,1 & 0,2 & A \\
\hline LEP & 29,5 & 1,3 & A & 33,0 & 1,6 & A & 28,6 & 4,1 & A & 29,9 & 0,2 & A & 32,0 & 1,0 & A \\
\hline LEPR & 26,9 & 1,2 & A & 28,9 & 1,2 & A & 28,7 & 1,2 & A & 27,3 & 0,9 & A & 29,1 & 1,8 & A \\
\hline STAT1 & 20,6 & 1,7 & A & 18,5 & 1,4 & A & 20,5 & 1,2 & A & 20,0 & 0,6 & A & 19,4 & 2,4 & A \\
\hline STAT4 & 24,0 & 1,6 & A & 22,9 & 1,3 & A & 25,2 & 1,3 & A & 23,4 & 0,6 & A & 23,7 & 2,4 & A \\
\hline SOCS1 & 28,4 & 1,4 & A & 26,2 & 0,2 & $\mathrm{AB}$ & 23,7 & 0,6 & B & 27,9 & 0,6 & A & 28,3 & 1,8 & A \\
\hline SOCS2 & 23,2 & 1,8 & $\mathrm{~A}$ & 23,1 & 0,3 & A & 21,6 & 0,3 & A & 22,5 & 1,3 & $\mathrm{~A}$ & 23,0 & 1,6 & A \\
\hline IL4 & 32,1 & 2,3 & A & 29,2 & 2,0 & A & & 2,9 & A & & 1,1 & A & 30,6 & 2,8 & A \\
\hline IL5 & 32,9 & 1,8 & $\mathrm{AB}$ & 30,6 & 0,6 & B & 34,7 & 1,1 & A & 32,0 & 0,8 & $\mathrm{AB}$ & 32,2 & 1,6 & $\mathrm{AB}$ \\
\hline IL13 & 30,2 & 0,4 & $\mathrm{AB}$ & 27,6 & 0,8 & B & 28,6 & 0,8 & $\mathrm{AB}$ & 30,9 & 1,5 & $\mathrm{AB}$ & 31,3 & 1,8 & A \\
\hline STAT6 & 26,9 & 1,8 & A & 26,5 & 0,7 & A & 24,8 & 1,6 & $A$ & 25,3 & 0,4 & $\mathrm{~A}$ & 26,7 & 0,3 & A \\
\hline SOCS3 & 30,4 & 1,4 & A & 27,2 & 0,7 & A & 28,6 & 1,3 & A & 29,5 & 0,1 & A & 30,0 & 2,9 & A \\
\hline INDO & 21,4 & 2,0 & A & 20,6 & 0,4 & A & 17,3 & 0,5 & B & 21,9 & 0,2 & A & 21,9 & 1,3 & A \\
\hline NOS2A & 35,4 & 1,6 & A & 34,3 & 0,6 & A & 34,3 & 1,4 & A & 34,2 & 0,6 & A & 34,8 & 0,6 & A \\
\hline ARG1 & 33,5 & 2,1 & $\mathrm{AB}$ & 35,3 & 2,1 & A & 25,8 & 3,3 & B & 33,5 & 3,0 & $\mathrm{AB}$ & 31,1 & 0,7 & $\mathrm{AB}$ \\
\hline SLC11A1 & 35,0 & 2,2 & A & 30,0 & 0,2 & $\mathrm{AB}$ & 27,1 & 1,0 & $\mathrm{~B}$ & 32,2 & 1,0 & $\mathrm{AB}$ & 27,3 & 3,7 & B \\
\hline SLC11A2 & 24,6 & 0,1 & A & 24,6 & 0,5 & A & 24,6 & 0,4 & A & 24,4 & 0,1 & A & 22,7 & 2,0 & A \\
\hline IGM & 22,4 & 1,3 & $\mathrm{~A}$ & 21,5 & 1,1 & A & 21,7 & 0,5 & A & 21,1 & 1,3 & A & 20,7 & 0,2 & A \\
\hline IGG & 21,0 & 0,2 & $\mathrm{AB}$ & 21,1 & 1,2 & A & 22,4 & 1,2 & A & 21,3 & 1,4 & $\mathrm{~A}$ & 17,2 & 0,8 & B \\
\hline IGA & 22,2 & 0,5 & A & 20,5 & 0,8 & A & 21,9 & 1,7 & A & 20,8 & 1,1 & A & 21,6 & 1,5 & A \\
\hline CD3E & 19,4 & 0,4 & A & 19,3 & 0,5 & A & 20,4 & 1,1 & A & 19,1 & 0,1 & A & 19,5 & 0,5 & A \\
\hline CD19 & 27,2 & 0,6 & $\mathrm{AB}$ & 26,1 & 1,2 & B & 29,0 & 1,0 & A & 26,4 & 0,8 & $\mathrm{AB}$ & 27,6 & 0,7 & $\mathrm{AB}$ \\
\hline CD69 & 21,4 & 0,8 & A & 20,5 & 0,4 & A & 22,8 & 1,3 & A & 21,2 & 0,4 & A & 21,7 & 2,0 & A \\
\hline IL2 & 28,8 & 1,9 & A & 27,1 & 0,3 & A & 30,7 & 1,2 & A & 28,7 & 0,8 & A & 29,2 & 2,0 & A \\
\hline IL2RA & 25,8 & 1,9 & A & 24,5 & 1,7 & A & 26,2 & 0,9 & A & 24,7 & 0,0 & A & 26,3 & 2,3 & A \\
\hline IL10 & 30,1 & 0,9 & A & 27,6 & 1,3 & A & 28,6 & 1,0 & A & 28,8 & 0,6 & A & 28,6 & 2,7 & A \\
\hline TGFB1 & 26,2 & 1,3 & A & 25,0 & 0,8 & A & 26,3 & 0,5 & A & 24,6 & 0,8 & A & 25,4 & 1,9 & A \\
\hline TGFB2 & 23,0 & 0,8 & A & 23,1 & 0,2 & A & 24,7 & 1,3 & A & 23,1 & 0,3 & A & 23,4 & 1,7 & A \\
\hline TGFB3 & 29,3 & 0,4 & $\mathrm{AB}$ & 28,8 & 0,3 & $\mathrm{AB}$ & 28,7 & 0,8 & $\mathrm{AB}$ & 29,5 & 0,2 & $\mathrm{~A}$ & 26,1 & 2,1 & B \\
\hline CSF2 & 29,2 & 1,5 & A & 28,4 & 0,8 & A & 26,9 & 1,5 & $\mathrm{~A}$ & 29,2 & 0,2 & A & 28,9 & 1,0 & A \\
\hline MHC2TA & 21,9 & 1,1 & $\mathrm{~A}$ & 20,8 & 0,5 & A & 22,1 & 1,2 & $\mathrm{~A}$ & 21,5 & 0,2 & $\mathrm{~A}$ & 20,7 & 0,1 & A \\
\hline
\end{tabular}

${ }^{1}$ DPI - dias pós-infecção, ${ }^{2}$ letras distintas na mesma linha indicam diferença estatística 
Tabela 4.1.7 - Resultados da Real-Time RT-PCR em amostras de linfonodo hepato-esplênico dos suínos do EXP I. Valores médios de $\mathrm{Ct}$ e respectivos desvios padrões (DP) nos grupos controle e infectados de acordo com o dia após a infecção com $T$. gondii. Diferença estatística (Estat.) segundo o teste de Tukey-Kramer $(\alpha=$ $0,05)$ - Beltsville -2003

\begin{tabular}{|c|c|c|c|c|c|c|c|c|c|c|c|c|c|c|c|}
\hline \multirow{2}{*}{ Gene } & \multicolumn{3}{|c|}{ Controle } & \multicolumn{3}{|c|}{ 2DPI ${ }^{1}$} & \multicolumn{3}{|c|}{ 4DPI } & \multicolumn{3}{|c|}{ 7DPI } & \multicolumn{3}{|c|}{ 14DPI } \\
\hline & Média & DP & Estat. $^{2}$ & Média & $\mathrm{DP}$ & Estat. & Média & DP & Estat. & Média & DP & Estat. & Média & DP & Estat. \\
\hline RPL13A & 19,7 & 1,2 & $\mathrm{~A}$ & 19,9 & 0,4 & $\mathrm{~A}$ & 19,4 & 0,2 & A & 19,5 & 0,4 & A & 19,1 & 0,1 & A \\
\hline RPL32 & 17,0 & 0,8 & A & 17,1 & 0,4 & A & 17,1 & 0,2 & A & 16,8 & 0,4 & $\mathrm{~A}$ & 16,5 & 0,2 & A \\
\hline IFNA & 28,1 & 1,8 & A & 28,9 & 0,7 & A & 27,6 & 0,4 & A & 28,6 & 0,1 & A & 28,3 & 0,8 & A \\
\hline IL1B & 26,7 & 1,6 & $\mathrm{AB}$ & 27,0 & 0,4 & $\mathrm{AB}$ & 25,9 & 0,8 & B & 29,1 & 0,1 & A & 28,8 & 0,5 & A \\
\hline IL6 & 24,8 & 1,0 & $\mathrm{~A}$ & 24,4 & 0,5 & A & 23,3 & 0,7 & A & 24,9 & 0,4 & A & 24,1 & 0,6 & A \\
\hline ORM1 & 23,9 & 5,6 & $\mathrm{AB}$ & 22,7 & 1,8 & $\mathrm{AB}$ & 20,1 & 1,3 & B & 27,9 & 0,3 & $\mathrm{AB}$ & 28,0 & 0,3 & $\mathrm{~A}$ \\
\hline TNF & 27,0 & 0,6 & $\mathrm{~A}$ & 26,3 & 0,4 & $\mathrm{AB}$ & 25,2 & 0,5 & B & 26,4 & 0,1 & $\mathrm{AB}$ & 26,1 & 0,1 & $\mathrm{AB}$ \\
\hline TNFRSF1A & 20,6 & 1,1 & A & 20,5 & 0,5 & $\mathrm{~A}$ & 19,7 & 0,1 & A & 20,7 & 0,4 & $\mathrm{~A}$ & 20,3 & 0,5 & A \\
\hline TLR2 & 21,8 & 0,9 & A & 21,9 & 0,3 & A & 21,2 & 0,1 & A & 21,9 & 0,4 & A & 21,5 & 0,5 & A \\
\hline TLR4 & 21,8 & 1,7 & A & 21,8 & 0,5 & $\mathrm{~A}$ & 20,9 & 0,1 & A & 22,9 & 0,4 & $\mathrm{~A}$ & 22,5 & 0,5 & A \\
\hline IFNG & 26,1 & 1,3 & $\mathrm{AB}$ & 26,3 & 0,4 & $\mathrm{~A}$ & 24,3 & 0,4 & B & 25,1 & 0,7 & $\mathrm{AB}$ & 24,8 & 0,1 & $\mathrm{AB}$ \\
\hline IL12A & 31,3 & 1,3 & $\mathrm{~A}$ & 30,9 & 0,6 & $\mathrm{~A}$ & 30,1 & 0,8 & A & 30,9 & 0,1 & $\mathrm{~A}$ & 30,2 & 0,1 & $\mathrm{~A}$ \\
\hline IL12B & 26,3 & 1,4 & A & 26,7 & 0,5 & $\mathrm{~A}$ & 28,6 & 1,0 & A & 26,3 & 0,1 & A & 26,1 & 0,4 & A \\
\hline IL12RB2 & 31,8 & 0,6 & A & 31,6 & 1,1 & A & 30,5 & 0,9 & A & 31,2 & 0,6 & A & 30,1 & 0,0 & A \\
\hline IL15 & 32,1 & 3,2 & $\mathrm{~A}$ & 31,4 & 1,7 & A & 28,6 & 1,8 & A & 31,0 & 1,0 & A & 30,6 & 0,4 & A \\
\hline IL18 & 20,2 & 1,2 & A & 20,4 & 0,2 & A & 20,1 & 0,4 & A & 20,2 & 0,4 & $\mathrm{~A}$ & 19,7 & 0,7 & A \\
\hline IL23A & 37,1 & 1,9 & A & 36,4 & 0,9 & A & 35,0 & 0,7 & A & 36,6 & 0,3 & A & 36,7 & 0,6 & A \\
\hline IRF1 & 19,9 & 1,4 & A & 19,4 & 0,6 & $\mathrm{~A}$ & 18,4 & 0,2 & A & 19,2 & 0,8 & A & 18,7 & 0,6 & A \\
\hline LEP & 29,7 & 0,4 & B & 30,2 & 0,4 & $\mathrm{AB}$ & 30,4 & 0,9 & $\mathrm{AB}$ & 31,0 & 1,3 & $\mathrm{AB}$ & 32,6 & 0,5 & A \\
\hline LEPR & 28,5 & 0,7 & A & 28,5 & 0,7 & $\mathrm{~A}$ & 28,1 & 1,7 & A & 28,9 & 0,2 & A & 29,5 & 0,3 & A \\
\hline STAT1 & 20,0 & 1,5 & A & 19,0 & 0,7 & $\mathrm{~A}$ & 17,6 & 0,3 & A & 19,1 & 0,7 & A & 18,5 & 0,4 & A \\
\hline STAT4 & 22,8 & 1,6 & A & 23,4 & 0,4 & $\mathrm{~A}$ & 22,9 & 0,2 & A & 22,4 & 0,4 & A & 22,0 & 0,1 & A \\
\hline SOCS1 & 28,8 & 1,6 & A & 27,8 & 1,1 & $\mathrm{AB}$ & 25,6 & 0,6 & B & 28,1 & 0,2 & $\mathrm{AB}$ & 28,1 & 0,1 & $\mathrm{AB}$ \\
\hline SOCS2 & 23,0 & 0,6 & A & 23,0 & 0,6 & $\mathrm{~A}$ & 23,0 & 0,0 & A & 23,1 & 0,5 & A & 22,9 & 0,5 & A \\
\hline IL4 & 31,1 & 1,3 & A & 31,3 & 0,7 & $\mathrm{~A}$ & 30,6 & 0,4 & A & 30,4 & 0,6 & $\mathrm{~A}$ & 29,8 & 0,6 & $\mathrm{~A}$ \\
\hline IL5 & 32,3 & 1,8 & A & 32,5 & 0,9 & A & 33,0 & 0,6 & $\mathrm{~A}$ & 31,3 & 0,0 & A & 31,1 & 0,5 & A \\
\hline IL13 & 30,2 & 1,5 & $\mathrm{AB}$ & 29,1 & 0,8 & $\mathrm{~B}$ & 30,3 & 0,8 & $\mathrm{AB}$ & 32,8 & 0,5 & A & 29,7 & 0,8 & $\mathrm{AB}$ \\
\hline STAT6 & 27,0 & 1,4 & $\mathrm{~A}$ & 26,7 & 0,3 & $\mathrm{~A}$ & 25,9 & 0,7 & A & 27,5 & 1,6 & $\mathrm{~A}$ & 26,4 & 0,3 & $\mathrm{~A}$ \\
\hline SOCS3 & 29,3 & 1,4 & A & 28,7 & 1,1 & A & 27,1 & 0,5 & A & 29,1 & 0,5 & A & 28,6 & 0,2 & A \\
\hline INDO & 21,7 & 0,7 & A & 21,3 & 0,7 & A & 19,1 & 0,2 & B & 21,5 & 0,1 & A & 21,0 & 0,0 & A \\
\hline NOS2A & 34,9 & 2,3 & A & 34,4 & 0,7 & $\mathrm{~A}$ & 33,3 & 0,9 & A & 33,6 & 0,2 & A & 33,4 & 0,9 & A \\
\hline ARG1 & 32,4 & 1,7 & $\mathrm{AB}$ & 33,7 & 2,1 & A & 29,0 & 1,1 & B & 34,1 & 0,1 & A & 33,7 & 0,4 & A \\
\hline SLC11A1 & 32,9 & 3,3 & $\mathrm{~A}$ & 32,9 & 0,9 & $\mathrm{~A}$ & 29,6 & 0,8 & A & 32,4 & 0,5 & $\mathrm{~A}$ & 30,8 & 0,6 & $\mathrm{~A}$ \\
\hline SLC11A2 & 25,1 & 1,2 & A & 25,4 & 0,4 & A & 24,7 & 0,2 & A & 24,4 & 0,7 & A & 24,3 & 0,5 & A \\
\hline IGM & 20,3 & 1,1 & A & 20,1 & 0,3 & A & 19,5 & 0,4 & $\mathrm{~A}$ & 20,0 & 0,1 & A & 18,9 & 0,4 & A \\
\hline IGG & 19,3 & 1,8 & $\mathrm{AB}$ & 19,5 & 0,7 & A & 18,6 & 0,5 & $\mathrm{AB}$ & 19,3 & 0,8 & $\mathrm{AB}$ & 16,6 & 0,2 & B \\
\hline IGA & 20,9 & 1,5 & $\mathrm{~A}$ & 21,8 & 1,4 & $\mathrm{~A}$ & 21,2 & 0,8 & A & 22,6 & 0,1 & $\mathrm{~A}$ & 21,7 & 1,6 & A \\
\hline CD3E & 20,1 & 1,6 & A & 20,5 & 0,8 & $\mathrm{~A}$ & 19,9 & 0,2 & A & 19,5 & 0,6 & $\mathrm{~A}$ & 19,2 & 0,4 & $\mathrm{~A}$ \\
\hline CD19 & 25,8 & 0,8 & A & 25,8 & 0,1 & A & 25,8 & 0,6 & A & 26,0 & 0,3 & A & 25,6 & 0,6 & A \\
\hline CD69 & 21,0 & 1,3 & A & 21,2 & 0,6 & $\mathrm{~A}$ & 20,5 & 0,1 & A & 20,6 & 0,4 & A & 20,3 & 0,5 & A \\
\hline IL2 & 28,9 & 1,6 & A & 29,1 & 0,3 & A & 29,4 & 0,2 & A & 28,4 & 0,3 & A & 28,2 & 0,1 & A \\
\hline IL2RA & 24,4 & 1,2 & A & 24,2 & 0,7 & A & 24,5 & 0,1 & A & 24,0 & 0,5 & A & 24,3 & 0,1 & A \\
\hline IL10 & 28,9 & 0,8 & A & 27,7 & 0,6 & A & 25,6 & 0,2 & B & 28,8 & 0,6 & $\mathrm{~A}$ & 27,8 & 1,0 & $\mathrm{~A}$ \\
\hline TGFB1 & 24,8 & 1,8 & A & 25,1 & 0,9 & A & 24,8 & 0,7 & A & 24,3 & 0,8 & A & 23,6 & 1,0 & A \\
\hline TGFB2 & 22,6 & 1,0 & A & 22,5 & 0,5 & A & 22,4 & 0,4 & A & 22,9 & 0,2 & A & 22,7 & 0,6 & A \\
\hline TGFB3 & 28,9 & 1,0 & A & 28,7 & 0,6 & $\mathrm{~A}$ & 28,3 & 0,4 & A & 28,8 & 0,7 & A & 28,8 & 0,6 & $\mathrm{~A}$ \\
\hline CSF2 & 29,8 & 0,8 & $\mathrm{AB}$ & 29,2 & 0,2 & B & 29,6 & 0,4 & $\mathrm{AB}$ & 30,8 & 0,1 & $\mathrm{~A}$ & 30,2 & 0,3 & $\mathrm{AB}$ \\
\hline MHC2TA & 20,9 & 1,1 & $\mathrm{~A}$ & 20,5 & 0,5 & A & 20,0 & 0,3 & $\mathrm{~A}$ & 20,8 & 0,5 & A & 20,1 & 0,9 & A \\
\hline
\end{tabular}

${ }^{1}$ DPI - dias pós-infecção, ${ }^{2}$ letras distintas na mesma linha indicam diferença estatística 
Tabela 4.1.8 - Resultados da Real-Time RT-PCR em amostras de células mononucleares do sangue periférico dos suínos do EXP I. Valores médios de Ct e respectivos desvios padrões (DP) nos grupos controle e infectados de acordo com o dia após a infecção com T. gondii. Diferença estatística (Estat.) segundo o teste de TukeyKramer $(\alpha=0,05)$ - Beltsville -2003

\begin{tabular}{|c|c|c|c|c|c|c|c|c|c|c|c|c|c|c|c|}
\hline \multirow{2}{*}{ Gene } & \multicolumn{3}{|c|}{ Controle } & \multicolumn{3}{|c|}{ 2DPI ${ }^{1}$} & \multicolumn{3}{|c|}{ 4DPI } & \multicolumn{3}{|c|}{ 7DPI } & \multicolumn{3}{|c|}{ 14DPI } \\
\hline & Média & DP & Estat. $^{2}$ & Média & $\mathrm{DP}$ & Estat. & Média & DP & Estat. & Média & DP & Estat. & Média & $\mathrm{DP}$ & Estat. \\
\hline RPL13A & 21,5 & 1,3 & $\mathrm{~A}$ & 20,7 & 0,7 & $\mathrm{~A}$ & 22,0 & 1,0 & $\mathrm{~A}$ & 20,6 & 0,4 & $\mathrm{~A}$ & 21,3 & 0,2 & $\mathrm{~A}$ \\
\hline RPL32 & 17,1 & 0,3 & A & 17,5 & 0,4 & A & 18,2 & 0,8 & A & 17,4 & 0,1 & A & 17,5 & 0,1 & A \\
\hline IFNA & 32,5 & 2,0 & A & 32,3 & 1,4 & $\mathrm{~A}$ & 32,8 & 1,1 & A & 31,5 & 0,7 & A & 32,3 & 0,8 & A \\
\hline IL1B & 25,4 & 0,6 & A & 24,1 & 2,0 & A & 25,0 & 1,5 & A & 23,9 & 0,9 & A & 25,0 & 1,2 & A \\
\hline IL6 & 32,2 & 1,2 & A & 31,0 & 0,4 & $\mathrm{~A}$ & 29,7 & 3,8 & $\mathrm{~A}$ & 30,4 & 1,0 & A & 31,4 & 1,0 & A \\
\hline ORM1 & 29,4 & 0,4 & A & 29,2 & 0,6 & $\mathrm{~A}$ & 29,5 & 0,9 & A & 28,4 & 0,5 & A & 28,5 & 1,6 & A \\
\hline TNF & 28,3 & 0,6 & A & 28,4 & 0,4 & A & 28,1 & 1,7 & A & 27,3 & 2,0 & A & 27,7 & 1,2 & A \\
\hline TNFRS & 22,0 & 1,1 & A & 21,0 & 0,9 & $\mathrm{~A}$ & 21,6 & 1,0 & A & 20,6 & 1,1 & A & 21,7 & 0,4 & A \\
\hline TLR2 & 23,5 & 1,0 & A & 22,1 & 0,8 & A & 23,1 & 1,8 & A & 22,0 & 1,3 & A & 23,3 & 0,7 & A \\
\hline TLR4 & 23,4 & 1,0 & A & 22,5 & 0,7 & A & 22,9 & 2,2 & A & 22,2 & 1,9 & A & 23,5 & 0,7 & A \\
\hline IFNG & 25,4 & 2,4 & A & 25,9 & 1,0 & $\mathrm{~A}$ & 25,9 & 1,3 & A & 24,7 & 0,8 & A & 24,7 & 1,0 & A \\
\hline IL12A & 33,1 & 1,9 & A & 32,4 & 1,1 & A & 33,8 & 1,7 & A & 32,3 & 0,4 & A & 33,5 & 0,2 & A \\
\hline IL12B & 37,1 & 2,2 & A & 36,5 & 0,6 & A & 36,9 & 1,5 & A & 34,6 & 1,4 & A & 37,4 & 0,6 & A \\
\hline IL12RB2 & 31,2 & 1,1 & A & 30,8 & 1,5 & A & 31,5 & 1,4 & A & 29,5 & 0,8 & A & 31,3 & 1,2 & A \\
\hline IL15 & 29,9 & 1,9 & A & 29,0 & 1,0 & A & 29,2 & 2,4 & $\mathrm{~A}$ & 27,9 & 2,0 & A & 29,2 & 0,8 & A \\
\hline IL18 & 26,7 & 0,2 & A & 25,9 & 0,3 & A & 26,5 & 1,4 & A & 25,8 & 0,9 & A & 26,7 & 0,6 & A \\
\hline IL23A & 37,9 & 0,9 & A & 37,6 & 2,0 & A & 37,4 & 1,8 & A & 37,1 & 0,9 & A & 38,4 & 1,1 & A \\
\hline IRF1 & 19,4 & 1,3 & A & 19,0 & 0,7 & A & 19,4 & 1,7 & $\mathrm{~A}$ & 19,2 & 1,1 & A & 19,4 & 0,6 & A \\
\hline LEP & 34,0 & 1,0 & A & 35,3 & 2,5 & $\mathrm{~A}$ & 36,3 & 1,6 & $\mathrm{~A}$ & 32,9 & $\mathrm{xx}$ & A & 36,3 & 0,1 & A \\
\hline LEPR & 28,3 & 1,3 & A & 29,2 & 0,8 & A & 30,5 & 1,4 & A & 30,4 & 1,8 & A & 30,1 & 0,6 & A \\
\hline STAT1 & 20,0 & 1,6 & A & 18,5 & 0,7 & A & 19,6 & 1,6 & A & 18,4 & 1,5 & A & 19,7 & 0,4 & A \\
\hline STAT4 & 23,6 & 1,3 & A & 22,7 & 0,8 & A & 24,1 & 1,2 & A & 22,9 & 0,1 & A & 23,3 & 0,7 & A \\
\hline SOCS1 & 28,7 & 0,9 & A & 29,4 & 1,3 & A & 30,0 & 1,8 & A & 28,9 & 0,6 & A & 30,4 & 1,1 & A \\
\hline SOCS2 & 21,3 & 1,9 & A & 22,7 & 0,2 & A & 23,4 & 0,9 & A & 22,5 & 0,6 & A & 23,5 & 0,6 & A \\
\hline IL4 & 33,1 & 2,2 & A & 34,0 & 1,7 & A & 34,2 & 1,1 & A & 32,2 & 0,3 & A & 33,5 & 0,1 & A \\
\hline IL5 & 31,3 & 2,0 & A & 30,9 & 0,3 & A & 32,4 & 1,2 & A & 30,7 & 1,4 & A & 31,5 & 0,8 & A \\
\hline IL13 & $\mathrm{xx}$ & $\mathrm{xx}$ & $\mathrm{xx}$ & $\mathrm{xx}$ & $\mathrm{xx}$ & $\mathrm{xx}$ & $\mathrm{xx}$ & $\mathrm{xx}$ & $\mathrm{xx}$ & $\mathrm{xx}$ & $\mathrm{xx}$ & $\mathrm{xx}$ & $\mathrm{xx}$ & $\mathrm{xx}$ & $\mathrm{xx}$ \\
\hline STAT6 & 27,1 & 1,0 & A & 27,6 & 0,5 & A & 27,5 & 1,8 & A & 27,4 & 0,3 & A & 27,7 & 0,8 & A \\
\hline SOCS3 & 29,8 & 1,5 & A & 27,7 & 0,9 & A & 28,8 & 1,3 & A & 28,0 & 1,2 & A & 28,5 & 0,4 & A \\
\hline INDO & 21,6 & 3,8 & A & 21,7 & 1,0 & A & 22,6 & 5,4 & A & 21,8 & 5,0 & A & 25,5 & 0,9 & A \\
\hline NOS2A & 34,3 & 1,7 & A & 34,5 & 2,1 & A & 33,9 & 0,6 & A & 33,2 & 0,6 & A & 34,1 & 1,4 & A \\
\hline ARG1 & 22,4 & 1,6 & A & 24,5 & 1,9 & A & 22,5 & 1,9 & A & 22,3 & 1,9 & A & 22,1 & 1,1 & A \\
\hline SLC11A1 & 28,6 & 1,9 & A & 27,3 & 0,2 & A & 26,5 & 3,4 & A & 26,0 & 2,5 & A & 27,6 & 1,4 & A \\
\hline SLC11A2 & 26,0 & 1,1 & A & 25,4 & 0,5 & A & 25,4 & 0,5 & A & 24,7 & 0,6 & A & 24,1 & 1,0 & A \\
\hline IGM & 23,0 & 1,8 & A & 21,7 & 0,8 & A & 23,2 & 0,8 & A & 22,3 & 1,0 & A & 22,6 & 0,7 & A \\
\hline IGG & 23,6 & 1,6 & A & 22,1 & 1,0 & A & 23,2 & 1,1 & A & 22,3 & 1,1 & A & 23,1 & 0,9 & A \\
\hline IGA & & 1,5 & A & 21,9 & 1,5 & A & 23,2 & 1,0 & A & 22,4 & 0,5 & A & 24,0 & 0,4 & A \\
\hline CD3E & 19,8 & 0,6 & A & 19,6 & 0,9 & A & 20,6 & 0,9 & A & 19,6 & 0,4 & A & 19,1 & 0,7 & A \\
\hline CD19 & 29,1 & 1,6 & A & 27,3 & 1,7 & A & 28,7 & 0,9 & A & 28,0 & 0,5 & A & 29,3 & 0,4 & A \\
\hline CD69 & 21,4 & 1,7 & A & 20,3 & 0,4 & A & 21,8 & 1,2 & A & 20,5 & 0,6 & A & 20,5 & 0,3 & A \\
\hline IL2 & 33,1 & 1,5 & A & 31,6 & 1,3 & A & 32,7 & 2,6 & A & 32,1 & 0,7 & A & 32,0 & 0,4 & A \\
\hline IL2RA & 28,0 & 1,2 & A & 26,5 & 0,5 & A & 28,0 & 1,3 & A & 27,1 & 0,4 & A & 27,7 & 0,5 & A \\
\hline IL10 & 28,3 & 1,1 & A & 27,6 & 0,6 & A & 28,2 & 2,1 & A & 26,8 & 1,3 & A & 27,4 & 0,2 & A \\
\hline TGFB1 & 26,4 & 1,7 & A & 25,3 & 0,7 & A & 26,5 & 1,1 & A & 25,0 & 0,5 & A & 26,0 & 0,1 & A \\
\hline TGFB2 & 24,8 & 1,0 & A & 24,7 & 0,6 & A & 24,2 & 1,9 & A & 22,1 & 1,6 & A & 23,6 & 0,9 & A \\
\hline TGFB3 & 34,3 & 0,8 & A & 33,5 & 0,5 & A & 33,5 & 1,2 & A & 32,6 & 0,6 & A & 33,7 & 0,7 & A \\
\hline CSF2 & 34,6 & 1,2 & A & 35,5 & 2,2 & A & 36,5 & 1,6 & A & 36,4 & 0,4 & A & 36,5 & 0,3 & A \\
\hline MHC2TA & 24,1 & 1,2 & A & 22,7 & 0,6 & $\mathrm{~A}$ & 23,1 & 1,1 & $\mathrm{~A}$ & 22,6 & 0,6 & A & 23,6 & 0,5 & A \\
\hline
\end{tabular}

${ }^{1}$ DPI - dias pós-infecção, ${ }^{2}$ letras distintas na mesma linha indicam diferença estatística, $\mathrm{xx}=$ não detectado 
Tabela 4.1.9 - Resultados da Real-Time RT-PCR em amostras de fígado dos suínos do EXP I. Valores médios de $\mathrm{Ct}$ e respectivos desvios padrões (DP) nos grupos controle e infectados de acordo com o dia após a infecção com $T$. gondii. Diferença estatística (Estat.) segundo o teste de Tukey-Kramer $(\alpha=0,05)$ - Beltsville - 2003

\begin{tabular}{|c|c|c|c|c|c|c|c|c|c|}
\hline \multirow{2}{*}{ Gene } & \multicolumn{3}{|c|}{ Controle } & \multicolumn{3}{|c|}{ 2DPI ${ }^{1}$} & \multicolumn{3}{|c|}{ 4DPI } \\
\hline & Média & $\mathrm{DP}$ & Estat. $^{2}$ & Média & $\mathrm{DP}$ & Estat. & Média & DP & Estat. \\
\hline RPL13A & 24,8 & 2,3 & A & 24,7 & 0,7 & $\mathrm{~A}$ & 24,2 & 3,2 & $\mathrm{~A}$ \\
\hline RPL32 & 18,3 & 2,1 & A & 17,6 & 1,2 & A & 17,9 & 1,5 & A \\
\hline IFNA & 34,4 & 1,8 & $\mathrm{~A}$ & 33,3 & 1,1 & A & 29,7 & 1,6 & A \\
\hline IL1B & 31,8 & 4,0 & A & 30,5 & 0,4 & A & 29,6 & 3,8 & A \\
\hline IL6 & 28,0 & 1,6 & A & 30,2 & 0,0 & A & 27,8 & 0,7 & A \\
\hline ORM1 & 14,1 & 0,0 & A & 14,3 & 0,1 & A & 14,3 & 0,5 & A \\
\hline TNF & 30,1 & 1,7 & A & 28,0 & 1,4 & A & 27,1 & 1,0 & A \\
\hline TNFRSF1A & 26,9 & 1,0 & A & 25,1 & 1,3 & A & 22,8 & 3,4 & A \\
\hline TLR2 & 28,0 & 3,5 & A & 26,9 & 0,3 & A & 25,5 & 3,2 & A \\
\hline TLR4 & 24,3 & 1,3 & A & 25,4 & 0,5 & A & 23,2 & 1,1 & A \\
\hline IFNG & 33,8 & 1,4 & A & 30,9 & 0,1 & A & 29,3 & 3,7 & A \\
\hline IL12A & 36,5 & $\mathrm{xx}$ & A & 37,2 & 1,0 & A & 34,9 & 1,9 & A \\
\hline IL12B & 34,1 & 0,8 & A & 37,1 & 0,8 & A & 34,5 & 2,1 & A \\
\hline IL12RB2 & 37,5 & 1,1 & A & 37,8 & 1,8 & A & 35,0 & 3,6 & A \\
\hline IL15 & 31,2 & 1,1 & A & 32,3 & 0,4 & A & 30,4 & 1,4 & A \\
\hline IL18 & 23,3 & 0,0 & A & 23,2 & 0,1 & A & 21,7 & 1,3 & A \\
\hline IL23A & 39,2 & $\mathrm{xx}$ & A & 38,0 & 2,1 & A & 36,1 & 1,8 & A \\
\hline IRF1 & 23,0 & 1,1 & A & 20,1 & 1,1 & $\mathrm{AB}$ & 18,5 & 0,7 & B \\
\hline LEP & 36,4 & $\mathrm{xx}$ & A & 33,9 & 3,3 & A & 33,4 & 2,5 & A \\
\hline LEPR & 22,6 & 2,5 & A & 20,9 & 2,1 & A & 20,7 & 1,0 & A \\
\hline STAT1 & 25,5 & 3,6 & A & 22,2 & 1,2 & A & 20,3 & 3,4 & A \\
\hline STAT4 & 32,0 & 2,2 & A & 30,9 & 0,4 & A & 29,7 & 3,0 & A \\
\hline SOCS1 & 29,7 & 2,6 & A & 28,3 & 1,6 & A & 26,2 & 0,7 & A \\
\hline SOCS2 & 23,0 & 4,5 & A & 21,4 & 1,6 & A & 22,0 & 1,9 & A \\
\hline IL4 & 38,1 & 2,1 & A & 37,3 & 0,3 & A & 35,2 & 2,8 & A \\
\hline IL5 & 32,1 & 1,2 & A & 34,4 & 0,1 & A & 34,7 & 1,6 & A \\
\hline IL13 & 32,3 & 0,4 & A & 30,5 & 2,8 & A & 32,6 & 2,2 & A \\
\hline STAT6 & 27,9 & 1,6 & A & 27,5 & 1,4 & A & 26,5 & 1,3 & A \\
\hline SOCS3 & 36,1 & 4,0 & A & 33,2 & 1,5 & A & 30,8 & 3,4 & A \\
\hline INDO & 29,4 & 2,8 & A & 24,1 & 2,7 & $\mathrm{AB}$ & 20,7 & 2,0 & B \\
\hline NOS2A & 37,7 & 0,8 & A & 39,4 & 0,0 & A & 37,5 & 1,0 & A \\
\hline ARG1 & 22,4 & 2,6 & A & 20,5 & 4,2 & A & 18,5 & 1,5 & A \\
\hline SLC11A1 & 32,3 & 0,7 & A & 31,0 & 0,3 & A & 27,7 & 0,8 & B \\
\hline SLC11A2 & 25,0 & 0,6 & A & 26,4 & 0,8 & A & 24,1 & 0,8 & A \\
\hline IGM & 28,9 & 2,9 & A & 27,8 & 0,8 & A & 26,4 & 2,7 & A \\
\hline IGG & 24,9 & 1,3 & A & 27,7 & 1,4 & A & 25,8 & 1,9 & A \\
\hline IGA & 26,4 & 1,1 & A & 28,3 & 0,6 & A & 27,6 & 1,1 & A \\
\hline CD3E & 25,1 & 1,5 & A & 25,8 & 0,3 & A & 24,5 & 1,3 & A \\
\hline CD19 & 33,1 & 1,8 & A & 34,0 & 0,8 & A & 33,4 & 1,2 & A \\
\hline CD69 & 27,3 & 1,0 & A & 27,6 & 0,2 & A & 26,8 & 0,2 & A \\
\hline IL2 & 34,5 & 0,6 & A & 36,1 & 1,0 & A & 35,2 & 0,8 & A \\
\hline IL2RA & 35,3 & 3,5 & A & 33,2 & 1,3 & A & 31,5 & 2,7 & A \\
\hline IL10 & 34,9 & 2,4 & A & 30,8 & 1,7 & A & 29,5 & 1,7 & A \\
\hline TGFB1 & 30,6 & 3,7 & A & 29,9 & 0,1 & A & 29,1 & 3,4 & A \\
\hline TGFB2 & 25,0 & 1,3 & A & 26,6 & 0,6 & A & 25,7 & 1,1 & A \\
\hline TGFB3 & 29,2 & 1,0 & A & 30,9 & 0,8 & A & 29,3 & 0,9 & A \\
\hline CSF2 & 33,8 & 0,1 & A & 32,1 & 0,8 & A & 31,4 & 1,1 & A \\
\hline MHC2TA & 25,6 & 0,2 & A & 26,2 & 0,2 & A & 23,3 & 0,6 & B \\
\hline
\end{tabular}

${ }^{1}$ DPI - dias pós-infecção, ${ }^{2}$ letras distintas na mesma linha indicam diferença estatística 
Tabela 4.1.10 - Resultados da Real-Time RT-PCR em amostras de baço dos suínos do EXP I. Valores médios de Ct e respectivos desvios padrões (DP) nos grupos controle e infectados de acordo com o dia após a infecção com $T$. gondii . Diferença estatística (Estat.) segundo o teste de Tukey-Kramer $(\alpha=0,05)$ - Beltsville -2003

\begin{tabular}{|c|c|c|c|c|c|c|c|c|c|}
\hline \multirow{2}{*}{ Gene } & \multicolumn{3}{|c|}{ Controle } & \multicolumn{3}{|c|}{ 2DPI ${ }^{1}$} & \multicolumn{3}{|c|}{ 4DPI } \\
\hline & Média & $\mathrm{DP}$ & Estat. $^{2}$ & Média & $\mathrm{DP}$ & Estat. & Média & DP & Estat. \\
\hline RPL13A & 21,2 & 1,8 & A & 21,7 & 1,1 & $\mathrm{~A}$ & 21,0 & 2,0 & $\mathrm{~A}$ \\
\hline RPL32 & 15,6 & 0,1 & A & 16,1 & 1,2 & A & 16,1 & 0,6 & A \\
\hline IFNA & 30,0 & 0,1 & A & 31,5 & 1,8 & A & 29,5 & 1,4 & A \\
\hline IL1B & 28,5 & 2,3 & A & 28,1 & 1,6 & A & 27,3 & 0,9 & A \\
\hline IL6 & 23,9 & 0,3 & A & 24,6 & 0,7 & A & 24,0 & 1,2 & A \\
\hline ORM1 & 22,0 & 2,0 & A & 21,4 & 1,9 & A & 20,9 & 1,5 & A \\
\hline $\mathrm{TNF}$ & 24,4 & 0,1 & A & 23,7 & 1,6 & A & 24,5 & 1,5 & A \\
\hline TNFRSF1A & 22,3 & 2,3 & A & 22,1 & 1,7 & A & 20,5 & 1,4 & A \\
\hline TLR2 & 24,5 & 2,5 & A & 23,7 & 1,5 & A & 22,3 & 1,4 & A \\
\hline TLR4 & 21,5 & 1,3 & A & 21,7 & 1,0 & A & 20,7 & 1,1 & A \\
\hline IFNG & 29,2 & 2,1 & A & 28,4 & 1,7 & A & 26,7 & 1,0 & A \\
\hline IL12A & 33,0 & 1,3 & A & 32,3 & 0,9 & A & 31,4 & 1,4 & A \\
\hline IL12B & 31,7 & 0,7 & A & 32,7 & 1,9 & A & 33,1 & 0,8 & A \\
\hline IL12RB2 & 31,6 & 0,2 & A & 31,1 & 3,1 & A & 31,6 & 3,4 & A \\
\hline IL15 & 28,7 & 0,3 & $\mathrm{AB}$ & 30,3 & 0,9 & A & 27,2 & 0,9 & B \\
\hline IL18 & 19,5 & 0,3 & B & 21,4 & 0,8 & A & 19,6 & 0,6 & B \\
\hline IL23A & 34,4 & 3,5 & A & 35,8 & 0,6 & A & 34,9 & 0,7 & A \\
\hline IRF1 & 19,3 & 1,0 & A & 18,4 & 0,6 & A & 17,9 & 0,7 & A \\
\hline LEP & 30,7 & 3,5 & A & 32,1 & 1,9 & A & 31,3 & 0,4 & A \\
\hline LEPR & 25,3 & 0,6 & A & 26,5 & 1,8 & A & 26,0 & 1,2 & A \\
\hline STAT1 & 22,1 & 2,8 & A & 19,8 & 1,5 & A & 18,1 & 1,5 & A \\
\hline STAT4 & 25,6 & 2,5 & A & 25,4 & 1,7 & A & 23,6 & 1,8 & A \\
\hline SOCS1 & 26,6 & 1,3 & A & 26,5 & 2,0 & A & 26,0 & 0,3 & A \\
\hline SOCS2 & 20,6 & 0,8 & A & 21,8 & 1,0 & A & 21,6 & 0,6 & A \\
\hline IL4 & 33,7 & 1,6 & A & 34,5 & 1,3 & A & 34,2 & 1,6 & A \\
\hline IL5 & 34,0 & 1,1 & A & 34,9 & 1,7 & A & 33,8 & 2,7 & A \\
\hline IL13 & 32,4 & 0,7 & A & 33,5 & 0,4 & A & 32,8 & 0,6 & A \\
\hline STAT6 & 25,2 & 1,8 & A & 26,0 & 0,9 & A & 25,5 & 0,2 & A \\
\hline SOCS3 & 30,9 & 2,7 & A & 29,5 & 1,2 & $\mathrm{~A}$ & 28,8 & 1,5 & A \\
\hline INDO & 22,4 & 0,1 & A & 21,0 & 2,1 & $\mathrm{AB}$ & 17,5 & 1,0 & B \\
\hline NOS2A & 35,2 & 2,3 & A & 37,5 & 1,2 & A & 35,7 & 0,8 & A \\
\hline ARG1 & 21,7 & 0,0 & A & 23,5 & 2,2 & A & 25,2 & 1,1 & A \\
\hline SLC11A1 & 25,6 & 2,3 & $\mathrm{AB}$ & 28,6 & 0,4 & A & 24,7 & 1,4 & B \\
\hline SLC11A2 & 24,7 & 0,9 & A & 26,4 & 1,1 & A & 24,8 & 0,6 & A \\
\hline IGM & 19,2 & 1,8 & A & 18,7 & 1,2 & A & 17,5 & 1,8 & A \\
\hline IGG & 20,9 & 0,7 & A & 22,0 & 1,8 & A & 19,9 & 1,4 & A \\
\hline IGA & 24,7 & 2,3 & A & 25,7 & 1,0 & A & 25,7 & 1,4 & A \\
\hline CD3E & 19,4 & 0,1 & A & 20,9 & 0,8 & A & 19,5 & 0,8 & A \\
\hline CD19 & 26,8 & 1,1 & A & 27,7 & 1,3 & A & 27,9 & 1,3 & A \\
\hline CD69 & 24,2 & 2,0 & A & 24,0 & 0,9 & A & 23,3 & 1,4 & A \\
\hline IL2 & 31,5 & 0,6 & A & 33,2 & 1,6 & A & 32,9 & 1,3 & A \\
\hline IL2RA & 27,4 & 1,7 & A & 27,5 & 1,8 & A & 27,7 & 2,0 & $\mathrm{~A}$ \\
\hline IL10 & 30,1 & 1,6 & A & 29,8 & 0,9 & A & 27,5 & 1,5 & A \\
\hline TGFB1 & 26,0 & 2,1 & A & 26,6 & 0,8 & A & 25,1 & 1,8 & A \\
\hline TGFB2 & 23,7 & 0,3 & A & 25,4 & 0,8 & A & 25,0 & 0,7 & A \\
\hline TGFB3 & 27,6 & 0,6 & A & 29,3 & 1,2 & A & 28,0 & 0,9 & A \\
\hline CSF2 & 30,3 & 0,6 & A & 32,3 & 2,5 & A & 31,6 & 1,2 & $\mathrm{~A}$ \\
\hline MHC2TA & 21,5 & 0,8 & A & 22,1 & 1,0 & A & 21,2 & 1,0 & A \\
\hline
\end{tabular}

${ }^{1}$ DPI - dias pós-infecção, ${ }^{2}$ letras distintas na mesma linha indicam diferença estatística 
Tabela 4.1.11 - Resultados da Real-Time RT-PCR em amostras de timo dos suínos do EXP I. Valores médios de $\mathrm{Ct}$ e respectivos desvios padrões (DP) nos grupos controle e infectados de acordo com o dia após a infecção com $T$. gondii. Diferença estatística (Estat.) segundo o teste de Tukey-Kramer $(\alpha=0,05)$ - Beltsville - 2003

\begin{tabular}{|c|c|c|c|c|c|c|c|c|c|}
\hline \multirow{2}{*}{ Gene } & \multicolumn{3}{|c|}{ Controle } & \multicolumn{3}{|c|}{$2 \mathrm{DPI}^{1}$} & \multicolumn{3}{|c|}{ 4DPI } \\
\hline & Média & DP & Estat. $^{2}$ & Média & DP & Estat. & Média & DP & Estat. \\
\hline RPL13A & 19,3 & 0,3 & $\mathrm{~A}$ & 20,0 & 0,4 & $\mathrm{~A}$ & 20,9 & 0,7 & $\mathrm{~A}$ \\
\hline RPL32 & 17,1 & 0,1 & A & 16,4 & 1,4 & A & 17,5 & 1,1 & A \\
\hline IFNA & 28,4 & 0,7 & A & 27,7 & 1,6 & A & 28,4 & 1,2 & A \\
\hline IL1B & 26,2 & 0,6 & A & 26,5 & 0,6 & A & 26,2 & 0,6 & A \\
\hline IL6 & 26,9 & 0,3 & A & 27,6 & 0,2 & A & 28,0 & 0,3 & A \\
\hline ORM1 & 23,5 & 1,2 & A & 24,0 & 0,9 & A & 23,5 & 0,6 & A \\
\hline TNF & 27,9 & 0,1 & A & 26,1 & 1,8 & A & 26,3 & 1,8 & A \\
\hline TNFRSF1A & 20,7 & 0,3 & A & 21,5 & 0,7 & A & 21,6 & 0,3 & A \\
\hline TLR2 & 23,7 & 0,0 & A & 24,4 & 0,4 & A & 23,9 & 0,1 & A \\
\hline TLR4 & 23,4 & 0,2 & A & 24,5 & 0,7 & A & 23,6 & 0,0 & A \\
\hline IFNG & 29,6 & 0,2 & A & 29,1 & 1,4 & A & 29,8 & 0,5 & A \\
\hline IL12A & 29,1 & 0,2 & A & 29,7 & 0,5 & A & 29,5 & 0,3 & A \\
\hline IL12B & 28,0 & 0,2 & A & 28,5 & 0,3 & A & 29,6 & 1,2 & A \\
\hline IL12RB2 & 30,8 & 0,1 & A & 30,3 & 0,2 & A & 30,8 & 0,4 & A \\
\hline IL15 & 30,9 & 0,0 & A & 31,2 & 0,7 & A & 32,0 & 0,9 & A \\
\hline IL18 & 22,7 & 0,3 & A & 22,1 & 1,0 & A & 22,6 & 0,2 & A \\
\hline IL23A & 36,7 & 0,1 & A & 35,2 & 0,8 & A & 34,5 & 5,3 & A \\
\hline IRF1 & 20,8 & 0,1 & A & 20,8 & 0,2 & A & 20,2 & 1,5 & A \\
\hline LEP & 33,2 & 0,0 & A & 31,2 & 0,4 & A & 30,7 & 4,1 & A \\
\hline LEPR & 28,0 & 0,5 & A & 27,6 & 1,5 & A & 27,4 & 1,6 & A \\
\hline STAT1 & 20,2 & 0,1 & A & 21,0 & 0,4 & A & 20,6 & 0,0 & A \\
\hline STAT4 & 23,9 & 0,4 & A & 24,5 & 0,5 & A & 25,3 & 0,1 & A \\
\hline SOCS1 & 28,1 & 0,4 & A & 26,9 & 1,2 & A & 27,4 & 2,2 & A \\
\hline SOCS2 & 21,4 & 0,1 & A & 20,7 & 1,4 & A & 22,6 & 1,3 & A \\
\hline IL4 & 31,0 & 0,0 & A & 31,1 & 0,7 & A & 31,9 & 1,3 & A \\
\hline IL5 & 31,0 & 0,2 & A & 32,1 & 0,5 & A & 32,3 & 0,4 & A \\
\hline IL13 & 30,3 & 0,3 & A & 30,0 & 0,3 & A & 31,0 & 0,2 & A \\
\hline STAT6 & 26,7 & 0,7 & A & 26,6 & 0,9 & A & 25,8 & 1,8 & A \\
\hline SOCS3 & 29,4 & 0,0 & A & 29,6 & 0,8 & A & 30,2 & 0,3 & A \\
\hline INDO & 22,8 & 0,8 & A & 21,8 & 1,7 & A & 21,9 & 1,0 & A \\
\hline NOS2A & 35,6 & 1,1 & A & 36,0 & 1,2 & A & 36,1 & 0,5 & A \\
\hline ARG1 & 28,2 & 0,2 & A & 27,5 & 2,9 & A & 26,5 & 1,9 & A \\
\hline SLC11A1 & 31,6 & 0,7 & A & 33,0 & 1,3 & A & 30,5 & 0,8 & A \\
\hline SLC11A2 & 24,6 & 0,2 & A & 25,2 & 0,6 & A & 26,1 & 0,7 & A \\
\hline IGM & 24,8 & 0,3 & A & 25,0 & 0,2 & A & 25,7 & 0,0 & A \\
\hline IGG & 22,5 & 0,3 & A & 22,8 & 1,2 & A & 23,7 & 0,5 & A \\
\hline IGA & 22,9 & 1,5 & A & 23,2 & 0,1 & A & 25,1 & 0,9 & A \\
\hline CD3E & 18,1 & 0,0 & B & 17,9 & 0,4 & B & 19,2 & 0,2 & A \\
\hline CD19 & 30,2 & 0,2 & B & 30,3 & 0,0 & B & 31,2 & 0,0 & A \\
\hline CD69 & 21,0 & 0,3 & A & 21,4 & 0,5 & A & 21,3 & 0,6 & A \\
\hline IL2 & 28,5 & 0,1 & B & 29,3 & 0,8 & $\mathrm{AB}$ & 31,0 & 0,2 & B \\
\hline IL2RA & 25,0 & 0,2 & A & 25,7 & 0,7 & A & 26,2 & 0,1 & A \\
\hline IL10 & 30,9 & 0,5 & $\mathrm{AB}$ & 31,8 & 0,8 & A & 29,5 & 0,2 & B \\
\hline TGFB1 & 25,2 & 0,2 & B & 25,8 & 0,4 & $\mathrm{AB}$ & 26,3 & 0,1 & A \\
\hline TGFB2 & 25,0 & 0,2 & A & 25,5 & 0,4 & A & 25,9 & 0,3 & A \\
\hline TGFB3 & 29,3 & 0,1 & $\mathrm{C}$ & 29,6 & 0,0 & B & 30,3 & 0,0 & A \\
\hline CSF2 & 29,1 & 0,6 & A & 28,5 & 1,0 & A & 28,8 & 2,0 & A \\
\hline MHC2TA & 22,7 & 0,4 & A & 23,5 & 0,6 & A & 23,4 & 0,3 & A \\
\hline
\end{tabular}

${ }^{1}$ DPI - dias pós-infecção, ${ }^{2}$ letras distintas na mesma linha indicam diferença estatística 
Tabela 4.1.12 - Resultados da Real-Time RT-PCR em amostras de linfonodo íleo-cólico dos suínos do EXP I. Valores médios de Ct e respectivos desvios padrões (DP) nos grupos controle e infectados de acordo com o dia após a infecção com T. gondii . Diferença estatística (Estat.) segundo o teste de Tukey-Kramer $(\alpha=0,05)$ Beltsville -2003

\begin{tabular}{|c|c|c|c|c|c|c|c|c|c|}
\hline \multirow{2}{*}{ Gene } & \multicolumn{3}{|c|}{$\begin{array}{c}\text { Controle } \\
\end{array}$} & \multicolumn{3}{|c|}{ 2DPI ${ }^{1}$} & \multicolumn{3}{|c|}{ 4DPI } \\
\hline & Média & DP & Estat. $^{2}$ & Média & $\mathrm{DP}$ & Estat. & Média & DP & Estat. \\
\hline RPL32 & 15,4 & 0,2 & $\mathrm{~A}$ & 15,3 & 0,1 & $\mathrm{~A}$ & 15,4 & 0,2 & $\mathrm{~A}$ \\
\hline IFNA & 28,4 & 1,0 & $\mathrm{~A}$ & 28,6 & 0,2 & $\mathrm{~A}$ & 28,0 & 1,0 & $\mathrm{~A}$ \\
\hline IL1B & 28,5 & 0,1 & $\mathrm{~A}$ & 27,9 & 0,2 & A & 24,0 & 2,8 & A \\
\hline IL6 & 25,3 & 0,2 & $\mathrm{~A}$ & 24,9 & 0,2 & $\mathrm{~A}$ & 22,9 & 1,9 & $\mathrm{~A}$ \\
\hline TNF & 27,0 & 0,0 & $\mathrm{~A}$ & 25,9 & 0,4 & $\mathrm{AB}$ & 24,7 & 0,5 & $\mathrm{~B}$ \\
\hline IFNG & 23,9 & 0,1 & $\mathrm{~A}$ & 23,6 & 0,2 & A & 20,9 & 2,6 & A \\
\hline IL12B & 25,7 & 1,0 & $\mathrm{~A}$ & 25,7 & 0,0 & $\mathrm{~A}$ & 26,2 & 1,4 & $\mathrm{~A}$ \\
\hline IL12RB2 & 31,4 & 0,4 & $\mathrm{~A}$ & 30,0 & 2,9 & $\mathrm{~A}$ & 28,5 & 2,9 & A \\
\hline IL15 & 28,3 & 0,9 & $\mathrm{~A}$ & 27,9 & 0,4 & $\mathrm{~A}$ & 26,0 & 0,9 & A \\
\hline IL18 & 19,7 & 0,4 & $\mathrm{~A}$ & 19,7 & 0,6 & A & 19,7 & 0,4 & A \\
\hline IL23A & 36,4 & 0,0 & $\mathrm{AB}$ & 37,1 & 0,2 & A & 34,1 & 1,2 & B \\
\hline IRF1 & 20,6 & 0,3 & A & 19,8 & 0,4 & $\mathrm{AB}$ & 19,3 & 0,4 & B \\
\hline STAT1 & 19,3 & 0,1 & A & 18,9 & 0,3 & $\mathrm{AB}$ & 18,0 & 0,5 & B \\
\hline SOCS1 & 28,6 & 0,5 & $\mathrm{~A}$ & 27,9 & 0,4 & A & 25,7 & 1,3 & $\mathrm{~A}$ \\
\hline IL4 & 30,9 & 1,1 & A & 30,7 & 0,5 & A & 30,1 & 2,1 & A \\
\hline IL5 & 29,2 & 0,1 & A & 29,3 & 0,5 & A & 29,7 & 0,7 & A \\
\hline IL13 & 30,1 & 0,1 & $\mathrm{~A}$ & 29,4 & 0,4 & $\mathrm{~A}$ & 29,0 & 2,7 & $\mathrm{~A}$ \\
\hline SOCS3 & 29,1 & 0,1 & A & 27,1 & 1,3 & $\mathrm{AB}$ & 26,5 & 0,3 & B \\
\hline INDO & 22,1 & 0,0 & A & 22,0 & 0,2 & A & 19,0 & 1,5 & $\mathrm{~A}$ \\
\hline NOS2A & 34,5 & 0,1 & A & 33,3 & 2,8 & A & 32,7 & 1,0 & A \\
\hline SLC11A1 & 34,8 & 0,4 & $\mathrm{~A}$ & 34,0 & 1,0 & $\mathrm{~A}$ & 27,9 & 2,4 & B \\
\hline IL10 & 26,8 & 0,4 & A & 25,9 & 0,1 & $\mathrm{AB}$ & 24,6 & 0,9 & B \\
\hline TGFB1 & 24,2 & 0,1 & A & 23,6 & 0,6 & A & 23,2 & 0,8 & A \\
\hline TGFB3 & 29,9 & 0,5 & A & 27,4 & 2,6 & A & 27,3 & 1,4 & A \\
\hline
\end{tabular}

${ }^{1}$ DPI - dias pós-infecção, ${ }^{2}$ letras distintas na mesma linha indicam diferença estatística 
Tabela 4.1.13 - Resultados da Real-Time RT-PCR em amostras de jejuno dos suínos do EXP I. Valores médios de $\mathrm{Ct}$ e respectivos desvios padrões (DP) nos grupos controle e infectados de acordo com o dia após a infecção com $T$. gondii. Diferença estatística (Estat.) segundo o teste de Tukey-Kramer $(\alpha=0,05)$ - Beltsville 2003

\begin{tabular}{|c|c|c|c|c|c|c|c|c|c|}
\hline \multirow{2}{*}{ Gene } & \multicolumn{3}{|c|}{ Controle } & \multicolumn{3}{|c|}{ 2DPI ${ }^{1}$} & \multicolumn{3}{|c|}{ 4DPI } \\
\hline & Média & DP & Estat. $^{2}$ & Média & DP & Estat. & Média & DP & Estat. \\
\hline RPL32 & 16,2 & 0,1 & $\mathrm{~A}$ & 16,1 & 0,4 & $\mathrm{~A}$ & 15,6 & 0,1 & $\mathrm{~A}$ \\
\hline IFNA & 29,3 & 0,6 & $\mathrm{~A}$ & 29,3 & 0,8 & A & 28,6 & 1,4 & A \\
\hline IL1B & 27,0 & 0,0 & $\mathrm{~A}$ & 25,8 & 0,4 & $\mathrm{AB}$ & 24,1 & 1,4 & B \\
\hline IL6 & 30,2 & 0,1 & $\mathrm{~A}$ & 27,5 & 1,2 & $\mathrm{AB}$ & 26,0 & 0,8 & B \\
\hline TNF & 29,9 & 0,6 & A & 28,3 & 0,5 & $\mathrm{AB}$ & 26,8 & 1,5 & B \\
\hline IFNG & 24,8 & 0,5 & A & 22,9 & 1,1 & A & 20,7 & 0,6 & B \\
\hline IL12B & 29,6 & 0,1 & A & 28,6 & 0,6 & A & 28,6 & 0,5 & A \\
\hline IL12RB2 & 31,9 & 0,3 & A & 31,5 & 0,4 & A & 30,6 & 1,0 & A \\
\hline IL15 & 27,4 & 0,2 & $\mathrm{~A}$ & 27,0 & 0,5 & $\mathrm{~A}$ & 25,6 & 0,2 & B \\
\hline IL18 & 20,9 & 0,0 & A & 21,3 & 0,4 & A & 21,4 & 0,2 & A \\
\hline IL23A & 38,6 & 0,3 & $\mathrm{~A}$ & 36,8 & 0,6 & A & 34,9 & 2,2 & A \\
\hline IRF1 & 20,8 & 0,1 & A & 18,9 & 0,9 & B & 18,1 & 0,2 & B \\
\hline STAT1 & 20,1 & 0,1 & $\mathrm{~A}$ & 18,7 & 0,8 & $\mathrm{AB}$ & 17,8 & 0,3 & B \\
\hline SOCS1 & 29,2 & 0,1 & $\mathrm{~A}$ & 26,9 & 1,6 & $\mathrm{AB}$ & 24,5 & 1,3 & B \\
\hline IL4 & 32,1 & 1,0 & $\mathrm{~A}$ & 29,6 & 1,9 & A & 28,7 & 1,0 & A \\
\hline IL5 & 28,3 & 0,3 & $\mathrm{~A}$ & 28,6 & 1,0 & A & 29,6 & 0,1 & A \\
\hline IL13 & 31,7 & 0,3 & $\mathrm{~A}$ & 29,1 & 3,6 & A & 27,9 & 1,0 & A \\
\hline SOCS3 & 31,5 & 0,6 & A & 29,3 & 1,0 & $\mathrm{AB}$ & 27,3 & 1,0 & B \\
\hline INDO & 27,3 & 1,1 & $\mathrm{~A}$ & 24,7 & 0,6 & B & 20,3 & 0,8 & $\mathrm{C}$ \\
\hline NOS2A & 33,8 & 0,6 & $\mathrm{~A}$ & 29,5 & 2,0 & B & 26,3 & 1,1 & B \\
\hline SLC11A1 & 35,0 & 0,6 & $\mathrm{~A}$ & 32,9 & 0,5 & B & 27,5 & 0,7 & $\mathrm{C}$ \\
\hline IL10 & 29,8 & 0,4 & A & 27,4 & 1,0 & B & 26,1 & 0,5 & B \\
\hline TGFB1 & 26,4 & 0,6 & A & 25,6 & 0,6 & A & 24,8 & 0,7 & A \\
\hline TGFB3 & 30,1 & 0,1 & A & 29,1 & 0,2 & B & 28,1 & 0,4 & $\mathrm{C}$ \\
\hline
\end{tabular}

${ }^{1}$ DPI - dias pós-infecção, ${ }^{2}$ letras distintas na mesma linha indicam diferença estatística 
Tabela 4.1.14 - Resultados da Real-Time RT-PCR em amostras de íleo dos suínos do EXP I. Valores médios de $\mathrm{Ct}$ e respectivos desvios padrões (DP) nos grupos controle e infectados de acordo com o dia após a infecção com T. gondii. Diferença estatística (Estat.) segundo o teste de Tukey-Kramer $(\alpha=0,05)$ - Beltsville - 2003

\begin{tabular}{|c|c|c|c|c|c|c|c|c|c|}
\hline \multirow{2}{*}{ Gene } & \multicolumn{3}{|c|}{ Controle } & \multicolumn{3}{|c|}{$2 D P I^{1}$} & \multicolumn{3}{|c|}{ 4DPI } \\
\hline & Média & $\mathrm{DP}$ & Estat. $^{2}$ & Média & DP & Estat. & Média & DP & Estat. \\
\hline RPL32 & 15,7 & 0,4 & A & 16,2 & 0,5 & $\mathrm{~A}$ & 15,6 & 0,3 & $\mathrm{~A}$ \\
\hline IFNA & 28,4 & 0,3 & A & 27,8 & 1,4 & A & 28,4 & 0,6 & A \\
\hline IL1B & 26,1 & 0,0 & A & 25,5 & 1,1 & A & 23,7 & 1,9 & A \\
\hline IL6 & 26,8 & 0,8 & A & 25,6 & 1,6 & A & 23,7 & 1,6 & A \\
\hline TNF & 27,7 & 0,4 & A & 26,9 & 1,1 & A & 25,9 & 0,9 & A \\
\hline IFNG & 24,2 & 0,1 & A & 23,4 & 0,2 & $\mathrm{AB}$ & 21,6 & 1,2 & B \\
\hline IL12B & 27,7 & 0,6 & A & 28,1 & 0,5 & A & 27,6 & 0,7 & A \\
\hline IL12RB2 & 31,6 & 0,4 & A & 30,4 & 2,2 & A & 30,6 & 0,7 & A \\
\hline IL15 & 28,1 & 1,6 & A & 28,7 & 3,0 & A & 26,1 & 2,0 & A \\
\hline IL18 & 20,9 & 0,2 & A & 20,9 & 0,7 & A & 20,1 & 0,3 & $\mathrm{~A}$ \\
\hline IL23A & 36,2 & 0,1 & A & 36,1 & 2,3 & A & 34,6 & 2,2 & A \\
\hline IRF1 & 20,3 & 0,0 & A & 20,5 & 0,3 & A & 18,5 & 0,4 & B \\
\hline STAT1 & 19,1 & 0,1 & A & 19,2 & 0,5 & A & 17,7 & 0,4 & B \\
\hline SOCS1 & 27,7 & 0,0 & A & 27,1 & 1,2 & A & 24,7 & 1,4 & A \\
\hline IL4 & 31,5 & 1,1 & A & 31,2 & 1,2 & A & 29,6 & 1,4 & A \\
\hline IL5 & 29,0 & 0,4 & A & 28,5 & 1,2 & $\mathrm{~A}$ & 29,3 & 0,3 & A \\
\hline IL13 & 32,1 & 0,0 & A & 28,6 & 4,4 & A & 28,8 & 1,6 & A \\
\hline SOCS3 & 29,6 & 0,3 & A & 28,7 & 0,6 & $\mathrm{AB}$ & 27,0 & 1,1 & B \\
\hline INDO & 23,5 & 0,2 & A & 24,0 & 0,7 & A & 19,6 & 1,5 & B \\
\hline NOS2A & 31,0 & 0,9 & A & 30,1 & 0,7 & $\mathrm{AB}$ & 27,7 & 1,1 & B \\
\hline SLC11A1 & 34,1 & 0,4 & A & 33,4 & 1,2 & A & 27,7 & 1,9 & B \\
\hline IL10 & 27,0 & 0,4 & A & 26,7 & 0,5 & A & 25,4 & 0,7 & A \\
\hline TGFB1 & 24,8 & 1,1 & A & 23,4 & 2,7 & A & 24,1 & 1,1 & $\mathrm{~A}$ \\
\hline TGFB3 & 29,1 & 0,3 & $\mathrm{~A}$ & 29,3 & 0,4 & $\mathrm{~A}$ & 27,5 & 1,2 & A \\
\hline
\end{tabular}

${ }^{1}$ DPI - dias pós-infecção, ${ }^{2}$ letras distintas na mesma linha indicam diferença estatística 


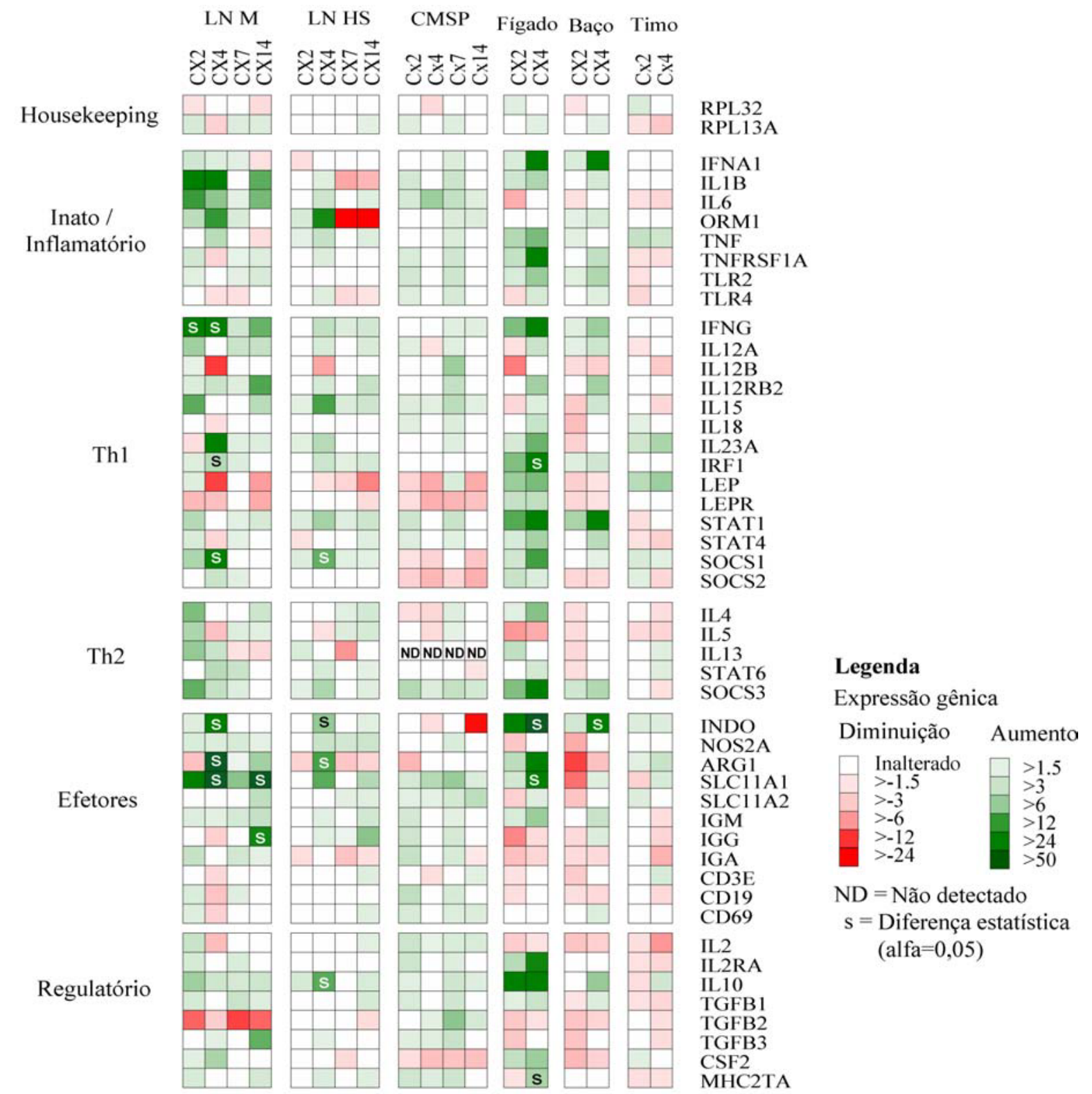

Figura 4.1.1 - Efeito da infecção pelo T. gondii na expressão gênica no linfonodo mesentérico (LN M), no linfonodo hepato-esplênico (LN HS), nas células mononucleares do sangue periférico (CMSP), no figado, no baço e no timo de suínos mensurado pela Real-Time RT-PCR. Aumento ou diminuição da expressão de mRNA nos grupos infectados em relação ao controle não-infectado - Beltsville - 2003 


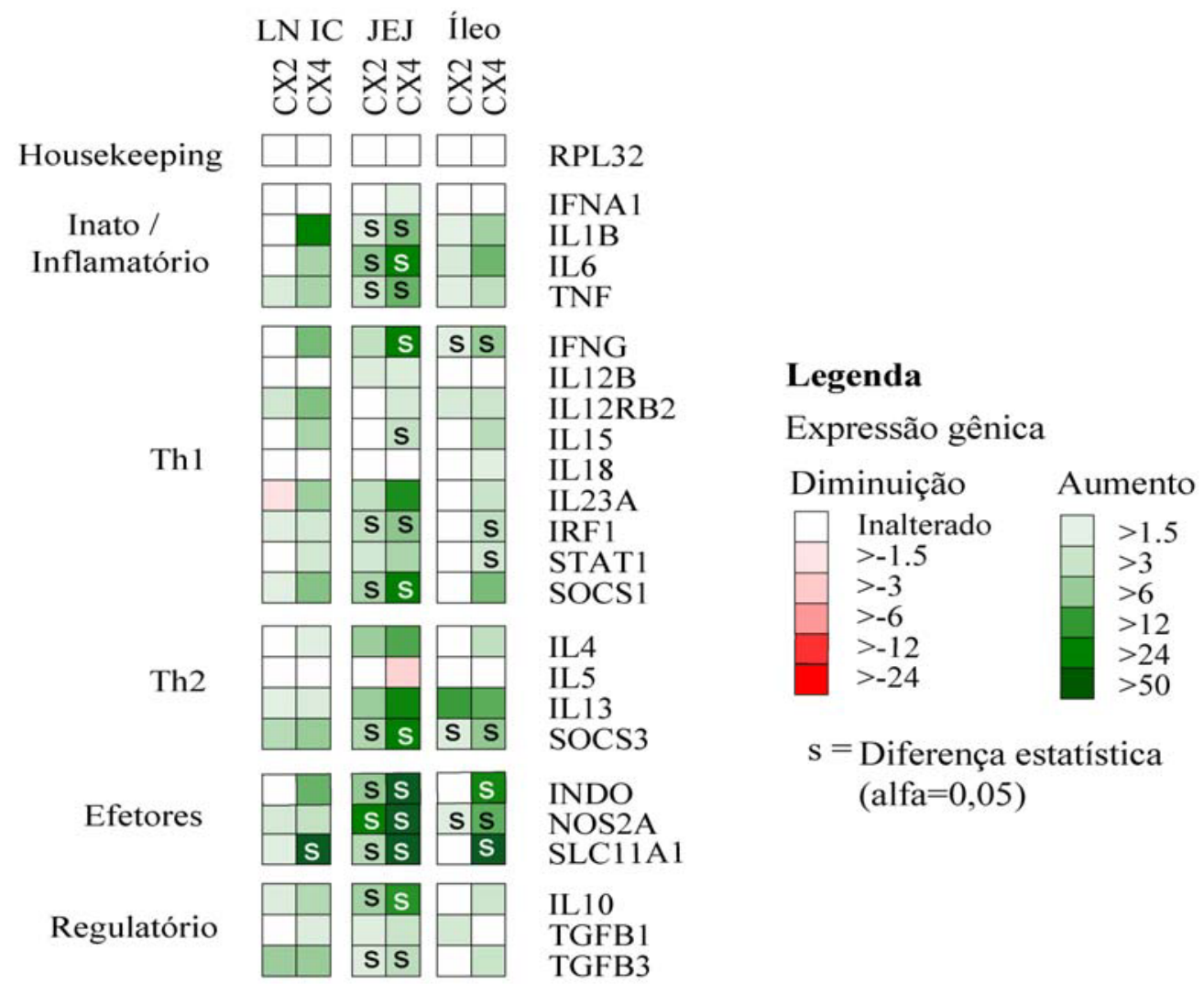

Figura 4.1.2 - Efeito da infecção pelo T. gondii na expressão gênica no linfonodo íleo-cólico (LN IC), no jejuno e no íleo de suínos mensurado pela Real-Time RT-PCR. Aumento ou diminuição da expressão de mRNA nos grupos infectados em relação ao controle não-infectado - Beltsville - 2003 
Tabela 4.1.15 · Variação da expressão gênica em suínos após infecção pelo $T$. gondii mensurado pela Real-Time RT-PCR. Aumento (valores positivos) ou diminuição (valores negativos) da expressão de mRNA nos linfonodos mesentérico (LN M), hepato-esplênico (LN HS) e células mononucleares do sangue periférico (CMSP) dos grupos infectados em relação ao controle não-infectado - Beltsville - 2003

\begin{tabular}{|c|c|c|c|c|c|c|c|c|c|c|c|c|}
\hline \multirow{2}{*}{ Gene } & \multicolumn{4}{|c|}{ LN M } & \multicolumn{4}{|c|}{ LN HS } & \multicolumn{4}{|c|}{ CMSP } \\
\hline & $\mathrm{CX} 2$ & $\mathrm{CX} 4$ & CX7 & CX14 & $\mathrm{CX} 2$ & $\mathrm{CX} 4$ & CX7 & CX14 & $\mathrm{CX} 2$ & $\mathrm{CX} 4$ & $\mathrm{CX} 7$ & CX14 \\
\hline RPL13A & 2,3 & $-2,5$ & 1,9 & 1,9 & 0,0 & 0,0 & 0,0 & 1,5 & 1,7 & 0,0 & 1,8 & 0,0 \\
\hline RPL32 & $-1,6$ & 0,0 & 0,0 & $-2,0$ & 0,0 & 0,0 & 0,0 & 0,0 & 0,0 & $-2,1$ & 0,0 & 0,0 \\
\hline IFNA & 2,6 & 1,8 & 1,6 & $-1,7$ & $-1,8$ & 0,0 & $-1,5$ & 0,0 & 0,0 & 0,0 & 2,0 & 0,0 \\
\hline IL1B & 22,1 & 32,7 & 0,0 & 9,5 & 0,0 & 1,7 & $-5,1$ & $-4,1$ & 2,5 & 0,0 & 2,9 & 0,0 \\
\hline IL6 & 11,6 & 6,5 & 1,5 & 8,0 & 0,0 & 2,8 & 0,0 & 1,7 & 2,3 & 5,7 & 3,4 & 1,7 \\
\hline ORM1 & 3,9 & 12,0 & 2,1 & 0,0 & 2,3 & 13,8 & $-16,6$ & $-17,8$ & 0,0 & 0,0 & 2,0 & 1,9 \\
\hline TNF & 0,0 & 4,0 & 0,0 & $-1,8$ & 1,6 & 3,3 & 1,5 & 1,9 & 0,0 & 0,0 & 2,0 & 1,5 \\
\hline TNFRSF1A & 2,5 & $-2,4$ & 0,0 & 1,9 & 0,0 & 1,9 & 0,0 & 0,0 & 2,1 & 0,0 & 2,6 & 0,0 \\
\hline TLR2 & 1,6 & 0,0 & 1,6 & 2,2 & 0,0 & 1,5 & 0,0 & 0,0 & 2,6 & 0,0 & 2,8 & 0,0 \\
\hline TLR4 & 0,0 & $-1,7$ & $-1,7$ & 0,0 & 0,0 & 1,8 & $-2,1$ & $-1,6$ & 1,9 & 1,5 & 2,4 & 0,0 \\
\hline IFNG & 18,1 & 17,7 & 2,7 & 8,8 & 0,0 & 3,5 & 2,0 & 2,5 & 0,0 & 0,0 & 1,7 & 1,7 \\
\hline IL12A & 5,4 & 0,0 & 3,0 & 3,2 & 0,0 & 2,2 & 0,0 & 2,1 & 1,6 & $-1,6$ & 1,7 & 0,0 \\
\hline IL12B & 0,0 & $-11,6$ & 0,0 & 0,0 & 0,0 & $-5,1$ & 0,0 & 0,0 & 1,5 & 0,0 & 5,6 & 0,0 \\
\hline IL12RB2 & 2,0 & 3,0 & 1,8 & 10,2 & 0,0 & 2,3 & 1,5 & 3,1 & 0,0 & 0,0 & 3,3 & 0,0 \\
\hline IL15 & 9,6 & 0,0 & 0,0 & 3,9 & 1,5 & 10,7 & 2,1 & 2,8 & 1,9 & 1,6 & 3,9 & 1,6 \\
\hline IL18 & $-1,4$ & $-1,8$ & 0,0 & 0,0 & 0,0 & 0,0 & 0,0 & 0,0 & 1,7 & 0,0 & 1,9 & 0,0 \\
\hline IL23A & $-1,8$ & 24,0 & 1,7 & 1,9 & 1,6 & 4,1 & 0,0 & 0,0 & 0,0 & 0,0 & 1,8 & 0,0 \\
\hline IRF1 & 1,9 & 4,2 & 1,9 & 0,0 & 0,0 & 2,9 & 1,6 & 2,3 & 0,0 & 0,0 & 0,0 & 0,0 \\
\hline LEP & 1,8 & $-11,1$ & 0,0 & $-5,7$ & 0,0 & $-1,7$ & $-2,5$ & $-7,2$ & $-2,4$ & $-4,9$ & 2,1 & $-4,9$ \\
\hline LEPR & $-4,0$ & $-3,7$ & 0,0 & $-4,8$ & 0,0 & 0,0 & 0,0 & $-2,0$ & $-1,9$ & $-4,5$ & $-4,3$ & $-3,5$ \\
\hline STAT1 & 4,2 & 0,0 & 1,6 & 2,3 & 1,9 & 5,1 & 1,8 & 2,8 & 2,8 & 0,0 & 3,0 & 0,0 \\
\hline STAT4 & 2,1 & $-2,3$ & 1,5 & 0,0 & $-1,6$ & 0,0 & 0,0 & 1,7 & 1,9 & 0,0 & 1,6 & 0,0 \\
\hline SOCS1 & 4,7 & 26,6 & 0,0 & 0,0 & 1,9 & 9,1 & 1,6 & 1,6 & $-1,6$ & $-2,5$ & 0,0 & $-3,2$ \\
\hline SOCS2 & 0,0 & 3,0 & 1,6 & 0,0 & 0,0 & 0,0 & 0,0 & 0,0 & $-2,6$ & $-4,1$ & $-2,3$ & $-4,6$ \\
\hline IL4 & 7,5 & 0,0 & 0,0 & 2,8 & 0,0 & 1,4 & 1,6 & 2,5 & $-1,9$ & $-2,2$ & 1,8 & 0,0 \\
\hline IL5 & 4,6 & $-3,5$ & 1,9 & 1,6 & 0,0 & 0,0 & 1,9 & 2,3 & 0,0 & $-2,0$ & 1,5 & 0,0 \\
\hline IL13 & 6,1 & 3,0 & $-1,6$ & $-2,1$ & 2,1 & 0,0 & $-6,1$ & 0,0 & $\mathrm{xx}$ & $\mathrm{xx}$ & $\mathrm{xx}$ & $\mathrm{xx}$ \\
\hline STAT6 & 0,0 & 4,0 & 3,0 & 0,0 & 0,0 & 2,2 & 0,0 & 1,5 & 0,0 & 0,0 & 0,0 & $-1,5$ \\
\hline SOCS3 & 9,2 & 3,4 & 1,9 & 0,0 & 1,6 & 4,6 & 1,2 & 1,7 & 4,2 & 1,9 & 3,4 & 2,5 \\
\hline INDO & 1,8 & 16,8 & 0,0 & 0,0 & 0,0 & 6,1 & 0,0 & 1,6 & 0,0 & $-1,9$ & 0,0 & $-14,2$ \\
\hline NOS2A & 2,1 & 2,0 & 2,2 & 1,5 & 0,0 & 3,0 & 2,5 & 2,9 & 0,0 & 0,0 & 2,1 & 0,0 \\
\hline ARG1 & $-3,5$ & 203,2 & 0,0 & 5,3 & $-2,5$ & 10,8 & $-3,2$ & $-2,4$ & $-4,2$ & 0,0 & 0,0 & 0,0 \\
\hline SLC11A1 & 30,2 & 230,7 & 6,7 & 200,9 & 0,0 & 9,6 & 1,5 & 4,3 & 2,4 & 4,2 & 5,9 & 2,0 \\
\hline SLC11A2 & 0,0 & 0,0 & 0,0 & 3,6 & 0,0 & 0,0 & 1,6 & 1,7 & 1,6 & 1,5 & 2,5 & 3,7 \\
\hline IGM & 1,8 & 1,6 & 2,4 & 3,2 & 0,0 & 1,6 & 0,0 & 2,5 & 2,5 & 0,0 & 1,6 & 0,0 \\
\hline IGG & 0,0 & $-2,7$ & 0,0 & 13,9 & 0,0 & 1,6 & 0,0 & 6,7 & 2,8 & 0,0 & 2,4 & 0,0 \\
\hline IGA & 3,2 & 0,0 & 2,5 & 1,5 & $-1,9$ & 0,0 & $-3,4$ & $-1,7$ & 3,2 & 0,0 & 2,2 & 0,0 \\
\hline CD3E & 0,0 & $-2,1$ & 0,0 & 0,0 & 0,0 & 0,0 & 1,5 & 1,8 & 0,0 & $-1,8$ & 0,0 & 1,5 \\
\hline CD19 & 2,1 & $-3,4$ & 1,7 & 0,0 & 0,0 & 0,0 & 0,0 & 0,0 & 3,6 & 0,0 & 2,2 & 0,0 \\
\hline CD69 & 1,8 & $-2,6$ & 0,0 & 0,0 & 0,0 & 0,0 & 0,0 & 1,7 & 2,2 & 0,0 & 1,9 & 1,9 \\
\hline IL2 & 3,1 & $-3,8$ & 0,0 & 0,0 & 0,0 & 0,0 & 0,0 & 1,6 & 2,9 & 0,0 & 2,1 & 2,1 \\
\hline IL2R & 2,3 & 0,0 & 2,1 & 0,0 & 0,0 & 0,0 & 0,0 & 0,0 & 2,8 & 0,0 & 1,8 & 0,0 \\
\hline IL10 & 5,5 & 2,8 & 2,4 & 2,8 & 2,3 & 9,6 & 0,0 & 2,1 & 1,6 & 0,0 & 2,8 & 1,8 \\
\hline TGFB1 & 2,4 & 0,0 & 3,0 & 1,8 & 0,0 & 0,0 & 0,0 & 2,3 & 2,1 & 0,0 & 2,7 & 0,0 \\
\hline TGFB2 & $-9,1$ & $-2,9$ & $-11,1$ & $-9,0$ & 0,0 & 0,0 & 0,0 & $-2,0$ & 0,0 & 1,6 & 6,5 & 2,4 \\
\hline TGFB3 & 0,0 & 1,5 & 0,0 & 9,2 & 0,0 & 1,5 & 0,0 & 0,0 & 1,7 & 1,7 & 3,1 & 1,5 \\
\hline CSF2 & 1,6 & 4,9 & 0,0 & 0,0 & 0,0 & 0,0 & $-2,1$ & 0,0 & $-1,9$ & $-3,6$ & $-3,4$ & $-3,6$ \\
\hline MHC2TA & 2,2 & 0,0 & 0,0 & 2,4 & 0,0 & 1,8 & 0,0 & 1,7 & 2,6 & 1,9 & 2,8 & 0,0 \\
\hline
\end{tabular}


Tabela 4.1.16 - Variação da expressão gênica em suínos após infecção pelo T. gondii mensurado pela Real-Time RT-PCR. Aumento (valores positivos) ou diminuição (valores negativos) da expressão de mRNA em amostras de fígado, baço e timo dos grupos infectados em relação ao controle não-infectado - Beltsville - 2003

\begin{tabular}{|c|c|c|c|c|c|c|}
\hline \multirow{2}{*}{ Gene } & \multicolumn{2}{|c|}{ Fígado } & \multicolumn{2}{|c|}{ Baço } & \multicolumn{2}{|c|}{ Timo } \\
\hline & $\mathrm{CX} 2$ & $\mathrm{CX} 4$ & $\mathrm{CX} 2$ & $\mathrm{CX} 4$ & $\mathrm{CX} 2$ & $\overline{\mathrm{CX} 4}$ \\
\hline RPL13A & 0,0 & 1,6 & 0,0 & 1,6 & $-1,6$ & $-3,1$ \\
\hline RPL32 & 1,7 & 0,0 & 0,0 & 0,0 & 2,1 & 0,0 \\
\hline IFNA & 2,1 & 25,0 & 2,1 & 25,0 & 1,5 & 0,0 \\
\hline IL1B & 2,6 & 4,6 & 0,0 & 2,4 & 0,0 & 0,0 \\
\hline IL6 & $-4,6$ & 0,0 & $-1,6$ & 0,0 & $-1,6$ & $-2,2$ \\
\hline ORM1 & 0,0 & $-1,2$ & 0,0 & 2,1 & 0,0 & 0,0 \\
\hline TNF & 4,3 & 7,8 & 1,6 & 0,0 & 3,3 & 2,8 \\
\hline TNFRSF1A & 3,4 & 16,7 & 1,1 & 3,5 & $-1,7$ & $-1,8$ \\
\hline TLR2 & 2,2 & 5,9 & 1,6 & 4,5 & $-1,6$ & 0,0 \\
\hline TLR4 & $-2,0$ & 2,3 & 0,0 & 1,7 & $-2,2$ & 0,0 \\
\hline IFNG & 7,5 & 23,1 & 1,7 & 5,7 & 0,0 & 0,0 \\
\hline IL12A & $-1,6$ & 3,0 & 1,6 & 2,9 & $-1,5$ & 0,0 \\
\hline IL12B & $-7,6$ & 0,0 & $-2,0$ & $-2,6$ & 0,0 & $-3,0$ \\
\hline IL12RB2 & 0,0 & 5,3 & 0,0 & 5,3 & 0,0 & 0,0 \\
\hline IL15 & $-2,2$ & 1,8 & $-3,0$ & 2,8 & 0,0 & $-2,2$ \\
\hline IL18 & 0,0 & 3,1 & $-3,8$ & 0,0 & 1,5 & 0,0 \\
\hline IL23A & 2,3 & 8,6 & $-2,6$ & 0,0 & 2,8 & 4,8 \\
\hline IRF1 & 7,4 & 22,7 & 1,8 & 2,6 & 0,0 & 0,0 \\
\hline LEP & 5,7 & 7,8 & $-2,7$ & $-1,6$ & 3,9 & 5,6 \\
\hline LEPR & 3,3 & 3,6 & $-2,2$ & $-1,6$ & 0,0 & 0,0 \\
\hline STAT1 & 9,9 & 36,1 & 4,9 & 15,1 & $-1,8$ & 0,0 \\
\hline STAT4 & 2,2 & 5,1 & 0,0 & 3,9 & $-1,6$ & $-2,7$ \\
\hline SOCS1 & 2,7 & 11,1 & 0,0 & 1,5 & 2,2 & 1,6 \\
\hline SOCS2 & 3,1 & 2,0 & $-2,3$ & $-2,0$ & 1,6 & $-2,2$ \\
\hline IL4 & 1,6 & 7,0 & $-1,8$ & 0,0 & 0,0 & $-1,9$ \\
\hline IL5 & $-5,9$ & $-4,7$ & $-2,0$ & 0,0 & $-2,1$ & $-2,4$ \\
\hline IL13 & 3,6 & 0,0 & $-2,1$ & 0,0 & 0,0 & $-1,7$ \\
\hline STAT6 & 0,0 & 2,5 & $-1,8$ & 0,0 & 0,0 & 1,8 \\
\hline SOCS3 & 7,2 & 39,1 & 2,7 & 4,4 & 0,0 & $-1,7$ \\
\hline INDO & 40,0 & 430,3 & 2,5 & 29,5 & 2,0 & 1,9 \\
\hline NOS2A & $-3,2$ & 0,0 & $-4,8$ & 0,0 & 0,0 & 0,0 \\
\hline ARG1 & 3,8 & 15,3 & $-11,1$ & $-3,6$ & 1,6 & 3,1 \\
\hline SLC11A1 & 2,6 & 24,3 & $-8,5$ & 1,8 & $-2,5$ & 2,2 \\
\hline SLC11A2 & $-2,7$ & 1,8 & $-3,4$ & 0,0 & 1,9 & 0,0 \\
\hline IGM & 2,2 & 5,8 & 0,0 & 3,2 & 0,0 & $-1,9$ \\
\hline IGG & $-7,0$ & $-2,0$ & $-2,1$ & 2,0 & 0,0 & $-2,4$ \\
\hline IGA & $-3,6$ & $-2,3$ & $-2,0$ & $-2,1$ & 0,0 & $-4,5$ \\
\hline CD3E & $-1,6$ & 0,0 & $-2,9$ & 0,0 & 0,0 & $-2,2$ \\
\hline CD19 & $-1,8$ & 0,0 & $-1,8$ & $-2,1$ & 0,0 & $-2,1$ \\
\hline CD69 & 0,0 & 0,0 & 0,0 & 1,9 & 0,0 & 0,0 \\
\hline IL2 & $-2,9$ & $-1,6$ & $-3,3$ & $-2,7$ & $-1,8$ & $-6,0$ \\
\hline IL2RA & 4,1 & 14,2 & 0,0 & 0,0 & $-1,6$ & $-2,3$ \\
\hline IL10 & 17,5 & 41,2 & 0,0 & 5,9 & $-1,9$ & 2,6 \\
\hline TGFB1 & 1,6 & 3,0 & $-1,5$ & 1,9 & $-1,6$ & $-2,3$ \\
\hline TGFB2 & $-3,1$ & $-1,7$ & $-3,3$ & $-2,5$ & 0,0 & $-1,8$ \\
\hline TGFB3 & $-3,2$ & 0,0 & $-3,4$ & 0,0 & 0,0 & $-2,0$ \\
\hline CSF2 & 3,5 & 5,6 & $-4,0$ & $-2,5$ & 1,6 & 0,0 \\
\hline MHC2TA & $-1,5$ & 4,9 & 0,0 & 0,0 & $-1,8$ & $-1,6$ \\
\hline
\end{tabular}


Tabela 4.1.17 - Variação da expressão gênica em suínos após infecção pelo T. gondii mensurado pela Real-Time RT-PCR. Aumento (valores positivos) ou diminuição (valores negativos) da expressão de mRNA no linfonodo íleocólico (LN IC), no jejuno e no íleo dos grupos infectados em relação ao controle não-infectado - Beltsville - 2003

\begin{tabular}{lrrrrrrrr}
\hline \multirow{2}{*}{ Gene } & \multicolumn{2}{c}{ LN IC } & & \multicolumn{2}{c}{ Jejuno } & & \multicolumn{2}{c}{ Íleo } \\
\cline { 2 - 3 } \cline { 8 - 9 } \cline { 8 - 9 } & CX2 & CX4 & & CX2 & CX4 & & CX2 & CX4 \\
\hline RPL32A & 0,0 & 0,0 & & 0,0 & 0,0 & & 0,0 & 0,0 \\
IFNA1 & 0,0 & 0,0 & & 0,0 & 1,6 & & 1,5 & 0,0 \\
IL1B & 1,5 & 21,9 & & 2,2 & 7,5 & & 1,5 & 5,4 \\
IL6 & 0,0 & 5,0 & & 6,3 & 18,1 & & 2,2 & 8,5 \\
TNF & 2,1 & 5,0 & & 3,0 & 8,8 & & 1,7 & 3,6 \\
IFNG & 0,0 & 7,9 & & 3,5 & 16,2 & & 1,7 & 5,9 \\
IL12B & 0,0 & 0,0 & & 1,9 & 2,0 & & 0,0 & 0,0 \\
IL12RB2 & 2,6 & 7,2 & & 0,0 & 2,4 & & 2,2 & 2,0 \\
IL15 & 0,0 & 4,9 & & 0,0 & 3,4 & & $-1,5$ & 4,0 \\
IL18 & 0,0 & 0,0 & & 0,0 & 0,0 & & 0,0 & 1,7 \\
IL23A & $-1,6$ & 5,5 & & 3,6 & 13,3 & & 0,0 & 3,0 \\
IRF1 & 1,7 & 2,5 & & 3,6 & 6,5 & & 0,0 & 3,6 \\
STAT1 & 0,0 & 2,5 & & 2,6 & 4,9 & & 0,0 & 2,6 \\
SOCS1 & 1,6 & 7,0 & & 5,0 & 26,6 & & 1,5 & 7,8 \\
IL4 & 0,0 & 1,7 & & 5,7 & 10,3 & & 0,0 & 3,6 \\
IL5 & 0,0 & 0,0 & & 0,0 & $-2,5$ & & 0,0 & 0,0 \\
IL13 & 1,6 & 2,1 & & 5,9 & 14,2 & & 11,6 & 9,6 \\
SOCS3 & 4,1 & 5,9 & & 4,5 & 17,3 & & 1,9 & 6,2 \\
INDO & 0,0 & 8,8 & & 6,2 & 130,7 & & 0,0 & 14,0 \\
NOS2A & 2,3 & 3,4 & & 20,2 & 176,9 & & 1,8 & 9,5 \\
SLC11A1 & 1,7 & 112,7 & & 4,2 & 176,9 & & 1,5 & 79,7 \\
IL10 & 1,9 & 4,3 & & 5,3 & 12,7 & & 0,0 & 2,9 \\
TGFB1 & 0,0 & 1,9 & & 1,8 & 3,0 & & 2,5 & 1,5 \\
TGFB3 & 5,7 & 5,9 & & 1,9 & 3,8 & & 0,0 & 3,0 \\
\hline & & & & & & &
\end{tabular}




\subsection{EXPERIMENTO II}

\subsubsection{Pesquisa de Anticorpos Anti-T. gondii}

Todos os animais apresentavam-se soronegativos antes da inoculação de $T$. gondii. A prova de MAT não detectou anticorpos específicos nos animais dos grupos Controle, 2DPI e 4DPI. Duas amostras de soro do grupo 7DPI apresentaram reação à diluição 1:40 e um a 1:80. Todos suínos do 14DPI foram reagentes à diluição 1:80.

\subsubsection{Perfil Hepático}

A tabela 4.2.1 apresenta os valores de aspartato aminotransferase (AST), alanino aminotransferase (ALT), gamaglutamil transferase (GGT), bilirrubinas totais (TBILI), bilirrubina direta (DBILI), fosfatase alcalina (ALP), proteínas totais (PT), globulinas (GLOB), albumina (ALB) e a proporção albumina/globulina $(\mathrm{A} / \mathrm{G})$ no soro dos animais experimentais.

Elevação dos valores de AST séricos são observados nos suínos do 7DPI, sem diferença estatística significante (Gráfico 4.2.1). 
Tabela 4.2.1 - Média e desvio-padrão (DP) dos valores de aspartato aminotransferase (AST), alanino aminotransferase (ALT), gamaglutamil transferase (GGT), bilirrubinas totais (TBILI), bilirrubina direta (DBILI), fosfatase alcalina (ALP), proteínas totais (PT), globulinas (GLOB), albumina (ALB) e proporção albumina/globulina $(\mathrm{A} / \mathrm{G})$ em amostras de soro de suínos infectados com $T$. gondii e controles não infectados. Diferença estatística (Estat.) segundo teste de Tukey-Kramer $(\alpha=0,05)$ Beltsville - 2003

\begin{tabular}{|c|c|c|c|c|c|c|c|c|c|c|c|c|c|c|c|}
\hline \multirow{2}{*}{$\begin{array}{l}\text { Determinação } \\
\text { sérica }\end{array}$} & \multicolumn{3}{|c|}{ Controle } & \multicolumn{3}{|c|}{ 2DPI ${ }^{1}$} & \multicolumn{3}{|c|}{ 4DPI } & \multicolumn{3}{|c|}{ 7DPI } & \multicolumn{3}{|c|}{ 14DPI } \\
\hline & Média & DP & Estat. $^{2}$ & Média & DP & Estat. & Média & DP & Estat. & Média & DP & Estat. & Média & DP & Estat. \\
\hline AST (U/l) & 44,3 & 31,7 & $\mathrm{~A}$ & 38,3 & 9,0 & A & 43,7 & 4,9 & A & 155,3 & 121,6 & A & 66,7 & 4,0 & A \\
\hline ALT (U/1) & 30,3 & 5,9 & $\mathrm{AB}$ & 37,7 & 5,7 & A & 29,0 & 3,0 & $\mathrm{AB}$ & 21,7 & 9,6 & B & 23,7 & 3,5 & $\mathrm{AB}$ \\
\hline GGT (U/l) & 37,0 & 16,7 & A & 39,3 & 16,2 & A & 31,0 & 6,0 & A & 22,0 & 1,0 & A & 26,7 & 8,5 & A \\
\hline TBILI (mg/dl) & 0,2 & 0,1 & A & 0,2 & 0,1 & A & 0,2 & 0,1 & A & 0,2 & 0,0 & A & 0,2 & 0,1 & A \\
\hline DBILI (mg/dl) & 0,2 & 0,1 & A & 0,1 & 0,1 & A & 0,2 & 0,1 & A & 0,1 & 0,1 & A & 0,1 & 0,1 & A \\
\hline ALP (U/l) & 193,3 & 78,6 & A & 230,0 & 95,0 & A & 150,0 & 40,7 & A & 63,7 & 17,6 & A & 89,7 & 42,2 & A \\
\hline PT (g/dl) & 6,0 & 0,6 & A & 5,6 & 0,5 & A & 6,2 & 0,5 & A & 6,1 & 0,4 & A & 6,2 & 0,9 & A \\
\hline GLOB (g/dl) & 2,8 & 0,7 & B & 2,5 & 0,3 & B & 3,4 & 0,5 & $\mathrm{AB}$ & 3,6 & 0,2 & $\mathrm{AB}$ & 4,1 & 0,3 & A \\
\hline $\operatorname{ALB}(\mathrm{g} / \mathrm{dl})$ & 3,3 & 0,2 & A & 3,1 & 0,3 & A & 2,8 & 0,1 & $\mathrm{AB}$ & 2,5 & 0,2 & $\mathrm{AB}$ & 2,1 & 0,7 & B \\
\hline $\mathrm{A} / \mathrm{G}$ & 1,3 & 0,4 & A & 1,3 & 0,1 & A & 0,9 & 0,1 & $\mathrm{AB}$ & 0,7 & 0,0 & $\mathrm{AB}$ & 0,5 & 0,2 & B \\
\hline
\end{tabular}

${ }^{1}$ DPI - dias pós-infecção, ${ }^{2}$ letras distintas na mesma linha indicam diferença estatística

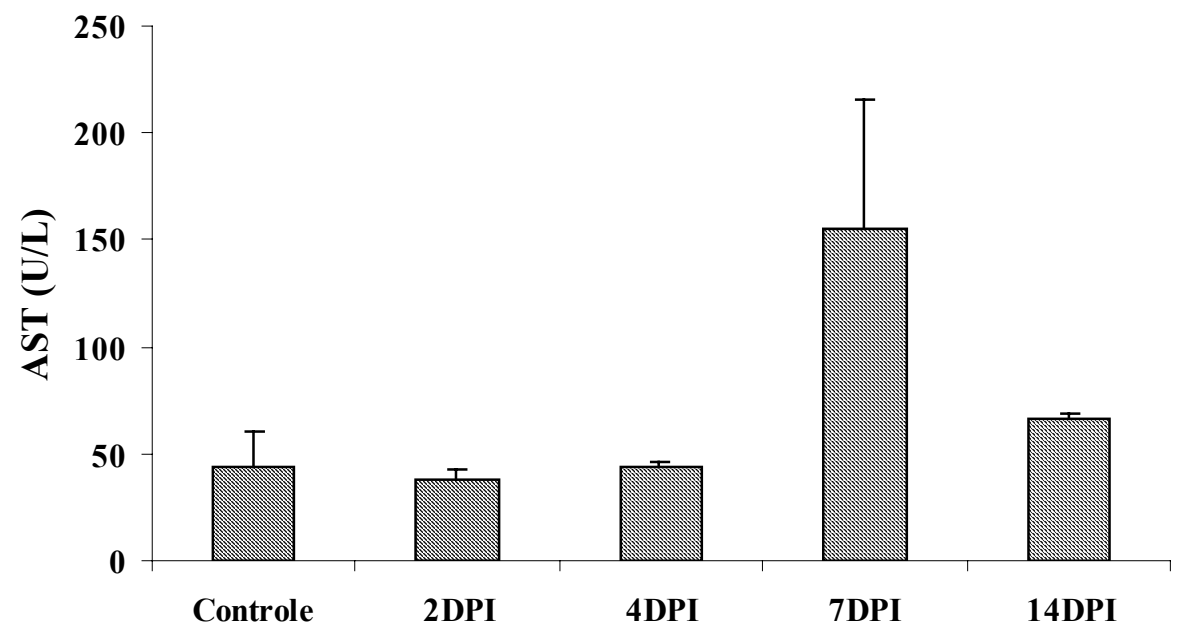

Gráfico 4.2.1 - Variação dos níveis de aspartato aminotransferase (AST) sérico em suínos dos grupos Controle e infectados pelo T. gondii - Beltsville - 2003 


\subsubsection{Determinação de IFN- $\gamma$}

A determinação de IFN- $\gamma$ no sobrenadante das culturas de células e das amostras de soro foram realizadas pelo método de ELISA. As curvas padrão apresentaram variação nos limiares de detecção de uma leitura para a outra.

Desta maneira, o limiar de detecção foi de $2,5 \mathrm{ng}$ IFN- $\gamma / \mathrm{ml}$ para as amostras do sobrenadante das células do LN HS e 7,5 ng/ml para as amostras de CMSP e LN M.

\subsubsection{IFN- $\gamma$ Sérico}

Não foi possível determinar a quantidade de IFN- $\gamma$ das amostras de soro, pois apresentaram valores abaixo do limite de detecção do teste.

\subsubsection{Produção de IFN- $\gamma$}

Células dos LN M e LN HS produziram quantidades significativamente $(\alpha=0,05)$ maiores de IFN- $\gamma$ que as CMSP no 7DPI. Esta diferença na produção de IFN- $\gamma$ foi somente observada no 7DPI (Gráfico 4.2.2). 


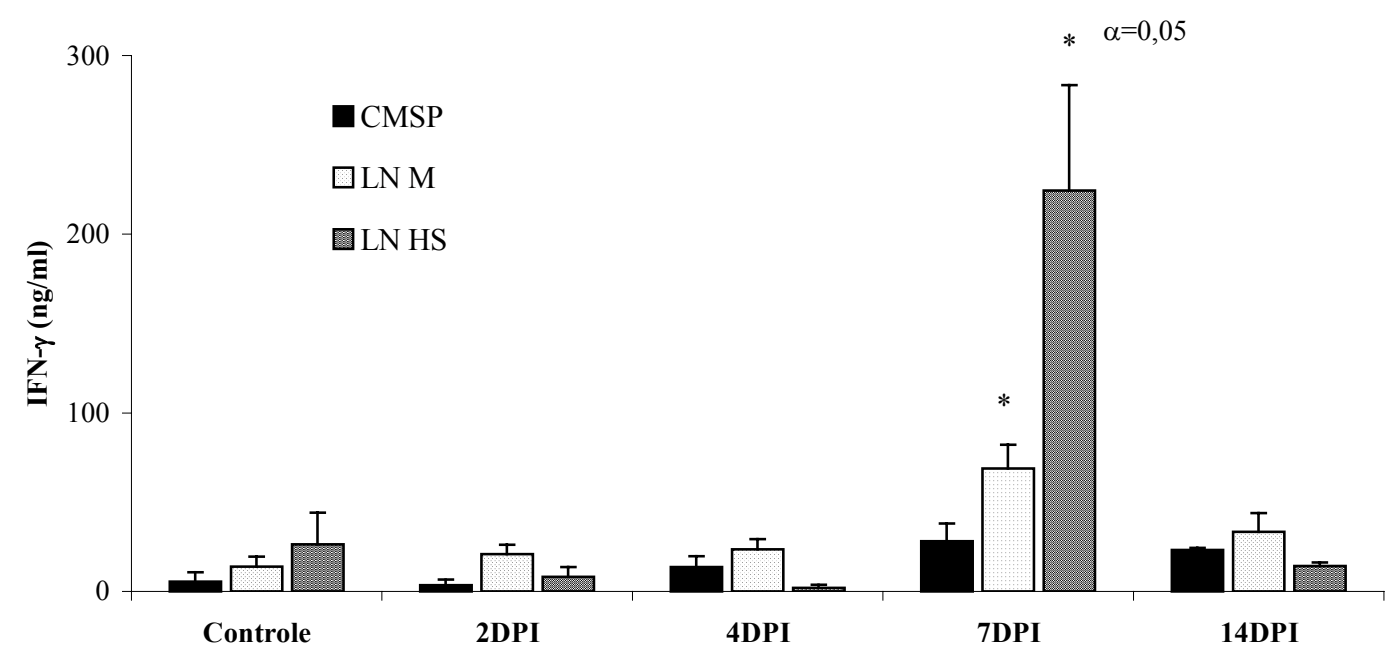

Gráfico 4.2.2 - Produção de IFN- $\gamma$ por células mononucleares do sangue periférico (CMSP), células do linfonodo mesentérico (LN M) e do linfonodo hepato-esplênico (LN HS) de suínos dos grupos controle e infectados pelo $T$. gondii durante cultivo em ConA por 24 horas medida pelo método de ELISA - Beltsville - 2003

\subsubsection{Determinação de Haptoglobina}

Foi observado um aumento significante $(\alpha=0,05)$ dos níveis de haptoglobina sérica nos animais dos grupos 4DPI, 7DPI e 14DPI em relação ao grupo Controle (Gráfico 4.2.3). Os valores detectados nos grupos 7DPI e 14DPI apresentam-se acima do limite de detecção do teste. Devido a falta de reagente para realização de diluições para determinação da concentração real destas amostras, os valores de haptoglobina dos grupos 7DPI e 14DPI foram indicados como $>10 \mathrm{mg} / \mathrm{dl}$. 


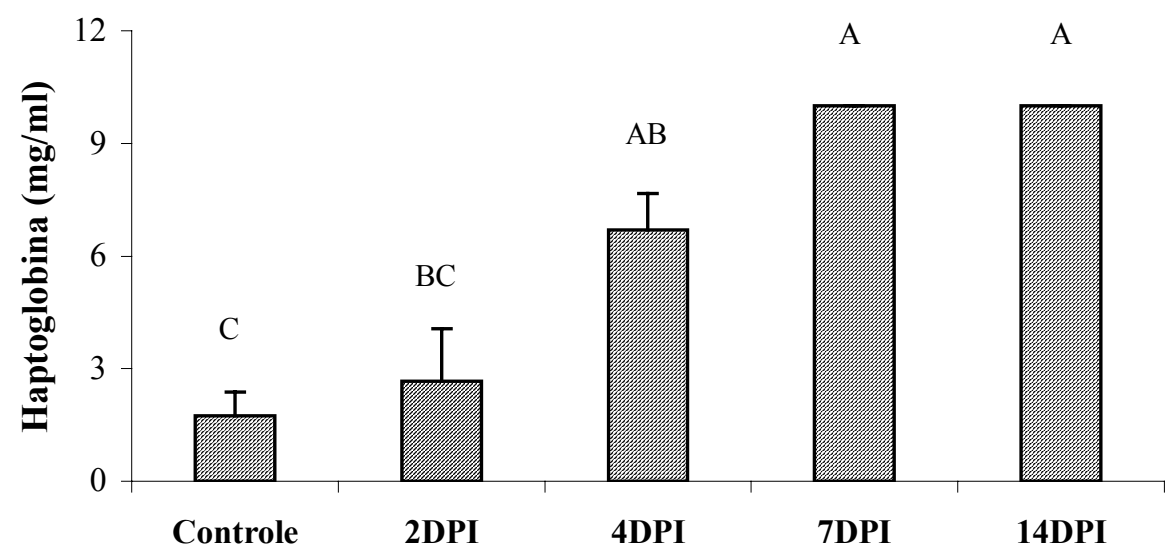

Gráfico 4.2.3 - Níveis de haptoglobina em suínos dos grupos controle e infectados pelo T. gondii medido por método colorimétrico. Letras distintas entre grupos experimentais indicam diferença estatística significante $(\alpha=0,05)$ - Beltsville - 2003

\subsubsection{Hemograma}

A tabela 4.2.2 apresenta os resultados do hemograma dos animais experimentais. Não foram observadas alterações significantes nas contagens do número total de leucócitos (Leu), número total $(\mathrm{T})$ e relativo $(\%)$ de neutrófilos $(\mathrm{Ne})$, linfócitos $(\mathrm{Li})$, monócitos $(\mathrm{Mo})$, eosinófilos (Eo), basófilos $(\mathrm{Ba})$, número total de eritrócitos $(\mathrm{He})$, concentração de hemoglobina $(\mathrm{Hb})$, volume globular $(\mathrm{Hct})$, volume corpuscular médio $(\mathrm{MCV})$, hemoglobina corpuscular média $(\mathrm{MCH})$ e concentração hemoglobínica corpuscular média (MCHC). 
Tabela 4.2.2 - Média e desvio-padrão (DP) da contagem do número total de leucócitos (Leu), número total (T) e relativo (\%) de neutrófilos ( $\mathrm{Ne})$, linfócitos (Li), monócitos (Mo), Eosinófilos (Eo), basófilos (Ba), número total de eritrócitos $(\mathrm{He})$, concentração de hemoglobina $(\mathrm{Hb})$, volume globular $(\mathrm{Hct})$, volume corpuscular médio $(\mathrm{MCV})$, hemoglobina corpuscular média $(\mathrm{MCH})$ e concentração hemoglobínica corpuscular média (MCHC) em suínos infectados com T. gondii e controle não-infectado. Diferença entre os grupos experimentais (Estat.) segundo teste de Tukey-Kramer, $\alpha=0,05$ - Beltsville - 2003

\begin{tabular}{|c|c|c|c|c|c|c|c|c|c|c|c|c|c|c|c|c|}
\hline \multirow{2}{*}{\multicolumn{2}{|c|}{$\begin{array}{c}\text { Valores do } \\
\text { hemograma }\end{array}$}} & \multicolumn{3}{|c|}{ Controle } & \multicolumn{3}{|c|}{ 2DPI ${ }^{1}$} & \multicolumn{3}{|c|}{ 4DPI } & \multicolumn{3}{|c|}{ 7DPI } & \multicolumn{3}{|c|}{ 14DPI } \\
\hline & & Média & DP & Estat. $^{2}$ & Média & DP & Estat. & Média & DP & Estat. & Média & $\mathrm{DP}$ & Estat. & Média & $\mathrm{DP}$ & Estat. \\
\hline \multicolumn{2}{|c|}{ Leu $\left(10^{3} / \mathrm{ml}\right)$} & 17,7 & 3,0 & $\mathrm{AB}$ & 10,9 & 2,1 & $\mathrm{AB}$ & 15,5 & 5,0 & $\mathrm{AB}$ & 12,1 & 5,1 & $\mathrm{~B}$ & 24,9 & 5,8 & $\mathrm{~A}$ \\
\hline \multirow{2}{*}{$\mathrm{Ne}$} & $\mathrm{T}$ & 7,2 & 2,6 & A & 5,5 & 1,1 & A & 9,9 & 4,7 & A & 4,8 & 0,8 & A & 11,1 & 4,0 & A \\
\hline & $\%$ & 40,3 & 10,0 & A & 50,5 & 0,6 & A & 62,5 & 14,6 & A & 44,1 & 17,3 & A & 43,8 & 5,4 & A \\
\hline \multirow{2}{*}{$\mathrm{Li}$} & $\mathrm{T}$ & 9,3 & 2,1 & $\mathrm{AB}$ & 4,9 & 0,7 & $\mathrm{AB}$ & 4,5 & 2,8 & B & 5,4 & 3,0 & $\mathrm{AB}$ & 11,9 & 2,4 & A \\
\hline & $\%$ & 52,9 & 10,8 & $\mathrm{~A}$ & 45,3 & 2,0 & A & 30,3 & 15,6 & A & 42,0 & 13,0 & A & 48,4 & 4,8 & A \\
\hline \multirow{2}{*}{ Mo } & $\mathrm{T}$ & 0,5 & 0,1 & $\mathrm{~A}$ & 0,3 & 0,1 & A & 0,3 & 0,1 & A & 0,6 & 0,5 & A & 0,8 & 0,2 & A \\
\hline & $\%$ & 2,8 & 0,1 & A & 2,8 & 0,0 & A & 1,7 & 0,1 & A & 4,1 & 2,1 & A & 3,2 & 0,5 & A \\
\hline \multirow{2}{*}{ Eo } & $\mathrm{T}$ & 0,7 & 0,3 & A & 0,2 & 0,2 & A & 0,7 & 0,2 & A & 1,2 & 1,1 & A & 0,9 & 1,0 & A \\
\hline & $\%$ & 3,8 & 0,8 & A & 1,3 & 1,3 & A & 5,1 & 2,0 & A & 8,4 & 5,7 & A & 4,0 & 4,8 & $\mathrm{~A}$ \\
\hline \multirow{2}{*}{$\mathrm{Ba}$} & $\mathrm{T}$ & 0,0 & 0,0 & A & 0,0 & 0,0 & A & 0,1 & 0,1 & A & 0,2 & 0,3 & A & 0,1 & 0,1 & A \\
\hline & $\%$ & 0,2 & 0,2 & A & 0,1 & 0,1 & A & 0,4 & 0,4 & A & 1,5 & 1,4 & A & 0,6 & 0,5 & $\mathrm{~A}$ \\
\hline \multicolumn{2}{|c|}{$\mathrm{He}\left(10^{6} / \mathrm{ml}\right)$} & 6,6 & 1,0 & A & 9,4 & 0,4 & A & 7,6 & 1,4 & A & 7,4 & 1,0 & A & 6,7 & 0,4 & A \\
\hline \multicolumn{2}{|c|}{$\mathrm{Hb}(\mathrm{g} / \mathrm{dl})$} & 11,6 & 0,5 & A & 11,2 & 0,7 & A & 11,3 & 1,2 & A & 10,7 & 0,3 & A & 9,6 & 1,1 & A \\
\hline \multicolumn{2}{|c|}{ Hct (\%) } & 33,1 & 2,1 & B & 43,2 & 0,6 & A & 38,3 & 4,5 & $\mathrm{AB}$ & 35,0 & 3,4 & $\mathrm{AB}$ & 33,5 & 2,7 & B \\
\hline \multicolumn{2}{|c|}{ MCV (fl) } & 51,0 & 4,5 & A & 46,2 & 2,8 & A & 50,6 & 3,3 & A & 47,7 & 2,2 & A & 49,7 & 1,9 & A \\
\hline \multicolumn{2}{|c|}{ MCH (pg) } & 17,9 & 2,0 & A & 12,0 & 1,3 & A & 15,1 & 2,1 & A & 14,7 & 2,1 & $\mathrm{~A}$ & 14,3 & 1,6 & A \\
\hline \multicolumn{2}{|c|}{$\mathrm{MCHC}(\mathrm{g} / \mathrm{dl})$} & 35,0 & 0,9 & A & 26,0 & 1,2 & $\mathrm{~B}$ & 29,7 & 2,7 & $\mathrm{AB}$ & 30,6 & 3,1 & $\mathrm{AB}$ & 28,6 & 2,5 & $\mathrm{AB}$ \\
\hline
\end{tabular}




\subsubsection{Expressão Gênica}

No EXP II foram testados cinco amostras de tecidos diferentes: LN M, LN HS, fígado, jejuno e íleo. Foram avaliados 48 genes, 30 genes previamente testados no EXP I e incorporados 18 novos genes:

As amostras de jejuno foram testadas separadamente e possuem um painel distinto de genes.

Os genes MYD88, ICSBP1, TBX21, CD28 e TNFRSF6 foram avaliadas no LN M, LN HS, fígado e íleo, mas não no jejuno.

Os genes IL8, CCL5, CCL2, STAT4, IL5 foram avaliados no jejuno, mas não no LN M, LN HS, fígado e íleo.

O gene IL23A foi testado em todas as amostras de tecido, mas somente as amostras de jejuno apresentaram resultados positivos.

As tabelas 4.2.3 a 4.2.7 mostram os valores médios de $\mathrm{Ct}$, respectivos desvios padrões e a diferença estatística entre grupos experimentais pelo teste de Tukey-Kramer $(\alpha=0,05)$.

A figura 4.2.1 ilustra o aumento ou a diminuição da expressão de mRNA nos diferentes tecidos pela Real-Time RT-PCR.

As tabelas 4.2.8 e 4.2.9 referem-se à figura 4.2.1 e mostram a variação da expressão de mRNA em valores numéricos, permitindo a observação da magnitude da resposta de forma mais pormenorizada. 
Tabela 4.2.3 - Resultados da Real-Time RT-PCR em amostras de linfonodo mesentérico dos suínos do EXP II. Valores médios de $\mathrm{Ct}$ e respectivos desvios padrões (DP) nos grupos controle e infectados de acordo com o dia após a infecção com $T$. gondii. Diferença estatística (Estat.) segundo o teste de Tukey$\operatorname{Kramer}(\alpha=0,05)$ - Beltsville -2003

\begin{tabular}{|c|c|c|c|c|c|c|c|c|c|c|c|c|c|c|c|}
\hline \multirow{2}{*}{ Gene } & \multicolumn{3}{|c|}{ Controle } & \multicolumn{3}{|c|}{$2 \mathrm{DPI}^{\mathbf{1}}$} & \multicolumn{3}{|c|}{ 4DPI } & \multicolumn{3}{|c|}{ 7DPI } & \multicolumn{3}{|c|}{ 14DPI } \\
\hline & Média & DP & Estat. $^{2}$ & Média & DP & Estat. & Média & DP & Estat. & Média & DP & Estat. & Média & $\mathrm{DP}$ & Estat. \\
\hline RPL32 & 16,6 & 0,4 & $\mathrm{~A}$ & 17,0 & 0,2 & $\mathrm{~A}$ & 16,8 & 0,1 & $\mathrm{~A}$ & 17,0 & 0,3 & $\mathrm{~A}$ & 17,3 & 0,5 & $\mathrm{~A}$ \\
\hline IFNA & 29,2 & 4,0 & A & 30,3 & 0,5 & A & 30,7 & 0,2 & A & 29,2 & 2,7 & A & 30,9 & 1,3 & A \\
\hline IL1B & 28,7 & 0,7 & A & 26,7 & 1,3 & $\mathrm{AB}$ & 24,4 & 3,0 & B & 24,3 & 0,3 & $\mathrm{~B}$ & 28,5 & 1,0 & A \\
\hline IL6 & 25,6 & 0,7 & A & 24,4 & 0,1 & $\mathrm{AB}$ & 23,1 & 1,6 & $\mathrm{~B}$ & 23,8 & 0,3 & $\mathrm{AB}$ & 26,0 & 0,8 & A \\
\hline TNF & 27,3 & 0,6 & A & 27,3 & 0,2 & $\mathrm{~A}$ & 26,9 & 0,6 & A & 27,0 & 0,8 & $\mathrm{~A}$ & 28,4 & 0,8 & A \\
\hline TLR2 & 23,1 & 0,4 & A & 23,3 & 0,7 & A & 22,4 & 0,7 & A & 22,1 & 0,1 & A & 23,4 & 0,5 & A \\
\hline TLR4 & 23,1 & 0,3 & $\mathrm{AB}$ & 23,9 & 0,2 & A & 22,2 & 0,7 & B & 20,9 & 0,1 & $\mathrm{C}$ & 22,8 & 0,5 & B \\
\hline CRP & 32,0 & 1,1 & A & 32,5 & 1,0 & A & 31,8 & 0,7 & A & 31,0 & 0,9 & A & 32,5 & 0,2 & A \\
\hline MYD88 & 21,6 & 0,5 & A & 21,6 & 0,3 & A & 21,1 & 0,3 & A & 20,8 & 0,5 & A & 21,9 & 0,4 & A \\
\hline FCGR3A & 18,7 & 0,3 & A & 18,8 & 0,4 & A & 18,5 & 0,3 & A & 17,6 & 0,2 & B & 18,4 & 0,3 & $\mathrm{AB}$ \\
\hline IFNG & 25,4 & 1,0 & A & 22,7 & 0,9 & $\mathrm{BC}$ & 21,4 & 1,1 & $\mathrm{C}$ & 22,2 & 1,0 & $\mathrm{C}$ & 24,7 & 0,5 & $\mathrm{AB}$ \\
\hline IFNGR & 21,4 & 0,6 & A & 21,9 & 0,7 & $\mathrm{~A}$ & 21,4 & 0,3 & A & 20,9 & 0,3 & A & 21,5 & 0,6 & $\mathrm{~A}$ \\
\hline IL12A & 30,2 & 1,6 & A & 31,3 & 0,0 & A & 30,5 & 0,7 & A & 29,5 & 1,6 & A & 32,1 & 0,9 & A \\
\hline IL12B & 25,9 & 1,0 & B & 26,7 & 0,4 & $\mathrm{AB}$ & 27,8 & 0,6 & $\mathrm{AB}$ & 28,7 & 1,5 & $\mathrm{~A}$ & 27,5 & 1,1 & $\mathrm{AB}$ \\
\hline IL12RB2 & 31,3 & 2,7 & A & 32,8 & 0,6 & $\mathrm{~A}$ & 31,7 & 0,9 & $\mathrm{~A}$ & 28,6 & 2,9 & A & 31,5 & 0,6 & $\mathrm{~A}$ \\
\hline IL15 & 30,3 & 1,3 & $\mathrm{AB}$ & 29,8 & 2,0 & $\mathrm{AB}$ & 28,5 & 0,8 & $\mathrm{AB}$ & 27,9 & 2,6 & B & 32,4 & 1,1 & A \\
\hline IL18 & 20,7 & 0,4 & $\mathrm{~A}$ & 21,6 & 1,1 & $\mathrm{~A}$ & 20,7 & 0,5 & $\mathrm{~A}$ & 20,6 & 0,4 & A & 21,6 & 0,8 & \\
\hline IL18R & 24,2 & 0,5 & A & 24,2 & 0,4 & A & 24,3 & 0,2 & A & 23,8 & 0,5 & A & 23,8 & 0,9 & A \\
\hline IL23A & $\mathrm{xx}$ & $\mathrm{xx}$ & $\mathrm{xx}$ & $\mathrm{xx}$ & $\mathrm{xx}$ & $\mathrm{xx}$ & $\mathrm{xx}$ & $\mathrm{xx}$ & $\mathrm{xx}$ & $\mathrm{xx}$ & $\mathrm{xx}$ & $\mathrm{xx}$ & $\mathrm{xx}$ & $\mathrm{xx}$ & $\mathrm{xx}$ \\
\hline IRF1 & 20,1 & 0,5 & $\mathrm{~A}$ & 19,2 & 0,4 & $\mathrm{AB}$ & 18,9 & 0,1 & $\mathrm{~B}$ & 19,5 & 0,8 & $\mathrm{AB}$ & 20,3 & 0,4 & A \\
\hline HLX1 & 29,7 & 0,5 & A & 29,8 & 0,2 & $\mathrm{~A}$ & 29,8 & 0,7 & A & 29,4 & 0,2 & $\mathrm{~A}$ & 30,4 & 0,8 & A \\
\hline ICSBP1 & 27,0 & 0,5 & A & 27,5 & 0,1 & A & 27,4 & 0,6 & A & 26,2 & 1,9 & A & 27,1 & 0,8 & A \\
\hline TBX21 & 27,9 & 0,4 & A & 27,7 & 0,4 & A & 27,9 & 0,7 & A & 27,3 & 0,6 & A & 27,4 & 0,1 & A \\
\hline STAT1 & 20,3 & 0,8 & $\mathrm{AB}$ & 19,0 & 0,5 & $\mathrm{AB}$ & 18,9 & 0,2 & B & 19,4 & 0,6 & $\mathrm{AB}$ & 20,5 & 0,5 & A \\
\hline IL4 & 28,0 & 0,9 & $\mathrm{~A}$ & 26,3 & 0,6 & $\mathrm{~A}$ & 26,3 & 1,4 & A & 27,3 & 1,3 & A & 28,6 & 0,6 & A \\
\hline IL13 & 31,4 & 0,8 & A & 28,2 & 1,0 & $\mathrm{~B}$ & 28,9 & 1,3 & $\mathrm{AB}$ & 32,0 & 1,6 & A & 31,5 & 1,0 & $\mathrm{AB}$ \\
\hline GATA3 & 23,1 & 0,5 & A & 23,7 & 0,5 & A & 23,9 & 0,3 & $\mathrm{~A}$ & 23,5 & 0,9 & A & 23,9 & 0,6 & $\mathrm{~A}$ \\
\hline INDO & 22,6 & 0,8 & A & 22,0 & 0,7 & $\mathrm{AB}$ & 19,8 & 1,1 & $\mathrm{BC}$ & 19,1 & 1,4 & $\mathrm{C}$ & 22,9 & 0,9 & A \\
\hline $\mathrm{NOS} 2 \mathrm{~A}$ & 33,7 & 0,6 & A & 34,1 & 0,1 & $\mathrm{~A}$ & 33,7 & 0,6 & $\mathrm{~A}$ & 30,0 & 1,9 & B & 33,4 & 1,1 & $\mathrm{~A}$ \\
\hline ARG1 & 35,5 & 1,6 & A & 34,8 & 2,0 & $\mathrm{AB}$ & 29,9 & 3,5 & $\mathrm{BC}$ & 26,5 & 0,5 & $\mathrm{C}$ & 34,1 & 2,6 & $\mathrm{AB}$ \\
\hline SLC11A1 & 35,6 & 0,9 & A & 33,4 & 1,2 & $\mathrm{AB}$ & 31,0 & 1,8 & $\mathrm{BC}$ & 27,2 & 1,4 & $\mathrm{C}$ & 32,6 & 1,9 & $\mathrm{AB}$ \\
\hline IGM & 20,5 & 0,6 & A & 22,3 & 1,1 & $\mathrm{~A}$ & 21,1 & 0,2 & $\mathrm{~A}$ & 17,1 & 2,0 & B & 21,6 & 0,3 & $\mathrm{~A}$ \\
\hline IGG & 21,9 & 0,7 & A & 21,9 & 1,6 & A & 21,7 & 0,6 & A & 19,4 & 2,5 & A & 19,4 & 1,7 & A \\
\hline IGA & 21,0 & 1,2 & A & 21,6 & 1,6 & A & 20,3 & 0,8 & A & 19,4 & 1,6 & $\mathrm{~A}$ & 21,9 & 0,7 & A \\
\hline IL10 & 25,6 & 0,6 & A & 25,2 & 0,6 & A & 24,5 & 0,8 & A & 24,7 & 0,8 & A & 26,2 & 0,7 & A \\
\hline TGFB1 & 24,9 & 0,2 & A & 24,8 & 0,4 & $\mathrm{~A}$ & 24,7 & 0,5 & $\mathrm{~A}$ & 24,3 & 1,1 & $\mathrm{~A}$ & 25,3 & 0,5 & A \\
\hline MHC2TA & 21,6 & 0,2 & $\mathrm{AB}$ & 21,7 & 0,3 & $\mathrm{AB}$ & 21,3 & 0,1 & B & 21,9 & 0,6 & $\mathrm{AB}$ & 22,3 & 0,2 & A \\
\hline ICOS & 21,0 & 0,6 & $\mathrm{~A}$ & 21,6 & 0,5 & $\mathrm{~A}$ & 20,9 & 0,2 & A & 21,5 & 1,2 & $\mathrm{~A}$ & 21,8 & 0,6 & A \\
\hline CD3E & 19,9 & 0,7 & A & 19,9 & 0,1 & A & 20,1 & 0,4 & $\mathrm{~A}$ & 20,4 & 1,0 & A & 20,6 & 0,7 & A \\
\hline CD28 & 23,2 & 0,7 & A & 23,0 & 0,0 & A & 23,3 & 0,1 & A & 23,6 & 1,1 & A & 23,9 & 0,8 & A \\
\hline CD69 & 21,6 & 0,8 & A & 21,8 & 0,2 & A & 21,6 & 0,3 & A & 22,4 & 1,1 & A & 22,7 & 1,0 & A \\
\hline CTLA4 & 24,9 & 0,5 & A & 25,0 & 0,7 & A & 24,0 & 0,7 & A & 23,5 & 1,4 & A & 25,2 & 0,3 & A \\
\hline TNFRSF5 & 20,7 & 0,6 & A & 21,1 & 0,8 & A & 20,4 & 0,6 & A & 20,4 & 0,8 & A & 21,6 & 0,6 & A \\
\hline TNFSF5 & 23,3 & 0,6 & A & 23,8 & 0,3 & A & 24,0 & 0,3 & A & 24,3 & 0,8 & A & 24,2 & 0,9 & A \\
\hline CD80 & 23,7 & 0,5 & A & 23,9 & 0,6 & A & 24,0 & 0,1 & A & 24,2 & 0,5 & A & 24,6 & 0,6 & A \\
\hline CD86 & 21,5 & 0,6 & A & 21,6 & 0,3 & A & 21,7 & 0,9 & A & 21,3 & 0,4 & A & 22,4 & 0,5 & A \\
\hline TNFRSF6 & 22,9 & 0,7 & A & 23,2 & 0,2 & A & 23,2 & 0,5 & A & 23,3 & 0,7 & A & 23,3 & 0,5 & A \\
\hline CASP1 & 22,8 & 1,1 & A & 22,4 & 0,2 & $\mathrm{AB}$ & 21,8 & 0,6 & $\mathrm{AB}$ & 20,9 & 0,7 & B & 22,9 & 0,4 & A \\
\hline
\end{tabular}

${ }^{1} \mathrm{DPI}$ - dias pós-infecção, ${ }^{2}$ letras distintas na mesma linha indicam diferença estatística, $\mathrm{xx}=$ não detectado 
Tabela 4.2.4 - Resultados da Real-Time RT-PCR em amostras de linfonodo hepato-esplênico dos suínos do EXP II. Valores médios de $\mathrm{Ct}$ e respectivos desvios padrões (DP) nos grupos controle e infectados de acordo com o dia após a infecção com $T$. gondii. Diferença estatística (Estat.) segundo o teste de TukeyKramer $(\alpha=0,05)$ - Beltsville -2003

\begin{tabular}{|c|c|c|c|c|c|c|c|c|c|c|c|c|c|c|c|}
\hline \multirow{2}{*}{ Gene } & \multicolumn{3}{|c|}{ Controle } & \multicolumn{3}{|c|}{ 2DPI ${ }^{1}$} & \multicolumn{3}{|c|}{ 4DPI } & \multicolumn{3}{|c|}{ 7DPI } & \multicolumn{3}{|c|}{ 14DPI } \\
\hline & Média & $\mathrm{DP}$ & Estat. $^{2}$ & Média & DP & Estat. & Média & DP & Estat. & Média & DP & Estat. & Média & DP & Estat. \\
\hline RPL32 & 16,5 & 0,2 & $\mathrm{~A}$ & 16,6 & 0,5 & A & 17,0 & 0,5 & A & 16,3 & 0,3 & A & 16,5 & 0,5 & A \\
\hline IFNA & 28,5 & 2,5 & A & 29,5 & 1,0 & A & 29,4 & 0,5 & A & 31,3 & 0,7 & A & 29,9 & 0,2 & A \\
\hline IL1B & 27,1 & 0,4 & $\mathrm{AB}$ & 27,7 & 0,6 & $\mathrm{AB}$ & 27,3 & 0,9 & $\mathrm{AB}$ & 25,4 & 1,3 & B & 28,7 & 1,0 & A \\
\hline IL6 & 25,6 & 0,5 & A & 25,3 & 0,5 & A & 25,2 & 0,9 & A & 24,1 & 0,8 & A & 25,4 & 0,6 & A \\
\hline TNF & 27,4 & 0,5 & A & 27,3 & 0,4 & A & 27,2 & 0,8 & A & 26,5 & 0,7 & A & 27,5 & 0,6 & A \\
\hline TLR2 & 22,5 & 0,4 & A & 22,6 & 0,4 & A & 22,7 & 0,7 & A & 21,8 & 0,7 & A & 22,7 & 0,8 & A \\
\hline TLR4 & 22,6 & 0,3 & A & 22,9 & 1,0 & A & 22,4 & 0,9 & A & 21,2 & 0,6 & A & 22,9 & 0,9 & A \\
\hline CRP & 29,9 & 2,2 & A & 28,2 & 2,0 & A & 25,2 & 4,3 & A & 29,5 & 1,9 & A & 27,5 & 2,5 & A \\
\hline MYD88 & 21,9 & 0,3 & A & 21,8 & 0,6 & $\mathrm{AB}$ & 21,7 & 0,8 & $\mathrm{AB}$ & 20,5 & 0,3 & B & 21,7 & 0,7 & $\mathrm{AB}$ \\
\hline FCGR3A & 16,7 & 4,8 & A & 19,1 & 0,5 & A & 18,8 & 0,8 & A & 17,5 & 0,4 & A & 19,0 & 0,4 & A \\
\hline IFNG & 25,6 & 0,1 & A & 26,1 & 0,4 & A & 25,2 & 1,2 & A & 22,0 & 0,9 & B & 24,7 & 0,7 & A \\
\hline IFNGR & 21,0 & 0,1 & A & 21,0 & 0,3 & $\mathrm{~A}$ & 21,3 & 0,7 & $\mathrm{~A}$ & 20,8 & 0,3 & A & 21,1 & 0,8 & A \\
\hline IL12A & 30,1 & 1,3 & A & 30,7 & 0,2 & A & 30,7 & 0,5 & A & 29,8 & 0,1 & A & 30,3 & 1,1 & A \\
\hline IL12B & 24,6 & 0,9 & A & 25,1 & 0,7 & A & 26,3 & 0,7 & A & 26,5 & 1,5 & A & 25,8 & 1,0 & A \\
\hline IL12RB2 & 27,4 & 7,7 & A & 31,9 & 0,8 & A & 31,4 & 1,0 & A & 29,2 & 0,6 & A & 31,3 & 0,1 & A \\
\hline IL15 & 31,5 & 0,6 & A & 31,1 & 2,2 & A & 30,1 & 0,4 & A & 28,9 & 0,2 & A & 29,2 & 1,1 & A \\
\hline IL18 & 20,8 & 0,4 & A & 20,6 & 0,5 & A & 20,6 & 1,0 & A & 20,1 & 0,2 & A & 20,7 & 0,3 & A \\
\hline IL18R & 23,5 & 0,2 & B & 23,8 & 0,2 & $\mathrm{AB}$ & 24,5 & 0,6 & A & 22,5 & 0,5 & $\mathrm{C}$ & 23,7 & 0,3 & $\mathrm{AB}$ \\
\hline IL23A & $\mathrm{xx}$ & $\mathrm{xx}$ & $\mathrm{xx}$ & $\mathrm{xx}$ & $\mathrm{xx}$ & $\mathrm{xx}$ & $\mathrm{xx}$ & $\mathrm{xx}$ & $\mathrm{xx}$ & $\mathrm{xx}$ & $\mathrm{xx}$ & $\mathrm{xx}$ & $\mathrm{xx}$ & $\mathrm{xx}$ & $\mathrm{xx}$ \\
\hline IRF1 & 20,2 & 0,2 & A & 19,9 & 0,9 & $\mathrm{AB}$ & 19,6 & 0,7 & $\mathrm{AB}$ & 18,7 & 0,3 & B & 20,1 & 0,6 & $\mathrm{AB}$ \\
\hline HLX1 & 28,9 & 0,3 & A & 28,6 & 0,7 & A & 28,7 & 0,8 & A & 28,7 & 0,5 & A & 29,0 & 0,2 & A \\
\hline ICSBP1 & 26,4 & 0,8 & A & 26,1 & 0,8 & A & 26,3 & 0,7 & A & 26,7 & 0,4 & A & 26,3 & 0,6 & A \\
\hline TBX21 & 27,9 & 0,6 & A & 27,6 & 0,7 & A & 27,7 & 1,0 & A & 25,4 & 0,2 & B & 26,8 & 0,1 & $\mathrm{AB}$ \\
\hline STAT1 & 20,6 & 0,5 & A & 20,0 & 1,1 & $\mathrm{AB}$ & 19,3 & 0,6 & $\mathrm{AB}$ & 18,7 & 0,2 & B & 20,0 & 0,6 & $\mathrm{AB}$ \\
\hline IL4 & 28,7 & 0,6 & A & 29,1 & 0,6 & A & 28,5 & 1,8 & A & 26,6 & 1,3 & A & 28,6 & 0,6 & A \\
\hline IL13 & 31,3 & 0,7 & A & 30,6 & 0,8 & A & 31,2 & 1,5 & A & 31,8 & 1,7 & A & 31,8 & 1,3 & A \\
\hline GATA3 & 22,2 & 0,4 & $\mathrm{AB}$ & 22,6 & 0,4 & $\mathrm{AB}$ & 22,9 & 0,6 & A & 21,6 & 0,4 & B & 22,8 & 0,1 & A \\
\hline INDO & 22,2 & 0,8 & A & 21,9 & 1,0 & A & 20,9 & 0,8 & $\mathrm{AB}$ & 18,9 & 0,9 & B & 21,5 & 0,7 & A \\
\hline NOS2A & 34,2 & 0,5 & A & 33,7 & 1,2 & A & 34,0 & 0,7 & A & 32,6 & 0,1 & A & 34,2 & 1,0 & A \\
\hline ARG1 & 32,9 & 2,1 & A & 31,6 & 2,2 & A & 31,2 & 4,2 & A & 33,3 & 4,5 & A & 31,7 & 0,5 & A \\
\hline SLC11A1 & 34,8 & 0,7 & A & 34,9 & 1,7 & A & 31,5 & 0,6 & B & 28,1 & 1,2 & $\mathrm{C}$ & 33,3 & 1,0 & $\mathrm{AB}$ \\
\hline IGM & 20,7 & 1,0 & A & 20,9 & 0,9 & A & 20,5 & 1,5 & A & 19,5 & 1,5 & A & 20,3 & 0,7 & A \\
\hline IGG & 20,5 & 0,8 & A & 19,9 & 1,0 & A & 20,1 & 1,7 & A & 21,1 & 1,7 & A & 18,4 & 0,5 & A \\
\hline IGA & 22,8 & 1,7 & A & 23,4 & 0,5 & A & 22,4 & 2,9 & A & 23,4 & 1,1 & A & 24,6 & 0,9 & $\mathrm{~A}$ \\
\hline IL10 & 26,4 & 0,4 & A & 26,0 & 0,3 & $\mathrm{AB}$ & 24,8 & 1,4 & $\mathrm{AB}$ & 24,0 & 1,2 & B & 26,2 & 0,4 & $\mathrm{AB}$ \\
\hline TGFB1 & 25,5 & 1,9 & A & 24,7 & 1,5 & A & 24,2 & 1,7 & A & 24,4 & 0,2 & A & 25,2 & 0,2 & A \\
\hline MHC2TA & 21,5 & 0,2 & A & 21,3 & 0,6 & A & 21,1 & 0,6 & A & 21,2 & 0,0 & A & 21,5 & 0,7 & A \\
\hline ICOS & 21,6 & 0,8 & $\mathrm{~A}$ & 22,0 & 0,5 & A & 21,8 & 0,9 & A & 20,3 & 0,8 & A & 21,0 & 0,6 & A \\
\hline CD3E & 20,1 & 0,3 & $\mathrm{AB}$ & 20,5 & 0,4 & A & 20,7 & 0,6 & A & 19,2 & 0,4 & B & 20,2 & 0,3 & $\mathrm{AB}$ \\
\hline $\mathrm{CD} 28$ & 23,3 & 0,4 & $\mathrm{AB}$ & 23,7 & 0,5 & $\mathrm{AB}$ & 24,3 & 0,8 & A & 22,5 & 0,4 & B & 23,4 & 0,4 & $\mathrm{AB}$ \\
\hline CD69 & 21,8 & 0,4 & A & 22,0 & 0,5 & A & 22,0 & 0,4 & A & 21,6 & 0,5 & A & 21,8 & 0,8 & A \\
\hline CTLA4 & 25,5 & 0,2 & A & 25,5 & 0,3 & A & 25,5 & 0,8 & A & 22,9 & 1,2 & B & 25,1 & 0,7 & A \\
\hline TNFRSF5 & 20,8 & 0,5 & A & 20,7 & 0,5 & A & 21,0 & 0,6 & A & 19,8 & 0,2 & A & 20,8 & 0,5 & A \\
\hline TNFSF5 & 23,5 & 0,3 & $\mathrm{AB}$ & 23,6 & 0,3 & A & 24,1 & 0,4 & A & 22,7 & 0,2 & B & 23,4 & 0,4 & $\mathrm{AB}$ \\
\hline CD80 & 23,6 & 0,3 & A & 23,3 & 0,5 & A & 23,8 & 0,4 & A & 23,2 & 0,3 & A & 23,4 & 0,4 & A \\
\hline CD86 & 21,8 & 0,5 & A & 21,5 & 0,6 & A & 21,5 & 0,9 & A & 20,6 & 0,4 & A & 21,8 & 0,6 & A \\
\hline TNFRSF6 & 23,5 & 0,6 & A & 23,6 & 0,6 & A & 23,5 & 1,0 & $\mathrm{~A}$ & 23,0 & 0,2 & A & 23,3 & 0,4 & A \\
\hline CASP1 & 23,1 & 0,6 & A & 22,9 & 0,7 & A & 22,3 & 0,9 & $\mathrm{AB}$ & 21,0 & 0,2 & B & 23,1 & 0,9 & A \\
\hline
\end{tabular}

${ }^{1} \mathrm{DPI}$ - dias pós-infecção, ${ }^{2}$ letras distintas na mesma linha indicam diferença estatística, $\mathrm{xx}=$ não detectado 
Tabela 4.2.5 - Resultados da Real-Time RT-PCR em amostras de fígado dos suínos do EXP II. Valores médios de Ct e respectivos desvios padrões (DP) nos grupos controle e infectados de acordo com o dia após a infecção com T. gondii . Diferença estatística (Estat.) segundo o teste de Tukey-Kramer $(\alpha=0,05)$ Beltsville -2003

\begin{tabular}{|c|c|c|c|c|c|c|c|c|c|c|c|c|c|c|c|}
\hline \multirow{2}{*}{ Gene } & \multicolumn{3}{|c|}{ Controle } & \multicolumn{3}{|c|}{ 2DPI ${ }^{1}$} & \multicolumn{3}{|c|}{ 4DPI } & \multicolumn{3}{|c|}{ 7DPI } & \multicolumn{3}{|c|}{ 14DPI } \\
\hline & Média & $\mathrm{DP}$ & Estat. $^{2}$ & Média & $\mathrm{DP}$ & Estat. & Média & $\mathrm{DP}$ & Estat. & Média & DP & Estat. & Média & $\mathrm{DP}$ & Estat. \\
\hline RPL32 & 18,2 & 0,4 & $\mathrm{~A}$ & 17,5 & 0,3 & A & 17,7 & 0,4 & A & 17,9 & 0,4 & A & 18,2 & 0,4 & $\mathrm{~A}$ \\
\hline IFNA & 32,4 & 0,7 & A & 31,9 & 1,1 & A & 32,8 & 0,4 & A & 30,1 & 2,9 & A & 33,6 & 1,4 & A \\
\hline IL1B & 29,7 & 0,5 & A & 29,0 & 0,2 & $\mathrm{AB}$ & 27,6 & 1,7 & $\mathrm{AB}$ & 26,5 & 1,2 & B & 29,4 & 0,9 & A \\
\hline IL6 & 29,9 & 1,1 & A & 28,8 & 0,4 & $\mathrm{AB}$ & 27,7 & 0,7 & B & 27,4 & 1,1 & B & 29,4 & 0,3 & $\mathrm{AB}$ \\
\hline TNF & 31,9 & 0,8 & A & 30,1 & 1,5 & $\mathrm{AB}$ & 29,7 & 0,4 & B & 29,0 & 0,6 & B & 30,8 & 0,6 & $\mathrm{AB}$ \\
\hline TLR2 & 25,6 & 0,3 & A & 24,7 & 1,1 & $\mathrm{ABC}$ & 23,5 & 0,6 & $\mathrm{BC}$ & 23,0 & 0,8 & $\mathrm{C}$ & 25,4 & 1,1 & $\mathrm{AB}$ \\
\hline TLR4 & 25,3 & 0,4 & A & 24,9 & 0,8 & A & 23,1 & 0,4 & $\mathrm{~B}$ & 22,9 & 0,5 & B & 24,8 & 0,7 & A \\
\hline CRP & 20,0 & 1,6 & A & 19,2 & 1,2 & $\mathrm{AB}$ & 15,9 & 0,1 & $\mathrm{C}$ & 16,4 & 0,0 & $\mathrm{BC}$ & 18,4 & 1,6 & $\mathrm{ABC}$ \\
\hline MYD88 & 24,0 & 0,5 & A & 23,2 & 0,2 & $\mathrm{AB}$ & 21,7 & 0,6 & $\mathrm{C}$ & 21,9 & 0,5 & $\mathrm{BC}$ & 23,6 & 0,7 & A \\
\hline FCGR3A & 21,7 & 0,4 & A & 20,9 & 0,5 & $\mathrm{~A}$ & 19,6 & 0,4 & A & 15,8 & 5,5 & A & 20,8 & 0,4 & A \\
\hline IFNG & 29,9 & 0,8 & A & 28,9 & 2,0 & A & 28,0 & 0,5 & A & 24,7 & 0,8 & B & 28,2 & 0,1 & A \\
\hline IFNGR & 23,7 & 0,5 & A & 23,3 & 0,2 & $\mathrm{AB}$ & 22,4 & 0,6 & B & 22,4 & 0,6 & B & 23,9 & 0,4 & A \\
\hline IL12A & 35,1 & 1,0 & A & 34,0 & 1,6 & $\mathrm{AB}$ & 32,9 & 0,1 & $\mathrm{AB}$ & 31,4 & 1,4 & B & 33,6 & 2,0 & $\mathrm{AB}$ \\
\hline IL12B & 33,5 & 1,1 & $\mathrm{AB}$ & 33,4 & 1,2 & $\mathrm{AB}$ & 33,9 & 1,5 & $\mathrm{~A}$ & 30,9 & 0,5 & B & 33,2 & 1,0 & $\mathrm{AB}$ \\
\hline IL12RB2 & 35,1 & 0,8 & A & 34,9 & 0,7 & A & 35,4 & 0,9 & A & 31,1 & 2,3 & B & 33,7 & 1,4 & $\mathrm{AB}$ \\
\hline IL15 & 32,3 & 0,8 & A & 30,8 & 3,4 & A & 31,4 & 2,2 & A & 31,8 & 2,9 & A & 33,4 & 1,0 & A \\
\hline IL18 & 24,2 & 0,4 & A & 23,6 & 0,9 & $\mathrm{AB}$ & 22,3 & 0,6 & B & 22,8 & 0,8 & $\mathrm{AB}$ & 24,2 & 0,6 & A \\
\hline IL18R & 28,1 & 0,3 & A & 27,9 & 0,7 & $\mathrm{~A}$ & 27,7 & 0,5 & A & 26,4 & 0,5 & $\mathrm{~B}$ & 27,5 & 0,3 & $\mathrm{AB}$ \\
\hline IL23A & $\mathrm{xx}$ & $\mathrm{xx}$ & $\mathrm{xx}$ & $\mathrm{xx}$ & $\mathrm{xx}$ & $\mathrm{xx}$ & $\mathrm{xx}$ & $\mathrm{xx}$ & $\mathrm{xx}$ & $\mathrm{xx}$ & $\mathrm{xx}$ & $\mathrm{xx}$ & $\mathrm{xx}$ & $\mathrm{xx}$ & $\mathrm{xx}$ \\
\hline IRF1 & 23,0 & 0,6 & A & 21,6 & 1,0 & $\mathrm{AB}$ & 20,0 & 0,5 & B & 20,6 & 0,9 & B & 22,4 & 0,3 & A \\
\hline HLX1 & 32,9 & 0,5 & $\mathrm{AB}$ & 32,5 & 1,1 & $\mathrm{AB}$ & 32,4 & 0,8 & $\mathrm{AB}$ & 31,2 & 0,7 & B & 33,3 & 0,4 & A \\
\hline ICSBP1 & 31,1 & 0,2 & $\mathrm{~A}$ & 29,9 & 1,5 & $\mathrm{~A}$ & 29,9 & 0,4 & $\mathrm{~A}$ & 29,5 & 0,5 & A & 31,4 & 0,4 & A \\
\hline TBX21 & 32,5 & 0,1 & A & 32,2 & 0,8 & $\mathrm{AB}$ & 31,0 & 0,4 & B & 29,2 & 0,4 & $\mathrm{C}$ & 30,9 & 0,6 & B \\
\hline STAT1 & 22,7 & 0,6 & A & 21,0 & 1,1 & $\mathrm{BC}$ & 19,0 & 0,3 & $\mathrm{D}$ & 19,9 & 0,7 & $\mathrm{CD}$ & 22,5 & 0,6 & $\mathrm{AB}$ \\
\hline IL4 & 33,1 & 1,0 & A & 32,6 & 0,6 & A & 32,2 & 0,4 & A & 29,5 & 1,6 & $\mathrm{~B}$ & 32,9 & 0,6 & A \\
\hline IL13 & 33,8 & 1,3 & A & 32,0 & 1,9 & A & 33,3 & 0,6 & A & 33,2 & 1,5 & A & 33,6 & 1,3 & A \\
\hline GATA3 & 27,4 & 0,3 & A & 27,4 & 0,5 & $\mathrm{~A}$ & 27,2 & 0,1 & A & 25,6 & 0,3 & B & 27,3 & 0,8 & A \\
\hline INDO & 30,0 & 0,4 & A & 27,3 & 2,7 & $\mathrm{AB}$ & 21,7 & 0,1 & $\mathrm{C}$ & 21,2 & 1,1 & $\mathrm{C}$ & 26,5 & 0,6 & B \\
\hline NOS2A & 38,3 & 0,2 & A & 37,2 & 2,0 & $\mathrm{AB}$ & 37,6 & 0,5 & $\mathrm{AB}$ & 35,3 & 1,2 & B & 36,4 & 1,1 & $\mathrm{AB}$ \\
\hline ARG1 & 22,0 & 1,5 & A & 21,8 & 1,8 & A & 20,2 & 0,7 & A & 20,5 & 1,6 & A & 21,5 & 1,3 & A \\
\hline SLC11A1 & 33,0 & 0,6 & A & 32,0 & 1,7 & A & 29,0 & 0,5 & B & 28,9 & 0,4 & B & 33,4 & 0,9 & A \\
\hline IGM & 25,4 & 0,6 & A & 24,8 & 1,1 & A & 24,8 & 0,7 & A & 22,2 & 0,9 & B & 25,3 & 1,1 & A \\
\hline IGG & 26,4 & 0,3 & A & 25,8 & 2,0 & A & 25,6 & 0,5 & A & 23,7 & 1,4 & A & 23,9 & 0,9 & A \\
\hline IGA & 28,3 & 1,1 & $\mathrm{AB}$ & 28,2 & 0,9 & $\mathrm{AB}$ & 28,6 & 0,3 & $\mathrm{AB}$ & 25,7 & 1,2 & B & 29,1 & 1,8 & A \\
\hline IL10 & 28,9 & 1,0 & A & 27,3 & 0,9 & $\mathrm{AB}$ & 25,3 & 0,9 & $\mathrm{~B}$ & 25,9 & 0,3 & B & 28,0 & 2,1 & $\mathrm{AB}$ \\
\hline TGFB1 & 28,5 & 0,8 & A & 28,1 & 1,5 & $\mathrm{~A}$ & 27,7 & 0,1 & A & 27,5 & 1,0 & A & 29,4 & 1,2 & A \\
\hline MHC2TA & 26,3 & 0,2 & A & 24,8 & 1,1 & $\mathrm{BC}$ & 24,0 & 0,6 & $\mathrm{C}$ & 23,6 & 0,2 & $\mathrm{C}$ & 25,6 & 0,2 & $\mathrm{AB}$ \\
\hline ICOS & 28,9 & 0,7 & A & 28,5 & 1,0 & $\mathrm{~A}$ & 27,7 & 0,3 & A & 24,8 & 0,8 & B & 27,7 & 0,6 & $\mathrm{~A}$ \\
\hline CD3E & 26,8 & 0,6 & A & 26,4 & 0,6 & $\mathrm{AB}$ & 25,8 & 0,2 & $\mathrm{AB}$ & 23,5 & 0,8 & $\mathrm{C}$ & 25,3 & 0,2 & B \\
\hline CD28 & 30,5 & 1,0 & A & 30,7 & 0,6 & $\mathrm{~A}$ & 30,3 & 0,2 & $\mathrm{~A}$ & 27,0 & 0,7 & B & 29,6 & 0,4 & A \\
\hline CD69 & 28,4 & 0,4 & A & 27,6 & 1,0 & A & 27,3 & 0,8 & A & 26,4 & 0,9 & A & 28,1 & 0,9 & A \\
\hline CTLA4 & 33,4 & 0,6 & A & 32,5 & 1,1 & $\mathrm{AB}$ & 30,7 & 0,2 & B & 26,6 & 1,3 & $\mathrm{C}$ & 31,7 & 0,2 & $\mathrm{AB}$ \\
\hline TNFRSF5 & 25,3 & 0,4 & A & 24,7 & 0,6 & $\mathrm{~A}$ & 23,3 & 0,2 & B & 22,7 & 0,6 & B & 25,3 & 0,2 & A \\
\hline TNFSF5 & 30,0 & 0,5 & A & 29,2 & 1,1 & $\mathrm{AB}$ & 28,7 & 0,4 & $\mathrm{AB}$ & 26,3 & 0,2 & $\mathrm{C}$ & 27,8 & 0,3 & B \\
\hline CD80 & 28,8 & 0,4 & A & 28,2 & 0,2 & $\mathrm{~A}$ & 28,0 & 0,4 & $\mathrm{AB}$ & 26,8 & 0,8 & B & 28,8 & 0,5 & A \\
\hline CD86 & 25,3 & 0,3 & A & 24,6 & 0,6 & $\mathrm{AB}$ & 23,5 & 0,1 & $\mathrm{BC}$ & 23,1 & 0,5 & $\mathrm{C}$ & 25,1 & 0,5 & A \\
\hline TNFRSF6 & 27,1 & 0,7 & A & 26,4 & 0,2 & $\mathrm{AB}$ & 23,4 & 0,8 & $\mathrm{C}$ & 24,4 & 0,9 & $\mathrm{BC}$ & 26,8 & 1,1 & A \\
\hline CASP1 & 24,9 & 0,5 & A & 23,7 & 0,6 & $\mathrm{~A}$ & 22,3 & 0,3 & B & 22,2 & 0,3 & $\mathrm{~B}$ & 24,3 & 0,8 & A \\
\hline
\end{tabular}

${ }^{1}$ DPI - dias pós-infecção, ${ }^{2}$ letras distintas na mesma linha indicam diferença estatística, $\mathrm{xx}=$ não detectado 
Tabela 4.2.6 - Resultados da Real-Time RT-PCR em amostras de íleo dos suínos do EXP II. Valores médios de $\mathrm{Ct}$ e respectivos desvios padrões (DP) nos grupos controle e infectados de acordo com o dia após a infecção com $T$. gondii. Diferença estatística (Estat.) segundo o teste de Tukey-Kramer $(\alpha=0,05)$ - Beltsville -2003

\begin{tabular}{|c|c|c|c|c|c|c|c|c|c|c|c|c|c|c|c|}
\hline \multirow{2}{*}{ Gene } & \multicolumn{3}{|c|}{ Controle } & \multicolumn{3}{|c|}{ 2DPI ${ }^{1}$} & \multicolumn{3}{|c|}{ 4DPI } & \multicolumn{3}{|c|}{ 7DPI } & \multicolumn{3}{|c|}{ 14DPI } \\
\hline & Média & DP & Estat. $^{2}$ & Média & $\mathrm{DP}$ & Estat. & Média & $\mathrm{DP}$ & Estat. & Média & DP & Estat. & Média & DP & Estat. \\
\hline RPL32 & 17,5 & 0,4 & A & 16,9 & 0,4 & A & 17,6 & 0,6 & A & 16,8 & 0,6 & A & 17,3 & 0,6 & A \\
\hline IFNA & 29,6 & 1,6 & A & 31,6 & 0,9 & A & 30,6 & 0,5 & A & 28,8 & 4,1 & A & 31,6 & 0,8 & A \\
\hline IL1B & 26,0 & 0,9 & A & 25,6 & 1,3 & A & 25,4 & 1,4 & A & 20,7 & 2,9 & B & 26,5 & 1,1 & A \\
\hline IL6 & 28,3 & 1,1 & A & 27,3 & 0,8 & $\mathrm{AB}$ & 27,9 & 1,6 & A & 23,7 & 2,7 & B & 28,1 & 0,8 & A \\
\hline TNF & 28,8 & 0,6 & A & 28,7 & 0,5 & A & 29,9 & 1,2 & $\mathrm{~A}$ & 25,0 & 1,4 & B & 29,5 & 0,9 & A \\
\hline TLR2 & 25,0 & 0,8 & A & 24,4 & 1,0 & $\mathrm{AB}$ & 24,8 & 0,7 & A & 22,0 & 1,2 & B & 24,8 & 1,1 & A \\
\hline TLR4 & 24,6 & 0,5 & A & 23,7 & 0,6 & $\mathrm{AB}$ & 24,6 & 1,4 & A & 21,5 & 1,4 & B & 24,3 & 0,8 & A \\
\hline CRP & 31,3 & 1,2 & A & 30,5 & 1,0 & A & 31,3 & 0,4 & A & 27,3 & 3,5 & A & 31,3 & 1,2 & A \\
\hline MYD88 & 21,8 & 0,4 & A & 21,1 & 0,4 & A & 22,1 & 0,9 & A & 20,6 & 0,9 & A & 22,1 & 0,9 & A \\
\hline CD16 & 19,8 & 0,4 & A & 19,0 & 0,5 & $\mathrm{AB}$ & 20,3 & 0,9 & A & 17,9 & 1,2 & B & 19,6 & 0,6 & $\mathrm{AB}$ \\
\hline IFNG & 24,5 & 2,2 & A & 24,6 & 1,8 & A & 25,0 & 1,2 & A & 23,4 & 1,8 & A & 25,2 & 0,6 & A \\
\hline IFNGR & 20,3 & 0,4 & A & 19,9 & 0,7 & A & 20,8 & 0,6 & A & 19,9 & 0,3 & A & 20,9 & 1,0 & A \\
\hline IL12A & 30,9 & 1,7 & A & 30,2 & 2,4 & A & 32,5 & 1,2 & A & 27,7 & 2,5 & A & 31,6 & 0,8 & A \\
\hline IL12B & 28,4 & 0,6 & A & 29,1 & 2,0 & A & 30,5 & 0,6 & A & 27,7 & 1,3 & A & 29,2 & 1,1 & A \\
\hline IL12RB2 & 30,9 & 2,8 & A & 32,6 & 4,5 & $\mathrm{~A}$ & 33,5 & 1,2 & A & 27,3 & 3,0 & A & 32,3 & 0,2 & A \\
\hline IL15 & 32,0 & 2,1 & A & 34,3 & 3,4 & A & 28,4 & 0,7 & A & 30,8 & 0,4 & A & 31,4 & 3,2 & A \\
\hline IL18 & 22,1 & 0,9 & $\mathrm{AB}$ & 21,8 & 0,8 & $\mathrm{AB}$ & 22,6 & 0,7 & $\mathrm{~A}$ & 20,2 & 1,1 & B & 21,9 & 0,7 & $\mathrm{AB}$ \\
\hline IL18R & 24,3 & 0,8 & A & 24,3 & 0,3 & A & 25,5 & 0,8 & $\mathrm{~A}$ & 24,0 & 1,6 & A & 24,5 & 0,8 & A \\
\hline IL23A & $\mathrm{xx}$ & $\mathrm{xx}$ & $\mathrm{xx}$ & $\mathrm{xx}$ & $x x$ & $\mathrm{xx}$ & $\mathrm{xx}$ & $\mathrm{xx}$ & $\mathrm{xx}$ & $\mathrm{xx}$ & $\mathrm{xx}$ & $\mathrm{xx}$ & $\mathrm{xx}$ & $\mathrm{xx}$ & $\mathrm{xx}$ \\
\hline IRF1 & 19,7 & 0,3 & A & 18,8 & 0,7 & A & 19,6 & 0,8 & A & 18,5 & 0,6 & A & 20,1 & 0,9 & A \\
\hline HLX1 & 29,7 & 0,3 & A & 29,6 & 0,8 & $\mathrm{AB}$ & 30,6 & 0,7 & A & 28,0 & 0,5 & B & 30,1 & 1,0 & A \\
\hline ICSBP1 & 28,2 & 0,7 & A & 28,4 & 0,5 & $\mathrm{~A}$ & 27,7 & 0,5 & A & 27,1 & 1,6 & A & 28,7 & 0,9 & A \\
\hline TBX21 & 29,7 & 1,1 & A & 29,6 & 0,7 & $\mathrm{AB}$ & 30,3 & 0,7 & A & 27,7 & 0,3 & B & 29,9 & 0,7 & A \\
\hline STAT1 & 19,2 & 0,1 & A & 18,2 & 0,4 & A & 19,1 & 1,1 & A & 18,2 & 0,9 & A & 19,9 & 1,5 & A \\
\hline IL4 & 28,3 & 0,4 & $\mathrm{AB}$ & 27,5 & 0,7 & $\mathrm{AB}$ & 28,4 & 1,3 & $\mathrm{AB}$ & 26,7 & 0,9 & B & 29,1 & 0,8 & A \\
\hline IL13 & 31,7 & 1,2 & A & 30,5 & 0,4 & A & 32,3 & 1,2 & A & 30,5 & 1,6 & A & 32,1 & 0,7 & A \\
\hline GATA3 & 23,9 & 1,0 & $\mathrm{AB}$ & 24,2 & 1,0 & $\mathrm{AB}$ & 25,5 & 0,9 & A & 22,8 & 1,0 & B & 24,9 & 1,0 & $\mathrm{AB}$ \\
\hline INDO & 25,9 & 1,5 & A & 23,9 & 1,6 & $\mathrm{AB}$ & 23,8 & 2,1 & $\mathrm{AB}$ & 19,7 & 2,1 & B & 25,1 & 1,0 & $\mathrm{~A}$ \\
\hline NOS2A & 29,5 & 0,6 & $\mathrm{AB}$ & 29,9 & 1,0 & $\mathrm{AB}$ & 29,2 & 0,9 & A & 27,7 & 1,4 & B & 31,9 & 2,0 & A \\
\hline ARG1 & 33,4 & 1,9 & A & 31,9 & 1,1 & A & 32,9 & 2,1 & $\mathrm{~A}$ & 26,7 & 2,5 & B & 33,9 & 0,7 & A \\
\hline SLC11A1 & 33,4 & 2,9 & A & 34,0 & 2,1 & A & 33,3 & 1,4 & A & 25,9 & 0,4 & B & 33,2 & 0,4 & A \\
\hline IGM & 21,0 & 1,0 & A & 21,8 & 0,9 & A & 22,2 & 0,5 & A & 18,7 & 2,7 & A & 20,8 & 2,3 & A \\
\hline IGG & 21,8 & 0,5 & A & 22,9 & 0,3 & A & 22,1 & 0,2 & A & 21,3 & 1,8 & A & 20,7 & 1,7 & A \\
\hline IGA & 19,3 & 2,3 & A & 21,0 & 2,2 & A & 20,2 & 1,4 & $\mathrm{~A}$ & 18,5 & 2,2 & A & 20,1 & 2,1 & A \\
\hline IL10 & 27,3 & 0,5 & A & 28,5 & 2,3 & A & 26,8 & 0,9 & $\mathrm{AB}$ & 23,9 & 1,3 & B & 27,6 & 1,0 & A \\
\hline TGFB1 & 27,2 & 0,3 & A & 27,1 & 0,3 & A & 27,0 & 0,9 & A & 24,9 & 0,5 & B & 27,4 & 0,7 & A \\
\hline MHC2TA & 23,7 & 0,8 & A & 22,9 & 0,5 & A & 23,9 & 1,2 & A & 21,9 & 1,1 & A & 23,6 & 0,7 & A \\
\hline ICOS & 24,2 & 0,8 & $\mathrm{AB}$ & 23,8 & 0,7 & $\mathrm{AB}$ & 24,6 & 0,6 & $\mathrm{AB}$ & 22,3 & 0,8 & B & 24,7 & 1,3 & A \\
\hline CD3E & 21,9 & 2,2 & A & 21,0 & 0,3 & A & 21,6 & 0,2 & A & 21,2 & 2,0 & A & 21,8 & 1,2 & A \\
\hline CD28 & 26,7 & 1,4 & A & 26,2 & 0,6 & A & 27,2 & 1,5 & A & 25,2 & 1,9 & A & 26,7 & 1,0 & A \\
\hline CD69 & 23,2 & 0,2 & A & 23,0 & 0,8 & $\mathrm{~A}$ & 23,9 & 0,7 & $\mathrm{~A}$ & 22,6 & 0,9 & A & 24,0 & 1,0 & A \\
\hline CTLA4 & 27,4 & 0,7 & A & 27,2 & 1,1 & $\mathrm{AB}$ & 27,1 & 1,1 & $\mathrm{AB}$ & 24,0 & 1,9 & B & 27,7 & 1,2 & A \\
\hline TNFRSF5 & 23,0 & 0,5 & A & 22,1 & 0,6 & $\mathrm{AB}$ & 23,3 & 1,3 & A & 20,3 & 1,2 & B & 22,9 & 0,9 & A \\
\hline TNFSF5 & 25,4 & 0,7 & A & 24,7 & 0,4 & A & 26,0 & 0,6 & A & 24,2 & 1,1 & A & 25,4 & 0,8 & A \\
\hline CD80 & 25,9 & 0,7 & A & 25,2 & 0,4 & A & 26,6 & 1,0 & $\mathrm{~A}$ & 24,5 & 1,3 & A & 26,2 & 0,9 & A \\
\hline CD86 & 22,7 & 0,5 & A & 21,9 & 1,2 & A & 22,3 & 1,3 & A & 21,0 & 1,1 & A & 22,7 & 1,1 & A \\
\hline TNFRSF6 & 24,1 & 0,5 & A & 23,6 & 0,9 & A & 23,8 & 1,5 & A & 23,0 & 1,5 & A & 24,3 & 1,2 & A \\
\hline CASP1 & 20,6 & 0,5 & A & 19,4 & 0,8 & A & 19,8 & 0,6 & A & 19,4 & 0,2 & A & 20,3 & 0,6 & A \\
\hline
\end{tabular}

${ }^{1} \mathrm{DPI}$ - dias pós-infecção, ${ }^{2}$ letras distintas na mesma linha indicam diferença estatística, $\mathrm{xx}=$ não detectado 
Tabela 4.2.7 - Resultados da Real-Time RT-PCR em amostras de jejuno dos suínos do EXP II. Valores médios de Ct e respectivos desvios padrões (DP) nos grupos controle e infectados de acordo com o dia após a infecção com T. gondii. Diferença estatística (Estat.) segundo o teste de Tukey-Kramer $(\alpha=0,05)$ -

\begin{tabular}{|c|c|c|c|c|c|c|c|c|c|c|c|c|c|c|c|}
\hline \multirow{2}{*}{ Gene } & \multicolumn{3}{|c|}{ Controle } & \multicolumn{3}{|c|}{ 2DPI ${ }^{1}$} & \multicolumn{3}{|c|}{ 4DPI } & \multicolumn{3}{|c|}{ 7DPI } & \multicolumn{3}{|c|}{ 14DPI } \\
\hline & Média & DP & Estat. $^{2}$ & Média & DP & Estat. & Média & DP & Estat. & Média & DP & Estat. & Média & $\mathrm{DP}$ & Estat. \\
\hline RPL32 & 17,6 & 0,4 & A & 17,2 & 0,1 & A & 17,2 & 0,2 & A & 17,7 & 0,2 & A & 17,6 & 0,2 & A \\
\hline IFNA & 30,3 & 0,5 & A & 30,7 & 0,8 & A & 30,7 & 0,4 & A & 30,4 & 0,3 & A & 30,5 & 0,8 & A \\
\hline IL1B & 26,2 & 1,1 & A & 25,5 & 0,4 & A & 25,6 & 0,8 & A & 24,9 & 1,0 & A & 26,6 & 0,8 & A \\
\hline IL6 & 29,3 & 0,7 & A & 28,5 & 0,7 & $\mathrm{ABC}$ & 27,3 & 0,4 & $\mathrm{C}$ & 27,9 & 0,4 & $\mathrm{BC}$ & 29,0 & 0,6 & $\mathrm{AB}$ \\
\hline IL8 & 20,8 & 0,8 & A & 20,4 & 0,1 & A & 20,4 & 0,2 & A & 20,5 & 0,3 & A & 21,6 & 0,5 & A \\
\hline CCL5 & 19,3 & 0,5 & A & 18,5 & 0,6 & A & 19,6 & 0,4 & A & 19,4 & 0,9 & A & 19,8 & 0,3 & A \\
\hline CCL2 & 21,4 & 0,9 & A & 20,8 & 0,6 & A & 20,4 & 0,6 & A & 20,4 & 0,5 & A & 21,4 & 0,4 & A \\
\hline TNF & 29,9 & 0,7 & $\mathrm{AB}$ & 29,7 & 0,4 & $\mathrm{AB}$ & 29,3 & 1,1 & $\mathrm{AB}$ & 28,5 & 0,3 & B & 30,3 & 0,2 & A \\
\hline TLR2 & 26,2 & 0,7 & A & 25,7 & 0,1 & A & 24,4 & 0,4 & $\mathrm{BC}$ & 23,3 & 0,5 & $\mathrm{C}$ & 25,2 & 0,3 & $\mathrm{AB}$ \\
\hline TLR4 & 24,3 & 0,5 & A & 24,4 & 0,6 & A & 23,2 & 0,8 & $\mathrm{AB}$ & 22,7 & 0,5 & B & 24,2 & 0,2 & $\mathrm{AB}$ \\
\hline CRP & 31,0 & 0,8 & A & 29,9 & 1,3 & A & 30,5 & 0,5 & A & 31,3 & 0,7 & A & 30,4 & 2,2 & $\mathrm{~A}$ \\
\hline FCGR3A & 19,4 & 0,8 & A & 19,0 & 0,7 & A & 19,1 & 0,3 & A & 18,8 & 0,6 & A & 19,7 & 0,3 & A \\
\hline IFNG & 26,5 & 0,8 & A & 25,4 & 0,9 & $\mathrm{AB}$ & 24,4 & 0,9 & $\mathrm{AB}$ & 23,8 & 0,7 & B & 25,1 & 1,1 & $\mathrm{AB}$ \\
\hline IFNGR & 19,9 & 0,6 & $\mathrm{AB}$ & 19,4 & 0,1 & $\mathrm{~B}$ & 19,8 & 0,2 & $\mathrm{AB}$ & 20,4 & 0,4 & $\mathrm{AB}$ & 20,5 & 0,4 & A \\
\hline IL12A & 33,0 & 1,0 & A & 31,9 & 1,4 & A & 32,3 & 0,4 & A & 32,2 & 0,1 & A & 33,3 & 0,9 & A \\
\hline IL12B & 30,8 & 0,7 & A & 30,3 & 1,4 & A & 32,4 & 0,8 & A & 31,1 & 1,2 & A & 30,9 & 0,5 & A \\
\hline IL12RB2 & 33,5 & 0,8 & A & 32,5 & 1,7 & $\mathrm{~A}$ & 32,7 & 0,9 & A & 31,7 & 1,0 & A & 33,2 & 0,2 & A \\
\hline IL15 & 28,0 & 0,4 & A & 27,6 & 0,6 & A & 27,4 & 0,1 & A & 28,1 & 0,4 & A & 28,4 & 0,7 & A \\
\hline IL18 & 21,0 & 1,4 & A & 21,0 & 0,3 & A & 21,8 & 0,5 & A & 21,5 & 0,2 & A & 22,2 & 0,4 & A \\
\hline IL18R & 22,9 & 1,5 & A & 22,7 & 0,5 & A & 23,6 & 0,3 & A & 23,8 & 0,3 & A & 23,7 & 0,6 & A \\
\hline IL23A & 38,9 & 1,2 & A & 38,9 & 0,6 & A & 37,9 & 0,3 & A & 38,8 & 0,2 & A & 39,2 & 0,3 & A \\
\hline IRF1 & 19,9 & 0,7 & A & 19,0 & 0,4 & $\mathrm{AB}$ & 18,3 & 0,1 & B & 19,2 & 0,5 & $\mathrm{AB}$ & 20,2 & 0,4 & A \\
\hline HLX1 & 30,2 & 0,5 & A & 30,2 & 0,7 & $\mathrm{~A}$ & 29,9 & 0,7 & A & 29,6 & 0,2 & A & 30,3 & 0,6 & A \\
\hline STAT1 & 19,7 & 0,6 & A & 18,7 & 0,4 & $\mathrm{AB}$ & 17,9 & 0,2 & B & 18,6 & 0,3 & B & 19,8 & 0,3 & A \\
\hline STAT4 & 25,7 & 0,7 & A & 25,1 & 0,7 & A & 25,3 & 0,3 & A & 24,7 & 0,3 & A & 25,7 & 0,5 & A \\
\hline IL4 & 28,6 & 0,4 & $\mathrm{AB}$ & 28,1 & 0,4 & $\mathrm{AB}$ & 26,8 & 1,4 & B & 27,4 & 0,8 & $\mathrm{AB}$ & 29,0 & 0,7 & A \\
\hline IL5 & 29,1 & 0,8 & $\mathrm{AB}$ & 28,4 & 0,5 & $\mathrm{~B}$ & 30,0 & 0,5 & $\mathrm{AB}$ & 30,3 & 0,6 & A & 29,6 & 0,9 & $\mathrm{AB}$ \\
\hline IL13 & 31,7 & 0,6 & $\mathrm{AB}$ & 31,4 & 0,5 & $\mathrm{AB}$ & 30,7 & 0,8 & B & 31,8 & 0,2 & $\mathrm{AB}$ & 32,6 & 0,3 & A \\
\hline GATA3 & 24,5 & 0,4 & $\mathrm{~A}$ & 23,8 & 0,7 & A & 24,4 & 0,2 & A & 23,9 & 0,4 & A & 24,5 & 0,2 & A \\
\hline INDO & 26,0 & 0,7 & A & 25,5 & 1,2 & A & 22,1 & 0,8 & B & 20,5 & 0,5 & B & 24,3 & 0,4 & A \\
\hline NOS2A & 33,8 & 1,3 & $\mathrm{AB}$ & 31,8 & 1,0 & $\mathrm{BC}$ & 30,6 & 0,2 & $\mathrm{C}$ & 31,0 & 0,2 & $\mathrm{C}$ & 34,8 & 1,3 & A \\
\hline ARG1 & 30,0 & 0,2 & $\mathrm{AB}$ & 29,7 & 1,3 & $\mathrm{AB}$ & 30,4 & 0,5 & $\mathrm{AB}$ & 28,1 & 1,5 & B & 30,8 & 0,2 & A \\
\hline SLC11A1 & 34,0 & 1,1 & A & 33,4 & 1,4 & $\mathrm{AB}$ & 31,0 & 1,3 & $\mathrm{BC}$ & 28,8 & 0,3 & $\mathrm{C}$ & 33,4 & 1,4 & $\mathrm{AB}$ \\
\hline IGM & 20,9 & 0,4 & A & 20,0 & 0,7 & $\mathrm{~A}$ & 20,4 & 0,4 & A & 20,5 & 0,7 & A & 20,3 & 0,4 & A \\
\hline IGG & 21,9 & 0,6 & $\mathrm{AB}$ & 22,6 & 0,5 & A & 22,1 & 0,3 & A & 22,0 & 1,5 & $\mathrm{AB}$ & 19,9 & 0,5 & B \\
\hline IGA & 19,3 & 1,2 & $\mathrm{~A}$ & 19,4 & 1,1 & A & 19,1 & 0,3 & A & 19,4 & 0,7 & A & 19,4 & 0,4 & A \\
\hline IL10 & 30,0 & 0,7 & A & 29,6 & 0,4 & $\mathrm{AB}$ & 28,4 & 0,9 & B & 28,4 & 0,2 & B & 30,1 & 0,3 & A \\
\hline TGFB1 & 27,0 & 0,4 & A & 26,7 & 0,3 & A & 26,8 & 0,3 & A & 25,4 & 0,5 & B & 26,5 & 0,2 & $\mathrm{~A}$ \\
\hline MHC2TA & 23,5 & 0,7 & A & 22,8 & 0,6 & $\mathrm{AB}$ & 22,3 & 0,2 & $\mathrm{~B}$ & 22,3 & 0,1 & B & 23,1 & 0,3 & $\mathrm{AB}$ \\
\hline ICOS & 22,8 & 0,8 & A & 22,4 & 0,5 & $\mathrm{AB}$ & 21,9 & 0,5 & $\mathrm{AB}$ & 21,3 & 0,3 & B & 22,8 & 0,4 & A \\
\hline CD3E & 21,0 & 0,5 & A & 20,3 & 0,6 & A & 20,8 & 0,3 & A & 20,8 & 0,3 & A & 21,4 & 0,2 & A \\
\hline CD69 & 23,0 & 0,6 & A & 23,0 & 0,4 & A & 22,4 & 0,5 & $\mathrm{~A}$ & 23,3 & 0,2 & A & 23,1 & 0,0 & $\mathrm{~A}$ \\
\hline CTLA4 & 27,9 & 0,7 & A & 27,5 & 0,3 & A & 25,6 & 0,5 & B & 24,6 & 0,4 & B & 27,4 & 0,2 & A \\
\hline TNFRSF5 & 23,7 & 1,6 & A & 23,6 & 1,4 & A & 22,8 & 1,0 & A & 23,0 & 0,3 & A & 24,4 & 0,3 & A \\
\hline TNFSF5 & 25,1 & 0,9 & A & 24,7 & 0,5 & A & 24,6 & 0,2 & A & 24,5 & 0,4 & A & 24,8 & 0,1 & $\mathrm{~A}$ \\
\hline CD80 & 25,9 & 0,5 & A & 25,2 & 0,3 & $\mathrm{AB}$ & 25,4 & 0,3 & $\mathrm{AB}$ & 25,0 & 0,2 & B & 25,7 & 0,3 & $\mathrm{AB}$ \\
\hline CD86 & 22,2 & 0,9 & A & 21,3 & 0,1 & $\mathrm{AB}$ & 20,6 & 0,4 & B & 21,2 & 0,3 & $\mathrm{AB}$ & 22,1 & 0,2 & A \\
\hline CASP1 & 19,6 & 0,9 & A & 18,8 & 0,5 & A & 18,7 & 0,3 & A & 19,5 & 0,4 & A & 19,9 & 0,4 & A \\
\hline
\end{tabular}

${ }^{1}$ DPI - dias pós-infecção, ${ }^{2}$ letras distintas na mesma linha indicam diferença estatística 


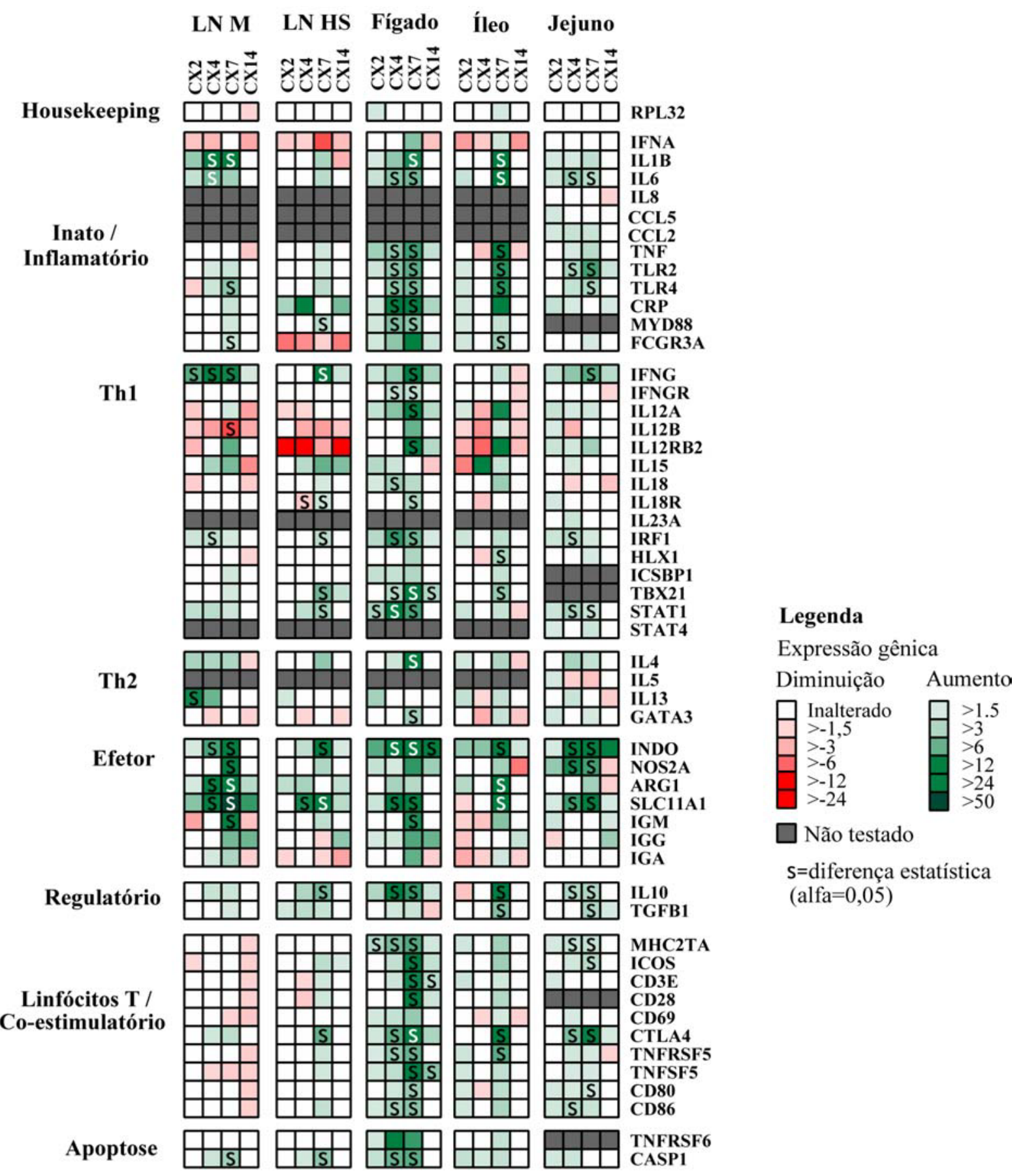

Figura 4.2.1 - Efeito da infecção pelo T. gondii na expressão de genes no linfonodo mesentérico (LN M), no linfonodo hepato-esplênico (LN HS), no fígado, no íleo e no jejuno de suínos mensurado pela Real-Time RT-PCR. Aumento ou diminuição da expressão de mRNA nos grupos nos grupos infectados em relação ao controle não-infectado - Beltsville - 2003 
Tabela 4.2.8 - Variação da expressão gênica em suínos após infecção pelo $T$. gondii, mensurado pela Real-Time RTPCR. Aumento (valores positivos) ou diminuição (valores negativos) da expressão de mRNA nos linfonodos mesentérico (LN M), hepato-esplênico (LN HS) e fígado dos grupos infectados em relação ao controle não-infectado - Beltsville - 2003

\begin{tabular}{|c|c|c|c|c|c|c|c|c|c|c|c|c|}
\hline \multirow{2}{*}{ Gene } & \multicolumn{4}{|c|}{ LN M } & \multicolumn{4}{|c|}{ LN HS } & \multicolumn{4}{|c|}{ Fígado } \\
\hline & CX2 & CX4 & CX7 & $\overline{\text { CX14 }}$ & CX2 & CX4 & CX7 & $\overline{\text { CX14 }}$ & $\mathrm{CX} 2$ & CX4 & CX7 & CX14 \\
\hline RPL32 & 0,0 & 0,0 & 0,0 & $-1,6$ & 0,0 & 0,0 & 0,0 & 0,0 & 1,7 & 0,0 & 0,0 & 0,0 \\
\hline IFNA & $-2,2$ & $-2,8$ & 0,0 & $-3,3$ & $-2,0$ & $-1,8$ & $-6,9$ & $-2,5$ & 0,0 & 0,0 & 4,7 & $-2,3$ \\
\hline IL1B & 4,0 & 19,7 & 22,5 & 0,0 & 0,0 & 0,0 & 3,3 & $-3,0$ & 1,6 & 4,2 & 9,0 & 0,0 \\
\hline IL6 & 2,3 & 5,6 & 3,6 & 0,0 & 0,0 & 0,0 & 2,7 & 0,0 & 2,1 & 4,6 & 5,5 & 0,0 \\
\hline TNF & 0,0 & 0,0 & 0,0 & $-2,1$ & 0,0 & 0,0 & 1,8 & 0,0 & 3,6 & 4,5 & 7,5 & 2,2 \\
\hline TLR2 & 0,0 & 1,6 & 2,0 & 0,0 & 0,0 & 0,0 & 1,7 & 0,0 & 1,9 & 4,3 & 6,4 & 0,0 \\
\hline TLR4 & $-1,8$ & 1,9 & 4,4 & 0,0 & 0,0 & 0,0 & 2,6 & 0,0 & 0,0 & 4,4 & 5,3 & 0,0 \\
\hline CRP & 0,0 & 0,0 & 2,1 & 0,0 & 3,3 & 26,2 & 0,0 & 5,2 & 1,8 & 17,5 & 12,4 & 3,1 \\
\hline MYD88 & 0,0 & 0,0 & 1,7 & 0,0 & 0,0 & 0,0 & 2,7 & 0,0 & 1,8 & 5,0 & 4,4 & 0,0 \\
\hline FCGR3A & 0,0 & 0,0 & 2,1 & 0,0 & $-5,5$ & $-4,4$ & $-1,8$ & $-5,1$ & 1,7 & 4,3 & 58,6 & 1,9 \\
\hline IFNG & 6,5 & 15,7 & 9,4 & 1,6 & 0,0 & 0,0 & 12,0 & 1,9 & 2,0 & 3,7 & 35,3 & 3,2 \\
\hline IFNGR & 0,0 & 0,0 & 0,0 & 0,0 & 0,0 & 0,0 & 0,0 & 0,0 & 0,0 & 2,5 & 2,5 & 0,0 \\
\hline IL12A & $-2,1$ & 0,0 & 1,7 & $-3,6$ & $-1,5$ & $-1,6$ & 0,0 & 0,0 & 2,2 & 4,6 & 12,8 & 2,7 \\
\hline IL12B & $-1,9$ & $-3,7$ & $-7,1$ & $-3,2$ & 0,0 & $-3,2$ & $-3,8$ & $-2,3$ & 0,0 & 0,0 & 5,9 & 0,0 \\
\hline IL12RB2 & $-2,8$ & 0,0 & 6,2 & 0,0 & $-22,5$ & $-15,5$ & $-3,4$ & $-14,4$ & 0,0 & 0,0 & 16,7 & 2,8 \\
\hline IL15 & 0,0 & 3,3 & 5,2 & $-4,4$ & 0,0 & 2,7 & 6,0 & 4,9 & 2,8 & 1,9 & 0,0 & $-2,1$ \\
\hline IL18 & $-1,9$ & 0,0 & 0,0 & $-1,9$ & 0,0 & 0,0 & 1,6 & 0,0 & 1,6 & 3,8 & 2,7 & 0,0 \\
\hline IL18R & 0,0 & 0,0 & 0,0 & 0,0 & 0,0 & $-2,0$ & 2,0 & 0,0 & 0,0 & 0,0 & 3,2 & 0,0 \\
\hline IL23A & $\mathrm{xx}$ & $\mathrm{xx}$ & $\mathrm{xx}$ & $\mathrm{xx}$ & $\mathrm{xx}$ & $\mathrm{xx}$ & $\mathrm{xx}$ & $\mathrm{xx}$ & $\mathrm{xx}$ & $\mathrm{xx}$ & $\mathrm{xx}$ & $\mathrm{xx}$ \\
\hline IRF1 & 1,9 & 2,5 & 1,6 & 0,0 & 0,0 & 0,0 & 2,7 & 0,0 & 2,8 & 8,0 & 5,5 & 1,5 \\
\hline HLX1 & 0,0 & 0,0 & 0,0 & $-1,6$ & 0,0 & 0,0 & 0,0 & 0,0 & 0,0 & 0,0 & 3,1 & 0,0 \\
\hline ICSBP1 & 0,0 & 0,0 & 1,8 & 0,0 & 0,0 & 0,0 & 0,0 & 0,0 & 2,3 & 2,2 & 3,0 & 0,0 \\
\hline TBX21 & 0,0 & 0,0 & 1,6 & 0,0 & 0,0 & 0,0 & 5,6 & 2,2 & 0,0 & 2,9 & 10,1 & 3,0 \\
\hline STAT1 & 2,4 & 2,6 & 1,9 & 0,0 & 0,0 & 2,4 & 3,8 & 0,0 & 3,4 & 12,6 & 7,1 & 0,0 \\
\hline IL4 & 3,3 & 3,1 & 3,1 & $-1,6$ & 0,0 & 0,0 & 4,2 & 0,0 & 0,0 & 1,9 & 12,0 & 0,0 \\
\hline IL13 & 9,4 & 5,7 & 0,0 & 0,0 & 1,7 & 0,0 & 0,0 & 0,0 & 3,5 & 0,0 & 0,0 & 0,0 \\
\hline GATA3 & 0,0 & $-1,7$ & 0,0 & $-1,7$ & 0,0 & $-1,6$ & 0,0 & $-1,5$ & 0,0 & 0,0 & 3,6 & 0,0 \\
\hline INDO & 1,6 & 7,1 & 11,5 & 0,0 & 0,0 & 2,4 & 9,9 & 1,6 & 6,6 & 314,7 & 436,4 & 11,7 \\
\hline NOS2A & 0,0 & 0,0 & 13,0 & 0,0 & 0,0 & 0,0 & 3,1 & 0,0 & 2,2 & 1,6 & 8,1 & 3,7 \\
\hline ARG1 & 1,6 & 48,2 & 516,6 & 2,7 & 2,5 & 3,4 & 0,0 & 2,3 & 0,0 & 3,4 & 2,8 & 0,0 \\
\hline SLC11A1 & 4,6 & 23,8 & 330,5 & 7,9 & 0,0 & 9,2 & 99,6 & 2,7 & 2,0 & 16,4 & 16,8 & 0,0 \\
\hline IGM & $-3,5$ & 0,0 & 10,9 & $-2,2$ & 0,0 & 0,0 & 2,4 & 0,0 & 0,0 & 0,0 & 8,8 & 0,0 \\
\hline IGG & 0,0 & 0,0 & 5,4 & 5,6 & 0,0 & 0,0 & $-1,6$ & 4,2 & 1,6 & 1,8 & 6,8 & 5,8 \\
\hline IGA & 0,0 & 1,6 & 3,1 & $-1,8$ & $-1,6$ & 0,0 & $-1,6$ & $-3,5$ & 0,0 & 0,0 & 6,1 & $-1,8$ \\
\hline IL10 & 0,0 & 2,1 & 1,9 & 0,0 & 0,0 & 3,0 & 5,4 & 0,0 & 3,0 & 12,3 & 8,0 & 1,9 \\
\hline TGFB1 & 0,0 & 0,0 & 1,6 & 0,0 & 1,7 & 2,5 & 2,1 & 0,0 & 0,0 & 1,8 & 2,0 & $-1,9$ \\
\hline MHC2TA & 0,0 & 0,0 & 0,0 & $-1,7$ & 0,0 & 0,0 & 0,0 & 0,0 & 2,9 & 5,2 & 6,7 & 1,7 \\
\hline ICOS & $-1,5$ & 0,0 & 0,0 & $-1,8$ & 0,0 & 0,0 & 2,5 & 1,5 & 0,0 & 2,3 & 16,8 & 2,2 \\
\hline CD3E & 0,0 & 0,0 & 0,0 & $-1,7$ & 0,0 & $-1,5$ & 1,8 & 0,0 & 0,0 & 1,9 & 9,5 & 2,7 \\
\hline $\mathrm{CD} 28$ & 0,0 & 0,0 & 0,0 & $-1,7$ & 0,0 & $-2,0$ & 1,8 & 0,0 & 0,0 & 0,0 & 10,7 & 1,9 \\
\hline CD69 & 0,0 & 0,0 & $-1,7$ & $-2,1$ & 0,0 & 0,0 & 0,0 & 0,0 & 1,7 & 2,2 & 4,0 & 0,0 \\
\hline CTLA4 & 0,0 & 1,8 & 2,5 & 0,0 & 0,0 & 0,0 & 5,9 & 0,0 & 1,8 & 6,1 & 108,4 & 3,2 \\
\hline TNFRSF5 & 0,0 & 0,0 & 0,0 & $-1,9$ & 0,0 & 0,0 & 2,0 & 0,0 & 1,5 & 4,0 & 5,9 & 0,0 \\
\hline TNFSF5 & 0,0 & $-1,6$ & $-1,9$ & $-1,8$ & 0,0 & 0,0 & 1,7 & 0,0 & 1,7 & 2,4 & 13,0 & 4,5 \\
\hline CD80 & 0,0 & 0,0 & 0,0 & $-1,8$ & 0,0 & 0,0 & 0,0 & 0,0 & 0,0 & 1,8 & 3,9 & 0,0 \\
\hline CD86 & 0,0 & 0,0 & 0,0 & $-1,8$ & 0,0 & 0,0 & 2,3 & 0,0 & 1,6 & 3,5 & 4,5 & 0,0 \\
\hline TNFRSF6 & 0,0 & 0,0 & 0,0 & 0,0 & 0,0 & 0,0 & 0,0 & 0,0 & 1,7 & 12,7 & 7,8 & 0,0 \\
\hline CASP1 & 0,0 & 2,0 & 3,6 & 0,0 & 0,0 & 1,8 & 4,3 & 0,0 & 2,2 & 5,8 & 6,4 & 0,0 \\
\hline
\end{tabular}


Figura 4.2.9 - Variação da expressão gênica em suínos após infecção pelo T. gondii, mensurado pela Real-Time RT-PCR. Aumento (valores positivos) ou diminuição (valores negativos) da expressão de mRNA no íleo e no jejuno dos grupos infectados em relação ao controle nãoinfectado - Beltsville - 2003

(continua)

\begin{tabular}{|c|c|c|c|c|c|c|c|c|}
\hline \multirow{2}{*}{ Gene } & \multicolumn{4}{|c|}{ Íleo } & \multicolumn{4}{|c|}{ Jejuno } \\
\hline & CX2 & CX4 & CX7 & $\overline{\text { CX14 }}$ & CX2 & CX4 & CX7 & CX14 \\
\hline RPL32 & 0,0 & 0,0 & 1,6 & 0,0 & 0,0 & 0,0 & 0,0 & 0,0 \\
\hline IFNA & $-3,8$ & $-2,0$ & 1,8 & $-3,9$ & 0,0 & 0,0 & 0,0 & 0,0 \\
\hline IL1B & 0,0 & 0,0 & 37,3 & 0,0 & 1,6 & 1,5 & 2,4 & 0,0 \\
\hline IL6 & 2,1 & 0,0 & 23,9 & 0,0 & 1,8 & 4,0 & 2,7 & 0,0 \\
\hline IL8 & NT & NT & NT & NT & 0,0 & 0,0 & 0,0 & $-1,7$ \\
\hline CCL5 & NT & NT & NT & NT & 1,7 & 0,0 & 0,0 & 0,0 \\
\hline CCL2 & NT & NT & NT & NT & 1,6 & 2,1 & 2,0 & 0,0 \\
\hline TNF & 0,0 & $-2,2$ & 13,6 & $-1,7$ & 0,0 & 1,5 & 2,6 & 0,0 \\
\hline TLR2 & 1,6 & 0,0 & 8,4 & 0,0 & 0,0 & 3,4 & 7,4 & 2,0 \\
\hline TLR4 & 1,8 & 0,0 & 8,5 & 0,0 & 0,0 & 2,2 & 3,2 & 0,0 \\
\hline CRP & 1,8 & 0,0 & 15,9 & 0,0 & 2,2 & 1,5 & 0,0 & 1,5 \\
\hline MYD88 & 1,6 & 0,0 & 2,2 & 0,0 & NT & NT & NT & NT \\
\hline FCGR3A & 1,8 & 0,0 & 3,9 & 0,0 & 0,0 & 0,0 & 1,6 & 0,0 \\
\hline IFNG & 0,0 & 0,0 & 2,2 & $-1,6$ & 2,2 & 4,3 & 6,6 & 2,7 \\
\hline IFNGR & 0,0 & 0,0 & 0,0 & $-1,6$ & 0,0 & 0,0 & 0,0 & $-1,5$ \\
\hline IL12A & 1,6 & $-3,0$ & 9,3 & $-1,6$ & 2,1 & 1,6 & 1,8 & 0,0 \\
\hline IL12B & $-1,6$ & $-4,3$ & 1,6 & $-1,8$ & 1,5 & $-2,9$ & 0,0 & 0,0 \\
\hline IL12RB2 & $-3,1$ & $-6,0$ & 11,8 & $-2,6$ & 2,0 & 1,8 & 3,6 & 0,0 \\
\hline IL15 & $-4,9$ & 12,4 & 2,2 & 0,0 & 0,0 & 1,6 & 0,0 & 0,0 \\
\hline IL18 & 0,0 & 0,0 & 3,8 & 0,0 & 0,0 & $-1,7$ & 0,0 & $-2,2$ \\
\hline IL18R & 0,0 & $-2,3$ & 0,0 & 0,0 & 1,6 & 0,0 & 0,0 & 0,0 \\
\hline IL23A & $\mathrm{xx}$ & $\mathrm{xx}$ & $\mathrm{xx}$ & $\mathrm{xx}$ & 0,0 & 2,0 & 0,0 & 0,0 \\
\hline IRF1 & 1,9 & 0,0 & 2,4 & 0,0 & 1,9 & 3,0 & 1,6 & 0,0 \\
\hline HLX1 & 0,0 & $-1,8$ & 3,3 & 0,0 & 0,0 & 0,0 & 1,5 & 0,0 \\
\hline ICSBP1 & 0,0 & 0,0 & 2,2 & 0,0 & NT & NT & NT & NT \\
\hline TBX21 & 0,0 & 0,0 & 4,1 & 0,0 & NT & NT & NT & NT \\
\hline STAT1 & 2,0 & 0,0 & 2,1 & $-1,6$ & 2,0 & 3,4 & 2,1 & 0,0 \\
\hline STAT4 & NT & NT & NT & NT & 1,5 & 0,0 & 1,9 & 0,0 \\
\hline
\end{tabular}


Figura 4.2.9 - Variação da expressão gênica em suínos após infecção pelo $T$. gondii, mensurado pela Real-Time RT-PCR. Aumento (valores positivos) ou diminuição (valores negativos) da expressão de mRNA no íleo e no jejuno dos grupos infectados em relação ao controle nãoinfectado - Beltsville - 2003

(conclusão)

\begin{tabular}{|c|c|c|c|c|c|c|c|c|}
\hline \multirow{2}{*}{ Gene } & \multicolumn{4}{|c|}{ Íleo } & \multicolumn{4}{|c|}{ Jejuno } \\
\hline & CX2 & $\mathrm{CX} 4$ & CX7 & CX14 & CX2 & $\mathrm{CX} 4$ & CX7 & CX14 \\
\hline IL4 & 1,7 & 0,0 & 3,0 & $-1,8$ & 0,0 & 3,3 & 2,2 & 0,0 \\
\hline IL5 & NT & NT & NT & NT & 1,6 & $-1,8$ & $-2,3$ & 0,0 \\
\hline IL13 & 2,3 & $-1,5$ & 2,3 & 0,0 & 0,0 & 2,0 & 0,0 & $-1,9$ \\
\hline GATA3 & 0,0 & $-3,1$ & 2,1 & $-2,1$ & 1,7 & 0,0 & 1,6 & 0,0 \\
\hline INDO & 4,0 & 4,5 & 76,4 & 1,8 & 1,5 & 15,6 & 45,1 & 15,6 \\
\hline NOS2A & 0,0 & 0,0 & 3,5 & $-5,2$ & 4,1 & 9,3 & 7,3 & $-1,9$ \\
\hline ARG1 & 2,8 & 0,0 & 103,5 & 0,0 & 0,0 & 0,0 & 3,6 & $-1,8$ \\
\hline SLC11A1 & $-1,6$ & 0,0 & 177,8 & 0,0 & 1,5 & 7,7 & 37,0 & 1,5 \\
\hline IGM & $-1,8$ & $-2,3$ & 4,7 & 0,0 & 1,9 & 0,0 & 0,0 & 1,5 \\
\hline IGG & $-2,2$ & 0,0 & 0,0 & 2,1 & $-1,6$ & 0,0 & 0,0 & 3,8 \\
\hline IGA & $-3,2$ & $-1,8$ & 1,8 & $-1,7$ & 0,0 & 0,0 & 0,0 & 0,0 \\
\hline IL10 & $-2,2$ & 0,0 & 10,7 & 0,0 & 0,0 & 3,0 & 3,0 & 0,0 \\
\hline TGFB1 & 0,0 & 0,0 & 4,8 & 0,0 & 0,0 & 0,0 & 3,1 & 1,5 \\
\hline MHC2TA & 1,8 & 0,0 & 3,5 & 0,0 & 1,6 & 2,4 & 2,3 & 0,0 \\
\hline ICOS & 0,0 & 0,0 & 3,7 & 0,0 & 0,0 & 1,8 & 2,8 & 0,0 \\
\hline CD3E & 1,9 & 0,0 & 1,7 & 0,0 & 1,6 & 0,0 & 0,0 & 0,0 \\
\hline CD28 & 0,0 & 0,0 & 2,9 & 0,0 & NT & NT & NT & NT \\
\hline CD69 & 0,0 & $-1,6$ & 1,6 & $-1,7$ & 0,0 & 1,5 & 0,0 & 0,0 \\
\hline CTLA4 & 0,0 & 0,0 & 10,6 & 0,0 & 0,0 & 5,1 & 9,7 & 1,5 \\
\hline TNFRSF5 & 1,9 & 0,0 & 6,5 & 0,0 & 0,0 & 1,8 & 1,6 & $-1,7$ \\
\hline TNFSF5 & 1,7 & 0,0 & 2,3 & 0,0 & 0,0 & 1,5 & 1,5 & 0,0 \\
\hline CD80 & 1,6 & $-1,6$ & 2,5 & 0,0 & 1,6 & 1,5 & 1,9 & 0,0 \\
\hline CD86 & 1,7 & 0,0 & 3,1 & 0,0 & 1,8 & 2,9 & 2,0 & 0,0 \\
\hline TNFRSF6 & 0,0 & 0,0 & 2,2 & 0,0 & NT & NT & NT & NT \\
\hline CASP1 & 2,3 & 1,7 & 2,3 & 0,0 & 1,7 & 1,9 & 0,0 & 0,0 \\
\hline
\end{tabular}




\section{DISCUSSÃO}

A infecção oral é a via de infecção que melhor simula a evolução da toxoplasmose na espécie suína, retratando desta forma os mecanismos ativados durante uma infecção em condições reais. Ao considerar as atuais condições de criação da suinocultura comercial os oocistos esporulandos são a principal forma infectante. A probabilidade de acesso a restos teciduais, possível fonte de cistos e taquizoítos, é bastante remota. Os taquizoítos, por sua vez, apresentam baixo risco por serem sensíveis à digestão péptica ácida e facilmente destruídos pelas enzimas digestivas (DUBEY, 1998; DUBEY; BEATTIE, 1988).

Comparativamente aos estudos que utilizam parasitas mortos ou somente antígenos específicos de $T$. gondii, as infecções experimentais com organismos vivos indicam a existência de múltiplos mecanismos de ativação (SUBAUSTE; WESSENDARP, 2000). No caso do $T$. gondii sabe-se que a atividade parasitária, a invasão celular e a multiplicação de taquizoítos geram sinais que são reconhecidos pela imunidade inata. Assim, as diferenças na virulência e na patogenicidade entre as diferentes cepas de $T$. gondii geram diferentes níveis de resposta no hospedeiro (ROBBEN et al., 2004).

Suínos experimentalmente infectados com oocistos de $T$. gondii da cepa VEG não apresentaram sintomas clínicos, mas desenvolveram infecção crônica com formação de cistos teciduais mesmo quando receberam doses infectantes equivalentes a um único oocisto (DUBEY et al., 1996; SOLANO-AGUILAR et al., 2001).

Em camundongos existe uma evidente variação de resposta a infecção pelo $T$. gondii nas diferentes linhagens, levando a variados níveis de resistência. Não existem entretanto publicações 
referentes a variações de resistência à toxoplasmose entre as raças de suínos. Em experimento utilizando mini-porcos com haplótipos conhecidos, Solano-Aguilar et al. (2001) não observaram variações de resposta à infecção entre os haplótipos $\mathrm{SLA}^{\mathrm{a} / \mathrm{a}}, \mathrm{SLA}^{\mathrm{c} / \mathrm{c}}$ e SLA ${ }^{\mathrm{d} / \mathrm{d}}$.

A detecção de organismos de T. gondii nos diversos tecidos após a inoculação dos oocistos fornece indícios da dinâmica da infecção. No 2DPI os parasitas foram encontrados somente no LMN. No 4DPI foram detectados em todos os tecidos testados e em maior quantidade, indicando a disseminação sistêmica e a proliferação dos taquizoítos. No 7DPI além da presença dos parasitas, foi observada uma intensa resposta local caracterizada por um intenso infiltrado de células inflamatórias, focos múltiplos de edema e necrose tecidual. No 14DPI foram encontrados um menor número de organismos e um menor grau de lesão tecidual que sugerem a inibição da atividade parasitária e a reorganização do tecido.

Ao mesmo tempo, com intuito de avaliar a magnitude da lesão celular, foram realizadas determinações das enzimas hepáticas. Dentre estas enzimas a aspartato aminotransferase (AST) foi a que apresentou maior variação. Em condições normais ela é encontrada em elevadas concentrações no citoplasma de células hepáticas. O aumento dos níveis de AST no soro é utilizado como um indicador de lise celular e pode ser detectado por até 24 a 36 horas após a injúria (COLES, 1986; DUNCAN; PRASSE, 1987). O aumento de AST sérico foi observado no 4DPI, atingindo valores máximos no 7DPI, resultados coerentes aos focos de necrose observados nos exames histopatológicos.

Os valores de alanino aminotransferase (ALT) embora apresentem variações estatisticamente significantes, não representam alterações patológicas, pois apresentam-se dentro dos valores de normalidade para a espécie animal. A ausência de alterações nos valores séricos de gamaglutamil transferase (GGT), bilirrubinas totais (TBILI), bilirrubina direta (DBILI), fosfatase alcalina (ALP), proteínas totais (PT), globulinas (GLOB), albumina (ALB) e proporção 
albumina/globulina $(\mathrm{A} / \mathrm{G})$ mostram que tais lesões não foram suficientes para afetar a função do órgão.

A produção de reagentes nitrogenados tóxicos é um processo induzido em fagócitos ativados com intuito de destruir microrganismos invasores (PAUL, 1999). Em camundongos este é um importante fator de inibição microbiana. No presente experimento, os suínos infectados pelo T. gondii apresentaram uma significante elevação de NO sérico no 4DPI.

A haptoglobina é uma proteína de fase aguda associada a diversas afecções que acometem os animais. Tanto no EXP I quanto no EXP II foram observadas elevações significantes dos níveis de haptoglobina sérica nos grupos 4DPI, 7DPI e 14DPI.

A detecção do parasita nos tecidos, a elevação de AST, somado ao aumento de NO e haptoglobina são concordantes às variações detectadas pela Real-Time RT-PCR. Já no 2DPI foram observadas indução de alguns genes, seguida de um aumento no 4DPI e no 7DPI e diminuição de resposta no 14DPI. A combinação destes achados permitiu associar a lesão e a reação tecidual à presença do $T$. gondii.

Os resultados listados no apêndice $\mathrm{G}$ indicam a possibilidade de variações de resposta de um animal para o outro. Esta variação individual pôde ser notada nos animais do 7DPI que apresentaram diferentes níveis de infecção pelo $T$. gondii e diferentes valores de IFN- $\gamma$, NO e AST séricos. Infelizmente não foi possível traçar uma comparação individual entre o perfil de indução de mRNA nos tecidos com a quantidade de parasitas em multiplicação. Portanto embora sujeito a estas variações de ordem individual, os dados foram simplesmente reunidos e analisados em grupo.

A análise estatística indicou portanto a diferença entre grupos onde houve baixa variação de resposta entre os indivíduos do grupo, isto é, onde houve baixo desvio-padrão. Em algumas ocasiões foram observadas grande elevação ou indução de uma determinada variável, mas 
estatisticamente não foi possível comprovar uma diferença significante entre grupos. As principais limitações encontradas estão relacionadas ao pequeno número de animais por grupo e a ocorrência destas variações de resposta individual.

Enfocando o IFN- $\gamma$ como a citocina-chave no estudo da resistência contra a infecção pelo T. gondii foram realizadas avaliações da expressão de IFNG nos tecidos e determinações de produção de IFN- $\gamma$ por células. Similarmente aos camundongos e aos humanos, o gene IFNG é fortemente induzido nos suínos infectados pelo $T$. gondii. A elevação da expressão de mRNA foi detectada pela Real-Time RT-PCR em praticamente todos os tecidos e é possível afirmar que esta indução gênica foi traduzida em proteína, dada pela observação de aumento de IFN- $\gamma$ circulante no soro e também pela determinação da produção de IFN- $\gamma$ pelas células cultivadas in vitro.

A técnica da Real-Time RT-PCR não permite quantificar o nível de produção de IFN- $\gamma$ nos diferentes tecidos, entretanto o isolamento e o cultivo in vitro de CMSP e células dos LN M, LN HS e LN TB demonstra diferentes níveis de ativação das células pela determinação de IFN- $\gamma$ no sobrenadante. Ao observar que células dos LN M e LN HS produziram maior quantidade de IFN- $\gamma$ que as CMSP e células do LN TB, torna-se claro que a estimulação de células ocorre de forma diferenciada e localizada, mesmo se tratando de uma infecção de distribuição sistêmica.

A variação das sub-populações de células dos LN M, LN HS, LN TB e CMSP indica uma possível participação das células NK no processo de resposta contra o $T$. gondii. Dentre as subpopulações analisadas, as células CD2 / CD16 DP foram as únicas que apresentaram variação estatisticamente significante em todas as amostras testadas a partir do 4DPI, com tendência de valores máximos no 7DPI. 
Em períodos precoces da infecção as células NK agiriam em conjunto com os macrófagos na produção de IFN- $\gamma$ e seriam estimuladas pela presença de citocinas como a IL-12 e o TNF- $\alpha$ (FILISETTI; CANDOLFI, 2004).

No presente experimento, as proporções relativas de células $\mathrm{CD} 4^{+}, \mathrm{CD} 8^{+}$e CD4/CD8 DP não apresentaram variações estatisticamente significantes no decurso da infecção, entretanto sabe-se que controle da infecção pelo $T$. gondii é dependente de ambas as populações de linfócitos $\mathrm{T} \mathrm{CD}^{+}$e $\mathrm{CD}^{+}$(CASCIOTTI et al., 2002; GAZZINELLI et al., 1991). Em infecções experimentais em mini-porcos induzidas com cerca de 1000 oocistos por via oral, Solano-Aguilar et al. (2001) observaram aumento das sub-populações de $\mathrm{CD}^{+}$no $10^{\mathrm{o}}$ dia pós-infecção e de CD4 / CD8 DP no $10^{\circ}$ e $17^{\circ}$ DPI. Embora utilizando uma quantidade de inóculo maior no presente experimento em relação ao estudo de Solano-Aguilar, a variação nas sub-populações foi menor, provavelmente a análise foi prejudicada pelo pequeno número de animais avaliados por grupo.

Não foram detectadas variações nas proporções relativas das sub-populações de células T ativadas (CD3/CD25 DP) e de monócitos e macrófagos (SWC3/SLAII DQ DP).

Infelizmente a repetição do exame de FCM nos animais do EXP II, assim como a marcação de IFN- $\gamma$ intracelular, não apresentaram bons resultados e foram omitidos na análise final dos dados. Entretanto os valores registrados no EXP I poderão ser futuramente explorados para o delineamento de novos estudos das populações celulares e a produção de IFN- $\gamma$.

No hemograma não foram observadas alterações sugestivas de patologia nas contagens do número total de eritrócitos e leucócitos, assim como na contagem diferencial de leucócitos circulantes no sangue periférico. A perda dos dados de FCM do EXP II impossibilitou a comparação do número absoluto de leucócitos e a proporção de sub-população de células pela FCM. 
Os resultados obtidos pela Real-Time RT-PCR confirmam a boa aplicabilidade desta metodologia para este tipo de estudo. A reprodutibilidade dos resultados do EXP I no EXP II reforça a consistência e a robustez da prova, contornando em parte a fragilidade estatística dada pelo baixo número de animais testados em cada grupo experimental.

Blader, Mangers e Boothroyd (2001) analisaram ao redor de 22 mil genes e ESTs em microarranjos e observaram predominantemente a indução de genes associados ao metabolismo de carboidratos, lipídios e aminoácidos, controle transcripcional, síntese e degradação de proteínas, sinalização intracelular, inflamação, ciclo celular e apoptose nas primeiras 24 horas pós-infecção pelo T. gondii em culturas de fibroblastos.

Chaussabel et al. (2003) avaliaram a expressão 4057 genes em macrófagos e DCs expostas a diferentes patógenos utilizando microarranjos e descrevem padrões de resposta distintos para cada agente infeccioso e expressão diferenciada de genes entre macrófagos e DCs.

Comparativamente ao microarranjo, a técnica da Real-Time RT-PCR apresenta vantagens por permitir a quantificação da expressão de genes de uma forma mais refinada. A desvantagem da prova está na limitação do número de genes a serem testados o que obriga a uma prévia seleção dos genes-alvo.

Ao analisar os resultados da Real-Time RT-PCR, a constância na amplificação de genes housekeeping é um indicador da adequada extração do RNA, síntese de cDNA e reação de PCR. Variações na detecção de gene housekeeping poderiam sugerir degradação da amostra ou falhas na realização das reações de RT ou da PCR. Em ambos os experimentos, observou-se uma baixa variação nos genes housekeeping. No EXP I a variação na expressão do gene RPL13A foi de 3,1 a $+2,3$ e do gene RPL32 foi de $-2,1$ a $+2,1$. No EXP II a variação na expressão do gene RPL32 foi de $-1,6 \mathrm{a}+1,7$. 
Em oposição aos genes housekeeping apresentando expressão de forma constante ou com baixa variação, genes induzidos ao longo da infecção indicam os mecanismos ativados em resposta ao patógeno.

$\mathrm{Na}$ literatura é freqüente o uso dos genes housekeeping para a normalização dos dados de expressão gênica (BUSTIN, 2000; 2002; THELLIN et al., 1999). Nestes casos o cálculo da variação da expressão gênica utiliza o gene housekeeping como referência. No presente trabalho, entretanto, optou-se pelo uso do valor de RNA total, sem normalização pelo housekeeping, devido a evidências de influência das infecções por diferentes agentes e de diferentes estímulos na expressão dos genes constitutivos (HAMALAINEN et al., 2001; SCHMITTGEN; ZAKRAJSEK, 2000; TRICARICO et al., 2002).

A variação de resposta entre os tecidos foi marcante. Dos nove diferentes tipos de tecido testados no EXP I, as amostras dos linfonodos, do fígado e dos segmentos intestinais foram as que apresentaram a maior intensidade de resposta, enquanto que CMSP, baço e timo sofreram poucas mudanças na expressão de mRNA.

As CMSP e os esplenócitos são bastante utilizados em experimentos com camundongos e em testes in vitro, mas revelaram baixo potencial informativo quando comparados aos demais tecidos do presente trabalho. Teoricamente as CMSP seriam o material de escolha para o estudo da evolução clínica de pacientes, possibilitando a obtenção de amostras seriadas do mesmo animal ao longo da infecção. No entanto, os resultados observados do EXP I em CMSP foram particularmente frustrantes devido a baixa variação na expressão dos genes.

O timo foi incluído no EXP I para avaliar a variação da resposta em um tecido em que hipoteticamente houvesse baixa ou ausência de variação. A baixa magnitude de resposta observada no timo é, portanto, concordante com o esperado. 
Dentre os tecidos que apresentaram intensa resposta à infecção, o fígado destaca-se pela intensidade de estimulação e pela quantidade de genes ativados. Esta observação evidencia a importância do órgão no desenvolvimento da resposta contra o $T$. gondii e enfatiza a necessidade de estudos mais aprofundados sobre a função imune deste órgão.

Embora parte desta resposta detectada no fígado possa estar associada ao infiltrado de leucócitos atraídos ao local da lesão, os hepatócitos também são capazes de produzir quimiocinas e proteínas de fase aguda, expressam receptores para citocinas e moléculas co-estimulatórias possuindo a capacidade de modular a resposta inata e a específica (MOCHIZUKI et al., 1997; WICK; LEITHÄUSER; REIMANN, 2002).

O parênquima hepático é também responsável pela síntese e pela liberação das proteínas de fase aguda. Estas proteínas plasmáticas são produzidas em resposta a processos infecciosos, inflamatórios, neoplásicos e agressões de ordem química ou mecânica, possuindo várias funções biológicas que envolvem o transporte de outras proteínas, a coagulação e a modulação da imunidade, e de uma forma geral, todas participam da restauração da homeostase pós-infecção ou pós-injúria.

As concentrações plasmáticas das proteínas de fase aguda são, por este motivo, intensamente estudadas para o acompanhamento da resposta a terapias e vacinas, embora nãoespecíficas são indicadores sensíveis e precoces de inflamação e mais recentemente têm sido propostos para programas de monitoramento na inspeção de animais para consumo humano (HISS et al., 2003; PYORALA, 2003; SKINNER, 2001).

Além do aumento dos níveis de haptoglobina sérica nos grupos 4DPI, 7DPI e 14DPI, os suínos infectados por T. gondii apresentaram elevação na expressão de outras proteínas de fase aguda. O gene ORM1 apresentou indução de 12 a 13 vezes respectivamente em amostras de LN 
M e LN HS no 4DPI e o gene CRP apresentou indução de 26 e 17 vezes respectivamente em amostras de LN HS e fígado no 4DPI e de 16 e 12 vezes no íleo e fígado no 7DPI.

A estimulação da produção das proteínas de fase aguda pode ser ativada pelas citocinas IL-1, IL-6, TNF- $\alpha$ e TGF- $\beta$ (CASTELL et al., 1988; MACKIEWICZ et al., 1990; MACKIEWICZ et al., 1991; SZALAI et al., 2000) que também apresentaram-se estimuladas nos suínos experimentais.

A função exata de cada uma destas proteínas ainda não está completamente elucidada. $\mathrm{O}$ efeito imunomodulatório tem sido descrito na interação da haptoglobina com células $\mathrm{T}$, inibindo a proliferação celular e a liberação de citocinas Th2, favorecendo a ativação da resposta Th1 (ARREDOUANI et al., 2003).

A indução destas proteínas associada às citocinas pró-inflamatórias e à ativação do sistema complemento sugerem sua participação nos mecanismos inespecíficos de defesa. A deficiência de ORM1 em camundongos foi associada a baixa resistência a infecções por bactérias Gram-negativas (HOCHEPIED et al., 2000).

Os TLR são capazes de reconhecer padrões antigênicos específicos associados a microrganismos e levam a ativação de sinais através da molécula adaptadora MYD88 (AKIRA, 2003). Dentre os 10 TLRs descritos até o momento em células de mamíferos, o TLR2 e o TLR4 parecem estar envolvidos no reconhecimento do T. gondii. Em camundongos, a deficiência de TLR2 aumenta a suscetibilidade à infecção pelo T. gondii (MUN et al., 2003). Nos suínos do presente experimento a expressão de ambos os TLRs testados apresentou elevação (variando de quatro a seis vezes) no fígado e nos segmentos intestinais.

Neutrófilos estimulados por IFN- $\gamma$ e antígenos solúveis de T. gondii (STAg) produzem CCL2 envolvendo a participação de TLR2 (DEL RIO et al., 2004). A variação da expressão de 
CCL2 foi somente testada em amostras de jejuno do EXP II apresentando uma discreta indução (duas vezes) nos grupos 4DPI e 7DPI. A CCL2 possui efeito de quimiotaxia sobre monócitos, linfócitos $\mathrm{T}$, basófilos e mastócitos, além de ação direta contra o parasita e pode contraditoriamente estimular a produção de IL-4 (KARPUS et al., 1997).

A deficiência de MYD88 em camundongos gera alterações fenotípicas similares à deficiência de IL12 e IFNG (SCANGA et al., 2002), revelando importante pista sobre os mecanismos de ativação da imunidade inata. Nos animais do presente experimento houve uma estimulação significativa (2,7 a cinco vezes) do gene MYD88 no LN HS e no fígado.

$\mathrm{Na}$ infecção pela via oral, os tecidos intestinais, o fígado, o LN M e o LN HS representam a primeira barreira de defesa contra a invasão pelo $T$. gondii e conforme foi observado, são os tecidos com maior intensidade de resposta inflamatória. Os sinais gerados durante esta resposta inicial são importantes peças na geração da resposta celular específica e a ativação dos genes IL1B, IL6, TNF, TLR2, TLR4, CRP, MYD88 e FCGR3A reforçam a necessidade de mais investigações sobre a imunidade inata.

Como esperado os genes associados à resposta inflamatória e relacionados ao IFNG foram os que apresentaram maiores variações ao longo da infecção pelo T. gondii. Entretanto, dentre os genes indutores da resposta Th1, os genes IL12A, IL12B e IL12RB2 não apresentaram a mesma estimulação observada em camundongos, e são concordantes aos resultados observados por Solano-Aguilar et al. (2001) em suínos.

A IL12 deve estar de alguma maneira ligada a elevada produção de TNF- $\alpha$, IFN- $\gamma$ e NO em camundongos, causando lesão hepática e elevada taxa de mortalidade. Camundongos IL12 deficientes infectados com T. gondii e Schistosoma mansoni apresentaram maior quantidade de IL5 e IL10, sobreviveram por mais tempo e apresentaram menos lesões no fígado quando comparados aos camundongos normais (ARAUJO et al., 2001). 
STATs são fatores de ativação da transcrição encontrados no citosol que quando ativados são mobilizados para o núcleo da célula. Ao se ligar com o DNA-alvo, iniciam o processo de transcrição. Ainda existem várias dúvidas acerca da forma de ação e da especificidade destes fatores sobre a ativação da transcrição de citocinas, mas sabe-se que a estimulação de citocinas como IL-12 e IFN- $\gamma$ está fortemente associada à ativação de STAT4 e STAT1 (CAI et al., 2000; LEONARD, 1999).

É importante manter em mente que, para que estas proteínas possam exercer a sua atividade e funcionar como ativadores da transcrição, é necessário que sofram um processo de fosforilação e se apresentem na forma de dímeros (LEONARD, 1999). O estudo da variação da expressão gênica destas proteínas deve ser portanto, feita de forma associada a outros indicadores da atividade dos STATs.

Dentre os STATs avaliados no presente experimento, o STAT1 foi o que apresentou maior estimulação durante a infecção pelo T. gondii. A maior indução foi observada em amostras de fígado, variando de 3,4 a 9,9 vezes no 2DPI, atingindo valores máximos de 12,6 a 36,1 vezes no 4DPI e diminuindo a 7,1 vezes no 7DPI. Variações foram detectadas também em amostras dos LN HS, LN M e jejuno.

A indução do IFNG e da via do STAT1 foi também observada por Chaussabel et al. (2003) em macrófagos e DCS infectados por T. gondii, interessantemente a estimulação do STAT1 não foi detectada em infecções por outros patógenos.

Camundongos deficientes do gene STAT4 produzem baixos níveis de IFN- $\gamma$ e morrem em poucos dias após a infecção pelo T. gondii (CAI et al., 2000). Nos suínos do presente experimento, a maior indução de STAT4 foi observada em amostras de fígado ( 5,1 vezes) e baço (3,9 vezes). 
A descrição inicial dos genes SOCS foi associada à atividade dos STATs. Os genes SOCS seriam induzidos pelos STATs e teriam função inibitória sobre a sinalização dos STATs (FUJIMOTO; NAKA, 2003). Observou-se elevação na expressão de SOCS1 e SOCS3 nos suínos do EXP I, principalmente nas amostras de fígado, linfonodos e segmentos intestinais.

A indução do IFN- $\gamma$ nos suínos experimentais pode ser resultante da ação sinérgica entre diferentes citocinas. Apesar de pouco intensa, a indução do IL12 está acompanhada da estimulação do IL23A no EXP I (24 vezes no LN M; 13,3 vezes no jejuno e 8,6 vezes no fígado) e do IL18 no EXP II (3,8 vezes no fígado e no íleo). Lieberman et al. (2004) e Cai, Kastelein e Hunter (2000) referem respectivamente à IL-23 e à IL-18 como citocinas importantes na resistência à toxoplasmose aguda em camundongos. Embora possam estimular a produção de IFN- $\gamma$, a IL-23 e a IL-18 dependem da presença de IL-12.

O grau de indução de alguns genes associados aos mecanismos efetores da resposta imune são bastante marcantes, atigindo valores superiores a 100 vezes de aumento.

O gene SLC11A1 apresentou uma elevação de 200 vezes no LN M no 4DPI e no 14 DPI; aumento de 110 vezes no LN IC no 4DPI e de 170 vezes no jejuno no 4DPI. O gene SLC11A1 está associado a resistência macrofágica às infecções e provavelmente estaria envolvido na remoção de íons de ferro necessários ao metabolismo parasitário (STAFFORD; NEUMANN; BELOSEVIC, 2002). A mobilização de íons ferro do citoplasma e a alteração da acidez intracitoplasmática afetariam também a função de fatores de transcrição. Em camundongos a ativação do gene SLC11A1 aumenta a expressão do gene NOS2A e a produção de NO, envolvendo também os genes IRF1 e STAT1 (FRITSCHE et al., 2003).

A produção da enzima INDO é induzida pelo IFN- $\gamma$ e estaria possivelmente associada a depleção de triptofano dos tecidos (FUJIGAKI et al., 2002). A remoção de triptofano por si só 
não é efetivo para combater a multiplicação do parasita (MACKENZIE et al., 1999), mas a destacada indução da expressão deste gene levanta um ponto para futuras investigações. Em amostras de fígado dos suínos infectados pelo $T$. gondii registrou-se um aumento de 430 vezes na expressão de INDO no 4DPI.

Um outro fator a ser ponderado é a geração de metabólitos intermediários com ação próapoptótica durante o processo de degradação do triptofano. O acúmulo destes metabólitos em estados de imune ativação persistente afetam a manutenção e a proliferação de linfócitos $\mathrm{T}$ (GROHMANN; FALLARINO; PUCCETTI, 2003).

O ARG1 é o gene associado à enzima responsável pela degradação da arginina. Apresentou um pico de indução no 4DPI no EXP I e no 7DPI no EXP II. A estimulação foi de 200 vezes em amostras de LN M do EXP I e de 516 vezes no LN M e 100 vezes no íleo e LN HS do EXP II. A indução deste mecanismo reforça a hipótese da inibição da replicação do parasita através da depleção de nutrientes.

A indução da enzima arginase pode também ser interpretada como uma condição favorecedora ao parasita, pois a enzima NO sintase utiliza a L-arginina como substrato para a produção de NO, que possui ação tóxica sobre o parasita (VINCENDEAU et al., 2003).

Do ponto de vista da regeneração tecidual, ambas as enzimas (arginase e NO sintase) exercem papéis importantes. A produção de NO inibiria a multiplicação parasitária e favoreceria a vasodilatação, enquanto que a arginase criaria condições favoráveis para a proliferação de fibroblastos e produção de colágeno (SHEARER et al., 1997).

Além do balanço NO sintase e arginase, existe também influência da NO sintase sobre a INDO. A presença de altos níveis de NO é capaz de inibir a expressão de INDO (ALBERATIGIANI et al., 1997). 
O gene NOS2A apresentou indução em amostras de jejuno (aumento de 20 vezes no 2DPI e 176 vezes no 4DPI) e íleo (9,5 vezes no 4DPI) do EXP I e em amostras do LN M (13 vezes no 7DPI), fígado (oito vezes no 7DPI), jejuno (quatro vezes no 2DPI; 9,3 vezes no 4DPI e 7,3 vezes no 7DPI) e íleo (3,5 vezes no 7DPI) do EXP II. A elevação da expressão do gene é concordante com a determinação de NO sérico no EXP I (Gráfico 4.1.4) que atingiu de valores máximos no 4DPI.

Ao analisar o efeito da infecção pelo T. gondii em culturas de fibroblastos utilizando microarranjos, Blader, Manger e Boothroyd (2001) observaram indução de genes ligados à síntese e degradação de proteínas, síntese de colesterol e à glicólise, mostrando a interferência da infecção sobre outras vias metabólicas além destas testadas no presente experimento.

Além dos genes ligados a resposta Th1, alguns genes associados a resposta Th2 também apresentaram estimulação. Esta observação reforça a teoria de que a resposta do tipo Th1 ou Th2 seria a resultante do predomínio de um conjunto de citocinas, isto é, não é a simples presença ou a ausência de uma dada citocina que determina a resposta. A indução da resposta Th1 seria, portanto, observada na predominância de sinais Th1 inibindo o desenvolvimento da resposta Th2 (JANKOVIC; LIU; GAUSE, 2001; SZABO et al., 2003).

A estimulação da expressão de genes Th2 durante o desenvolvimento da resposta imune contra o T. gondii ocorreria por mecanismos inespecíficos de ativação. O gene GATA3 foi primariamente associado a células do tipo Th2, entretanto sua expressão já foi observada em células $\mathrm{T}$ virgens não-ativadas e em células Th1, apresentando-se aumentada nas células Th2 (COUSINS; LEE; STAYNOV, 2002).

No presente experimento o GATA3 apresentou indução no 7DPI. Aumento não significativo de 1,6 vezes no jejuno e de 2,1 vezes no íleo e variação significativa de 3,6 vezes no fígado. Nos demais grupos experimentais apresentou-se inalterado ou reprimido. 
Apesar de estar classicamente associada a resposta Th2, alguns autores têm citado a participação da IL-4 na indução da resposta imune agindo em conjunto com o IFNG e a IL-12. Camundongos IL4 deficientes apresentaram menor grau de hemorragia e necrose intestinal, refletindo em menor taxa de mortalidade após a infecção oral por $T$. gondii, observou-se porém um aumento de lesão hepática, com presença de trombos de fibrina e necrose isquêmica secundária (NICKDEL et al., 2004; NICKDEL et al., 2001).

Nos suínos infectados com T. gondii houve aumento da expressão de IL4 no LN M, LN HS, jejuno, íleo e fígado. Neste último, a variação de IL4 atingiu indução de sete vezes no 4DPI no EXP I e de 12 vezes no 7DPI no EXP II.

Em camundongos a IL5 (NICKDEL et al., 2001) foi associada a uma maior resistência à infecção oral por T. gondii. Este gene apresentou uma discreta indução no LN M nos grupos 7DPI e 14DPI e no LN HS no 7DPI e 14DPI, mas manteve-se reprimido ou inalterado nos demais tecidos. No LN M excepcionalmente observou-se indução de 4,6 vezes.

A hiperativação dos mecanismos inflamatórios e de defesa Th1 pode, entretanto, gerar auto-destruição de células do hospedeiro. Seguindo este raciocínio, fatores reguladores da inflamação e da resposta imune cumprem um importante papel no período de recuperação.

A IL-10 possui efeito inibitório sobre a produção de NO, compostos oxidativos nos macrófagos e assim como o TGF- $\beta$ inibe a produção de citocinas inflamatórias como o IFN- $\gamma$, o TNF- $\alpha$ e a IL-2 reduzindo os efeitos imunopatológicos nos tecidos intestinais e cerebral (GAZZINELLI et al., 1992; ROSENBERG; GALLIN, 1999; SUZUKI et al., 2000).

Suzuki et al. (2000) observaram severas lesões necróticas nos intestinos e no fígado de camundongos IL10-deficientes infectados por T. gondii. O bloqueio da atividade do IFN- $\gamma$, da IL12 ou das células CD4, foi capaz de prevenir a formação das lesões e aumentar a sobrevida dos 
camundongos. Nos suínos infectados por T. gondii observou-se elevação na expressão de IL10 em amostras de fígado, jejuno e linfonodos.

Em mamíferos o TGF- $\beta$ é encontrado em três isoformas, $\beta 1, \beta 2$ e $\beta 3$, que apresentam ao redor de 70 a 76\% de homologia entre si. A atividade biológica in vitro é praticamente idêntica entre estas três isoformas, entretanto existem diferenças no padrão de expressão durante a embriogênese e diferenças fenotípicas em camundongos geneticamente deficientes sugerindo possíveis diferenças funcionais. Acredita-se que a isoforma $\beta 1$ esteja ligada a funções imunológicas e as isoformas $\beta 2$ e $\beta 3$ sejam reguladoras da diferenciação celular e embriogênese (KRAKAUER; VILCEK; OPPENHEIM, 1999).

No EXP I a expressão do TGFB1 e do TGFB3 apresentaram indução durante a infecção pelo T. gondii. A isoforma TGFB2 apresentou indução somente nas CMSP e apresentou-se inibida nas demais amostras de tecido. A atividade do TGF- $\beta 1$ depende de uma série de circunstâncias, variando de acordo com o local, o tipo celular e o grau de ativação das células envolvidas. De um modo geral, tende a um efeito supressor a nível sistêmico e efeito inflamatório local em tecidos, auxiliando também no processo de reparação tecidual (KRAKAUER; VILCEK; OPPENHEIM, 1999). O efeito modulatório parece envolver a IL-6 inibindo a produção de algumas proteínas de fase aguda e de fibrinogênio (MACKIEWICZ et al., 1990).

À primeira vista, os dados do EXP II são concordantes ao do EXP I. Como anteriormente mencionado há uma discreta diferença no tempo de resposta local dos tecidos detectada pela Real-Time RT-PCR que poderia estar relacionada a diferença de idade dos animais dos EXP I e EXP II e à diferença nas condições do inóculo. Entretanto ao analisar o tipo de resposta que é produzida, é possível observar padrões em comum. 
A resposta tecidual dos suínos do EXP I tende a apresentar valores máximos no 4DPI enquanto que no EXP II, o pico de resposta parece estar no grupo 7DPI. A observação de um número maior de genes apresentando variação estatisticamente significante no EXP II, pode ser explicado pelo aumento do número de animais testados por grupo.

No EXP II, da mesma forma que no EXP I, há uma intensa indução da resposta inflamatória, envolvendo os genes IL1B, IL6, TNF, TLR2 e TLR4. Além destes, os genes CRP, MYD88 e FCGR3A testados somente no EXP II também apresentaram estimulação.

Quanto aos genes ligados a resposta Th1, houve similar estimulação dos genes IFNG, IRF1 e STAT1 e também de IFNGR, HLX1 e TBX21 não testados no EXP I.

O TBX21 é um fator de transcrição recentemente descrito que está envolvido em eventos precoces do desenvolvimento da resposta Th1 e na indução da produção de IFN- $\gamma$ por células Th1 e NK (SZABO et al., 2000).

A primeira citação de indução do TBX21 durante a toxoplasmose em suínos foi publicada por Dawson et al. (2004). Neste trabalho, realizou-se a amplificação e o seqüenciamento de CD28, ICSBP1, MYD88 e TBX21 da espécie suína e a avaliação da expressão em amostras de LN M e fígado. Foi observada a indução da expressão de TBX21, IFNG, CD28, HLX1, IRF1, MYD88, STAT1 no fígado.

De forma similar, foram detectadas variações significativas na expressão de TBX21 em amostras de fígado, LN HS e íleo dos animais do presente experimento.

É interessante notar uma indução marcante de genes ligados aos mecanismos regulatórios e co-estimulatórios (IL10, MHC2TA, ICOS, CD3E, CD28, CTLA4, TNFRSF5, TNFSF5, CD80 e CD86) no tecido hepático e intestinal, porém uma baixa estimulação nas amostras de linfonodo.

Os mecanismos co-estimulatórios são principalmente ativados por parasitas vivos. Subauste e Wessendarp (2000) compararam a resposta induzida por taquizoítos vivos e mortos 
em DCs humanas e observaram que DCs infectadas por parasitas vivos apresentaram indução da expressão de TNFRSF5, CD80 e CD86 e foram capazes de estimular uma produção maior de IFN- $\gamma$ em linfócitos T do que as DCs que somente fagocitaram parasitas mortos. Esta produção de IFN- $\gamma$ foi associada a estimulação de IL-12 e envolveu a sinalização co-estimulatória do CD28 e TNFSF5.

A sinalização gerada via interação do CD80/CD86-CD28 e do TNFRSF5-TNFSF5 é também capaz de induzir a produção de IFN- $\gamma$ independente da presença do IL-12 (SUBAUSTE; WESSENDARP, 2000).

A elevação da expressão do gene IGG foi detectada em amostras de LN M (13,9 vezes) e LN HS (6,7 vezes) no 14DPI no EXP I e em amostras de LN M (5,4 vezes no 7DPI e 5,6 vezes no 14DPI), LN HS (4,2 vezes no 14DPI) e fígado (6,8 vezes no 7DPI e 5,8 no 14DPI) do EXP II. Aumento na expressão de IGM foi detectada em amostras de LN M (10,9 vezes) e fígado (8,8 vezes) do EXP II no 7DPI. Estes resultados são concordantes com os observados na prova do MAT. Anticorpos específicos anti-T. gondii foram detectados no 14DPI no EXP I e nos 7DPI e 14DPI no EXP II e são concordantes com os resultados sorológicos observados na literatura (DUBEY; BEATTIE, 1988).

A expressão de gene CASP1 ligado a apoptose apresentou um aumento significante nos linfonodos do grupo 7DPI e no fígado do 4DPI e 7DPI, indicando a ativação de mecanismos de morte celular programada.

A necrose hepática também pode ser resultante da citotoxicidade envolvendo TNFRSF6 (CD95) mediada por células $\mathrm{T}$, NK, DC e pelos próprios hepatócitos $\mathrm{CD}$ 55 $\mathrm{L}^{+}$(WICK; LEITHÄUSER; REIMANN, 2002) ou pela ação hepatotóxica da IL4 (GUILLOT et al., 2001). 
O efeito final da ação das citocinas depende do conjunto e do equilíbrio das moléculas envolvidas. O TNF- $\alpha$ possui efeito citotóxico para os hepatócitos, produzindo lesões intensas quando associado ao IFN- $\gamma$. Níveis elevados do TNF- $\alpha$ são detectados em infecções letais em camundongos (MATSUSHITA et al., 1999), entretanto, esta citocina participa da regeneração hepática quando associado à IL6 (WICK; LEITHÄUSER; REIMANN, 2002).

A técnica da Real-Time RT-PCR permitiu avaliar a diversidade da resposta a infecção pelo T. gondii indicando não somente quais os genes induzidos, mas também o grau de indução destes genes. Além disso, a variação da intensidade da resposta de um tecido para o outro sugere a importância da adequada seleção da amostragem tecidual.

Em continuidade aos resultados aqui observados, o isolamento e o estudo das populações de células presentes no fígado e nos segmentos intestinais torna-se uma necessidade para a compreensão dos mecanismos de interação entre a imunidade inata e a específica e os mecanismos de diferenciação dos linfócitos T (ABO, 2001).

O enfoque a tipos celulares específicos fornecem importantes contribuições para a compreensão da dinâmica das populações de células, assim como a quimiotaxia e a avaliação dos mecanismos da resposta local e sistêmica. As células com capacidade de reconhecimento de patógenos são as peças-chave para a compreensão das vias de diferenciação da resposta celular.

Utilizando a técnica dos microarranjos, Chaussabel et al. (2003) descreveram a capacidade de DCs e macrófagos de expressar diferentes padrões de resposta à infecção pelo $T$. gondii, Leishmania major, L. donovani, Mycobacterium tuberculosis e Brugia malayi. Similarmente aos resultados aqui observados, detectaram forte indução de genes relacionados ao IFNG, como o STAT1, STAT4, IRF4 e envolvimento da via dos TLRs, IL1R, MYD88 e TNF na resposta contra o T. gondii. 
Os mastócitos presentes no tecido conjuntivo adjacente a vasos e em mucosas são capazes de interagir com taquizoítos de $T$. gondii e induzir a migração de neutrófilos, macrófagos e linfócitos para o local da lesão (FERREIRA et al., 2004). Sabe-se também que a depleção de neutrófilos em camundongos diminui a resistência à infecção pelo T. gondii (BLISS et al., 2001).

O conjunto dos resultados aqui observados incentiva o estudo da interação hospedeiroparasita de uma forma holística. O estudo da função das citocinas leva invariavelmente a uma intrincada rede de sinais estimulatórios e inibitórios regulatórios, justificando o investimento na composição de painéis cada vez mais complexos para a determinação de diferentes citocinas.

De forma concordante, a revisão de Burger e Dayer (2002) enfatiza a importância do estudo em conjunto dos mecanismos de sinergismo e de inibição para a correta interpretação dos dados experimentais, desencorajando estudos em que são realizados a determinação dos níveis de uma única citocina.

Ao estudar a influência de diferentes citocinas na produção de proteínas de fase aguda em células de origem hepática, Mackiewics et al. (1991) chegam à conclusão de que a produção das proteínas é reflexo da combinação de citocinas e não o efeito de uma única citocina.

Durante o desenvolvimento da resposta de defesa imune contra o $T$. gondii observou-se indução tanto de citocinas pró-inflamatórias quanto de citocinas anti-inflamatórias sugerindo ativação escalonada de diversos mecanismos resultando no controle da infecção. A fase de recuperação depende de um bom equilíbrio entre os mecanismos efetores de proteção e de mecanismos de controle da resposta imune.

Comparado aos camundongos, a espécie suína apresenta características de resistência à toxoplasmose bastante similares à espécie humana, fortalecendo a importância dos resultados aqui obtidos. 
Em continuidade ao estudo da genômica, a identificação de proteínas ou de fatores de transcrição envolvidos na indução e na modulação da resposta de defesa poderão no futuro ser aplicados em imunoterapias e no desenvolvimento de vacinas.

O estudo da genômica funcional em animais de produção permitirá também a identificação de genes candidatos para programas de melhoramento animal visando selecionar qualidades até então pouco estudadas como por exemplo a maior resistência a doenças.

A seleção de marcadores genéticos de resistência a doenças deve considerar genes associados não somente à indução da resposta imune, mas também de genes ligados a inibição da resposta e recuperação tecidual. Além da melhora da qualidade do rebanho animal, estudos comparativos contribuirão para a compreensão dos mecanismos comuns de resposta a doenças e a identificação de pontos de convergência entre a fisiologia humana e a dos animais. 


\section{CONCLUSÕES}

A utilização da técnica da Real-Time RT-PCR permitiu a quantificar a variação da expressão de genes em tecidos de suínos infectados pelo $T$. gondii revelando a ativação de diversos mecanismos de defesa do hospedeiro.

A avaliação conjunta de 69 genes ao longo da infecção pelo $T$. gondii revela uma ativação coordenada da resposta inata, indução de mecanismos inflamatórios, geração de um padrão de resposta do tipo Th1, envolvendo mecanismos co-estimulatórios e regulatórios que levaram ao controle da infecção.

A indução da reposta imune local ocorreu de forma e de intensidade diferentes de acordo com a localização e do tipo de tecido. As amostras de fígado, LN M, LN HS e segmentos intestinais foram as que apresentaram maior intensidade de variação, enquanto que amostras de CMSP e timo apresentaram baixa variação na expressão de genes.

De forma concordante, células dos LN M e LN HS apresentaram maior produção de IFN$\gamma$ que células do LN TB e CMSP quando cultivadas in vitro revelando um padrão de resposta localizada e diferenciada frente a uma infecção sistêmica.

A adequada escolha da amostra tecidual é um importante fator para a observação da resposta local. Embora sejam alvo de inúmeras publicações, as CMSP apresentaram baixa variação na expressão de genes.

A ativação da imunidade inata é um importante passo no desenvolvimento da defesa contra o $T$. gondii, produzindo moléculas com ação tóxica anti-microbiana e gerando sinais para a formação da resposta imune específica. 
Foi possível detectar a ativação de alguns genes já no 2DPI, com aumento de intensidade nos dias 4 e 7 pós-infecção. A diminuição da quantidade de parasitas nos tecidos sugerem êxito no controle da multiplicação parasitária ao redor do 14DPI.

Os genes IL1B, IL6, TNF, TLR2, TLR4, CRP, MYD88 ligados a mecanismos inatos e inflamatórios apresentaram ativação durante a infecção pelo $T$. gondii.

A indução de genes associados à resposta Th1 IFNG, IFNGR, IL12A, IL12RB2, IL18, IL18R, IL23A, IRF1, TBX21, STAT1 revelam as possíveis vias de ativação da resposta imune específica.

A expressão de genes associados à resposta Th2 (IL4, GATA3), assim como a estimulação de genes ligados a mecanismos regulatórios (IL10 e TGFB1) indicam uma resposta balanceada, inibindo a exacerbação da resposta Th1.

A intensa ativação de genes da resposta inflamatória, regulatória e co-estimulatória nos tecidos intestinais e fígado sugerem um importante papel desses órgãos na defesa inata e na geração de sinais para o desenvolvimento da resposta tardia específica.

Além da produção de componentes tóxicos, mecanismos de depleção de nutrientes e alteração do meio intracitoplasmático podem estar ligados ao controle da multiplicação parasitária. A marcante indução dos genes ARG1, INDO e SLC11A1, ligados ao metabolismo de aminoácidos e ferro evidencia a importância destas vias efetoras.

A infecção experimental com organismos vivos revelam múltiplas vias de ativação e ação do sistema imune. A correta interpretação dos resultados deve, portanto, considerar a intrincada rede de interações de sinais estimulatórios e inibitórios. 


\section{REFERÊNCIAS ${ }^{1}$}

$\mathrm{ABO}, \mathrm{T}$. Extrathymic pathways of T-cell differentiation and immunomodulation. International Immunopharmacology, v. 1, n. 7, p. 1261-1273, 2001.

AKIRA, S. Mammalian Toll-like receptors. Current Opinion in Immunology, v. 15, n. 2, p. $238,2003$.

ALBERATI-GIANI, D.; MALHERBE, P.; RICCIARDI-CASTAGNOLI, P.; KOHLER, C.; DENIS- DONINI, S.; CESURA, A. Differential regulation of indoleamine 2,3-dioxygenase expression by nitric oxide and inflammatory mediators in IFN- $\gamma$-activated murine macrophages and microglial cells. Journal of Immunology, v. 159, n. 1, p. 419-426, 1997.

ARAUJO, M. I.; BLISS, S. K.; SUZUKI, A.; ALCARAZ, A.; DENKERS, E. Y.; PEARCE, E. J. Interleukin-12 promotes pathologic liver changes and death in mice co-infected with Schistosoma mansoni and Toxoplasma gondii. Infection and Immunity, v. 69, n. 3, p. 1454-1462, 2001.

ARREDOUANI, M.; MATTHIJS, P.; VAN HOEYVELD, E.; KASRAN, A.; BAUMANN, H.; CEUPPENS, J. L.; STEVENS, E. Haptoglobin directly affects T cells and suppresses T helper cell type 2 cytokine release. Immunology, v. 108, n. 2, p. 144-151, 2003.

BLADER, I. J.; MANGER, I. D.; BOOTHROYD, J. C. Microarray analysis reveals previously unknown changes in Toxoplasma gondii-infected human cells. Journal of Biological Chemistry, v. 276, n. 26, p. 24223-24231, 2001.

BLISS, S. K.; GAVRILESCU, L. C.; ALCARAZ, A.; DENKERS, E. Y. Neutrophil depletion during Toxoplasma gondii infection leads to impaired immunity and lethal systemic pathology. Infection and Immunity, v. 69, n. 8, p. 4898-4905, 2001.

BOHNE, W.; HEESEMANN, J.; GROSS, U. Induction of bradyzoite-specific Toxoplasma gondii antigens in gamma interferon treated mouse macrophages. Infection and Immunity, v. 61, n. 3, p. 1141-1145, 1993.

BRENIER-PINCHART, M. P.; VIGAN, I.; JOUVIN-MARCHE, E.; MARCHE, P. N.; PELET, E.; GROSS, U.; AMBROISE-THOMAS, P.; PELLOUX, H. Monocyte chemotactic protein-1 secretion and expression after Toxoplasma gondii infection in vitro depend on the stage of the parasite. FEMS Microbiology Letters, v. 214, n. 1, p. 45-49, 2002.

BUSTIN, S. A. Absolute quantification of mRNA using real-time reverse transcription polymerase chain reaction assays. Journal of Molecular Endocrinology, v. 25, p. 169-193, 2000.

\footnotetext{
${ }^{1}$ Conforme as diretrizes para apresentação de dissertações e teses na Faculdade de Medicina Veterinária e Zootecnia da Universidade de São Paulo. 4. ed. São Paulo: FMVZ-USP, 2003. 84p.
} 
BUSTIN, S. A. Quantification of mRNA using real-time RT-PCR: trends and problems. Journal of Molecular Endocrinology, v. 29, p. 23-39, 2002.

CAI, G.; KASTELEIN, R.; HUNTER, C. A. Interleukin-18 (IL-18) enhances innate IL-12mediated resistance to Toxoplasma gondii. Infection and Immunity, v. 68, n. 12, p. 6932-6938, 2000.

CAI, G.; RADZANOWSKI, T.; VILLEGAS, E. N.; KASTELEIN, R.; HUNTER, C. A. Identification of STAT4-dependent and independent mechanisms of resistance to Toxoplasma gondii. Journal of Immunology, v. 165, n. 5, p. 2619-2627, 2000.

CASCIOTTI, L.; ELY, K. H.; WILLIAMS, M. E.; KHAN, I. A. CD8 ${ }^{+}$-T-cell imunity against Toxoplasma gondii can be induced but not maintained in mice lacking conventional $\mathrm{CD}^{+} \mathrm{T}$ cells. Infection and Immunity, v. 70, n. 2, p. 434-443, 2002.

CASTELL, J. V.; GÓMEZ-LECHÓN, M. J.; DAVID, M.; HIRANO, T.; KISHIMOTO, T.; HEINRICH, P. C. Recombinant human interleukin-6 (IL-6/BSF-2/HSF) regulates the synthesis of acute phase proteins in human hepatocytes. Federation of European Biochemical Societies Letters, v. 232, n. 2, p. 347-350, 1988.

CHANNON, J. Y.; MISELIS, K. A.; MINNS, L. A.; DUTTA, C.; KASPER, L. H. Toxoplasma gondii induces granulocyte colony-stimulating factor and granulocyte-macrophage colonystimulating factor secretion by human fibroblasts: implications for neutrophil apoptosis.

Infection and Immunity, v. 70, n. 11, p. 6048-6057, 2002.

CHAUSSABEL, D.; SEMNANI, R. T.; MCDOWELL, M. A.; SACKS, D.; SHER, A.;

NUTMAN, T. B. Unique gene expression profiles of human macrophages and dendritic cells to phylogenetically distinct parasites. Blood, v. 102, n. 2, p. 672-681, 2003.

COLES, E. H. Veterinary Clinical Pathology. Philadelphia: W.B. Saunders, 1986. p. 486

COUSINS, D. J.; LEE, T. H.; STAYNOV, D. Z. Cytokine coexpression during human Th1/Th2 cell differentiation: Direct evidence for coordinated expression of Th2 cytokines. Journal of Immunology, v. 169, n. 5, p. 2498-2506, 2002.

DAWSON, H.; BESHAH, E.; NISHI, S.; SOLANO-AGUILAR, G. I.; MORIMOTO, M.; ZHAO, A.; MADDEN, K.; KRINGEL, H.; LEDBETTER, T.; DUBEY, J. P.; LUNNEY, J.; URBAN Jr, J. F. Verification of a Th1/Th2 paradigm of cytokine gene expression in swine infected with Toxoplasma gondii and Ascaris suum using Real-time RT-PCR analysis. In: ANNUAL MEETING OF THE AMERICAN ASSOCIATION OF VETERINARY PARASITOLOGISTS, 47., 2002a, Nashville. Proceedings... v.1, p. 25.

DAWSON, H. D.; BESHAH, E.; NISHI, S. M.; LUNNEY, J. K.; URBAN, J. F. Development of Real-time RT-PCR assays for porcine cytokine gene expression. The FASEB Journal, v. 16, p. A679, 2002b. 
DAWSON, H. D.; ROYAEE, A. R.; NISHI, S. M.; KUHAR, D.; SCHNITZLEIN, W. M.; ZUCKERMANN, F. A.; URBAN Jr, J. F.; LUNNEY, J. K. Identification of key immune mediators regulating $T$ helper 1 responses in swine. Veterinary Immunology and Immunopathology, v. 100, n. 1-2, p. 105-111, 2004.

DEL RIO, L.; BUTCHER, B. A.; BENNOUNA, S.; HIENY, S.; SHER, A.; DENKERS, E. Y. Toxoplasma gondii triggers myeloid differentiation factor 88-dependent IL-12 and chemokine ligand 2 (monocyte chemoattractant protein 1) responses using distinct parasite molecules and host receptors. Journal of Immunology, v. 172, n. 11, p. 6954-6960, 2004.

DENKERS, E. Y. T lymphocyte-dependent effector mechanisms of immunity to Toxoplasma gondii. Microbes and Infection, v. 1, n. 9, p. 699-708, 1999.

DENNEY, C. F.; ECKMANN, L.; REED, S. L. Chemokine secretion of human cells in response to Toxoplasma gondii infection. Infection and Immunity, v. 67, n. 4, p. 1547-1552, 1999.

DUBEY, J. P. Validation of the specificity of the modified agglutination test for toxoplasmosis in pigs. Veterinary Parasitology, v. 71, n. 4, p. 307-310, 1997.

DUBEY, J. P. Re-examination of resistance of Toxoplasma gondii tachyzoites and bradyzoites to pepsin and trypsin digestion. Parasitology, v. 116, p. 43-50, 1998.

DUBEY, J. P.; BEATTIE, C. P. Toxoplasmosis of animals and man. Boca Raton: CRC Press, 1988. p. 220

DUBEY, J. P.; DESMONTS, G. Serological responses of equids fed Toxoplasma gondii oocysts. Equine Veterinary Journal, v. 19, n. 4, p. 337-339, 1987.

DUBEY, J. P.; LUNNEY, J. K.; SHEN, S. K.; KWOK, O. C. H. Immunity to toxoplasmosis in pigs fed irradiated Toxoplasma gondii oocysts. Journal of Parasitology, v. 84, n. 4, p. 749-752, 1998.

DUBEY, J. P.; LUNNEY, J. K.; SHEN, S. K.; KWOK, O. C. H.; ASHFORD, D. A.; THULLIEZ, P. Infectivity of low numbers of Toxoplasma gondii oocysts to pigs. Journal of Parasitology, v. 82, n. 3, p. 438-443, 1996.

DUNCAN, J. R.; PRASSE, K. W. Veterinary laboratory medicine: clinical pathology. Ames: Iowa State University, 1987. p. 258

FERREIRA, G. L. S.; MINEO, J. R.; OLIVEIRA, J. G.; FERRO, E. A. V.; SOUZA, M. A.; SANTOS, A. A. D. Toxoplasma gondii and mast cell interactions in vivo and in vitro: Experimental infection approaches in Calomys callosus (Rodentia, Cricetidae). Microbes and Infection, v. 6, n. 2, p. 172-181, 2004.

FILISETTI, D.; CANDOLFI, E. Immune response to Toxoplasma gondii. Annali dell'Istituto Superiore di Sanità, v. 40, n. 1, p. 71-80, 2004. 
FRITSCHE, G.; DLASKA, M.; BARTON, H.; THEURL, I.; GARIMORTH, K.; WEISS, G. Nramp1 functionally increases inducible nitric oxide synthase transcription via stimulation of IFN regulatory factor 1 expression. Journal of Immunology, v. 171, p. 1994-1998, 2003.

FUJIGAKI, S.; SAITO, K.; TAKEMURA, M.; MAEKAWA, N.; YAMADA, Y.; WADA, H.; SEISHIMA, M. L-Tryptophan-L-kynurenine pathway metabolism accelerated by Toxoplasma gondii infection is abolished in gamma interferon-gene-deficient mice: Cross-regulation between inducible nitric oxide synthase and indoleamine-2,3-dioxygenase. Infection and Immunity, v. 70, n. 2, p. 779-786, 2002.

FUJIMOTO, M.; NAKA, T. Regulation of cytokine signaling by SOCS family molecules. Trends in Immunology, v. 24, n. 12, p. 659-666, 2003.

GAVRILESCU, L. C.; DENKERS, E. Y. IFN- $\gamma$ overproduction and high level apoptosis are associated with high but not low virulence Toxoplasma gondii infection. Journal of Immunology, v. 167, n. 2, p. 902-909, 2001.

GAZZINELLI, R.; HAKIM, F.; HIENY, S.; SHEARER, G.; SHER, A. Synergistic role of CD4 ${ }^{+}$ and $\mathrm{CD}^{+} \mathrm{T}$ lymphocytes in IFN- $\gamma$ production and protective immunity induced by an attenuated Toxoplasma gondii vaccine. Journal of Immunology, v. 146, n. 1, p. 286-292, 1991.

GAZZINELLI, R.; WYSOCKA, M.; HAYASHI, S.; DENKERS, E.; HIENY, S.; CASPAR, P.; TRINCHIERI, G.; SHER, A. Parasite-induced IL-12 stimulates early IFN- $\gamma$ synthesis and resistance during acute infection with Toxoplasma gondii. Journal of Immunology, v. 153, n. 6, p. 2533-2543, 1994.

GAZZINELLI, R. T.; HIENY, S.; WYNN, T. A.; WOLF, S.; SHER, A. Interleukin 12 is required for the T-lymphocyte-independent induction of interferon $\gamma$ by an intracellular parasite and induces resistance in T-cell-deficient hosts. Proceedings of the National Academy of Sciences of the United States of America, v. 90, p. 6115-6119, 1993.

GAZZINELLI, R. T.; OSWALD, I.; JAMES, S.; SHER, A. IL-10 inhibits parasite killing and nitrogen oxide production by interferon-gamma activated macrophages. Journal of Immunology, v. 148, p. 1792-1796, 1992.

GROHMANN, U.; FALLARINO, F.; PUCCETTI, P. Tolerance, DCs and tryptophan: much ado about IDO. Trends in Immunology, v. 24, n. 5, p. 242-248, 2003.

GUILLOT, C.; COATHALEM, H.; CHETRITT, J.; DAVID, A.; LOWENSTEIN, P.; GILBERT, E.; TESSON, L.; VAN ROOIJEN, N.; CUTURI, M. C.; SOULILLOU, J. P.; ANEGON, I. Lethal hepatitis after gene transfer of IL-4 in the liver is independent of immune resposnes and depend on apoptosis of hepatoocytes: a rodent model of IL-4 induced hepatitis. Journal of Immunology, v. 166, p. $5225-5235,2001$. 
HAMALAINEN, H. K.; TUBMAN, J. C.; VIKMAN, S.; KYROLA, T.; YLIKOSKI, E.; WARRINGTON, J. A.; LAHESMAA, R. Identification and validation of endogenous reference genes for expression profiling of T helper cell differentiation by Quantitative Real-Time RTPCR. Analytical Biochemistry, v. 299, n. 1, p. 63-70, 2001.

HAYASHI, S.; CHAN, C. C.; GAZZINELLI, R. T.; ROBERGE, F. G. Contribution of nitric oxide to the host parasite equilibrium in toxoplasmosis. Journal of Immunology, v. 156, n. 4, p. 1476-1481, 1996.

HEIN, W. R.; GRIEBEL, P. J. A road less travelled: Large animal models in immunological research. Nature Reviews Immunology, v. 3, n. 1, p. 79-84, 2003.

HISS, S.; KNURA-DESZCZKA, S.; REGULA, G.; HENNIES, M.; GYMNICH, S.; PETERSEN, B.; SAUERWEIN, H. Development of an enzyme immuno assay for the determination of porcine haptoglobin in various body fluids: Testing the significance of meat juice measurements for quality monitoring programs. Veterinary Immunology and Immunopathology, v. 96, n. 1-2, p. 73-82, 2003.

HOCHEPIED, T.; VAN MOLLE, W.; BERGER, F. G.; BAUMANN, H.; LIBERT, C. Involvement of the acute phase protein $\alpha_{1}$-acid glycoprotein in nonspecific resistance to a lethal Gram-negative infection. Journal of Biological Chemistry, v. 275, n. 20, p. 14903-14909, 2000.

HOWE, D. K.; HONORÉ, S.; DEROUIN, F.; SIBLEY, L. D. Determination of genotypes of Toxoplasma gondii strains isolated from patients with toxoplasmosis. Journal of Clinical Microbiology, v. 35, n. 6, p. 1411-1414, 1997.

JANKOVIC, D.; LIU, Z.; GAUSE, W. C. Th1- and Th2-cell commitment during infectious disease: asymmetry in divergent pathways. Trends in Immunology, v. 22, n. 8, p. 450-457, 2001.

JAUREGUI, L. H.; HIGGINS, J.; ZARLENGA, D.; DUBEY, J. P.; LUNNEY, J. K.

Development of a Real-Time PCR assay for detection of Toxoplasma gondii in pig and mouse tissues. Journal of Clinical Microbiology, v. 39, n. 6, p. 2065-2071, 2001.

JMP. User's guide. Cary: SAS Institute, 2002.

JONES, C.; BIENTZ, A.; ERB, P. In vitro cultivation of Toxoplasma gondii cysts in astrocytes in the presence of gamma infection. Infection and Immunity, v. 51, n. 1, p. 147-156, 1985.

KARPUS, W. J.; LUKACS, N. W.; KENNEDY, K. J.; SMITH, W. S.; HURST, S. D.; BARRETT, T. A. Differential CC chemokine-induced enhancement of T helper cell cytokine production. Journal of Immunology, v. 158, n. 9, p. 4129-4136, 1997. 
KRAKAUER, T.; VILCEK, J.; OPPENHEIM, J. J. Pro-inflammatory cytokines. In: PAUL, W.E. Fundamental Immunology. Philadelphia: Lippincott-Raven, 1999. p. 775-811.

LANGERMANS, J. A. M.; NIBBERING, P. H.; VAN VUREN-VAN DER HULST, M. E. B.; VAN FURTH, R. Transforming growth factor- $\beta$ suppresses interferon- $\gamma$-induced toxoplasmastatic activity in murine macrophages by inhibition of tumor necrosis factor- $\alpha$ production. Parasite Immunology, v. 23, p. 169-175, 2001.

LEONARD, W. J. Type I cytokines and interferons and their receptors. In: PAUL, W.E. Fundamenal Immunology. Philadelphia: Lippincott-Raven, 1999. p. 741-774.

LIEBERMAN, L. A.; CARDILLO, F.; OWYANG, A. M.; RENNICK, D. M.; CUA, D. J.; KASTELEIN, R. A.; HUNTER, C. A. IL-23 provides a limited mechanism of resistance to acute toxoplasmosis in the absence of IL-12. Journal of Immunology, v. 173, n. 3, p. 1887-1893, 2004.

LUNNEY, J. K. Cytokines orchestrating the immune response. Revue Scientifique et Technique International Office of Epizootics, v. 17, n. 1, p. 84-94, 1998.

MACKENZIE, C. R.; LANGEN, R.; TAKIKAWA, O.; DÄUBENER, W. Inhibition of indoleamine 2,3-dioxygenase in human macrophages inhibits interferon- $\gamma$-induced bacteriostasis but does not abrogate toxoplasmosis. European Journal of Immunology, v. 29, p. 3254-3261, 1999.

MACKIEWICZ, A.; GANAPATHI, M. K.; SCHULTZ, D.; BRABENEC, A.; WEINSTEIN, J.; KELLEY, M. F.; KUSHNER, I. Transforming Growth Factor $\beta 1$ Regulates Production of AcutePhase Proteins. Proceedings of the National Academy of Sciences of the United States of America, v. 87, n. 4, p. 1491-1495, 1990.

MACKIEWICZ, A.; SPEROFF, T.; GANAPATHI, M. K.; KUSHNER, I. Effects of cytokine combinations on acute phase protein production in two human hepatoma cell lines. Journal of Immunology, v. 146, n. 9, p. 3032-3037, 1991.

MATEU DE ANTONIO, E.; HUSMANN, R. J.; HANSEN, R.; LUNNEY, J. K.; STROM, D.; MARTIN, S.; ZUCKERMANN, F. A. Quantitative detection of porcine interferon-gamma in response to mitogen, superantigen and recall viral antigen. Veterinary Immunology and Immunopathology, v. 61, n. 2-4, p. 265-277, 1998.

MATSUSHITA, T.; ANDO, K.; KIMURA, K.; OHNISHI, H.; IMAWARI, M.; MUTO, Y. E. A. IL-12 induces specific toxicity against regenerating hepatocytes in vivo. International Immunology, v. 11, p. 657-665, 1999.

MCLEOD, R.; EISENHAUER, P.; MACK, D.; BROWN, C.; FILICE, G.; SPITALNY, G. Immune responses associated with early survival after peroral infection with Toxoplasma gondii. Journal of Immunology, v. 142, n. 9, p. 3247-3255, 1989. 
MESTAS, J.; HUGHES, C. C. W. Of mice and not men: Differences between mouse and human immunology. Journal of Immunology, v. 172, n. 5, p. 2731-2738, 2004.

MOCHIZUKI, K.; HAYASHI, N.; KATAYAMA, K.; HIRAMATSU, N.; KANTO, T.; MITA, E.; TATSUMI, T.; KUZUSHITA, N.; KASAHARA, A.; FUSAMOTO, H.; YOKOCHI, T.; KAMADA, T. B7/BB-1 expression and hepatitis activity in liver tissues of patients with chronic hepatitis C. Hepatology, v. 25, n. 3, p. 713-718, 1997.

MORDUE, D. G.; MONROY, F.; LA REGINA, M.; DINARELLO, C. A.; SIBLEY, L. D. Acute toxoplasmosis leads to lethal overproduction of Th1 cytokines. Journal of Immunology, v. 167, n. 8, p. 4574-4584, 2001.

MUN, H. S.; AOSAI, F.; NOROSE, K.; CHEN, M.; PIAO, L. X.; TAKEUCHI, O.; AKIRA, S.; ISHIKURA, H.; YANO, A. TLR2 as an essential molecule for protective immunity against Toxoplasma gondii infection. International Immunology, v. 15, n. 9, p. 1081-1087, 2003.

NATHAN, C.; XIE, Q. Nitric oxide synthases: roles, tolls and controls. Cell, v. 78, p. 915-918, 1994.

NICKDEL, M. B.; LYONS, R. E.; ROBERTS, F.; BROMBACHER, F.; HUNTER, C. A.; ALEXANDER, J.; ROBERTS, C. W. Intestinal pathology during acute toxoplasmosis is IL-4 dependent and unrelated to parasite burden. Parasite Immunology, v. 26, n. 2, p. 75-82, 2004.

NICKDEL, M. B.; ROBERTS, F.; BROMBACHER, F.; ALEXANDER, J.; ROBERTS, C. W. Counter-Protective role for interleukin-5 during acute Toxoplasma gondii infection. Infection and Immunity, v. 69, n. 2, p. 1044-1052, 2001.

NICOLLE, C.; MANCEAUX, L. Sur une infection a corps de Leishman (ou organisms voisins) du gondii. Clinical Reviews of Academic Science, v. 147, p. 763-766, 1908.

PAUL, W. E. Fundamental Immunology. Philadelphia: Lippincott-Raven, 1999. p. 1589

PEARCE, E. J.; SCOTT, P. A.; SHER, A. Immune regulation in parasitic infection and disease. In: PAUL, W.E. Fundamental Immunology. Philadelphia: Lippincott-Raven, 1999. p. 12711294.

PFEFFERKORN, E. Interferon- $\gamma$ blocks the growth of Toxoplasma gondii in human fibroblasts by inducing the host cell to degrade tryptophan. Proceedings of the National Academy of Sciences of the United States of America, v. 81, p. 908-912, 1984.

PYORALA, S. Indicators of inflammation in the diagnosis of mastitis. Veterinary Research, v. 34, n. 5, p. 565-578, 2003.

REICHMANN, G.; WALKER, W.; VILLEGAS, E. N.; CRAIG, L.; CAI, G.; ALEXANDER, J.; HUNTER, C. A. The CD40/CD40 ligand interaction is required for resistance to toxoplasmic encephalitis. Infection and Immunity, v. 68, n. 3, p. 1312-1318, 2000. 
ROBBEN, P. M.; MORDUE, D. G.; TRUSCOTT, S. M.; TAKEDA, K.; AKIRA, S.; SIBLEY, L. D. Production of IL-12 by macrophages infected with Toxoplasma gondii depends on the parasite genotype. Journal of Immunology, v. 172, n. 6, p. 3686-3694, 2004.

ROSENBERG, H. F.; GALLIN, J. I. Inflammation. In: PAUL, W.E. Fundamental Immunology. Philadelphia: Lippincott-Raven, 1999. p. 1051-1066.

SAALMUELLER, A.; PAULY, T.; LUNNEY, J. K.; BOYD, P.; AASTED, B.; SACHS, D. H.; ARN, S.; BIANCHI, A.; BINNS, R. M.; LICENSE, S.; WHYTE, A.; BLECHA, F.; CHEN, Z.; CHU, R. M.; DAVIS, W. C.; DENHAM, S.; YANG, H.; WHITTALL, T.; PARKHOUSE, R. M.; DOMINGUEZ, J.; EZGUERRA, A.; ALONSO, F.; HORSTICK, G.; HOWARD, C.; SOPP, P.; KIM, Y. B.; LIPP, J.; MACKAY, C.; MAGYAR, A.; MCCULLOUGH, K.; ARRIENS, A.; SUMMERFIELD, A.; MURTAUGH, M.; NIELSEN, J.; NOVIKOV, J.; PESCOVITZ, M. D.; SCHUBERTH, H. J.; LEIBOLD, W.; SCHUTT, C.; SHIMIZU, M.; STOKES, C.; HAVERSON, K.; BAILEY, M.; TLASKALOVA, H.; TREBICHAVSKY, I.; VALPOTIC, I.; WALKER, J.; LEE, R.; ZUCKERMANN, F. Overview of the second international workshop to define swine leukocyte cluster of differentiation (CD) antigens. Veterinary Immunology and Immunopathology, v. 60, p. 207-228, 1998.

SCANGA, C. A.; ALIBERTI, J.; JANKOVIC, D.; TILLOY, F.; BENNOUNA, S.; DENKERS, E. Y.; MEDZHITOV, R.; SHER, A. MyD88 is required for resistance to Toxoplasma gondii infection and regulates parasite-induced IL-12 production by dendritic cells. Journal of Immunology, v. 168, n. 12, p. 5997-6001, 2002.

SCHARTON-KERSTEN, T.; CASPAR, P.; SHER, A.; DENKERS, E. Y. Toxoplasma gondii: Evidence for interleukin-12-dependent and -independent pathways of interferon- $\gamma$ production induced by an attenuated parasite strain. Experimental Parasitology, v. 84, n. 2, p. 102-114, 1996a.

SCHARTON-KERSTEN, T. M.; WYNN, T. A.; DENKERS, E. Y.; BALA, S.; GRUNVALD, E.; HIENY, S.; GAZZINELLI, R. T.; SHER, A. In the absence of endogenous IFN- $\gamma$, mice develop unimpaired IL-12 responses to Toxoplasma gondii while failing to control acute infection. Journal of Immunology, v. 157, n. 9, p. 4045-4054, 1996b.

SCHMITTGEN, T. D.; ZAKRAJSEK, B. A. Effect of experimental treatment on housekeeping gene expression: validation by real-time, quantitative RT-PCR. Journal of Biochemical and Biophysical Methods, v. 46, n. 1-2, p. 69-81, 2000.

SCOTT, P.; HUNTER, C. A. Dendritic cells and immunity to leishmaniasis and toxoplasmosis. Current Opinion in Immunology, v. 14, n. 4, p. 466-470, 2002.

SHEARER, J. D.; RICHARDS, J. R.; MILLS, C. D.; CALDWELL, M. D. Differential regulation of macrophage arginine metabolism: a proposed role in wound healing. American Journal of Physiology, v. 272, p. E181-E190, 1997.

SKINNER, J. G. International standardization of acute phase proteins. Veterinary Clinical Pathology, v. 30, n. 1, p. 2-7, 2001. 
SOLANO-AGUILAR, G. I.; BESHAH, E.; VENGROSKI, K. G.; ZARLENGA, D.; JAUREGUI, L.; COSIO, M.; DOUGLASS, L. W.; DUBEY, J. P.; LUNNEY, J. K. Cytokine and lymphocyte profiles in miniature swine after oral infection with Toxoplasma gondii oocysts. International Journal for Parasitology, v. 31, n. 2, p. 187-195, 2001.

SOLANO-AGUILAR, G. I.; VENGROSKI, K. G.; BESHAH, E.; LUNNEY, J. K. Isolation and purification of lymphocyte subsets from gut-associated lymphoid tissue in neonatal swine.

Journal of Immunological Methods, v. 241, n. 1-2, p. 185-199, 2000.

SOLANO-AGUILAR, G. I.; ZARLENGA, D.; BESHAH, E.; VENGROSKI, K.; GASBARRE, L.; JUNKER, D.; COCHRAN, M.; WESTON, C.; VALENCIA, D.; CHIANG, C.; DAWSON, H.; URBAN, J. F.; LUNNEY, J. K. Limited effect of recombinant porcine interleukin-12 on porcine lymphocytes due to a low level of IL-12 beta2 receptor. Veterinary Immunology and Immunopathology, v. 89, n. 3-4, p. 133-148, 2002.

STAFFORD, J. L.; NEUMANN, N. F.; BELOSEVIC, M. Macrophage-mediated innate host defense against protozoan parasites. Critical Reviews in Microbiology, v. 28, n. 3, p. 187-248, 2002.

SUBAUSTE, C. S.; WESSENDARP, M. Human dendritic cells discriminate between viable and killed Toxoplasma gondii tachyzoites: Dendritic cell activation after infection with viable parasites results in CD28 and CD40 Ligand signaling that controls IL-12-dependent and independent $T$ cell production of IFN- $\gamma$. Journal of Immunology, v. 165, n. 3, p. 1498-1505, 2000.

SUZUKI, Y.; SHER, A.; YAP, G.; PARK, D.; NEYER, L. E.; LIESENFELD, O.; FORT, M.; KANG, H.; GUFWOLI, E. IL-10 is required for prevention of necrosis in the small intestine and mortality in both genetically resistant BALB/c and susceptible C57BL/6 mice following peroral infection with Toxoplasma gondii. Journal of Immunology, v. 164, n. 10, p. 5375-5382, 2000.

SZABO, S. J.; KIM, S. T.; COSTA, G. L.; ZHANG, X.; FATHMAN, C. G.; GLIMCHER, L. A novel transcription factor, T-bet, directs Th1 lineage commitment. Cell, v. 100, p. 655-669, 2000.

SZABO, S. J.; SULLIVAN, B. M.; PENG, S. L.; GLIMCHER, L. Molecular mechanisms regulating Th1 immune responses. Annual Review of Immunology, v. 21, p. 713-758, 2003.

SZALAI, A. J.; VAN GINKEL, F. W.; WANG, Y.; MCGHEE, J. R.; VOLANAKIS, J. E. Complement-dependent acute-phase expression of C-reactive protein and serum amyloid $\mathrm{P}$ component. Journal of Immunology, v. 165, n. 2, p. 1030-1035, 2000.

THELLIN, O.; ZORZI, W.; LAKAYE, B.; DE BORMAN, B.; COUMANS, B.; HENNEN, G.; GRISAR, T.; IGOUT, A.; HEINEN, E. Housekeeping genes as internal standards: use and limits. Journal of Biotechnology, v. 75, n. 2-3, p. 291-295, 1999. 
TRICARICO, C.; PINZANI, P.; BIANCHI, S.; PAGLIERANI, M.; DISTANTE, V.;

PAZZAGLI, M.; BUSTIN, S. A.; ORLANDO, C. Quantitative real-time reverse trancription polymerase chain reaction: normalization to rRNA or single housekeeping genes is inappropiate for human tissue biopsies. Analytical Biochemistry, v. 309, n. 2, p. 293-300, 2002.

VERDON, C. P.; BURTON, B. A.; PRIOR, R. L. Sample pretreatment with nitrate reductase and glucose-6-phosphate dehydrogenase quantitatively reduces nitrate while avoiding interference by $\mathrm{NADP}+$ when the Griess reaction is used to assay for nitrite. Analytical Biochemistry, v. 224, n. 2, p. 502-508, 1995.

VINCENDEAU, P.; GOBERT, A. P.; DAULOUÈDE, S.; MOYNET, D.; DJAVAD MOSSALAYI, M. Arginases in parasitic diseases. Trends in Parasitology, v. 19, n. 1, p. 9-12, 2003.

VOLK, H.-D.; ASADULLAH, K.; GALLAGHER, G.; SABAT, R.; GRÜTZ, G. IL-10 and its homologs: important immune mediators and emerging immunotherapeutic agents. Trends in Immunology, v. 22, n. 8, p. 414-417, 2001.

WICK, M. J.; LEITHÄUSER, F.; REIMANN, J. The hepatic immune system. Critical Reviews in Immunology, v. 22, n. 1, p. 47-103, 2002.

YAP, G.; PESIN, M.; SHER, A. IL-12 is required for the maintenance of IFN- $\gamma$ production in T cells mediating chronic resistance to the intracellular pathogen, Toxoplasma gondii. Journal of Immunology, v. 165, n. 2, p. 628-631, 2000.

YAP, G. S.; ORTMANN, R.; SHEVACH, E.; SHER, A. A heritable defect in IL-12 signaling in B10.Q/J mice. II. Effect on acute resistance to Toxoplasma gondii and rescue by IL-18 treatment. Journal of Immunology, v. 166, n. 9, p. 5720-5725, 2001.

YAP, G. S.; SCHARTON-KERSTEN, T.; CHAREST, H.; SHER, A. Decreased resistance of TNF receptor $\mathrm{p} 55$ - and $\mathrm{p} 75$-deficient mice to chronic toxoplasmosis despite normal activation of inducible nitric oxide synthase in vivo. Journal of Immunology, v. 160, n. 3, p. 1340-1345, 1998.

YAP, G. S.; SHER, A. Effector cells of both nonhemopoietic and hemopoietic origin are required for interferon (IFN)- $\gamma$ - and tumor necrosis factor (TNF)- $\alpha$-dependent host resistance to the intracellular pathogen, Toxoplasma gondii. Journal of Experimental Medicine, v. 189, n. 7, p. 1083-1092, 1999.

ZARLENGA, D. S.; HIGGINS, J. PCR as a diagnostic and quantitative technique in veterinary parasitology. Veterinary Parasitology, v. 101, n. 3-4, p. 215-230, 2001. 
APÊNDICE A - MEIO DE COLHEITA

500 ml Hank's Balanced Salt Solution (HBSS) sem Ca e Mg (Gibco BRL)

$5 \mathrm{ml}$ Gentamicina 50\% (Sigma)

2,5 ml Penicilina-estreptomicina (2000UI e 2mg em $100 \mathrm{ml}$, Sigma)

$5 \mathrm{ml} N$-2-hydroxyethylpiperazine- $N$ '-2-ethanesulfonic acid 1M (HEPES, Gibco)

Filtrado a $0,22 \mu \mathrm{m}, \mathrm{pH} 7,4$

APÊNDICE B - MEIO PBL

$50 \mathrm{ml}$ 10X HBSS sem Ca e Mg

$25 \mathrm{ml}$ Ácido etileno diamino tetracetato sódico 0,2M (EDTA)

$5 \mathrm{ml}$ HEPES 1M (Gibco)

$420 \mathrm{ml}$ água destilada

Filtrado a $0,22 \mu \mathrm{m}$.

APÊNDICE C - MEIO BLASTOGÊNICO

870 ml RPMI-1640

$100 \mathrm{ml}$ soro fetal bovino (SFB)

$10 \mathrm{ml}$ L-glutamina

$10 \mathrm{ml} \mathrm{Pen/Strep} \mathrm{(10,000} \mathrm{U.I.} \mathrm{penicilina/10,000 \mu g} \mathrm{estreptomicina)}$

$10 \mathrm{ml}$ HEPES $1 \mathrm{M}$

$1 \mathrm{ml}$ 2-Mercaptoetanol (2-ME)

Filtrado a $0,22 \mu \mathrm{m}$. 
APÊNDICE D - MEIO COMPLETO PARA CULTIVO DE CÉLULAS MONONUCLEARES

$1000 \mathrm{ml}$ RPMI-1640

$100 \mathrm{ml} \mathrm{SFB}$

$20 \mathrm{ml}$ HEPES

$10 \mathrm{ml}$ L-Glutamina

$1 \mathrm{ml} 2-\mathrm{ME}(55 \mathrm{mM})$

$10 \mathrm{ml} \mathrm{Pen/Strep}$

$0,5 \mathrm{ml} \mathrm{Gentamicina}(50 \mathrm{mg} / \mathrm{ml})$

$10 \mathrm{ml}$ NEAA

$10 \mathrm{ml}$ Piruvato

Concanavalin A (solução estoque a $500 \mathrm{ug} / \mathrm{ml}$ em PBS)

Uso: $10 \mu \mathrm{l} / \mathrm{ml}$ (Usar $125 \mu \mathrm{g} /$ flasco $=250 \mathrm{ul} \mathrm{em} \mathrm{12,5} \mathrm{ml} \mathrm{media)}$

Cultivo: $3,12 \times 10^{7}$ células em 12,5 ml (volume final). 


\section{APÊNDICE E - CRITÉRIOS ADOTADOS PARA DESENHO DE PRIMERS E SONDAS}

As seqüências de referência (RefSeq) foram obtidas do Genbank (NCBI) e do TIGR. Na ausência de seqüências completas, foram utilizadas as seqüências parciais de publicação recente contendo o maior número de informações e anotações sobre introns e exons.

As seqüências foram testadas (BLAST <http://www.ncbi.nlm.nih.gov/BLAST/>) em diferentes databases, em busca de variações que pudessem representar erros de seqüenciamento ou áreas de polimorfismo.

Para o desenho de primers e sondas foi utilizado o software Primer Express versão 1.5a (PE Applied Biosystems, Foster City, EUA) que é parte integrante do pacote que acompanha o equipamento ABI Prism 7700 Sequence Detection System (PE Applied Biosystems, Foster City, EUA). Maiores informações podem ser obtidas no site <http://www.appliedbiosystems.com>

O passo inicial foi a escolha da sonda. Foram evitadas seqüências de nucleotídeos idênticos, especialmente quatro ou mais guaninas (Gs). O conteúdo de citosina (C) e G foi mantido entre 30 e $80 \%$, com predomínio de Cs em relação às Gs. Evitando-se sempre a finalização da extremidade $5^{\prime}$ com G.

Primers senso e anti-senso possuem Tm (temperatura de fusão) iguais, tamanho de 15 a 30 bases e conteúdo de $\mathrm{C}+\mathrm{G}$ entre 30 a $80 \%$.

Foram evitadas seqüências de nucleotídeos repetidos, especialmente Gs. Regiões com quatro ou mais Gs seguidos foram eliminados.

A soma de Cs e Gs nos últimos cinco nucleotídeos da extremidade 3' não superior a dois.

Tamanho máximo do amplicon não ultrapassa 400 bp (sempre que possível buscando o tamanho ideal entre 50 e 150 bases).

Quando possível, os primers estão sobre as junções de exons e introns.

Os primers possuem $\mathrm{Tm}$ de 58 a $60^{\circ} \mathrm{C}$ e sondas com valor de $\mathrm{Tm} 10^{\circ} \mathrm{C}$ superior aos primers.

As seqüências de cDNA da região de hibridização dos primers e da sonda foram testadas (BLAST) nas databases para ESTs e NRs. As sondas foram redesenhadas quando houve homologia a outras seqüências que não a seqüência-alvo. 


\section{APÊNDICE F - ETAPAS DA PADRONIZAÇÃO DA REAL-TIME PCR}

Referência básica: Bulletin \#2 e Bulletin \#5 (Applied Biosystems, Foster City, EUA)

Os primers e sondas foram sintetizados por Biosource (Biosource International Inc., Camarillo, EUA) <www.keydna.com>

Soluções estoque de primers foram preparados a $90 \mu \mathrm{m}$ e as sondas a $25 \mu \mathrm{m}$ em tampão $\mathrm{TE}(\mathrm{pH} 8,0)$ e mantidos em freezer $-20^{\circ} \mathrm{C}$ protegidos da luz.

Fonte de cDNA: Foram testados cDNAs sintetizados a partir de RNA de células de suíno estimuladas 24 a 72 horas com ConA (Concanavalin A, lectina da Conavalia ensiformis, Sigma, EUA) ou PMA (Phorbol 12-myristate 13-acetate, Sigma, EUA).

Primers (senso e anti-senso) foram testados a 50, 300 e $900 \mathrm{nM}$ frente a concentrações constantes de cDNA e sondas.

Concentrações adequadas de primers foram definidas considerando os melhores valores de $\mathrm{Ct}$ e $\Delta \mathrm{Rn}$, onde $\mathrm{Ct}$ é o número de ciclos necessários para a detecção da reação e $\Delta \mathrm{Rn}$ a intensidade da fluorescência.

Após a escolha da melhor concentração de primers, testou-se diferentes concentrações de sondas: 50, 100, 150, 200 e $250 \mathrm{nM}$.

Foi escolhida a concentração que apresentasse boa intensidade de fluorescência nas reações positivas e baixa ou ausência de ruído nas reações negativas, sem alteração do valor de Ct.

Definidas as concentrações ótimas de primers e sondas foram realizadas diluições seriadas de cDNA para cálculo de linearidade e eficiência da reação para cada um dos genes testados.

Todas as seqüências testadas apresentaram linearidade superior a 0,950 dada pelo valor de RQUAD $\left(\mathrm{R}^{2}\right)$ e valores de inclinação entre $-3,404 \pm 0,2$ calculadas em planilha MS Excel (Microsoft, EUA) (DAWSON et al., 2002b).

Após o processo de otimização, o produto da reação do Real-Time RT-PCR foi submetido a eletroforese em gel de agarose a $4 \%$, corado com brometo de etídio e visualizado sob luz ultravioleta (UV) para confirmar a formação de banda única em tamanho compatível com o esperado. 
APÊNDICE G - Detecção de T. gondii nos tecidos, valores de aspartato aminotransferase (AST), óxido nítrico (NO) haptoglobina (Hp) e IFN- $\gamma$ séricos e produção de IFN- $\gamma$ por células mononucleares do sangue periférico (CMSP), linfonodo mesentérico (LN M), hepato-esplênico (LN HS) e traqueo-bronquial (LN TB) nos suínos do EXP I - Beltsville - 2003

\begin{tabular}{|c|c|c|c|c|c|c|c|c|c|c|}
\hline \multirow{2}{*}{ Grupo } & \multirow{2}{*}{ Animal } & \multirow{2}{*}{ T. gondii $^{1}$} & \multirow{2}{*}{$\begin{array}{l}\text { AST } \\
(\mathrm{U} / \mathrm{L})\end{array}$} & \multirow{2}{*}{$\begin{array}{l}\text { NO } \\
(\mu \mathrm{M})\end{array}$} & \multirow{2}{*}{$\begin{array}{c}\text { Hp } \\
(\mathrm{mg} / \mathrm{ml})\end{array}$} & \multicolumn{5}{|c|}{ Interferon- $\gamma^{2}$} \\
\hline & & & & & & Soro & CMSP & LN M & LN HS & LN TB \\
\hline \multirow[t]{4}{*}{ Controle } & $1 \mathrm{C}$ & $(-)$ & 23 & 13,5 & 0,1 & 0 & 1,01 & 0,95 & 0,75 & 0,64 \\
\hline & $2 \mathrm{C}$ & $(-)$ & 33 & 11,1 & 1,0 & 0 & 0,2 & 0,29 & 0,14 & 0,24 \\
\hline & Média & & 28,0 & 12,3 & 0,6 & 0,0 & 0,6 & 0,6 & 0,4 & 0,4 \\
\hline & DP & & 7,1 & 1,7 & 0,6 & 0,0 & 0,6 & 0,5 & 0,4 & 0,3 \\
\hline \multirow[t]{5}{*}{ 2DPI } & $1-2$ & $(++)$ & 28 & 37,3 & 0,8 & 424 & 0,56 & 1,02 & 0,28 & 0,26 \\
\hline & $2-2$ & $(+)$ & 29 & 22,9 & 1,3 & 0 & 0,47 & 1,02 & 0,31 & 0,2 \\
\hline & $3-2$ & $(+)$ & 28 & 20,4 & 0,5 & 452 & 0,49 & 5,54 & 1 & 0,82 \\
\hline & Média & & 28,3 & 26,9 & 0,9 & 292,0 & 0,5 & 2,5 & 0,5 & 0,4 \\
\hline & DP & & 0,6 & 9,1 & 0,4 & 253,3 & 0,0 & 2,6 & 0,4 & 0,3 \\
\hline \multirow[t]{5}{*}{ 4DPI } & $1-4$ & $(+++)$ & 59 & 173,2 & 4,0 & 11700 & 2,15 & 9,8 & 1,68 & 0,47 \\
\hline & $2-4$ & $(+++)$ & 58 & 168,9 & 6,9 & 12200 & 10,74 & 11,62 & 1,72 & 0,32 \\
\hline & $3-4$ & $(++)$ & 56 & 149,6 & 4,5 & 1472 & 4,51 & 16,19 & 0,57 & 0,34 \\
\hline & Média & & 57,7 & 163,9 & 5,1 & 8457,3 & 5,8 & 12,5 & 1,3 & 0,4 \\
\hline & DP & & 1,5 & 12,6 & 1,5 & 6054,6 & 4,4 & 3,3 & $\mathbf{0 , 7}$ & 0,1 \\
\hline \multirow[t]{4}{*}{ 7DPI } & $1-7$ & $(-)$ & 31 & 56,9 & 3,5 & 80 & 9,58 & 5,21 & 13,41 & 4,24 \\
\hline & $2-7$ & $(+++)$ & 173 & 104,3 & 5,3 & 1920 & 1,75 & 98 & 127 & 8,15 \\
\hline & Média & & 102,0 & 80,6 & 4,4 & 1000,0 & 5,7 & 51,6 & 70,2 & 6,2 \\
\hline & DP & & 100,4 & 33,5 & 1,3 & 1301,1 & 5,5 & 65,6 & 80,3 & 2,8 \\
\hline \multirow[t]{4}{*}{ 14DPI } & $1-14$ & $(+)$ & 37 & 90,3 & 4,9 & 0 & 0,83 & 2,59 & 1,19 & 0,96 \\
\hline & $2-14$ & $(+)$ & 23 & 45,9 & 4,6 & 0 & 14,35 & 27,31 & 18,52 & 13,11 \\
\hline & Média & & 30,0 & 68,1 & 4,8 & 0,0 & 7,6 & 15,0 & 9,9 & 7,0 \\
\hline & DP & & $\mathbf{9 , 9}$ & 31,4 & 0,2 & $\mathbf{0 , 0}$ & 9,6 & 17,5 & 12,3 & 8,6 \\
\hline
\end{tabular}

${ }^{1}$ Detecção de T. gondii : (-) ausente, $(+)$ pouca, $(++)$ moderada, $(+++)$ elevada quantidade

${ }^{2} \mathrm{IFN}-\gamma$ sérico $\mathrm{pg} / \mathrm{ml}$, IFN- $\gamma$ no sobrenadante $\mathrm{ng} / \mathrm{ml}$ 